\title{
AGR-1 Post Irradiation Examination Final Report
}

The INL is a

U.S. Department of Energy

National Laboratory

operated by

Battelle Energy Alliance

Paul A. Demkowicz, John D. Hunn, Robert N. Morris, Isabella van Rooyen, Tyler Gerczak, Jason M. Harp, Scott A. Ploger

August 2015
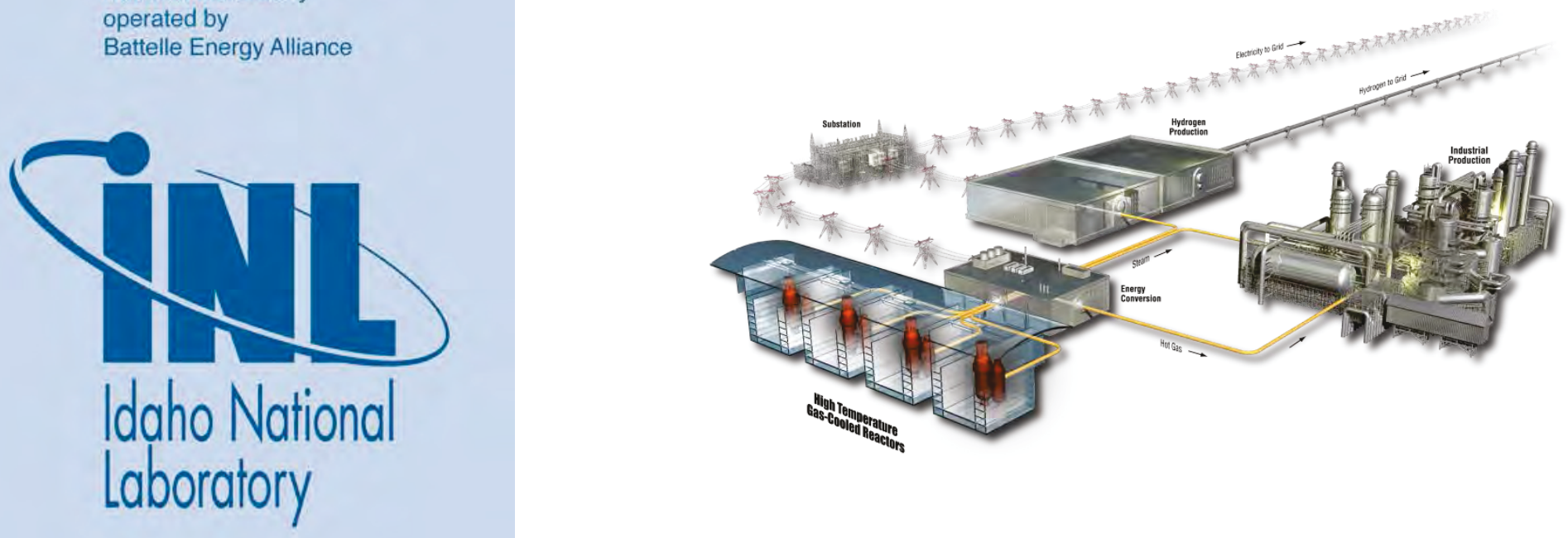


\section{DISCLAIMER}

This information was prepared as an account of work sponsored by an agency of the U.S. Government. Neither the U.S. Government nor any agency thereof, nor any of their employees, makes any warranty, expressed or implied, or assumes any legal liability or responsibility for the accuracy, completeness, or usefulness, of any information, apparatus, product, or process disclosed, or represents that its use would not infringe privately owned rights. References herein to any specific commercial product, process, or service by trade name, trade mark, manufacturer, or otherwise, does not necessarily constitute or imply its endorsement, recommendation, or favoring by the U.S. Government or any agency thereof. The views and opinions of authors expressed herein do not necessarily state or reflect those of the U.S. Government or any agency thereof. 
INL/EXT-15-36407

Revision 0

\section{AGR-1 Post Irradiation Examination Final Report}

Paul A. Demkowicz, John D. Hunn, Robert N. Morris, Isabella van Rooyen, Tyler Gerczak, Jason M. Harp, Scott A. Ploger

August 2015

Idaho National Laboratory

INL ART Program

Idaho Falls, Idaho 83415

http://www.inl.gov

Prepared for the

U.S. Department of Energy

Office of Nuclear Energy

Under DOE Idaho Operations Office

Contract DE-AC07-05ID14517 



\title{
INL ART Program
}

\section{AGR-1 Post Irradiation Examination Final Report}

\author{
INL/EXT-15-36407 \\ Revision 0
}

August 2015

Approved by:

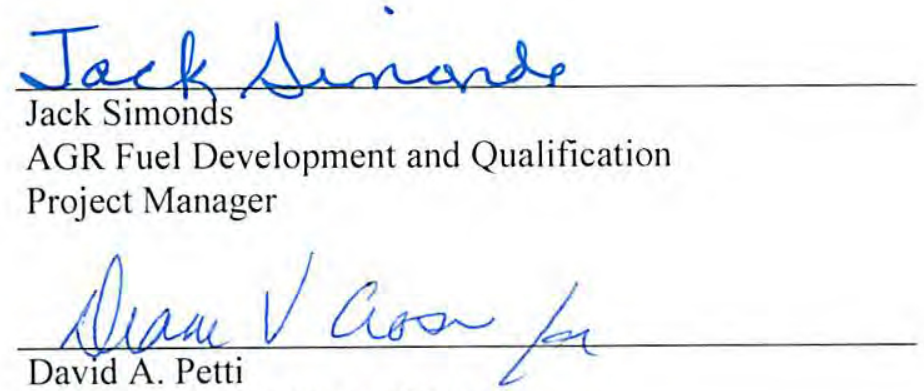

INL, ART TDO Project Manager
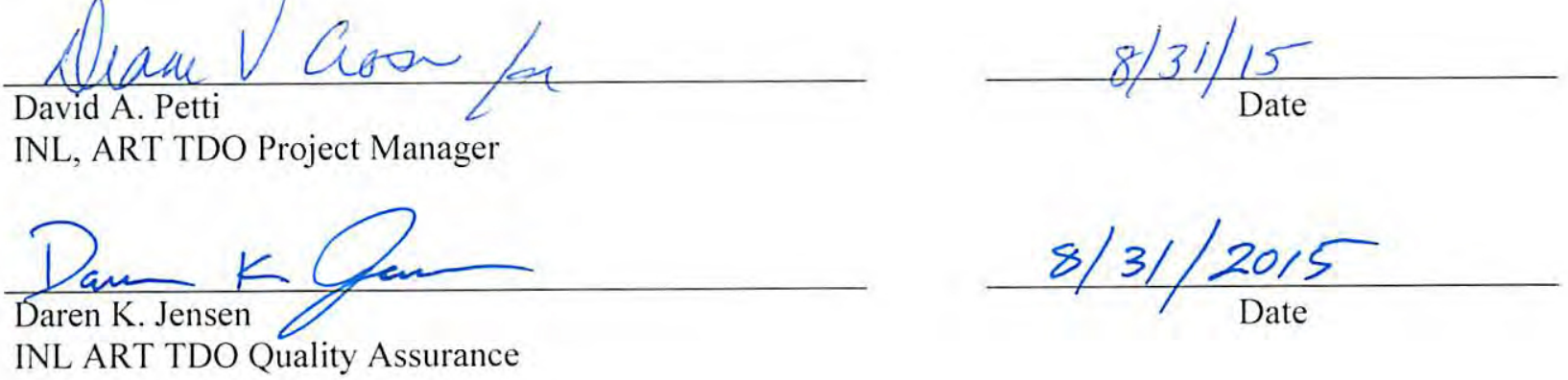



\section{SUMMARY}

The post-irradiation examination (PIE) of the Advanced Gas Reactor (AGR)-1 experiment was a multi-year, collaborative effort between Idaho National Laboratory (INL) and Oak Ridge National Laboratory (ORNL) to study the performance of UCO (uranium carbide, uranium oxide) tristructural isotropic (TRISO) coated particle fuel fabricated in the U.S. and irradiated at the Advanced Test Reactor at INL to a peak burnup of $19.6 \%$ fissions per initial metal atom. This work involved a broad array of experiments and analyses to evaluate the level of fission product retention by the fuel particles and compacts (both during irradiation and during post-irradiation heating tests to simulate reactor accident conditions), investigate the kernel and coating layer morphology evolution and the causes of coating failure, and explore the migration of fission products through the coating layers.

The results have generally confirmed the excellent performance of the AGR-1 fuel, first indicated during the irradiation by the observation of zero TRISO coated particle failures out of 298,000 particles in the experiment. Overall release of fission products was determined by PIE to have been relatively low during the irradiation. As an example, maximum capsule-average fractional releases from the fuel compacts were $1 \times 10^{-5}, 3 \times 10^{-5}$, and $5 \times 10^{-4}$ for ${ }^{134} \mathrm{Cs},{ }^{90} \mathrm{Sr}$, and ${ }^{154} \mathrm{Eu}$, respectively, with significantly lower values in some capsules. The elements strontium and europium, in particular, exhibited a relatively high level of retention in the carbonaceous outer pyrolytic carbon (OPyC) and compact matrix, such that the majority of the inventory released through the silicon carbide (SiC) layer of the particles was in fact retained within the compacts.

A significant finding was the extremely low levels of cesium released through intact coatings. This was true both during the irradiation and during post-irradiation heating tests to temperatures as high as $1800^{\circ} \mathrm{C}$. It was found that cesium release from a particle was related primarily to discrete failure of the $\mathrm{SiC}$ layer, which could result in a particle releasing the majority of its cesium inventory, while in the absence of such failures the release was extremely low (capsule-average release from compacts in the absence of $\mathrm{SiC}$ failures was $<3 \times 10^{-6}$ ). Several new and innovative characterization techniques were used during the AGR-1 PIE to locate specific particles that experienced SiC failure based on their level of cesium release, and then perform detailed microstructural examinations to explore the causes of SiC layer failure in a manner not previously demonstrated in coated particle PIE efforts. It was discovered that the predominant cause of $\mathrm{SiC}$ failure is a two-part mechanism involving (1) fracture of the inner pyrolytic carbon (IPyC) layer due to densification of an adherent buffer layer and (2) localized palladium accumulation at the IPyC-SiC interface in the region of the IPyC fracture and subsequent degradation of the $\mathrm{SiC}$ layer through chemical reaction with palladium. In the absence of IPyC layer fracture, widespread chemical attack of the $\mathrm{SiC}$ layer by palladium was not observed. It was determined that four particles in the AGR-1 experiment experienced $\mathrm{SiC}$ layer failure during irradiation, which gives an in-pile SiC failure fraction of $<3.1 \times 10^{-5}$ at $95 \%$ confidence.

Post-irradiation safety test fuel performance was generally excellent. As an example, the maximum fractional releases from fuel compacts heated for 300 hours at $1600^{\circ} \mathrm{C}$ were approximately $2 \times 10^{-4}$ $\left({ }^{134} \mathrm{Cs}\right), 3 \times 10^{-3}\left({ }^{154} \mathrm{Eu}\right), 2 \times 10^{-3}\left({ }^{90} \mathrm{Sr}\right)$, and $4 \times 10^{-6}\left({ }^{85} \mathrm{Kr}\right)$. The maximum ${ }^{154} \mathrm{Eu},{ }^{134} \mathrm{Cs}$, and ${ }^{90} \mathrm{Sr}$ releases were roughly an order of magnitude higher at $1800^{\circ} \mathrm{C}$. In the case of ${ }^{134} \mathrm{Cs}$, release was clearly driven by a steady increase in the average number of $\mathrm{SiC}$ failures as the test temperature increased; in the absence of $\mathrm{SiC}$ failures, the maximum release at $1600^{\circ} \mathrm{C}$ was approximately $5 \times 10^{-6}$. The observed ${ }^{85} \mathrm{Kr}$ release at $1800^{\circ} \mathrm{C}$ increased as a result of increased coating failure frequency; the maximum ${ }^{85} \mathrm{Kr}$ release after 300 hours at $1800^{\circ} \mathrm{C}$ was approximately $5 \times 10^{-4}$, and was related to TRISO failures at this very high test temperature. Post-safety-test analysis of the fuel revealed that $\mathrm{SiC}$ failure usually proceeded by the same mechanism as observed for in-pile failures, but that the localized palladium attack of the $\mathrm{SiC}$ layer was accelerated at higher temperatures.

Silver release from the particles and compacts during irradiation was often very high, consistent with observations from previous TRISO fuel irradiation experiments. The evidence suggests that variation in 
the amount of silver released from different fuel specimens is primarily due to time-dependent temperature variations in the fuel. While silver release from fuel compacts during high-temperature postirradiation safety tests could be high (as high as $\sim 30 \%$ ), it was usually limited to the first few hours of the test, and was determined to be due to inventory that had been previously released from particles during the irradiation but retained within the OPyC layers or compact matrix. Little additional silver release from particles was measured during isothermal testing for up to 300 hours at 1600 and $1700^{\circ} \mathrm{C}$. Only at a test temperature of $1800^{\circ} \mathrm{C}$ was clear evidence of additional silver release through intact coatings observed. In addition, a single test indicated higher silver release at intermediate temperatures (peaking at $1150^{\circ} \mathrm{C}$ ); this requires further exploration in future tests.

Extensive microanalysis of fuel particles was performed after irradiation and after high-temperature safety testing to better understand fission product migration under a variety of conditions. This analysis included conventional techniques such as optical microcopy and scanning electron microscopy, as well as more advanced methods such as transmission electron microscopy and scanning transmission electron microscopy, coupled with several methods for elemental and crystallographic analysis. In some cases, these analytical techniques have not previously been applied to irradiated TRISO fuel, and enabled analysis of fission products within the coating layer microstructures down to nanometer-length scales.

In addition to the elucidation of the $\mathrm{SiC}$ failure mechanism discussed above, the results of particle microanalysis indicate that the UCO fuel is effective at controlling the oxygen partial pressure within the particle and limiting kernel migration. The observation of buffer densification and related fracture, along with IPyC fractures occasionally occurring when the buffer and IPyC layers stay adhered, resulted in a key conclusion that buffer-IPyC detachment is desirable to avoid fractures developing in the dense coating layers, which rarely show radiation-induced fracture in the absence of fracture in an adjoining layer. Fission products silver and palladium, along with uranium, were commonly observed within the $\mathrm{SiC}$ layer, usually at grain boundaries and often with other fission products. Such features were commonly observed through the entire thickness of intact SiC layers and could be extremely fine (down to a few nanometers in size). These results suggest grain-boundary transport of silver through $\mathrm{SiC}$, as well as the potential role of other fission products (including palladium) in silver transport.

Post-irradiation examination has provided the final body of data that speaks to the quality of the AGR-1 fuel, building on the as-fabricated fuel characterization and irradiation data. In addition to the extensive volume of results generated, the work also resulted in a number of novel analysis techniques and lessons learned that are being applied to the examination of fuel from subsequent TRISO fuel irradiations. This report provides a summary of the results obtained as part of the AGR-1 PIE campaign over its approximately 5-year duration. Numerous detailed interim and topical publications have been issued as the work progressed. These are referenced throughout for the reader to seek more detailed data as needed. 


\section{ACKNOWLEDGEMENTS}

This work was performed through the support and contributions of many dedicated and talented staff members at Idaho National Laboratory (INL) and Oak Ridge National Laboratory (ORNL). Key contributors of technical input to this report include Philip L. Winston, Haiming Wen, Les Scott, David V. Laug, Dawn Janney, James Madden, Tammy Trowbridge, Thomas O'Holleran, Tom Lillo, Connie Hill, Lance T. Cole, and Matthias A. Ebner at INL; and Charles A. Baldwin, Fred C. Montgomery, Chinthaka M. Silva, Traig W. Savage, and Jay S. Kehn at ORNL. The authors also gratefully acknowledge the support of the staff at the INL Hot Fuel Examination Facility, INL Analytical Laboratory, INL Electron Microscopy Laboratory, INL Center for Advanced Energy Studies, ORNL Irradiated Fuels Examination Laboratory, and ORNL Nuclear Analytical Chemistry \& Isotopics Laboratory. Additional support on advanced microscopy was provided by Jan Neethling, Mike Lee, Jaco Olivier, and William Goossen at the Nelson Mandela Metropolitan University; Terry Holesinger at Los Alamos National Laboratory; Daniel Goran at Bruker-Nano; and Bin Leng at the University of Wisconsin-Madison. 


\section{CONTENTS}

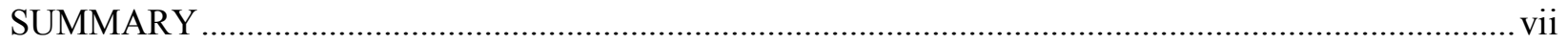

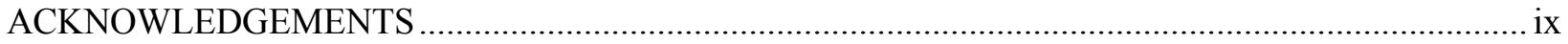

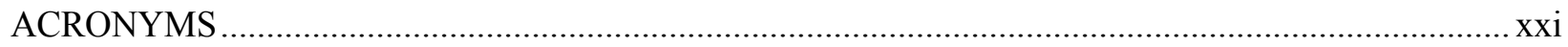

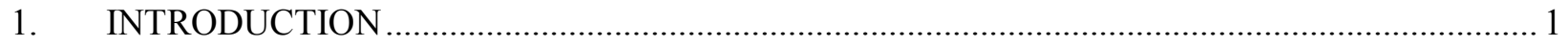

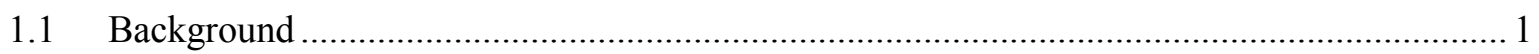

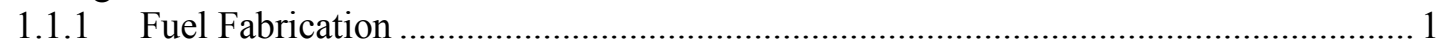

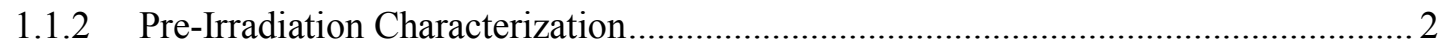

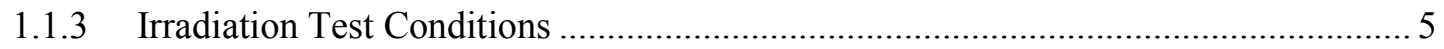

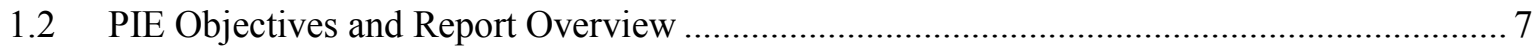

2. TEST TRAIN AND CAPSULE INSPECTION, DISASSEMBLY, AND METROLOGY ............. 7

2.1 Test Train Inspection and Gamma Scanning ................................................................. 7

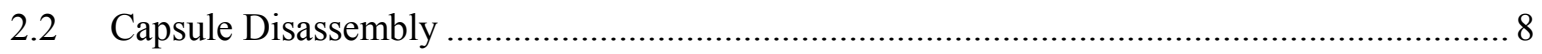

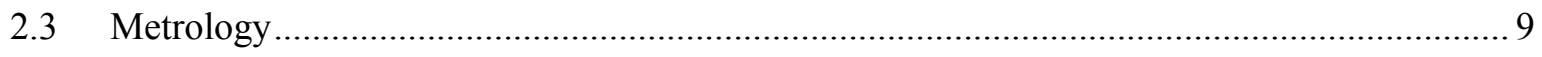

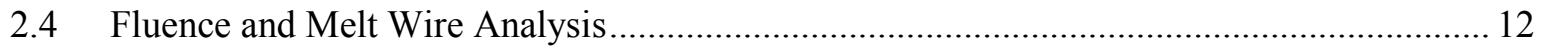

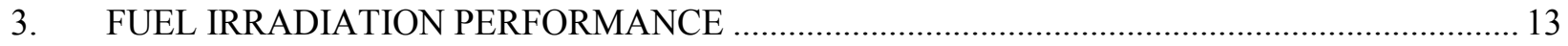

3.1 Overview of Objectives and Experimental Approach....................................................... 13

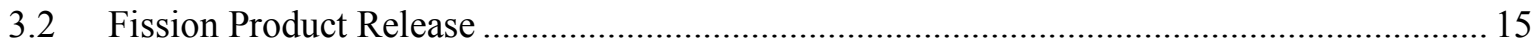

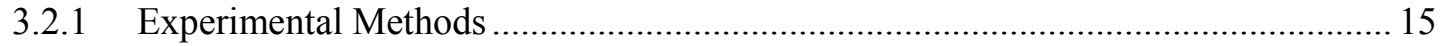

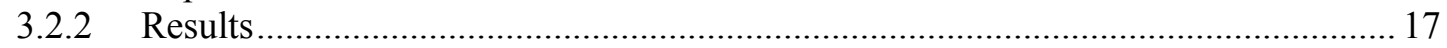

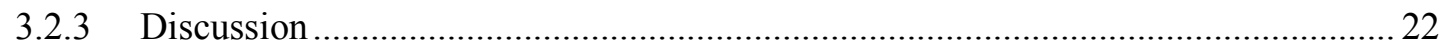

3.3 Burnup Analysis and Comparison of Isotopic Inventories with Predictions ....................... 25

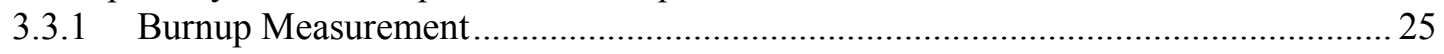

3.3.2 Comparison of Measured versus Calculated Inventories........................................ 26

3.4 Microstructure Evolution and Fission Product Distribution ............................................... 29

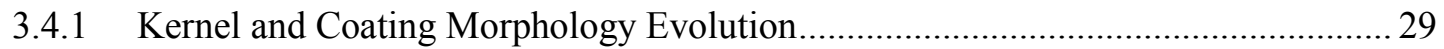

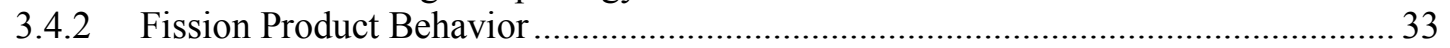

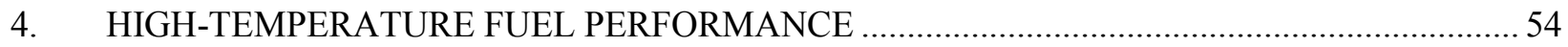

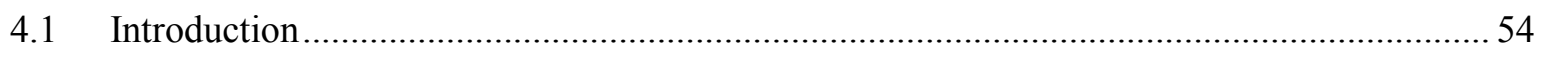

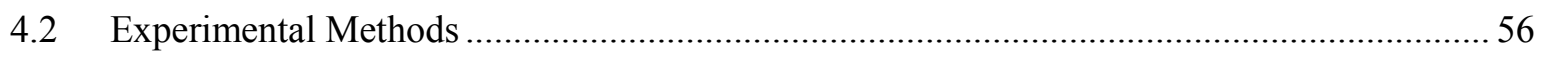

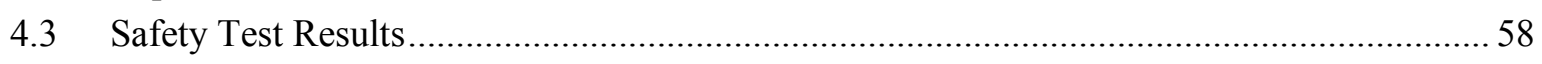

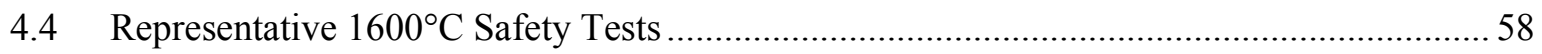

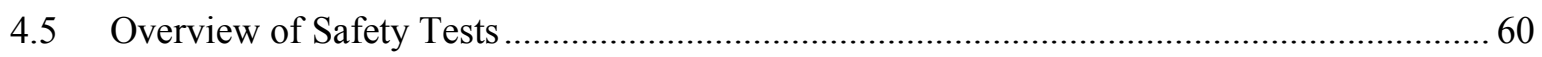

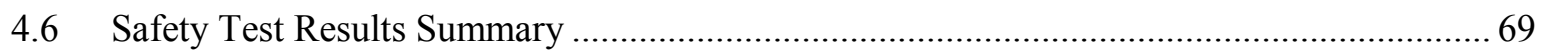

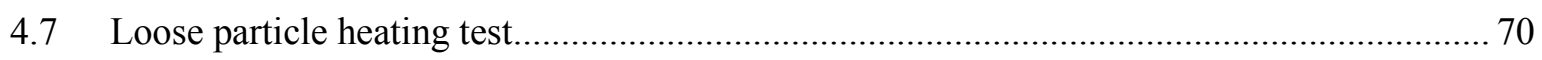

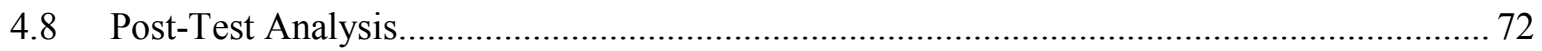

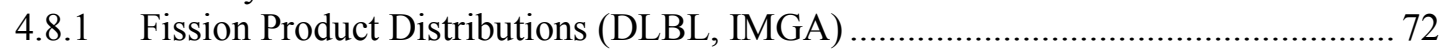

4.8.2 Microstructure Evolution and Fission Product Distribution ..................................... 74

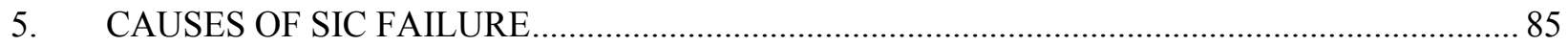




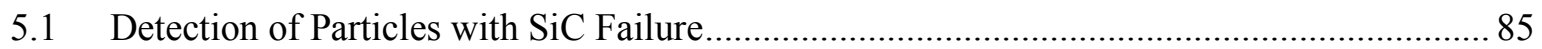

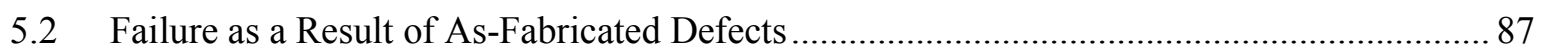

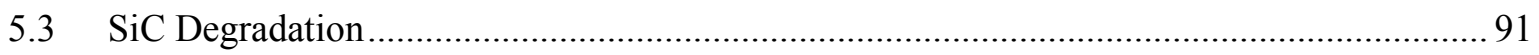

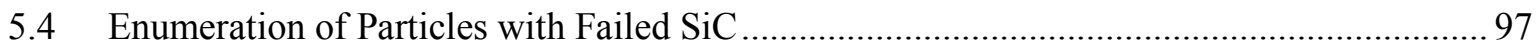

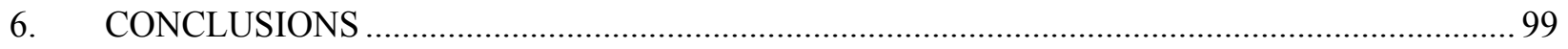

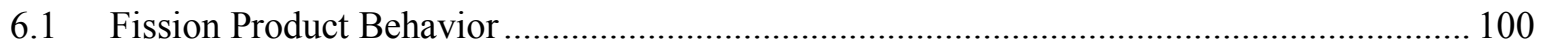

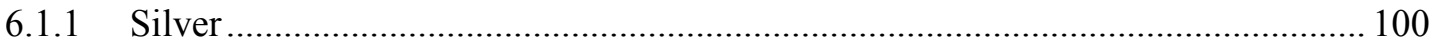

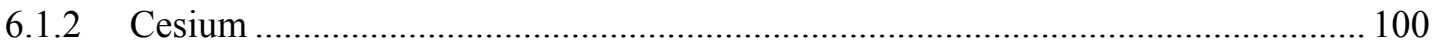

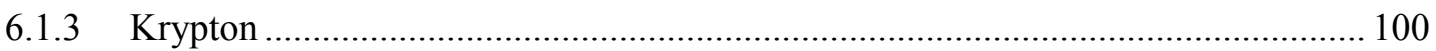

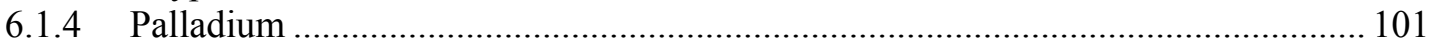

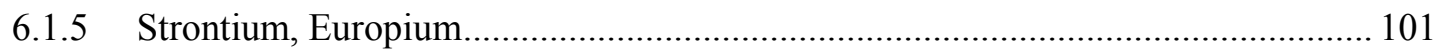

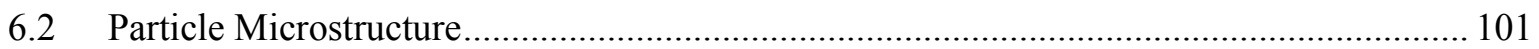

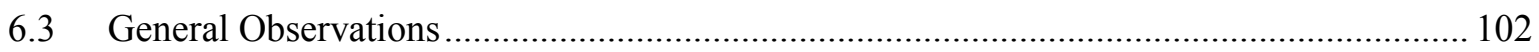

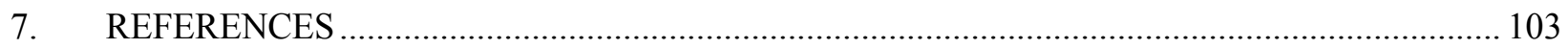

7.1 AGR-1 Post-Irradiation Examination Topical Reference List.......................................... 103

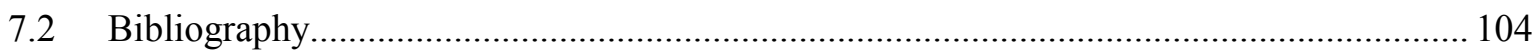

\section{FIGURES}

Figure 1. Cutaway diagram of an AGR-1 capsule showing (a) the key components and

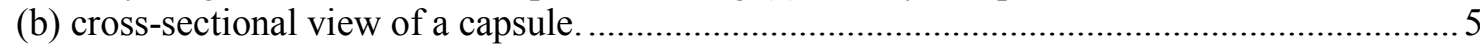

Figure 2. Numbering scheme used to identify compacts in the AGR-1 test train...................................... 6

Figure 3. Images from AGR-1 disassembly: (a) Capsule 5 graphite fuel holder after removal from the capsule; (b) a graphite spacer from Capsule 5; (c) head piece from Capsule 4, showing through tubes fractured during disassembly; (d) Capsule 4 after the shell was cut mid-length and the graphite holder fractured in two pieces; (e) Compact 2-3-3 after removal from the graphite holder.

Figure 4. Average diameter changes of individual AGR-1 compacts................................................... 9

Figure 5. Average diameter change for all AGR-1 compacts as a function of calculated fast neutron fluence $(\mathrm{E}>0.18 \mathrm{Mev})$. 10

Figure 6. Relative outer diameter change for AGR-1 graphite holders.

Figure 7. AGR-1 graphite holder outer diameter compared to as-fabricated diameter and the inner diameter of the steel capsule shell liner.

Figure 8. Deposited material near the top (left) and middle (right) of the steel shell from Capsule 6.

Figure 9. The range of inventory fractions found retained in irradiated compacts outside of the $\mathrm{SiC}$ layer (red columns) and on the capsule components (blue columns). The portions of the data circled and labeled as "SiC failures" are related to the presence of particles with failed SiC layers, as discussed in the text. The cross-hatched regions indicate values that correspond to measured inventories below the detection limit, which represent a conservative upper-bound on the range. 
Figure 10. Fraction of retained ${ }^{110 \mathrm{~m}} \mathrm{Ag}$ inventory in 56 of the 72 AGR-1 fuel compacts after irradiation. Data are plotted as a function of vertical position in the experiment (top of the experiment at the left) and by the stack number.

Figure 11. Distributions for the ${ }^{110 \mathrm{~m}} \mathrm{Ag}$ measured-to-calculated ratio in particles from three AGR-1 compacts.

Figure 12. Distributions for the ${ }^{134} \mathrm{Ce}$ and ${ }^{154} \mathrm{Eu}$ measured-to-calculated ratio in particles from Compact 4-4-2.

Figure 13. Calculated to Experimental (C/E) activity ratio for several different fission products for each fuel compact in the AGR-1 test train. Fuel compacts are plotted by vertical position in the AGR-1 test train, with the top of the test train at the left and the bottom at the right. There are three compacts at each axial location.

Figure 14. Irradiated AGR-1 Baseline fuel particle with continuous radial gap from inward shrinkage of the buffer layer.

Figure 15. Irradiated AGR-1 Baseline fuel particle with local buffer-IPyC bonding, buffer fracturing, and protruding kernel.

The kernel frequently protruded into a cavity where the buffer split apart, occasionally approaching the IPyC interior without obviously damaging it. Protrusion was typically more extensive on one side, as in the Figure 15 example, presumably where a cavity first opened. This behavior indicates that intact, inwardly shrinking buffers possessed some mechanical strength and constrained kernel growth. Kernels seemed to expand more in the rare particles with no buffer-IPyC delamination due to the outward densification of the buffer. Larger pores tended to be found in kernels with less constrained growth, especially toward the kernel center, as in Figure 15.

Despite kernel protrusions, no instances of kernel migration (commonly referred to as the "amoeba effect") were observed in cross sectioned AGR-1 particles. As seen historically in irradiation testing of uranium dioxide and uranium carbide particles, these kernels can migrate up the temperature gradient into the coating layers (Lindemer and Pearson 1977). The absence of kernel migration demonstrates that the UCO kernel chemistry effectively reduced the oxygen partial pressure during the AGR-1 experiment.

Figure 16. Irradiated AGR-1 Variant 1 particle, showing aligned buffer-IPyC fractures, IPyC-SiC debonds, and $\mathrm{SiC}$ crack formation.

Figure 17. Irradiated AGR-1 Variant 1 particle, showing IPyC fracturing, IPyC-SiC delamination, and $\mathrm{SiC}$ crack formation without evidence of buffer fracture.

Figure 18. BEC micrograph of the TRISO layers from a Compact 5-2-3 particle with very low Ag retention $(\mathrm{M} / \mathrm{C} \leq 0.09)$, bright areas at the IPyC-SiC interface and in the $\mathrm{SiC}$ layer are associated with segregated fission product features.

Figure 19. SEM micrograph showing $\mathrm{Pd} / \mathrm{Cs} / \mathrm{U}$ rich fission product features at the IPyC-SiC interface in AGR1-531-038, confirmed by WDS maps of Pd, Cs and U.

Figure 20. SEI/BEC-paired images of Compact 5-2-1, (a) very low Ag retention particle $(\mathrm{M} / \mathrm{C} \leq 0.25)$ and $(\mathrm{b})$ high $\mathrm{Ag}$ retention particle $(\mathrm{M} / \mathrm{C}=1.03)$. Areas of bright contrast in $\mathrm{BEC}$ micrograph indicate isolated fission product features.

Figure 21. SEM images of particle AGR1-531-038 showing (a) an image montage representing the distribution of precipitate clusters, (b) an optical micrograph of the particle cross section, and (c) a representative SEM image of the IPyC-SiC interface. 
Figure 22. Spherical cavities concentrated alongside SiC grain boundaries near a Pd-rich precipitate in the triple point (image is adapted from Van Rooyen et al. 2014b).

Figure 23. EPMA elemental maps at the tip of a crack in the IPyC layer of particle AGR1-523SP01. Maps were corrected for peak overlaps. Detection limits were computed for $\mathrm{x}$-ray images. Each image was scaled so that the lower end of the color scale is the detection limit in weight percent.

Figure 24. Results of an EPMA line scan on a cross section of particle AGR1-523-SP01. The red line indicates the path of quantitative radial traverse (analytical conditions $20 \mathrm{kV}$, 200nA, 30 seconds peaks, 10 seconds background).

Figure 25. Image showing (a) a high-angle annular dark field (HAADF) STEM image of grain boundaries containing silver (labeled 1 and 2) and a triple junction (labeled 3 ) at the edge of the $\mathrm{SiC}$ adjacent to the IPyC from lamella AGR1-632-035-6b . Image showing (b) the EDS spectrum identifying the $\mathrm{Ag} \mathrm{K \alpha l}$ peak at $22.163 \mathrm{keV}$ and the presence of $\mathrm{Cd}$ in the center of the triple junction shown in (a) $(\mathrm{Cu}$ is an artifact from the grid holder), (c) the EDS line scan profile through the triple junction indicating the presence of Ag, and (d) higher magnification of Area 3 in (a). Although no Pd was observed in the triple junction, $\mathrm{Pd}$ and $\mathrm{U}$ were identified in the $\mathrm{SiC}$ matrix adjacent to this triple junction (Van Rooyen et al. 2014d).

Figure 26. (a) Different types of nano-precipitates identified inside a SiC grain, (b) EDS spectrum indicates $\mathrm{S} 1$ is a Pd-Ag precipitate and (c) EDS spectrum indicates S2 is a Pd-rich precipitate (Leng et al. 2015).

Figure 27. An Ag-Pd-Cd precipitate at a stacking fault inside a $\mathrm{SiC}$ grain of particle AGR1-532-SP01. (a) STEM image showing the location of the Ag-Pd-Cd precipitate, whose composition was determined by EDS; (b) TEM image corresponding to (a); (c) a magnification of the red rectangle in (b); (d) a magnification of the red rectangle in (c), where stacking faults are present; (e) inverse FFT of the white square in (d), where the continuous lattice fringes indicate absence of grain boundary and confirm the presence of stacking faults (Wen et al. 2015c).

Figure 28. An overview of the precipitate type distribution found in particle AGR1-131-099 (figure adapted from Wen et al. 2015a). The predominant precipitate composition is shown for each area; additionally, small levels of $\mathrm{Cd}$ (denoted in green circles) were detected in the precipitates from the IPyC-SiC interface up to approximately the middle of the $\mathrm{SiC}$. 46

Figure 29. STEM micrograph showing evidence of a nano network of fission products at the outer edge of the $\mathrm{SiC}$ from particle AGR1-632-035-6b.

Figure 30. Zero-loss image of the second phase at triple junction (a) and corresponding EELS spectrum obtained at this area (b); EFTEM elemental maps of Ag and Si at this area (c) and (d), respectively (Van Rooyen et al. 2013).

Figure 31. Bright field (BF) STEM image (a) of a triple point containing Pd, Ag, and Cd, with the corresponding high-resolution BF STEM image (b), where fission product atoms (dark spots) are also visible deeper in the SiC grain (Van Rooyen et al. 2014a).

Figure 32. High resolution BF STEM image of a Pd precipitate (Pd atoms are indicated by the arrow in the figure), which accumulated at a stacking fault in a $\mathrm{SiC}$ grain. Some black atoms (dark spots representing fission product atoms) are also visible in the $\mathrm{SiC}$ grain (Van Rooyen et al. 2014a)..... 
Figure 33. HRSTEM image and EDS mapping of a small area containing precipitates in the IPyC layer of particle AGR1-131-099 close to the IPyC-SiC interface. Both single and multiphase precipitates are shown. The red arrows indicate the single phase precipitate.

Figure 34. HRSTEM image and EDS mapping of an area containing precipitates in the SiC layer of particle AGR1-131-099 close to the IPyC-SiC interface. Both single and multiphase precipitates are shown. The red arrows indicate the multi-phase precipitate.

Figure 35. HRTEM images of the interface between a fission product precipitate and the SiC matrix in particle AGR1-131-099 lamella 1.

Figure 36. Schematic overview of the work done as part of AGR-1 PIE with complementary projects and other funding sources to assess crystallographic data on the $\mathrm{SiC}$ layer of particles and determine grain boundary misorientation (stars indicating the most successful results obtained at present).

Figure 37. Distribution of grain boundary types for (a) inner, (b) center, and (c) outer areas in the $\mathrm{SiC}$ layer of an irradiated TRISO particle (AGR1-632-035) (adapted from Lillo et al. 2015b).

Figure 38. Distribution of grain boundary types for grain boundaries containing specific fission products in three inner areas in the SiC layer of particle AGR1-131-066: (a) grain boundaries containing Pd precipitate; (b) grain boundaries containing Pd-U precipitates. 53

Figure 39. Schematic of the CCCTF (a) and FACS (b) safety test furnaces. .57

Figure 40. Compact 6-2-1 test results. Cesium release was very low; higher ${ }^{137} \mathrm{Cs}$ accumulation, compared to ${ }^{134} \mathrm{Cs}$, indicates hot cell contamination.

Figure 41. Compact 4-1-2 test results. Cesium release above $10^{-4}$ indicates that this compact contained a particle whose $\mathrm{SiC}$ layer was not intact.

Figure 42. Fractional release of ${ }^{85} \mathrm{Kr}$ during safety testing. Only nine runs had measurable release, and Compact 4-3-2 showed the only TRISO failure.

Figure 43. Fractional release of ${ }^{90} \mathrm{Sr}$ during safety testing. Release increased with temperature.

Figure 44. Fractional release of ${ }^{110 \mathrm{~m}} \mathrm{Ag}$ during safety testing. Release peaked very early. Compact 3-3-2 showed secondary release related to thermal cycling of furnace.

Figure 45 . Fractional release of ${ }^{134} \mathrm{Cs}$ during safety testing. Sudden increases were due to $\mathrm{SiC}$ failure while either coming up to temperature or later in the run.

Figure 46. Scaled-release of ${ }^{134} \mathrm{Cs}$ illustrates the release history as a function of test temperature. The number of $\mathrm{SiC}$ failures increased with test temperature.

Figure 47. Fractional release of ${ }^{154} \mathrm{Eu}$ during safety testing. Release increased with temperature and exceeded single-particle inventory.

Figure 48. Comparison of the ${ }^{154} \mathrm{Eu}$ release from Baseline and Variant 1 (Compacts 3-2-3 and 5-1-3, respectively) versus Variant 3 Compacts 4-3-2 and 4-4-1; the Variant 3 compact behavior implies a diffusive release.

Figure 49. Comparison of the ${ }^{90} \mathrm{Sr}$ release from Baseline and Variant 1 (Compacts $32-3$ and 5-1-3, respectively) versus Variant 3 Compacts 4-3-2 and 4-4-1; this result is consistent with the ${ }^{154} \mathrm{Eu}$ data. 
Figure 50. Contrast in silver behavior between Variant 3 (compacts 4-3-2 and 4-4-1) compared to Baseline (Compact 3-2-3) and Variant 1 (Compact 5-1-3). The results are qualitatively similar to Eu and Sr results.

Figure 51. Collection of silver from Compact 4-2-2 during multiple-temperature safety test. The vertical axis shows the amount collected on the deposition cups; because the collection efficiency varied with temperature, this data may not directly scale to compact release.

Figure 52. Collection rate of silver from Compact 4-2-2 test. Note the temperature dependence

Figure 53. Summary of the average release fractions at the end of the safety tests for the three test temperatures. The general trend was a gradual increasing release with temperature, except for silver, which was almost independent of test temperature. Cesium release was an indicator of $\mathrm{SiC}$ failure, and krypton release was related to the same $\mathrm{SiC}$ failure (with highest release from Compact 4-3-2 due to concurrent TRISO failure).

Figure 54. Cumulative release of silver, europium, and strontium from Compact 4-4-2 loose particles at $1800^{\circ} \mathrm{C}$.

Figure 55. Ratio of measured ${ }^{110 \mathrm{~m}} \mathrm{Ag}$ retained in 75 particles versus calculated inventory, adjusted for variation in fissionable material and burnup with the measured ${ }^{106} \mathrm{Ru}$ activity; (a) as-irradiated and (b) after $1800^{\circ} \mathrm{C}$ heating test (detection limit at the end of the test was $\mathrm{M} / \mathrm{C}<0.21-0.41)$.

Figure 56. Radioisotope retention fraction of 75 particles after $1800^{\circ} \mathrm{C}$ safety testing. 72

Figure 57. X-ray tomographs near midplane of Compact 5-3-3 particles, safety-tested at $1600^{\circ} \mathrm{C}$ : (a) particle with undetectable ${ }^{110 \mathrm{~m}} \mathrm{Ag}$ inventory $(\mathrm{M} / \mathrm{C}<0.22)$, and (b) particle with average ${ }^{110 \mathrm{~m}} \mathrm{Ag}$ inventory $(\mathrm{M} / \mathrm{C}=0.88)$. Bright features at the IPyC-SiC interface are fission products. Rings in kernel are tomography artifacts.

Figure 58. Orthogonal x-ray tomographs of a Compact 3-3-1 particle, safety tested at $1700^{\circ} \mathrm{C}$ with average ${ }^{110 \mathrm{~m}} \mathrm{Ag}$ inventory near midplane (a) and offset from midplane (b) showing a fractured buffer, but no apparent IPyC damage. Bright features in the fractured buffer are fission product buildup.

Figure 59. X-ray tomograph near midplane of an $1800^{\circ} \mathrm{C}$ safety-tested Compact 4-4-1 particle with low silver retention, showing the typical buffer densification and delamination from the IPyC, as well as a $\mathrm{SiC} / \mathrm{OPyC}$ gap.

Figure 60. Optical micrographs of polished cross sections from $1600^{\circ} \mathrm{C}$ safety-tested Compact 3-2-2 particles with average silver retention, showing (a) typical buffer densification and delamination from the IPyC layer, and (b) buffer fracture and kernel protrusion due to limited delamination from the IPyC layer.

Figure 61. Optical micrographs near midplane of particles from $1600^{\circ} \mathrm{C}$ safety-tested Compact 5-3-3: (a) particle with high ${ }^{110 \mathrm{~m}} \mathrm{Ag}$ release $(\mathrm{M} / \mathrm{C}<0.21)$, (b) particle with moderate ${ }^{110 \mathrm{~m}} \mathrm{Ag}$ release $(\mathrm{M} / \mathrm{C}=0.58)$, (c) particle with approximately average ${ }^{110 \mathrm{~m}} \mathrm{Ag}$ $\mathrm{M} / \mathrm{C}(0.81)$, suggesting low or negligible release, and (d) particle with very low ${ }^{110 \mathrm{~m}} \mathrm{Ag}$ release $(\mathrm{M} / \mathrm{C}=1.10)$. .78

Figure 62. Optical micrograph near midplane of a typical particle from $1800^{\circ} \mathrm{C}$ safety-tested Compact 4-4-1 showing a wide gap between the SiC and OPyC (backfilled with epoxy during sample preparation), and a band of dark spots in the outer half of the $\mathrm{SiC}$ layer......

Figure 63. SEI/BEC-paired images of Compact 4-1-2, safety tested at $1600^{\circ} \mathrm{C}$ : (a) very low $\mathrm{Ag}$ retention particle $(M / C \leq 0.16)$ and $(b)$ high $A g$ retention particle $(M / C=1.12)$. Areas of bright contrast in BEC micrograph indicate isolated fission product features. 
Figure 64. Particle AGR1-433-001 showing (a) an SEM image montage representing the distribution of precipitate clusters, (b) an optical micrograph of the particle cross section, and (c) a representative SEM image of the IPyC-SiC interface.

Figure 65. SEM images of AGR1-433-001 showing kernel-buffer diffusion area, with no kernel-buffer debonding. 82

Figure 66. SEM images of AGR1-433-004 showing kernel-buffer diffusion area, with kernel-buffer debonding, and EDS and WDS maps of the area in (b).

Figure 67. SEI/BEC-paired images of Compact 5-1-1, safety tested at $1700^{\circ} \mathrm{C}$ : (a) low $\mathrm{Ag}$ retention particle $(\mathrm{M} / \mathrm{C} \leq 0.61)$ and $(\mathrm{b})$ high $\mathrm{Ag}$ retention particle $(\mathrm{M} / \mathrm{C}=1.01)$. Spots of bright contrast in BEC micrograph indicate isolated fission product features. The bright material in the SEI image in the lower left corner is due to charging of epoxy infiltrating the gap between the $\mathrm{SiC}$ and OPyC.

Figure 68. SEI/BEC-paired images of Compact 3-2-3, safety tested at $1800^{\circ} \mathrm{C}$ : (a) low $\mathrm{Ag}$ retention particle $(\mathrm{M} / \mathrm{C} \leq 0.25)$ and $(\mathrm{b})$ high $\mathrm{Ag}$ retention particle $(\mathrm{M} / \mathrm{C}=1.17)$. Areas of bright contrast in BEC micrograph indicate isolated fission product features.

Figure 69. Intensity map of ${ }^{134} \mathrm{Cs}$ activity in one section of Capsule 5 graphite holder showing hot spots (red) adjacent to Compacts 5-2-1 and 5-2-3 (Harp et al. 2012).....

Figure 70 . Fraction of the compact's cesium inventory released per hour during $1600^{\circ} \mathrm{C}$ safety testing of AGR-1 Compact 4-1-2. 86

Figure 71 . Fraction of the compact's cesium inventory released per hour during $1800^{\circ} \mathrm{C}$ safety testing of AGR-1 Compacts 3-2-3 and 5-1-3. 86

Figure 72. Cesium inventory distribution determined with IMGA for particles from $1800^{\circ} \mathrm{C}$ safety-tested AGR-1 Compact 3-2-3.

Figure 73. Particle that released cesium during $1600^{\circ} \mathrm{C}$ safety testing of Compact 3-3-2 due to an as-fabricated defect that led to $\mathrm{SiC}$ failure when the particle was heated above the irradiation temperature.

Figure 74. Particle that released cesium during safety testing of Compact 4-1-2; (a) x-ray tomograph and (b) semitransparent 3-D visualization of $\mathrm{SiC}$ surface.

Figure 75. Low Cs/Ce Particle 3 (511-SP02): oblique orthogonal x-ray tomographs showing a gross $\mathrm{SiC}$ inclusion (pre-irradiation defect), and only residual kernel material remaining after pre-burn leaching.

Figure 76. Compact 3-3-2 particle with soot inclusion defect that failed during $1600^{\circ} \mathrm{C}$ safety testing. A crack through intact $\mathrm{SiC}$ covering the porous region produced a pathway through the layer.

Figure 77. X-ray tomographs of AGR-1 particles with failed SiC; (a) Compact 3-2-3 Particle 5 after $1800^{\circ} \mathrm{C}$ safety testing, (b) Compact 3-3-1 Particle 1 after $1700^{\circ} \mathrm{C}$ safety testing, and (c) Compact 5-2-3 Particle 2 after completion of AGR-1 irradiation test.

Figure 78. Orthogonal x-ray tomographs showing kernel protruding to the $\mathrm{SiC}$ in Compact 3-2-3 Particle 6 after $1800^{\circ} \mathrm{C}$ safety testing.

Figure 79. X-ray tomograph/optical micrograph pairs showing how x-ray imaging was used to guide materialographic preparation of the Compact 5-2-3 particle in Figure 77c (grinding up from the bottom of that image). Optical images (right) show in-progress sectioning prior to final polish and cleaning. 
Figure 80. Compact 5-2-3 Particle 1 with $\mathrm{SiC}$ that failed during irradiation testing.

Figure 81. Particle from Compact 5-2-1 that failed during irradiation testing; (a) x-ray tomograph oriented to show low-density pathway through $\mathrm{SiC}$, and (b) optical micrograph

showing degraded area. 95

Figure 82. Successive polished planar sections showing corrosion progression through $\mathrm{SiC}$ of Compact 3-3-1 Particle 2 after $1700^{\circ} \mathrm{C}$ safety testing. .96

Figure 83. Polished planar section through degraded SiC area in Compact 3-3-1 Particle 1 (Figure $77 \mathrm{~b}$ ) after $1700^{\circ} \mathrm{C}$ safety testing; (a) SEI and (b) BEC images that show numerous white clusters of palladium and uranium and other dark gray areas that were predominately carbon. The SEI image shows bright spots where Pd and $\mathrm{U}$ are embedded close to the surface, while the BEC image shows additional Pd and $\mathrm{U}$ due to greater sensitivity and analysis depth. .96

\section{TABLES}

Table 1. Data packages for AGR-1 fuel particles and compacts. ......................................................... 2

Table 2. Summary of key properties for AGR-1 fuel particles............................................................... 3

Table 3. Summary of key properties for AGR-1 fuel compacts. ............................................................ 4

Table 4. Key attribute properties for AGR-1 fuel particles. ................................................................. 4

Table 5. Key attribute properties for AGR-1 fuel compacts.................................................................. 5

Table 6. Type of fuel compact used in each AGR-1 capsule................................................................... 6

Table 7. Comparison of fast neutron fluence $(\mathrm{E}>0.18 \mathrm{MeV})$ determined from measurement of fluence wires and from physics calculations (table from Sterbentz et al. 2015). ...................... 13

Table 8. Main AGR-1 PIE activities and objectives for evaluating fuel irradiation performance.............. 14

Table 9. Irradiated AGR-1 fuel compacts used for DLBL analysis and particle gamma counting. Corresponding references discussing DLBL and particle gamma counting are listed for each compact. 16

Table 10. Fractional inventory of fission products on the AGR-1 capsule components. …..................... 17

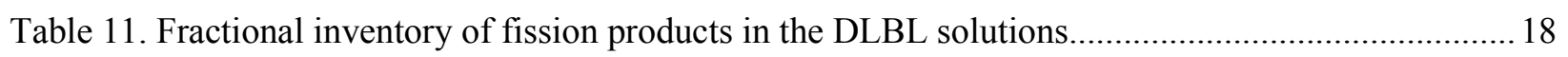

Table 12. Average fraction of ${ }^{110 \mathrm{~m}} \mathrm{Ag}$ retained in a sample of particles taken from the irradiated

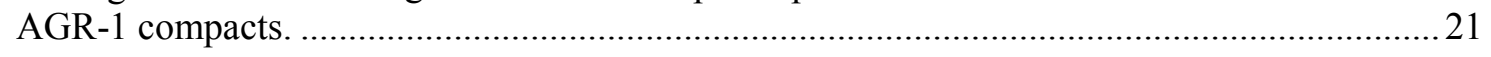

Table 13. Mass spectrometry burnup data compared to other techniques in \% FIMA............................. 26

Table 14. Experimentally determined average C/E values and corresponding M/C for all AGR-1

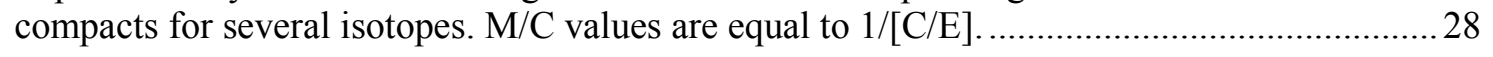

Table 15. Status summary of advanced microscopy activities for the AGR-1 PIE. ................................. 39

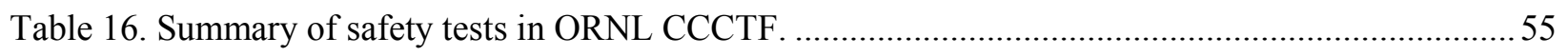

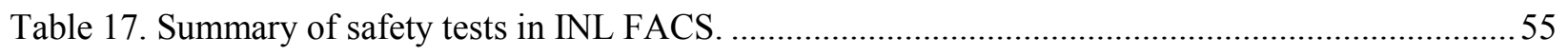

Table 18. Summary of safety test compact irradiation conditions.......................................................5

Table 19. Fractional inventory of fission products in the DLBL solutions after safety testing.................73 


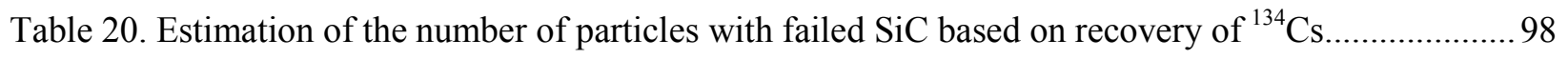

Table 21. Estimation of the number of particles with failed $\mathrm{SiC}$ based on identification by the IMGA and DLBL.

Table 22. Summary of SiC and TRISO failure fractions in AGR-1 fuel during irradiation and safety testing. .99

Table 23. AGR-1 PIE references listed by topical area. 103 


\section{ACRONYMS}

3D three-dimensional

AGR Advanced Gas Reactor Program

APT atom probe tomography

ART Advanced Reactor Technologies

ATR Advanced Test Reactor

BAFo optical Bacon anisotropy factor

BEC backscattered electron composition

BF bright field

$\mathrm{C} / \mathrm{E} \quad$ calculated to experimental

CAES Center for Advanced Energy Studies

CCCTF Core Conduction Cooldown Test Facility

CSL coincident site lattice

DLBL deconsolidation-leach-burn-leach analysis

EBSD electron back scatter diffraction

EDS energy dispersive spectroscopy

EELS electron energy loss spectroscopy

EFTEM Energy Filtered Transmission Electron Microscopy

EML the Electron Microscopy Laboratory

EPMA electron probe micro-analyzer

FACS Fuel Accident Condition Simulator

FEG field emission gun

FFT fast Fourier transformation

FIB focused ion beam

FIMA fissions per initial metal atom

HAADF high angle annular dark field

HF hydrofluoric acid

HFEF Hot Fuel Examination Facility

HRTEM High Resolution Transmission Electron Microscopy

ICP-MS inductively coupled plasma mass spectrometry

IMGA Irradiated Microsphere Gamma Analyzer

INL Idaho National Laboratory

IPyC inner pyrocarbon layer

LANL Los Alamos National Laboratory 


$\begin{array}{ll}\text { LEU } & \text { low enriched uranium } \\ \text { M/C } & \text { measured versus calculated } \\ \text { MaCS } & \text { Microscopy and Characterization Suite } \\ \text { MFC } & \text { Materials and Fuels Complex } \\ \text { N } & \text { diattenuation } \\ \text { NMMU } & \text { Nelson Mandela Metropolitan University } \\ \text { NRAD } & \text { Neutron Radiography } \\ \text { OPyC } & \text { outer pyrocarbon layer } \\ \text { ORNL } & \text { Oak Ridge National Laboratory } \\ \text { PED } & \text { precision electron scanner } \\ \text { PGS } & \text { Precision Gamma Scanner } \\ \text { PIE } & \text { post-irradiation examination } \\ \text { PNNL } & \text { Pacific Northwest National Laboratory } \\ \text { SAD } & \text { selected area diffraction } \\ \text { SEI } & \text { secondary electron imaging } \\ \text { SEM } & \text { scanning electron microscope } \\ \text { SiC } & \text { silicon carbide } \\ \text { STEM } & \text { scanning transmission electron microscopy } \\ \text { TAVA } & \text { time-average, volume average } \\ \text { TEM } & \text { transmission electron microscopy } \\ \text { TKD } & \text { transmission Kikuchi diffraction } \\ \text { TRISO } & \text { tristructural-isotropic } \\ \text { UCO } & \text { mixed uranium carbide/uranium oxide kernels } \\ \text { WDS } & \text { wavelength dispersive spectroscopy } \\ \text { Z } & \text { atomic number } \\ & \end{array}$




\section{AGR-1 Post Irradiation Examination Final Report}

\section{INTRODUCTION}

The Advanced Gas Reactor (AGR) Fuel Development and Qualification Program was established to perform the requisite research and development on tristructural isotropic (TRISO) coated particle fuel to support deployment of a high-temperature gas-cooled reactor (HTGR) (Petti et al. 2010). The work continues as part of the Advanced Reactor Technologies (ART) TRISO Fuel program. The overarching program goal is to provide a Baseline fuel qualification data set to support support Nuclear Regulatory Commission (NRC) licensing and operation of an HTGR. To achieve these goals, the program includes the elements of fuel fabrication, irradiation, post-irradiation examination (PIE) and safety testing, fuel performance, and fission product transport (INL 2014).

A series of fuel irradiation experiments is being planned and is being conducted in the Advanced Test Reactor (ATR) at Idaho National Laboratory (INL). These experiments will provide data on fuel performance under irradiation, support fuel process development, qualify the fuel for normal operating conditions, provide irradiated fuel for safety testing, and support the development of fuel performance and fission product transport models. The first of these irradiation tests, designated AGR-1, began irradiation in ATR in December 2006 and completed irradiation in November 2009. This experiment was conducted primarily to act as a shakedown test of the multicapsule test train design and provide early data on fuel performance for use in fuel fabrication process development. It also provided samples for post-irradiation safety testing, where fission product retention of the fuel at high temperatures will be experimentally measured. The capsule design and details of the AGR-1 experiment have been presented previously (Grover, Petti, and Maki 2010, Maki 2009).

The data and information produced in this document and the referenced documents within were generated under the approved Quality Assurance (QA) programs for the respective organizations including INL, Oak Ridge National Laboratory (ORNL), Los Alamos National Laboratory (LANL), and Pacific Northwest National Laboratory (PNNL) in compliance with the appropriate NQA-1 requirements. It is anticipated that all data will be robust enough to stand up to a review by the NRC as support for an HTGR.

\subsection{Background}

\subsubsection{Fuel Fabrication}

The AGR-1 compacts contained 19.7\% enriched mixed uranium carbide/uranium oxide (UCO) fuel kernels with a nominal diameter of $350 \mu \mathrm{m}$. The UCO kernels were identified as BWX Technologies Nuclear Operations Group (BWXT) composite G73D-20-69302. The low enriched uranium (LEU) fuel kernels were coated with a tristructural-isotropic (TRISO) coating in a 50-mm-diameter fluidized bed chemical vapor deposition coating furnace at the Oak Ridge National Laboratory (ORNL) (Lowden 2006). The TRISO-coated particles consisted of the spherical kernel coated with an approximately $50 \%$ dense carbon buffer layer (100- $\mu \mathrm{m}$-nominal thickness), followed by a dense inner pyrolytic carbon (IPyC)

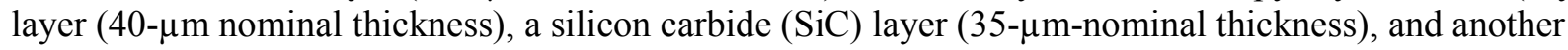
dense outer pyrolytic carbon (OPyC) layer (40- $\mu \mathrm{m}$-nominal thickness). Particles were overcoated at ORNL in a resinated graphite powder and then pressed into cylindrical compacts with nominal final dimensions of 25.0-mm long and 12.4-mm diameter (Pappano et al. 2008; Pappano 2006). Four fuel variants were produced: AGR-1 Baseline fuel compact lot LEU01-46T-Z, AGR-1 Variant 1 fuel compact lot LEU01-47T-Z, AGR-1 Variant 2 fuel compact lot LEU01-48T-Z, and AGR-1 Variant 3 fuel compact lot LEU01 49T Z. 
LEU01-46T-Z was a compact lot fabricated using AGR-1 Baseline particle composite LEU01 46T, which was a composite of four batches produced using coating conditions expected to closely replicate the coating properties of the German reference fuel. LEU01-47T-Z was a compact lot fabricated using Variant 1 particle composite LEU01-47T, which was a composite of three batches produced using coating conditions similar to the Baseline coated particles with the exception that the IPyC coating was deposited at $25^{\circ} \mathrm{C}$ higher temperature. LEU01-48T-Z was a compact lot fabricated using Variant 2 particle composite LEU01-48T, which was a composite of three batches produced using coating conditions similar to the Baseline coated particles with the exception that the IPyC coating was deposited at a coating gas fraction of 0.45 propylene/acetylene instead of the Baseline coating gas fraction of 0.30 . LEU01-49T-Z was a compact lot fabricated using Variant 3 particle composite LEU01-49T, which was a composite of three batches produced using coating conditions similar to the Baseline coated particles with the exception that the silicon carbide coating was deposited at a lower temperature $\left(1425^{\circ} \mathrm{C}\right.$ versus $1500^{\circ} \mathrm{C}$ ) using argon and hydrogen gas for fluidization in the coater as opposed to just hydrogen. Compact fabrication conditions were similar for all compact lots.

\subsubsection{Pre-Irradiation Characterization}

Data packages prepared for the AGR-1 fuel particles and compacts are listed in Table 1. The particle and compact data packages provide the information for product acceptance in accordance with the $A G R-1$ Fuel Product Specification and Characterization Guidance (Barnes 2006). These data packages contain analytical data for product acceptance, additional characterization data, and summaries of the fabrication processes. All fuel particle composites and compact lots were determined to meet the specified requirements, with the exception of some Baseline and Variant 2 compacts not meeting the minimum length specification. The disposition of this nonconformance was to "use-as-is". Additional pre-irradiation characterization of archive AGR-1 compacts has also been reported (Hunn, Savage, and Silva 2012) including optical imaging of compact surfaces and polished cross sections, $\mathrm{x}$-ray imaging of particle distributions, and post-heat treatment pyrocarbon anisotropy measurements.

Table 1. Data packages for AGR-1 fuel particles and compacts.

\begin{tabular}{|c|c|l|}
\hline \multicolumn{3}{|c|}{ Particles } \\
\hline LEU01-46T & ORNL/TM-2006/019 & $\begin{array}{l}\text { Data Compilation for AGR-1 Baseline Coated Particle } \\
\text { Composite LEU01-46T (Hunn and Lowden 2006a) }\end{array}$ \\
\hline LEU01-47T & ORNL/TM-2006/020 & $\begin{array}{l}\text { Data Compilation for AGR-1 Variant 1 Coated Particle } \\
\text { Composite LEU01-47T (Hunn and Lowden 2006b) }\end{array}$ \\
\hline LEU01-48T & ORNL/TM-2006/021 & $\begin{array}{l}\text { Data Compilation for AGR-1 Variant 2 Coated Particle } \\
\text { Composite LEU01-48T (Hunn and Lowden 2006c) }\end{array}$ \\
\hline LEU01-49T & ORNL/TM-2006/022 & $\begin{array}{l}\text { Data Compilation for AGR-1 Variant 3 Coated Particle } \\
\text { Composite LEU01-49T (Hunn and Lowden 2006d) }\end{array}$ \\
\hline LEU01-46T-Z & ORNL/TM-2006/507 & $\begin{array}{l}\text { Data Compilation for AGR-1 Baseline Compact Lot } \\
\text { LEU01-46T-Z (Hunn, Montgomery, and Pappano 2006a) }\end{array}$ \\
\hline LEU01-47T-Z & ORNL/TM-2006/508 & $\begin{array}{l}\text { Data Compilation for AGR-1 Variant 1 Compact Lot } \\
\text { LEU01-47T-Z (Hunn, Montgomery, and Pappano 2006b) }\end{array}$ \\
\hline LEU01-48T-Z & ORNL/TM-2006/509 & $\begin{array}{l}\text { Data Compilation for AGR-1 Variant 2 Compact Lot } \\
\text { LEU01-48T-Z (Hunn, Montgomery, and Pappano 2006c) }\end{array}$ \\
\hline LEU01-49T-Z & ORNL/TM-2006/510 & $\begin{array}{l}\text { Data Compilation for AGR-1 Variant 3 Compact Lot } \\
\text { LEU01-49T-Z (Hunn, Montgomery, and Pappano 2006d) }\end{array}$ \\
\hline
\end{tabular}


Table 2 and Table 3 provide a summary of some of the AGR-1 fuel data extracted from the particle and compact data packages, respectively. They give the mean values and standard deviations of key variable properties of the particle composites and compact lots. Detailed data report forms associated with the summary data in Table 2 and Table 3 can be found in the associated data packages in Table 1).

Table 2. Summary of key properties for AGR-1 fuel particles.

\begin{tabular}{|c|c|c|c|c|}
\hline Property & $\begin{array}{l}\text { LEU01-46T-Z } \\
\text { Baseline }\end{array}$ & $\begin{array}{l}\text { LEU01-47T-Z } \\
\text { Variant } 1\end{array}$ & $\begin{array}{l}\text { LEU01-48T-Z } \\
\text { Variant } 2\end{array}$ & $\begin{array}{l}\text { LEU01-49T-Z } \\
\text { Variant } 3\end{array}$ \\
\hline $\begin{array}{l}\text { Average bare kernel diameter }{ }^{a} \\
(\mu \mathrm{m})\end{array}$ & $\begin{array}{c}349.7 \\
(9) \\
\end{array}$ & $\begin{array}{c}349.7 \\
(9) \\
\end{array}$ & $\begin{array}{c}349.7 \\
(9) \\
\end{array}$ & $\begin{array}{c}349.7 \\
(9) \\
\end{array}$ \\
\hline $\begin{array}{l}\text { Average buffer thickness } \\
(\mu \mathrm{m})\end{array}$ & $\begin{array}{l}103.5 \\
(8.2)\end{array}$ & $\begin{array}{l}102.5 \\
(7.1)\end{array}$ & $\begin{array}{l}102.9 \\
(7.3)\end{array}$ & $\begin{array}{l}104.2 \\
(7.8)\end{array}$ \\
\hline $\begin{array}{l}\text { Average IPyC thickness } \\
(\mu \mathrm{m})\end{array}$ & $\begin{array}{l}39.4 \\
(2.3)\end{array}$ & $\begin{array}{l}40.5 \\
(2.4)\end{array}$ & $\begin{array}{l}40.1 \\
(2.8)\end{array}$ & $\begin{array}{l}38.8 \\
(2.1) \\
\end{array}$ \\
\hline $\begin{array}{l}\text { Average } \mathrm{SiC} \text { thickness } \\
(\mu \mathrm{m})\end{array}$ & $\begin{array}{l}35.3 \\
(1.3)\end{array}$ & $\begin{array}{l}35.7 \\
(1.2)\end{array}$ & $\begin{array}{l}35.0 \\
(1.0)\end{array}$ & $\begin{array}{l}35.9 \\
(2.1)\end{array}$ \\
\hline $\begin{array}{l}\text { Average OPyC thickness } \\
(\mu \mathrm{m})\end{array}$ & $\begin{array}{l}41.0 \\
(2.1)\end{array}$ & $\begin{array}{l}41.1 \\
(2.4)\end{array}$ & $\begin{array}{l}39.8 \\
(2.1)\end{array}$ & $\begin{array}{l}39.3 \\
(2.1)\end{array}$ \\
\hline $\begin{array}{l}\text { Mean particle diameter } \\
(\mu \mathrm{m})\end{array}$ & $\begin{array}{c}799.7 \\
(14) \\
\end{array}$ & $\begin{array}{c}804.0 \\
(13)\end{array}$ & $\begin{array}{c}798.3 \\
(14) \\
\end{array}$ & $\begin{array}{c}795.1 \\
(15) \\
\end{array}$ \\
\hline $\begin{array}{l}\text { Mean particle volume } \\
\left(\mathrm{cm}^{3}\right)\end{array}$ & $2.68 \mathrm{E}-4$ & $2.72 \mathrm{E}-4$ & $2.66 \mathrm{E}-4$ & $2.63 \mathrm{E}-4$ \\
\hline $\begin{array}{l}\text { Mean bare kernel weight }{ }^{a} \\
(\mathrm{~g})\end{array}$ & $\begin{array}{c}2.42 \mathrm{E}-4 \\
(1 \mathrm{E}-6)\end{array}$ & $\begin{array}{c}2.42 \mathrm{E}-4 \\
(1 \mathrm{E}-6)\end{array}$ & $\begin{array}{c}2.42 \mathrm{E}-4 \\
(1 \mathrm{E}-6)\end{array}$ & $\begin{array}{c}2.42 \mathrm{E}-4 \\
(1 \mathrm{E}-6)\end{array}$ \\
\hline $\begin{array}{l}\text { Mean particle weight } \\
(\mathrm{g})\end{array}$ & $\begin{array}{l}7.27 \mathrm{E}-4 \\
(1.0 \mathrm{E}-6)\end{array}$ & $\begin{array}{c}7.33 \mathrm{E}-4 \\
(3 \mathrm{E}-6)\end{array}$ & $\begin{array}{c}7.24 \mathrm{E}-4 \\
(2 \mathrm{E}-6)\end{array}$ & $\begin{array}{l}7.26 \mathrm{E}-4 \\
(1.7 \mathrm{E}-6)\end{array}$ \\
\hline $\begin{array}{l}\text { Mean uranium per particle } \\
(\mathrm{g} \mathrm{U})\end{array}$ & $2.18 \mathrm{E}-4$ & $2.18 \mathrm{E}-4$ & $2.18 \mathrm{E}-4$ & $2.18 \mathrm{E}-4$ \\
\hline $\begin{array}{l}\text { Bare kernel envelope density }{ }^{a} \\
\left(\mathrm{Mg} / \mathrm{m}^{3}\right)\end{array}$ & $\begin{array}{l}10.924 \\
(0.015)\end{array}$ & $\begin{array}{l}10.924 \\
(0.015)\end{array}$ & $\begin{array}{l}10.924 \\
(0.015)\end{array}$ & $\begin{array}{l}10.924 \\
(0.015)\end{array}$ \\
\hline $\begin{array}{l}\text { Buffer envelope density } \\
\left(\mathrm{Mg} / \mathrm{m}^{3}\right) \text { (interrupted batches) }\end{array}$ & 1.10 & 1.10 & 1.10 & 1.10 \\
\hline $\begin{array}{l}\text { IPyC sink/float density } \\
\left(\mathrm{Mg} / \mathrm{m}^{3}\right) \text { (interrupted batches) }\end{array}$ & 1.904 & 1.853 & 1.912 & 1.904 \\
\hline $\begin{array}{l}\mathrm{SiC} \text { sink/float density } \\
\left(\mathrm{Mg} / \mathrm{m}^{3}\right)\end{array}$ & $\begin{array}{l}3.208 \\
(0.003)\end{array}$ & $\begin{array}{r}3.206 \\
(0.002) \\
\end{array}$ & $\begin{array}{r}3.207 \\
(0.002) \\
\end{array}$ & $\begin{array}{r}3.2046 \\
(0.0010) \\
\end{array}$ \\
\hline $\begin{array}{l}\text { OPyC sink/float density } \\
\left(\mathrm{Mg} / \mathrm{m}^{3}\right) \text { (weighted average) }\end{array}$ & $\begin{array}{l}1.907 \\
(0.009)\end{array}$ & $\begin{array}{l}1.898 \\
(0.015)\end{array}$ & $\begin{array}{l}1.901 \\
(0.012)\end{array}$ & $\begin{array}{l}1.911 \\
(0.012)\end{array}$ \\
\hline $\begin{array}{l}\text { IPyC anisotropy } \\
\text { (BAFo equivalent) }{ }^{b}\end{array}$ & $\begin{array}{c}1.022 \\
(0.002)\end{array}$ & $\begin{array}{c}1.014 \\
(0.0014) \\
\end{array}$ & $\begin{array}{c}1.023 \\
(0.002) \\
\end{array}$ & $\begin{array}{c}1.029 \\
(0.002) \\
\end{array}$ \\
\hline $\begin{array}{l}\text { OPyC anisotropy } \\
\text { (BAFo equivalent) }^{b}\end{array}$ & $\begin{array}{c}1.019 \\
(0.003)\end{array}$ & $\begin{array}{c}1.013 \\
(0.0017)\end{array}$ & $\begin{array}{l}1.018 \\
(0.001)\end{array}$ & $\begin{array}{l}1.021 \\
(0.003)\end{array}$ \\
\hline \multicolumn{5}{|c|}{$\begin{array}{l}\text { Note: Numbers in parentheses are standard deviations. } \\
\text { a. Bare kernel diameter was measured prior to coating and does not include carbide skin; kernel density and weight were also } \\
\text { measured prior to coating and will not include reduction that occurred during carbide skin formation. } \\
\text { b. Optical Bacon anisotropy factor equivalent }(\mathrm{BAFo})=1+3 \mathrm{~N} \text { (where } \mathrm{N} \text { is the diattenuation). }\end{array}$} \\
\hline
\end{tabular}


Table 3. Summary of key properties for AGR-1 fuel compacts.

\begin{tabular}{|c|c|c|c|c|}
\hline Property & $\begin{array}{l}\text { LEU01-46T-Z } \\
\text { Baseline }\end{array}$ & $\begin{array}{l}\text { LEU01-47T-Z } \\
\text { Variant } 1\end{array}$ & $\begin{array}{c}\text { LEU01-48T-Z } \\
\text { Variant } 2\end{array}$ & $\begin{array}{c}\text { LEU01-49T-Z } \\
\text { Variant } 3\end{array}$ \\
\hline $\begin{array}{l}\text { Average number of } \\
\text { particles/compact }\end{array}$ & 4145 & 4150 & 4130 & 4126 \\
\hline $\begin{array}{l}\text { Mean uranium per compact } \\
(\mathrm{g} \mathrm{U})\end{array}$ & $\begin{array}{c}0.917 \\
(0.005) \\
\end{array}$ & $\begin{array}{c}0.915 \\
(0.004) \\
\end{array}$ & $\begin{array}{c}0.904 \\
(0.003) \\
\end{array}$ & $\begin{array}{c}0.912 \\
(0.002) \\
\end{array}$ \\
\hline $\begin{array}{l}\% \text { packing fraction } \\
\text { (particle volume / compact } \\
\text { volume) }\end{array}$ & 36.9 & 37.5 & 36.6 & 36.0 \\
\hline $\begin{array}{l}\text { Mean compact diameter } \\
(\mathrm{mm})\end{array}$ & $\begin{array}{c}12.37 \\
(0.009) \\
\end{array}$ & $\begin{array}{c}12.36 \\
(0.008) \\
\end{array}$ & $\begin{array}{c}12.36 \\
(0.007) \\
\end{array}$ & $\begin{array}{c}12.34 \\
(0.008) \\
\end{array}$ \\
\hline $\begin{array}{l}\text { Mean compact length } \\
(\mathrm{mm})\end{array}$ & $\begin{array}{l}25.05 \\
(0.07) \\
\end{array}$ & $\begin{array}{l}25.12 \\
(0.04)\end{array}$ & $\begin{array}{l}25.07 \\
(0.05)\end{array}$ & $\begin{array}{l}25.22 \\
(0.04) \\
\end{array}$ \\
\hline $\begin{array}{l}\text { Mean compact mass } \\
(\mathrm{g})\end{array}$ & $\begin{array}{c}5.482 \\
(0.012) \\
\end{array}$ & $\begin{array}{c}5.340 \\
(0.013) \\
\end{array}$ & $\begin{array}{c}5.367 \\
(0.027) \\
\end{array}$ & $\begin{array}{c}5.587 \\
(0.022) \\
\end{array}$ \\
\hline $\begin{array}{l}\text { Mean compact matrix density } \\
\left(\mathrm{g} / \mathrm{cm}^{3}\right)\end{array}$ & 1.30 & 1.22 & 1.25 & 1.34 \\
\hline
\end{tabular}

Table 4 and Table 5 summarize the measured defect fractions for AGR-1 fuel particles and compacts, respectively. Listed in Table 4 are the actual numbers of defects observed for the numbers of particles analyzed. In parentheses are the binomial distribution calculated upper limits of the $95 \%$ confidence interval on the various defect fractions. In other words, these values are the lowest tolerance limits for which the compact lot would be deemed acceptable at 95\% confidence, based on the particular sample that was measured. In many cases zero defects were observed. The defect fractions listed in the table for these cases are limited by the number of particles measured. The actual defect fraction could be much lower.

Table 4. Key attribute properties for AGR-1 fuel particles.

\begin{tabular}{|l|c|c|c|c|}
\hline \multicolumn{1}{|c|}{ Defect Property } & $\begin{array}{c}\text { LEU01-46T } \\
\text { Baseline }\end{array}$ & $\begin{array}{c}\text { LEU01-47T } \\
\text { Variant } 1\end{array}$ & $\begin{array}{c}\text { LEU01-48T } \\
\text { Variant 2 }\end{array}$ & $\begin{array}{c}\text { LEU01-49T } \\
\text { Variant 3 }\end{array}$ \\
\hline Particle aspect ratio $\geq 1.14$ & $\begin{array}{c}2 / 1626 \\
(\leq 3.9 \mathrm{E}-3)\end{array}$ & $\begin{array}{c}0 / 1808 \\
(\leq 1.7 \mathrm{E}-3)\end{array}$ & $\begin{array}{c}0 / 1795 \\
(\leq 1.7 \mathrm{E}-3)\end{array}$ & $\begin{array}{c}1 / 1709 \\
(\leq 2.8 \mathrm{E}-3)\end{array}$ \\
\hline SiC gold spot defect fraction & $\begin{array}{c}66 / 81507 \\
(\leq 1.0 \mathrm{E}-3)\end{array}$ & $\begin{array}{c}11 / 22461 \\
(\leq 8.2 \mathrm{E}-4)\end{array}$ & $\begin{array}{c}3 / 12233 \\
(\leq 6.4 \mathrm{E}-4)\end{array}$ & $\begin{array}{c}6 / 12190 \\
(\leq 9.8 \mathrm{E}-4)\end{array}$ \\
\hline Defective SiC coating fraction & $\begin{array}{c}0 / 120688 \\
(\leq 2.5 \mathrm{E}-5)\end{array}$ & $\begin{array}{c}1 / 121117 \\
(\leq 4.0 \mathrm{E}-5)\end{array}$ & $\begin{array}{c}1 / 50265 \\
(\leq 9.5 \mathrm{E}-5)\end{array}$ & $\begin{array}{c}1 / 120660 \\
(\leq 4.0 \mathrm{E}-5)\end{array}$ \\
\hline Missing OPyC coating fraction & $\begin{array}{c}0 / 31227 \\
(\leq 9.6 \mathrm{E}-5)\end{array}$ & $\begin{array}{c}0 / 31191 \\
(\leq 9.7 \mathrm{E}-5)\end{array}$ & $\begin{array}{c}0 / 31306 \\
(\leq 9.6 \mathrm{E}-5)\end{array}$ & $\begin{array}{c}0 / 31178 \\
(\leq 9.7 \mathrm{E}-5)\end{array}$ \\
\hline $\begin{array}{l}\text { Note: Numbers in parentheses are 95\% confidence defect fraction upper limits. } \\
\text { a. Defect fraction for particles with SiC soot inclusions not visible as gold spots. }\end{array}$ \\
\hline
\end{tabular}


Table 5. Key attribute properties for AGR-1 fuel compacts.

\begin{tabular}{|c|c|c|c|c|}
\hline Defect Property & $\begin{array}{c}\text { LEU01-46T-Z } \\
\text { Baseline }\end{array}$ & $\begin{array}{c}\text { LEU01-47T-Z } \\
\text { Variant } 1\end{array}$ & $\begin{array}{c}\text { LEU01-48T-Z } \\
\text { Variant 2 }\end{array}$ & $\begin{array}{c}\text { LEU01-49T-Z } \\
\text { Variant } 3\end{array}$ \\
\hline Exposed kernel fraction & $\begin{array}{c}0 / 99470 \\
(\leq 3.1 \mathrm{E}-5)\end{array}$ & $\begin{array}{c}0 / 74699 \\
(\leq 4.1 \mathrm{E}-5)\end{array}$ & $\begin{array}{c}0 / 99110 \\
(\leq 3.1 \mathrm{E}-5)\end{array}$ & $\begin{array}{c}0 / 99032 \\
(\leq 3.1 \mathrm{E}-5)\end{array}$ \\
\hline Defective SiC coating fraction & $\begin{array}{c}2 / 49735 \\
(\leq 1.3 \mathrm{E}-4)\end{array}$ & $\begin{array}{c}0 / 49799 \\
(\leq 6.1 \mathrm{E}-5)\end{array}$ & $\begin{array}{c}1 / 49555 \\
(\leq 9.6 \mathrm{E}-5)\end{array}$ & $\begin{array}{c}0 / 49516 \\
(\leq 6.1 \mathrm{E}-5)\end{array}$ \\
\hline Defective IPyC coating fraction & $\begin{array}{c}0 / 49735 \\
(\leq 6.1 \mathrm{E}-5)\end{array}$ & $\begin{array}{c}0 / 49799 \\
(\leq 6.1 \mathrm{E}-5)\end{array}$ & $\begin{array}{c}0 / 49555 \\
(\leq 6.1 \mathrm{E}-5)\end{array}$ & $\begin{array}{c}0 / 49516 \\
(\leq 6.1 \mathrm{E}-5)\end{array}$ \\
\hline Defective OPyC coating fraction & $\begin{array}{c}0 / 4145 \\
(\leq 7.3 \mathrm{E}-4)\end{array}$ & $\begin{array}{c}8 / 8300^{a} \\
(\leq 1.8 \mathrm{E}-3)\end{array}$ & $\begin{array}{c}0 / 4130 \\
(\leq 7.3 \mathrm{E}-4)\end{array}$ & $\begin{array}{c}0 / 4126 \\
(\leq 7.3 \mathrm{E}-4)\end{array}$ \\
\hline
\end{tabular}

Note: Numbers in parentheses are $95 \%$ confidence defect fraction upper limits

a. Eight particles with defective OPyC in Variant 1 may be an artifact of sieving.

\subsubsection{Irradiation Test Conditions}

The irradiation experiment consisted of six separate capsules, each with independent sweep gas flow and temperature monitoring and control. Each capsule contained 12 fuel compacts of a single fuel type retained in a graphite fuel holder in three stacks oriented in a triangular array (Figure 1), with each stack containing four compacts (Collin 2015). Table 6 lists the fuel type used in each capsule. Each compact has a unique identifier in the format $\mathrm{X}-\mathrm{Y}-\mathrm{Z}$ that denotes the original position in the experiment: $\mathrm{X}$ indicates the capsule, $\mathrm{Y}$ indicates the axial level within the capsule, and $\mathrm{Z}$ indicates the stack. Compact 6-1-1 was irradiated in Capsule 6, Level 1 (first level at the bottom of the capsule), Stack 1 (Figure 2).
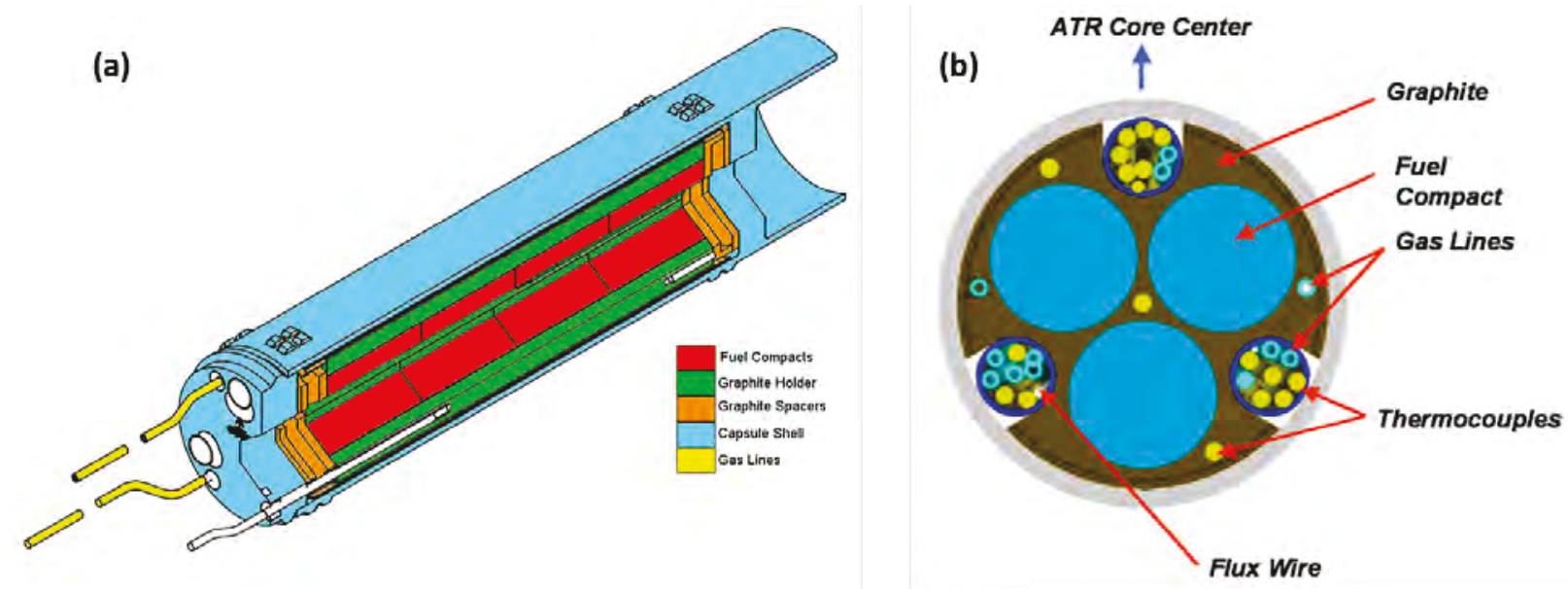

Figure 1. Cutaway diagram of an AGR-1 capsule showing (a) the key components and (b) cross-sectional view of a capsule. 
Table 6. Type of fuel compact used in each AGR-1 capsule.

\begin{tabular}{|c|c|}
\hline Fuel Type & Capsule \\
\hline Baseline & 6 \\
\hline Variant 1 & 5 \\
\hline Variant 3 & 4 \\
\hline Baseline & 3 \\
\hline Variant 2 & 2 \\
\hline Variant 3 & 1 \\
\hline
\end{tabular}

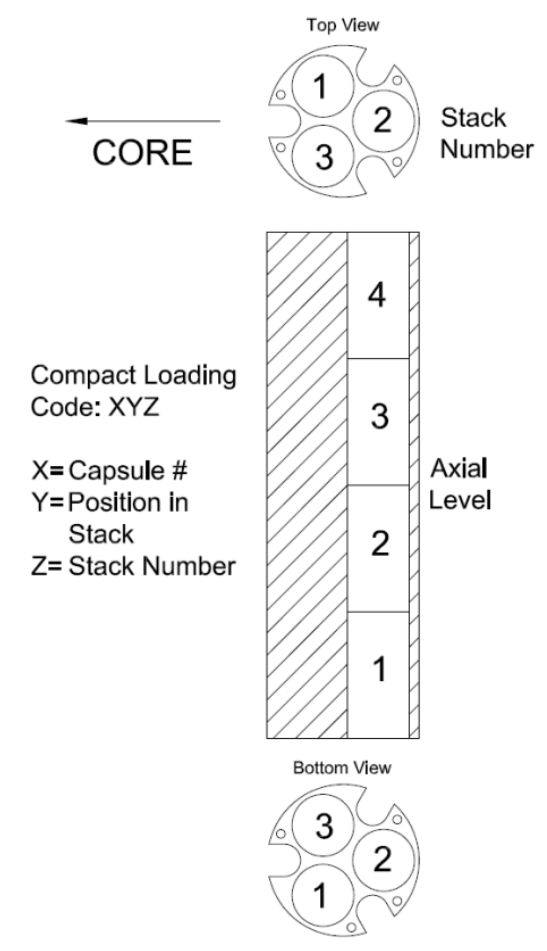

Figure 2. Numbering scheme used to identify compacts in the AGR-1 test train.

The irradiation was performed from December 2006 to November 2009 in the B-10 position in the ATR for a total of 620 effective full-power days. The calculated compact average burnup ranged from 11.3 to $19.6 \%$ fissions per initial metal atom (FIMA), and compact average fast neutron fluence $(\mathrm{E}>0.18 \mathrm{MeV})$ ranged from to 2.17 to $4.30 \times 10^{25} \mathrm{n} / \mathrm{m}^{2}$. The time-average, volume-average (TAVA) compact temperatures were $955-1136^{\circ} \mathrm{C}$ and the time-average maximum compact temperatures were $1069-1197^{\circ} \mathrm{C}$. Based on the low fission gas release-to-birth ratios in all of the capsules, there were zero TRISO-coating failures during the irradiation out of a total of approximately $2.98 \times 10^{5}$ particles in the experiment. Details of the irradiation experiment are provided in "AGR-1 Irradiation Test Final As-Run Report" (Collin 2015). 


\subsection{PIE Objectives and Report Overview}

In 2010, PIE of the AGR-1 experiment commenced at INL and ORNL. The primary objectives of the AGR-1 PIE and safety testing were to (a) assess the overall performance of the test train and components and provide data to verify the test train thermal analyses; (b) evalute the fission product retention of the fuel during the irradiation and during high-temperature post-irradiation safety tests; (c) characterize the fuel compacts and individual particles to assess the condition of the matrix material, kernels, and coatings and document any concerns; and (d) determine if there are fuel performance differences between the four different fuel types (Baseline fuel and three variants). Ultimately, the goal was a better understanding of the causes of coating degradation and failure, the role that fission products may play in these failures, and the transport behavior of fission products in fuel particles and compacts, both when coatings perform as designed and when they are damaged by irradiation or elevated temperature. Details of the activities planned as part of the PIE and safety testing, including the planned activities for specific compacts, have been described in "AGR-1 Post-Irradiation Examination Plan" (Demkowicz 2010).

This report focuses on the key results from the extensive AGR 1 post irradiation examination and safety testing. Numerous interim and topical reports and publications have been prepared as the work has progressed. These are listed in Section 7 for reference. The reader is encouraged to consult the appropriate references for further details on specific topics.

\section{TEST TRAIN AND CAPSULE INSPECTION, DISASSEMBLY, AND METROLOGY}

\subsection{Test Train Inspection and Gamma Scanning}

The fueled portion of the AGR-1 test train (i.e., the portion containing the six capsules) was transferred to the Hot Fuel Examination Facility (HFEF) at the Materials and Fuels Complex (MFC) on March 25, 2010. The inspection found no evidence of weld deterioration or other serious flaws on the test train exterior. The leadout section (i.e., approximately the first 1 meter of the test train immediately above Capsule 6) was transferred separately to HFEF on April 27, 2011, to remove the gas lines for analysis of fission products.

The fueled portion of the test train was gamma scanned using the Precision Gamma Scanner (PGS) at HFEF, primarily to nondestructively observe the position of the fuel compacts and determine if any relocation had taken place due to deterioration of internal capsule components. The test train was scanned in three different axial sweeps, and positioned such that only one of the fuel stacks was scanned by the collimator in each sweep. This required that a portion of each fuel stack toward the axial center of the capsule was not counted in each stack to avoid overlap (details are available in Demkowicz et al. 2010). Isotopic data from the gamma scans indicated that the dominant source of counts was from the capsule components (primarily ${ }^{60} \mathrm{Co}$ from the stainless steel capsule components, and ${ }^{181} \mathrm{Hf}$ from the hafnium shrouds). Isotopes from the fuel compacts were also observed (including ${ }^{137} \mathrm{Cs}$ and ${ }^{95} \mathrm{Zr}$ ). The data demonstrated that no relocation of fuel compacts had taken place during irradiation or during post-irradiation handling. No significant activity of fission products was observed above or below the region occupied by the fuel compacts; however, very small fractions of fission products were not likely to have been detected in the spectrum with gross signal in excess of $10^{6}$ counts.

The neutron radiography capability in HFEF was not available when the test train was first received due to an upgrade to the Neutron Radiography (NRAD) reactor. Neutron radiography was performed on Capsule 2 after it was separated from the other capsules, in part as an assessment of the efficacy of this method of nondestructive analysis on future AGR irradiation experiments. The results confirmed the absence of significant relocation or damage to interior capsule components. Slight bowing of the graphite spacers at the top and bottom of the capsule were observed. 


\subsection{Capsule Disassembly}

Disassembly proceeded by first separating the test train into individual capsules, and then disassembling each capsule to remove the fuel compacts and other interior components. Circumferential cuts for disassembly were made using custom tooling that incorporated a tubing lathe. The gas outlet lines were cut at the top of each capsule as it was removed from the test train and saved for subsequent analysis of any fission products that might have been deposited on their interior surfaces. Gas inlet lines and thermocouple leads were discarded.

The six AGR-1 capsules were disassembled in the order 1, 4, 6, 3, 5, 2. Figure 3 shows several images of the AGR-1 disassembly process. The initial plan for capsule disassembly involved making a cut just below the capsule head and sliding the capsule shell down to expose the graphite holder that was still retained by the through tubes. During capsule assembly, the through tubes were not firmly attached to the floor of the capsule (they were intended to have a non-binding "slip fit" to accommodate differential thermal expansion), and were expected to be removed rather easily after irradiation; on the other hand, the through tubes were brazed to the capsule head, and were expected to be firmly attached after irradiation. Disassembly activities promptly indicated that (a) through tubes could often be strongly adhered to the capsule floor, and (b) through tubes could often become detached from the capsule head and fracture during disassembly (Figure $3[\mathrm{c}]$ ). The procedure for disassembly had to be altered slightly to account for these possibilities. After discovering these issues during disassembly of Capsule 1, the approach employed for disassembly of Capsule 4 involved cutting the shell at a location roughly $3 / 4$ of the distance from the top of the capsule. Attempts to remove the lower half of the shell from this capsule resulted in the graphite holder being broken in two pieces at the axial level approximately between compact Levels 1 and 2 (Figure 3[d]). No compacts were severely damaged during this event, but the capsule disassembly procedure was modified as a result of this incident, and the remaining capsules were disassembled without significant damage to fuel holders or fuel compacts. Apparent swelling of the fuel holders in some capsules (later verified by metrological measurements, as discussed below) caused them to be very firmly retained by the through tubes. Minor damage to some of the remaining holders was incurred when removing them from the through tubes.

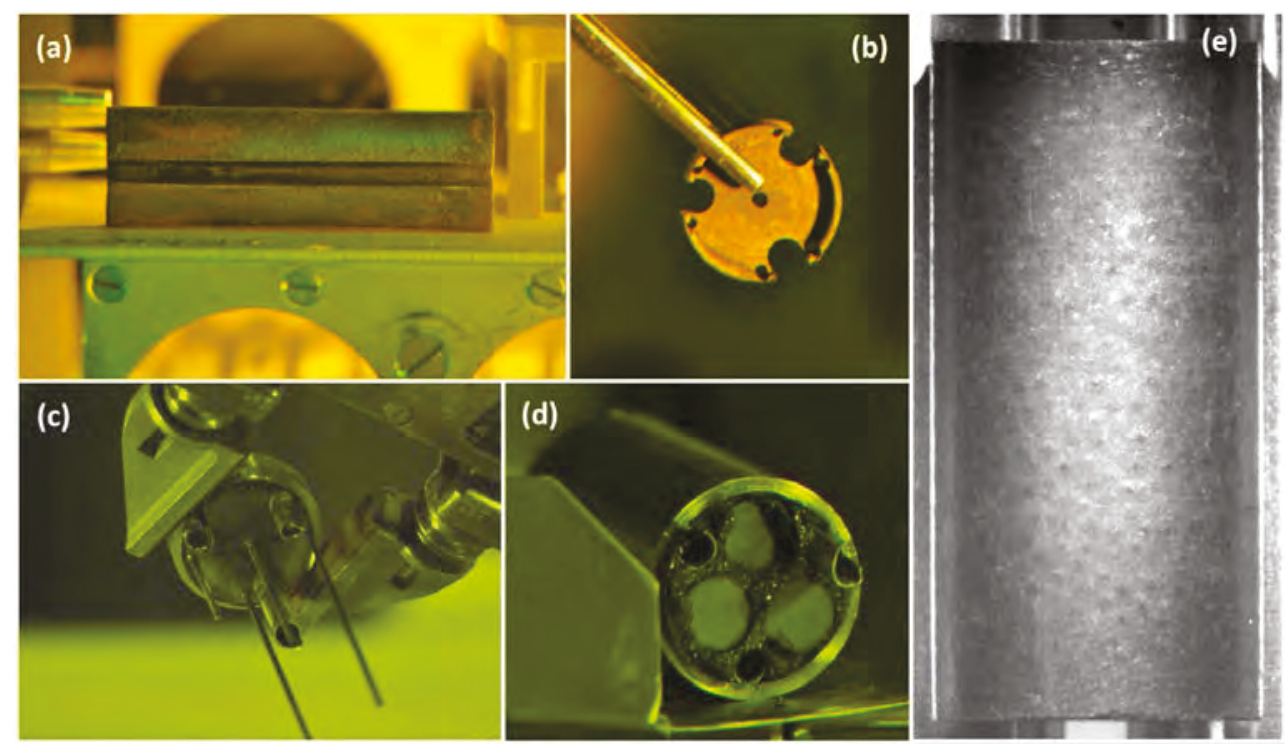

Figure 3. Images from AGR-1 disassembly: (a) Capsule 5 graphite fuel holder after removal from the capsule; (b) a graphite spacer from Capsule 5; (c) head piece from Capsule 4, showing through tubes fractured during disassembly; (d) Capsule 4 after the shell was cut mid-length and the graphite holder fractured in two pieces; (e) Compact 2-3-3 after removal from the graphite holder. 
The interior capsule components were saved for subsequent analysis of fission products. This included (1) the graphite holders, (2) the metallic capsule components (steel capsule shell, head, and floor piece), and (3) graphite and Grafoil spacers. Analysis of these components is discussed in Section 3.2.

The fuel compacts were in very good condition after removal from the graphite holders (see a typical example in Figure 3[e]). A few compacts exhibited minor surface deterioration (in some cases determined to be from post-irradiation handling) or edge chipping. One compact (4-1-3) exhibited a small crack near the top, presumed to be caused when the holder fractured in half during disassembly. None of the damage observed on the compacts was expected to have resulted in damage to particles or loss of particles from any compacts.

\subsection{Metrology}

High-resolution (6.6 megapixel) images of the compacts and graphite holders were acquired with a shielded in-cell camera and telecentric lens. Light-emitting diodes were used to illuminate the specimens. The specimens were imaged at three different azimuthal orientations, nominally 120 degrees apart, to image their entire surfaces. The images were used for extracting precise length and outer-diameter measurements of the specimens. Commercial bore gauges were used to measure the inner diameters of the fuel holes in the graphite holders and the steel capsule shells.

Measurements were made on three images for each compact, each image at a different azimuth. Four length measurements and 15 diameter measurements were made for each image. The length measurements for each compact (12 total) and the diameter measurements ( 45 total) were averaged to determine a single value for each compact. These values were compared with the as-fabricated dimensions from the AGR-1 compact data compilations (Table 1) to determine the percent dimensional change for each compact. The diameter data are summarized in Figure 4 (from Demkowicz et al. 2010). The data are plotted as a function of the original axial level of the fuel in the AGR-1 test train: the top (Capsule 6, Level 4) is on the left, and the bottom (Capsule 1, Level 1) is on the right. The data indicate shrinkage (negative diameter change) in all compacts during irradiation. The average diametrical shrinkage in the compacts ranged from -0.86 to $-1.4 \%$. There was a significant variation in the amount of shrinkage depending on the axial level in several of the capsules, with lower values often occurring at the axial ends of the capsules. All compacts also exhibited net negative average length change (data not shown), with values range from -0.23 to $-1.06 \%$.

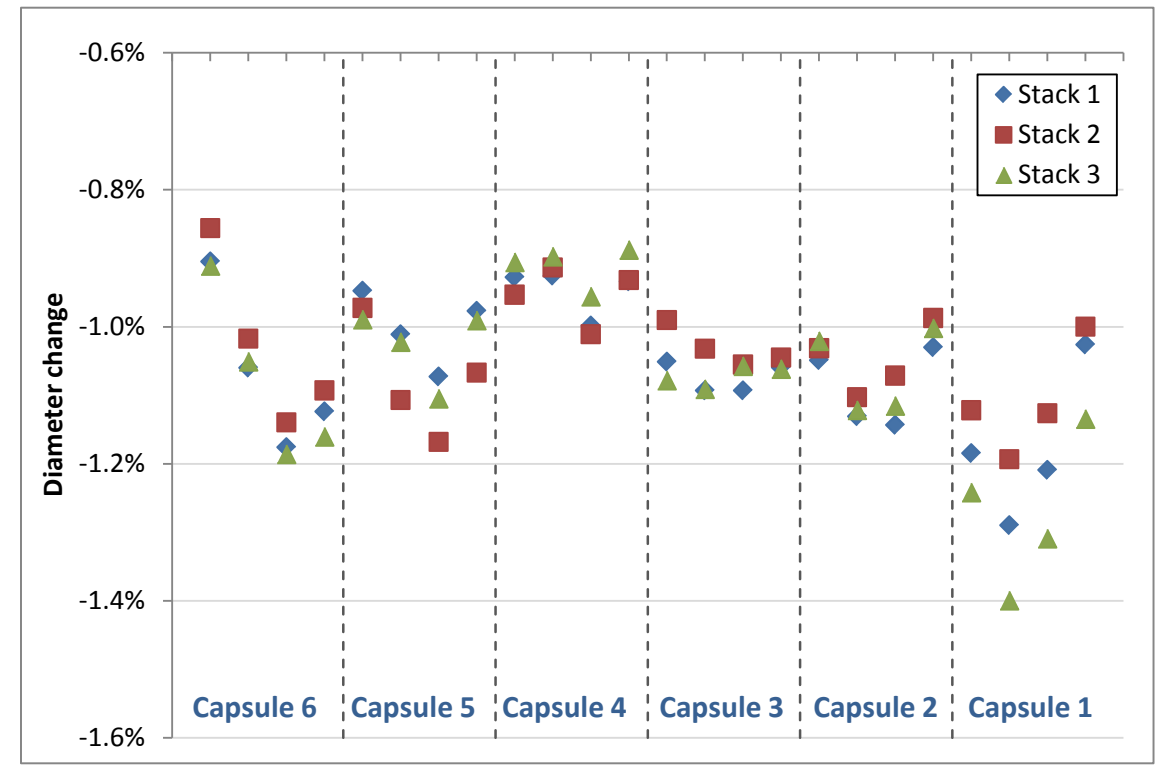

Figure 4. Average diameter changes of individual AGR-1 compacts. 
The individual diameter measurements were also used to explore changes in diameter along the axial length of the compacts. The results revealed that some compacts (most notably those at the top of Capsule 6 and the bottom of Capsule 1) had significant tapers in the measured diameters, suggesting appreciable differential shrinkage along the compact lengths (discussed in Demkowicz et al. 2010).

The average percent diameter change for each compact is plotted as a function of fast neutron fluence in Figure 5. The data indicate increasing shrinkage up to a fast fluence of approximately $3 \times 10^{25} \mathrm{n} \mathrm{m}^{-2}$. Above $3 \times 10^{25} \mathrm{n} \mathrm{m}^{-2}$, the trend exhibits negligible dependence on fast fluence, or slightly decreasing shrinkage with increasing fast fluence. Additional factors, such as the irradiation temperature, may also have a significant effect on the net dimensional change but are not explored in Figure 5.

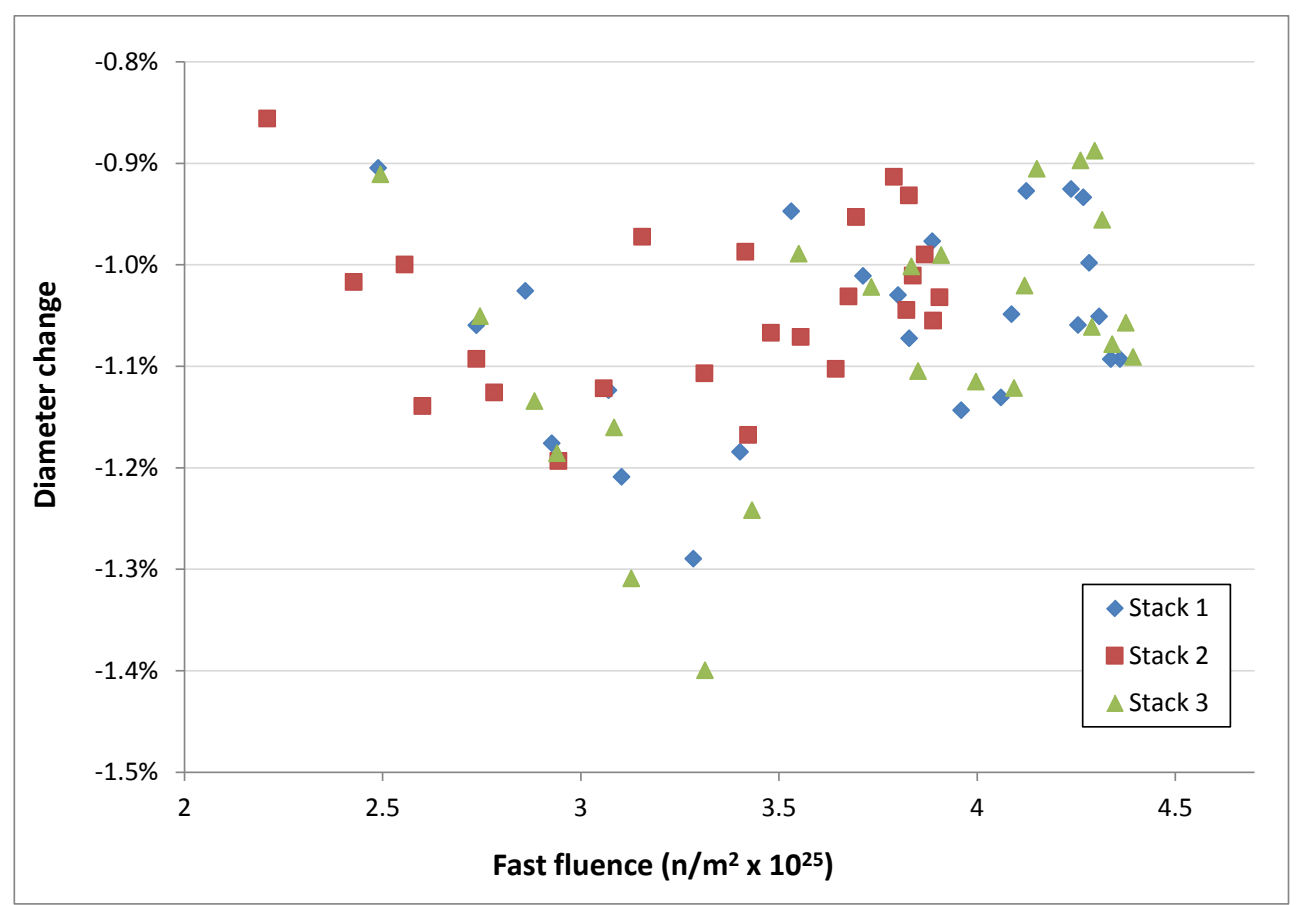

Figure 5. Average diameter change for all AGR-1 compacts as a function of calculated fast neutron fluence $(\mathrm{E}>0.18 \mathrm{Mev})$.

Due to the limited field of view of the telecentric lens, six separate images were digitally stitched together to make a composite image of each graphite holder at each of the three azimuths. Four length measurements and 30 diameter measurements (five measurements at each of six different displacements along the axial length of the holder) were made on each composite image. Diameter measurements were averaged for all azimuths to determine the average diameter at each of the six axial locations for each graphite holder. These values were compared with the as-fabricated diameter of each holder (only a single as-fabricated measurement was recorded for each holder) to determine the dimensional change due to irradiation. The data are presented in Figure 6 as a function of distance from the top of the graphite holder in Capsule 6. Note that data for Capsule 4 were not available, as this holder was fractured during disassembly.

As shown in Figure 6, the holders in Capsules 1 and 6 experienced net diametrical shrinkage, while those in Capsules 2, 3, and 5 experienced net swelling (based on observations during disassembly, it is likely that the holder in Capsule 4 also experience net swelling). The difference in dimensional change behavior among the AGR-1 graphite holders is believed to be related to a number of factors, including (a) fast neutron fluence, (b) irradiation temperature, and (c) the boron carbide content of the holders. The holders in the outer two capsules contained nominal $\mathrm{B}_{4} \mathrm{C}$ content of $5.5 \%$, compared to $7.0 \%$ in the inner four capsules. 
Figure 7 shows the outer diameter data for each holder compared to the as-fabricated diameter and the inner diameter of the steel capsule shell liner. The displacement between the holder outer diameter and the shell inner diameter constituted the gas control gap in each capsule. It is clear from Figure 7 that due to swelling of the holders in Capsules 2, 3, and 5, the gas gap decreased significantly (in the case of Capsule 3, the data suggest that the gap was almost completely eliminated), while the gap increased in Capsules 1 and 6.

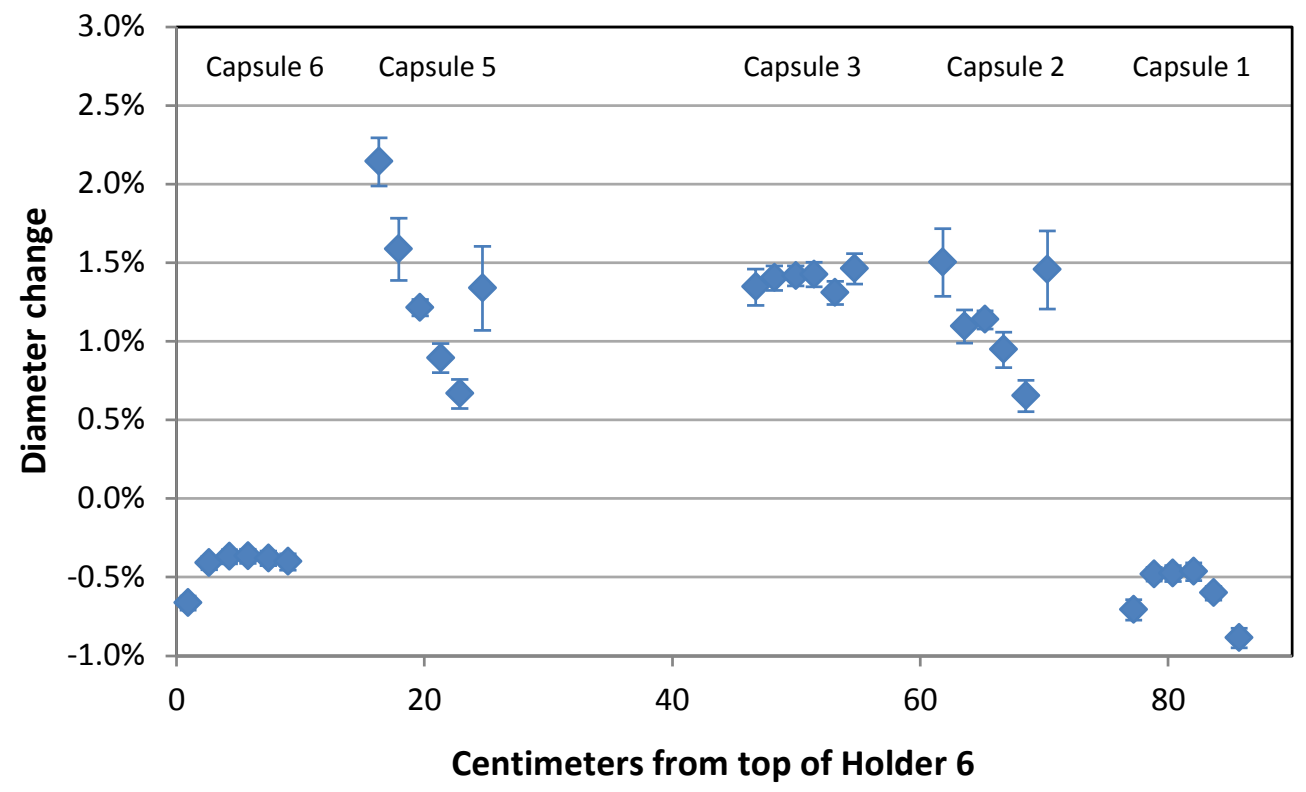

Figure 6. Relative outer diameter change for AGR-1 graphite holders.

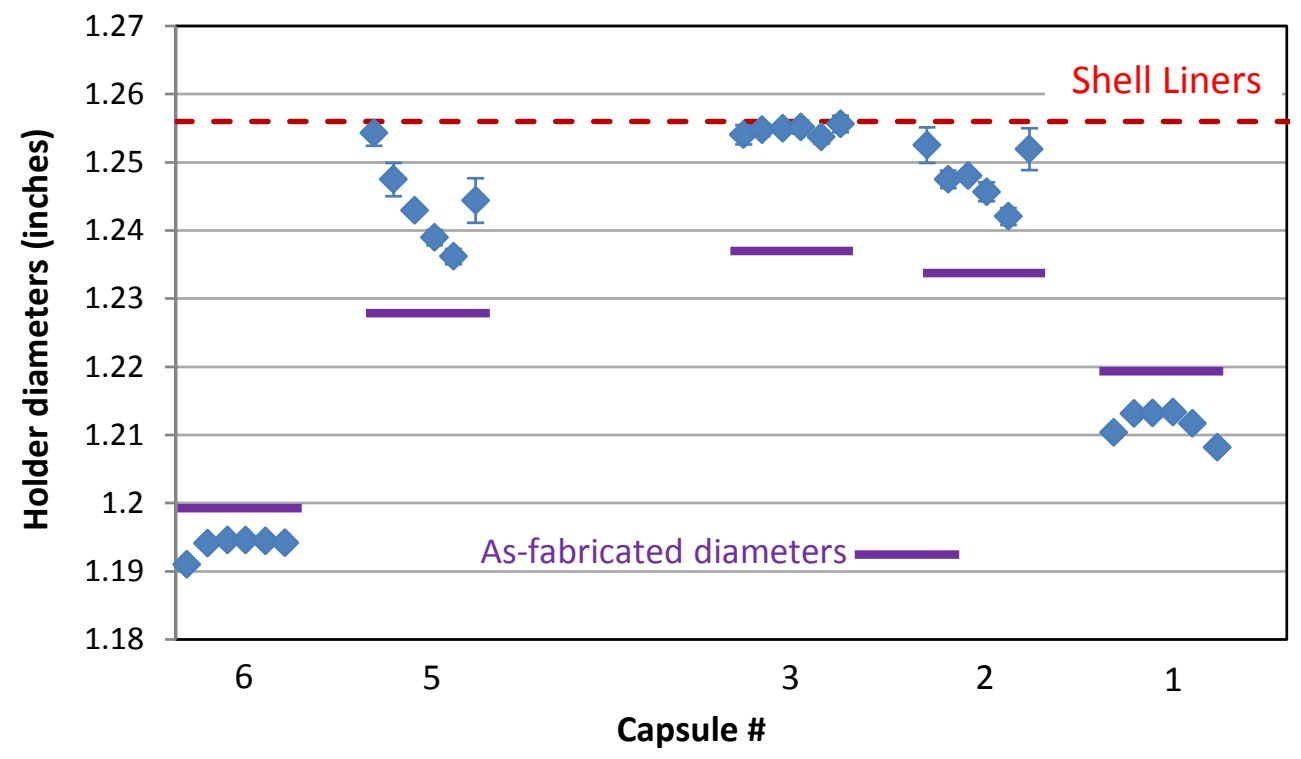

Figure 7. AGR-1 graphite holder outer diameter compared to as-fabricated diameter and the inner diameter of the steel capsule shell liner. 
Bore gauge measurements of the inner diameter of the fuel compact holes in the graphite holders were compared to the as-fabricated values to determine diameter change during irradiation. The results indicate that the inner diameters in Capsules 1 and 6 decreased, while those in Capsules 2, 3, and 5 increased. Thus, the inner diameters of the holes followed the same trend as the outer diameters of the holders. Comparing these data with the data on compact shrinkage, conclusions could be drawn regarding the magnitude of change in the compact-to-holder gaps in each capsule. While all compacts shrank, some holder holes shrank and some expanded. However, shrinkage of the compacts was always greater in magnitude than shrinkage in the corresponding hole; therefore, the compact-to-holder gaps in all capsules increased.

Inspection of the inner surfaces of the capsule shells following capsule disassembly indicated noticeable deposits. Figure 8 shows an example of these deposits on the inside of the Capsule 6 shell. The apparent thickness varied considerably among the six capsules, and was generally greater the farther the capsule was from the core centerline during irradiation. Deposit thickness was smallest in Capsules 3 and 4 and largest in Capsules 1 and 6. Bore gauge measurements of the capsule shell inner diameters indicated that Capsules 3 and 4 were near the as-fabricated dimensions, Capsules 2 and 5 had inner diameters slightly smaller than as-fabricated, and Capsules 1 and 6 had inner diameters as much as approximately $1.3 \%$ smaller than as-fabricated. Rather than indicating shrinkage of the steel shells, it is believed that these measurements reflect the thickness of the deposits. Analysis of these deposits removed from the Capsule 6 shell pieces (described in Demkowicz et al. 2013) revealed the presence of fission products, but these could not account for the majority of the mass. The chemical composition of the deposits remains unknown. Further details of the AGR-1 metrology can be found in Demkowicz et al. 2010.
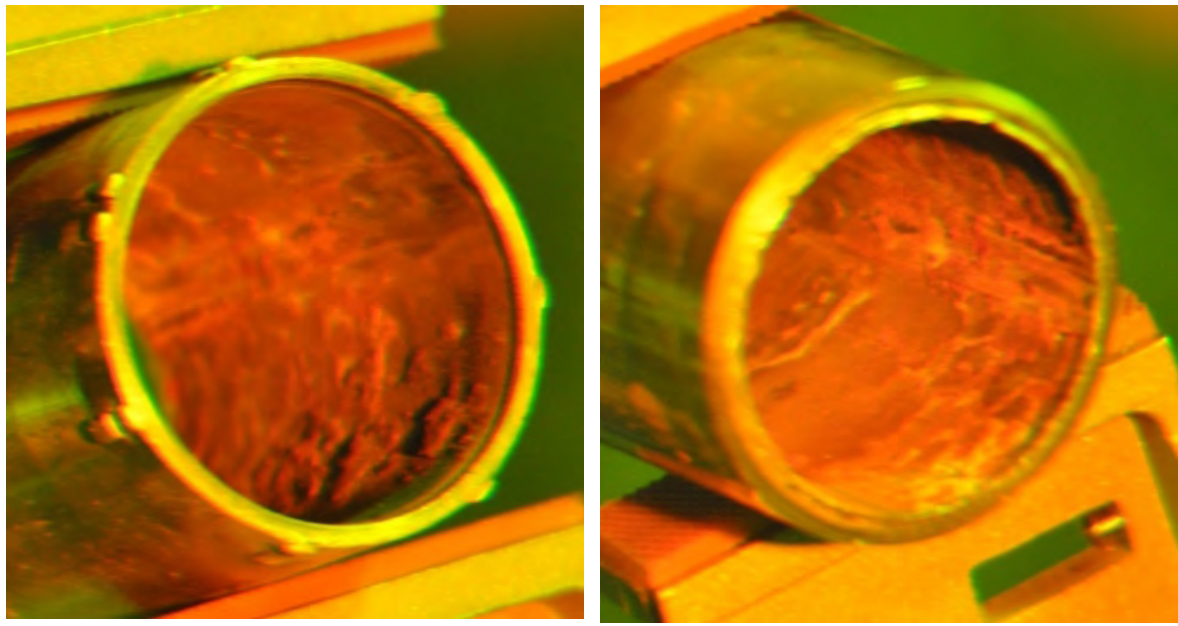

Figure 8. Deposited material near the top (left) and middle (right) of the steel shell from Capsule 6.

\subsection{Fluence and Melt Wire Analysis}

Each AGR-1 capsule contained three fluence wire packages and one melt wire package. These consisted of small wires encapsulated inside a sealed vanadium tube and were at various locations in the graphite fuel holders. Three types of fluence wires were used: iron, niobium, and $1 \% \mathrm{Co}-\mathrm{V}$. The melt wires were made of pure beryllium. 
Following capsule disassembly, an attempt was made to retrieve all of the fluence and melt wire packages from the graphite holders. Thirteen (out of 18 total) fluence wire packages were recovered, the rest being lost during handling operations in the hot cell. The melt wire packages proved very difficult to extract from the graphite holders. The packages would not fall from the holders under gravity. And for three of the AGR-1 capsules, attempts to crush the graphite in an effort to extract them resulted either in destruction of the melt wire packages or failure to locate them.

The recovered fluence and melt wire packages were sent to PNNL for analysis. The fluence wires were gamma counted to determine the inventory of the relevant activation products. Following gamma counting, the packages containing the niobium wires were opened, and the wires were removed and dissolved in acid. Aliquots of the solution were placed on filter paper for x-ray counting using low-energy photon spectrometers. The inventory of five different isotopes were ultimately determined for the wires $\left({ }^{54} \mathrm{Mn},{ }^{59} \mathrm{Fe},{ }^{60} \mathrm{Co},{ }^{93 \mathrm{~m}} \mathrm{Nb},{ }^{94} \mathrm{Nb}\right)$, and these were used to calculate neutron fluences in the capsules in the thermal, epithermal, and fast energy ranges (see Greenwood 2012 for details).

The results for fast neutron fluence $(\mathrm{E}>0.18 \mathrm{MeV})$ based on fluence wire measurements were compared with the predicted values from the as-run AGR-1 physics calculations for each capsule (with the exception of Capsule 1, for which no fluence wires were recovered). The comparison is shown in Table 7. The results demonstrated excellent agreement, as the difference between values from the two methods was within $<7 \%$ for all five capsules compared (Sterbentz et al. 2015).

Table 7. Comparison of fast neutron fluence $(\mathrm{E}>0.18 \mathrm{MeV})$ determined from measurement of fluence wires and from physics calculations (table from Sterbentz et al. 2015).

\begin{tabular}{|c|c|c|c|}
\hline \multirow{2}{*}{ Capsule } & \multicolumn{2}{|c|}{ Fast fluence $\left(10^{25} \mathrm{n} \mathrm{m}^{-2}\right)$} & \multirow{2}{*}{$\Delta$} \\
\cline { 2 - 3 } & Measured & Calculated & $+3.7 \%$ \\
\hline 6 & $2.33 \pm 7 \%$ & 2.42 & $-0.3 \%$ \\
\hline 5 & $3.06 \pm 7 \%$ & 3.05 & $+5.2 \%$ \\
\hline 4 & $3.25 \pm 7 \%$ & 3.43 & $+1.8 \%$ \\
\hline 3 & $3.33 \pm 7 \%$ & 3.39 & $-6.7 \%$ \\
\hline 2 & $3.19 \pm 7 \%$ & 2.99 & - \\
\hline 1 & - & 2.29 & \\
\hline
\end{tabular}

Analysis of the melt wires was performed by attempting to cut open the recovered melt wire packages and visually observe if the beryllium wires had melted. This proved problematic in almost all cases, as the packages were often in poor condition. And it often proved difficult to visually make a positive determination about the state of the wires. For the three melt wire packages that were recovered, it was determined that the wires in Capsules 2 and 4 were melted, while the result from the wire in Capsule 6 was inconclusive (Greenwood 2012). It is believed that due to the high temperatures at the melt wire locations in the capsules, the vanadium encapsulation may have reacted with the graphite to form the carbide and become severely embrittled, making recovery of the melt wire packages difficult.

\section{FUEL IRRADIATION PERFORMANCE}

\subsection{Overview of Objectives and Experimental Approach}

The evaluation of irradiation performance of the AGR-1 fuel focused primarily on assessing the level of fission product release from the fuel and examining the kernel and coating morphology evolution during irradiation. The specific examinations performed are summarized in Table 8. Results from these examinations will be summarized in this section. 
Table 8. Main AGR-1 PIE activities and objectives for evaluating fuel irradiation performance.

\begin{tabular}{|l|l|}
\hline \multicolumn{1}{|c|}{ Analysis } & \multicolumn{1}{|c|}{ Main objectives } \\
\hline $\begin{array}{l}\text { Fission product inventory on } \\
\text { irradiation capsule components }\end{array}$ & $\begin{array}{l}\text { Determine the cumulative inventory of fission products released } \\
\text { from all fuel compacts in a capsule during irradiation }\end{array}$ \\
\hline Fuel compact gamma scanning & $\begin{array}{l}\text { Determine the retained inventory of fission products in each } \\
\text { individual fuel compact; measure burnup of fuel compacts }\end{array}$ \\
\hline Deconsolidation-leach-burn leach & $\begin{array}{l}\text { Determine the inventory of fission products retained in the } \\
\text { compacts outside of the SiC layers; detect any particles with failed } \\
\text { SiC or failed TRISO layers; generate particles for subsequent } \\
\text { analyses }\end{array}$ \\
\hline Particle gamma counting & $\begin{array}{l}\text { Determine the retained inventory of fission products in the } \\
\text { particles }\end{array}$ \\
\hline Burnup evaluation & $\begin{array}{l}\text { Measure burnup using mass spectrometric techniques for } \\
\text { comparison with experimental values determined from gamma } \\
\text { spectrometry and for comparison with physics calculations }\end{array}$ \\
\hline $\begin{array}{l}\text { Compact cross-section } \\
\text { microanalysis }\end{array}$ & $\begin{array}{l}\text { Evaluate changes to compact and particle morphology during } \\
\text { irradiation }\end{array}$ \\
\hline Loose particle microanalysis & $\begin{array}{l}\text { Evaluate changes to kernel and coating morphology during } \\
\text { irradiation; gain better understanding of the causes of coating } \\
\text { failure; study the migration behavior of specific fission products in } \\
\text { the coating layers }\end{array}$ \\
\hline
\end{tabular}

Because of the large number of fuel specimens in the AGR-1 experiment and the associated time and monetary commitment involved in performing this work, the destructive analysis and safety testing of fuel compacts focused primarily on three of the fuel types (Baseline, Variant 1, and Variant 3 to assure that adequate data were collected on the fuel types of primary importance to the AGR program. Of particular interest was comparison of the performance between the Baseline $\mathrm{SiC}$ microstructure and the finer-grained $\mathrm{SiC}$ of Variant 3. In addition, initial observations of irradiated particle morphologies suggested that the lower-density IPyC layer in Variant 1 may have behaved differently relative to the Baseline IPyC and may play a role in coating layer failures, and so characterization of Variant 1 fuel was also considered of interest. Variant 2 was deemed a lower priority because the fuel properties were not significantly different from the Baseline (Table 2).

Fission product inventories were measured in a wide variety of examinations described in this section and the following section of this report. Measured inventories were often converted into a fraction of the predicted inventory in the specimen based on physics calculations for the AGR-1 experiment (Sterbentz 2013). Measured values were often decay-corrected to 1 day after the end of the AGR-1 irradiation (November 7, 2009, 12:00 GMT) to compare with predicted inventories on the same date. Decay-corrections were all performed using isotope half-life data taken from the ENDF/B-VII.1 library (Chadwick et al. 2011). 


\subsection{Fission Product Release}

\subsubsection{Experimental Methods}

\subsubsection{Analysis of Irradiation Capsule Components for Deposited Fission Products.}

The major components of the irradiation capsules-including the metal shells and structural components, the graphite fuel holders, and graphite spacers at the ends of the capsules - were analyzed at INL to determine the cumulative inventories of fission products released from the compacts during the irradiation. As there were 12 compacts in each irradiation capsule, the data provide information on the total inventory of fission products released from all 12 fuel compacts; release from each compact cannot be derived from these data.

The metal capsule shells were leached in acid to remove deposits. Analysis of the leach solutions included gamma spectrometry for gamma-emitting fission products, Sr separation and gas flow proportional counting for ${ }^{90} \mathrm{Sr}$, and inductively coupled plasma mass spectrometry (ICP-MS) for actinides and other non-gamma-emitting fission products. The graphite holders were gamma counted to determine the inventory of gamma-emitting fission products, and then crushed, oxidized, and leached and the solutions analyzed as described above. The graphite spacers at the axial ends of each capsule were gamma counted. Gas exit lines from the capsules were examined in $\sim 2.5 \mathrm{~cm}$ segments using gamma spectrometry, but negligible activity of any fission product was identified; therefore, the contribution is not included in the results presented in this report. Details of the experimental procedures and the inventories of specific isotopes on the various components can be found in Demkowicz et al. 2013 and Harp, Demkowicz, and Ploger 2012.

3.2.1.2 Gamma Scanning of Individual Fuel Compacts. All 72 AGR-1 compacts were individually gamma-scanned at INL to measure the inventory of fission products and determine burnup from cesium isotope inventories (discussed in detail in Section 3.3). Fifty-six of these compacts were gamma scanned with sufficiently long counting times to quantify ${ }^{110 \mathrm{~m}} \mathrm{Ag}$ inventory (Harp 2014). The experimental apparatus consists of a high-purity germanium detector with a Compton suppression system, and a rectangular collimator with a 2.5 -mm opening. Each compact was counted in 2.5 -mm axial "slices." The gamma scanning system was calibrated so that the total activity in a compact could be determined by adding the measured activity from all scans corresponding to a single compact. Interference from ${ }^{137} \mathrm{Cs}$ prevented the use of the primary ${ }^{110 \mathrm{~m}} \mathrm{Ag}$ gamma-ray, necessitating the use of the second- and third-most intense gamma-ray lines for activity determination. By comparing measured inventories with the predicted values, the data provide information on the level of silver retention in each compact analyzed. The experimental setup is described in further detail in Harp 2014 and Harp et al. 2014.

3.2.1.3 Deconsolidation and Leach-Burn-Leach Analysis of Fuel Compacts. Nine AGR-1 compacts were electrolytically deconsolidated in the as-irradiated state and leach-burn-leach analysis was performed at both INL and ORNL. The deconsolidation-leach-burn-leach (DLBL) analysis effectively measures the total inventory of fission products located in the compact outside of the SiC layer (i.e., it includes the contributions from both the $\mathrm{OPyC}$ and matrix), provided that no particles with a failed $\mathrm{SiC}$ layer are present ("SiC failure" refers to loss of integrity of the $\mathrm{SiC}$ layer, with at least one pyrocarbon layer remaining intact, and is distinct from complete TRISO-coating failure). Therefore, it is a measure of fission products that are released from particles but retained within the compact outside of the SiC layers, and are generated from uranium contamination in the compact matrix or OPyC and retained within the compact during irradiation. As the level of uranium contamination in the AGR-1 compacts was generally very low (average uranium contamination fractions were less than $4 \times 10^{-7}$ for all AGR-1 fuel types), the inventory measured from DLBL is typically dominated by release from the particles. In some cases, if measured values are very low (as is often the case with cesium, where release through intact $\mathrm{SiC}$ is found to be extremely low), then hot cell contamination can constitute a significant contribution to the total measured values. The nine AGR-1 compacts analyzed are listed in Table 9 with the fuel type and selected 
irradiation properties. The deconsolidation processes used at ORNL and INL are detailed in specific compact PIE reports and related publications (Table 23).

Table 9. Irradiated AGR-1 fuel compacts used for DLBL analysis and particle gamma counting. Corresponding references discussing DLBL and particle gamma counting are listed for each compact.

\begin{tabular}{|c|c|c|c|c|c|c|}
\hline Compact & Fuel type & $\begin{array}{c}\text { TAVA }^{\mathrm{a}} \text { Temp } \\
\left({ }^{\circ} \mathrm{C}\right)^{\mathrm{b}}\end{array}$ & $\begin{array}{l}\text { TA Max }^{\mathrm{c}} \\
\text { Temp } \\
\left({ }^{\circ} \mathrm{C}\right)^{\mathrm{b}}\end{array}$ & $\begin{array}{l}\text { Burnup } \\
(\% \text { FIMA })^{d}\end{array}$ & $\begin{array}{l}\text { Fast fluence } \\
\left(10^{25} \mathrm{n} / \mathrm{m}^{2}\right)^{\mathrm{d}}\end{array}$ & References \\
\hline $6-3-2$ & Baseline & 1070 & 1144 & 11.4 & 2.55 & Demkowicz et al. 2012 \\
\hline $6-1-1$ & Baseline & 1111 & 1197 & 15.3 & 2.43 & $\begin{array}{l}\text { Hunn et al. 2012b } \\
\text { Hunn et al. 2012a }\end{array}$ \\
\hline $3-2-1$ & Baseline & 1051 & 1143 & 19.1 & 4.21 & Demkowicz et al. $2015 \mathrm{~b}$ \\
\hline $5-2-1$ & Variant 1 & 1057 & 1140 & 17.4 & 3.71 & $\begin{array}{l}\text { Hunn et al. 2012b } \\
\text { Hunn et al. 2014b }\end{array}$ \\
\hline $5-2-3$ & Variant 1 & 1059 & 1141 & 17.4 & 3.77 & Hunn et al. 2014b \\
\hline $5-3-1$ & Variant 1 & 1040 & 1122 & 16.7 & 3.60 & Demkowicz et al. 2015c \\
\hline $4-4-2$ & Variant 3 & 1024 & 1139 & 16.6 & 3.59 & $\begin{array}{l}\text { Hunn et al. 2012b } \\
\text { Hunn et al. 2013a }\end{array}$ \\
\hline $4-1-1$ & Variant 3 & 1072 & 1182 & 19.4 & 4.13 & Demkowicz et al. $2015 \mathrm{a}$ \\
\hline $1-3-1$ & Variant 3 & 1092 & 1166 & 15.3 & 3.22 & Demkowicz et al. $2015 \mathrm{~d}$ \\
\hline $\begin{array}{ll}\text { a. Time av } \\
\text { b. Hawkes } \\
\text { c. Time av } \\
\text { d. Sterben }\end{array}$ & $\begin{array}{l}\text { ge, volum } \\
12 \\
\text { ge maxim } \\
2013 .\end{array}$ & $\begin{array}{l}\text { rage temperature } \\
\text { emperature }\end{array}$ & & & & \\
\hline
\end{tabular}

3.2.1.4 Gamma Counting of Individual Coated Particles. Individual deconsolidated particles were gamma counted at various stages of the DLBL process to determine the inventory of gamma-emitting fission products. Analysis of the fission product inventory present in the particles allows the relative degree of retention to be evaluated. This analysis has a two-fold objective.

Individual particles with abnormally low inventories of specific fission products can be identified, and this may be indicative of a defective $\mathrm{SiC}$ layer, as in the case of high cesium release. While cesium diffuses with relative ease through intact pyrocarbon, it is effectively retained by intact $\mathrm{SiC}$. However, a $\mathrm{SiC}$ layer defect or in-pile failure may allow cesium to readily escape from the particle at normal irradiation temperatures. Therefore, measurements of the relative ${ }^{137} \mathrm{Cs}$ inventory can be used to identify particles with failed $\mathrm{SiC}$. Such particles can then be retained for subsequent microstructural analysis to investigate the nature of the $\mathrm{SiC}$ failures. Identification and subsequent analysis of specific particles with failed $\mathrm{SiC}$ layers is discussed in Section 5.

In addition to finding particles with a defective $\mathrm{SiC}$ layer, the distribution of fission product activities among a population of particles can provide information about the varying degree of release through intact $\mathrm{SiC}$. This is primarily of interest for silver, which may exhibit significant release from particles (significantly exceeding one percent under normal irradiation conditions) such that differences can be detected above the uncertainty of the gamma counting technique. By measuring the ${ }^{110 \mathrm{~m}} \mathrm{Ag}$ retained in the particles, specific particles with high or low release can be selected for microstructural examination that may elucidate the causes of the behavior. For example, variations in $\mathrm{SiC}$ microstructure might be correlated with the level of silver release. 
Irradiated particle gamma counting was performed at both INL and ORNL. At INL, individual particles (typically 60 per compact) were manually placed in glass vials and counted using the gamma spectrometer and hardware in the Analytical Laboratory Hot Cell 4. Gamma counting of particles at ORNL was accomplished using the Advanced Irradiated Microsphere Gamma Analyzer (Advanced-IMGA), an automated system developed at ORNL specifically for TRISO particle examinations. Details of the gamma counting equipment and procedures are given in the specific compact PIE reports and related publications (see Table 23).

Subsets of particles from nine AGR-1 compacts (listed in Table 9) were gamma counted to assess the inventory of fission products such as ${ }^{110 \mathrm{~m}} \mathrm{Ag}$ and ${ }^{154} \mathrm{Eu}$. The measured inventory in each particle was compared to the predicted inventory in an average particle from that fuel compact to determine a ratio of the measured inventory to the calculated inventory ( $\mathrm{M} / \mathrm{C}$ ratio). To minimize the effect of particle-to-particle variation in fissile content (due to variation in kernel size, density, and stoichiometry) and burnup, the ratio was normalized using the ${ }^{137} \mathrm{Cs}$ activity, ${ }^{1}$ as in the following equation:

$$
\frac{A_{i}^{\text {Isotope }} / A_{\text {calc }}^{\text {Isotope }}}{A_{i}^{C s-137} / \sum_{j=1}^{n} \frac{1}{n} A_{j}^{C s-137}}
$$

where

$$
\begin{aligned}
& A_{i}^{\text {Istope }} \mathrm{A}_{\mathrm{i}}^{\mathrm{Ag}-110 \mathrm{~m}}=\text { decay-corrected measured inventory of a specific isotope in particle } i \\
& A_{\text {calc }}^{\text {Istope }}=\text { average calculated inventory of a specific isotope for a single particle in the compact } \\
& A_{i}^{C s-137}=\text { decay-corrected measured }{ }^{137} \mathrm{Cs} \text { activity for particle } i \\
& n \quad=\text { total number of particles counted. }
\end{aligned}
$$

\subsubsection{Results}

The inventory of key fission products released from the compacts to the capsule components is summarized in Table 10. These values represent the sum of inventories measured on the major

\begin{tabular}{|c|c|c|c|c|c|c|}
\hline Capsule No. & Fuel type & ${ }^{110 \mathrm{~m}} \mathrm{Ag}$ & ${ }^{144} \mathrm{Ce}$ & ${ }^{134} \mathrm{Cs}$ & ${ }^{154} \mathrm{Eu}$ & ${ }^{90} \mathrm{Sr}$ \\
\hline 6 & Baseline & $3.8 \mathrm{E}-1$ & $9.7 \mathrm{E}-6$ & $1.3 \mathrm{E}-5$ & $4.6 \mathrm{E}-4$ & $3.1 \mathrm{E}-6$ \\
\hline 5 & Variant 1 & $2.3 \mathrm{E}-1$ & $<2 \mathrm{E}-6$ & $1.2 \mathrm{E}-5$ & $1.4 \mathrm{E}-4$ & 7.1E-6 \\
\hline 4 & Variant 3 & $1.2 \mathrm{E}-1$ & $<4$ E-6 & $<3 \mathrm{E}-6$ & $1.3 \mathrm{E}-4$ & 9.7E-6 \\
\hline 3 & Baseline & $1.2 \mathrm{E}-2$ & $<4$ E-6 & $<3 \mathrm{E}-6$ & 4.3E-4 & $2.2 \mathrm{E}-6$ \\
\hline 2 & Variant 2 & $5.5 \mathrm{E}-2$ & $<2 \mathrm{E}-6$ & $<2 \mathrm{E}-6$ & $1.6 \mathrm{E}-4$ & $8.4 \mathrm{E}-7$ \\
\hline 1 & Variant 3 & $3.6 \mathrm{E}-1$ & $<3 \mathrm{E}-6$ & $<3 \mathrm{E}-6$ & $1.3 \mathrm{E}-4$ & $2.8 \mathrm{E}-5$ \\
\hline
\end{tabular}
components from each capsule (detailed data for isotopic inventory found on each capsule component has been presented in Demkowicz et al. 2013). Values in Table 10 are presented as a fraction of the predicted inventory in the capsule (i.e., this includes the predicted inventory in all 12 compacts in each capsule).

Table 10. Fractional inventory of fission products on the AGR-1 capsule components.

\footnotetext{
${ }^{1} \quad{ }^{137} \mathrm{Cs}$ was used most frequently for normalization, but other isotopes (notably ${ }^{144} \mathrm{Ce}$ ) were used in some instances instead.
} Details are available in the specific compact PIE reports (Table 23). 
Note that the ${ }^{134} \mathrm{Cs}$ inventory on the capsule components was significantly higher in Capsules 5 and 6 compared to the other capsules. This was found to be attributed to the presence of one or more particles with a $\mathrm{SiC}$ layer that failed during the irradiation. By gamma scanning the graphite fuel holders in these capsules after the fuel compacts had been removed, localized areas of elevated cesium activity were identified. This suggested that compacts originally at these locations during the irradiation contained particles with failed SiC layers, and allowed those compacts to be examined for recovery of the particles in question (discussed in Section 5).

The inventory of key fission products found outside the $\mathrm{SiC}$ layer in the nine compacts listed in Table 9 is given in Table 11 (based on DLBL data), where the totals include exposed fission products in the fuel compact detected by both the pre-burn and post-burn leaches. The values are presented as a fraction of the predicted inventory in the compact, and represent the inventory of fission products released from the particles but retained within the OPyC or compact matrix during irradiation. Note that in Table 10 and Table $11,{ }^{134} \mathrm{Cs}$ data have been presented instead of ${ }^{137} \mathrm{Cs}$, as the ${ }^{134} \mathrm{Cs}$ measurements were found to be less subject to bias from the presence of hot cell contamination due to the much shorter half-life $(2.07 \mathrm{y}$ for ${ }^{134} \mathrm{Cs}$ compared to $30.07 \mathrm{y}$ for ${ }^{137} \mathrm{Cs}$ ). In instances where hot-cell contamination had a minimal effect on the cesium measurements, the agreement between fractional releases calculated for ${ }^{134} \mathrm{Cs}$ and ${ }^{137} \mathrm{Cs}$ was generally very good. Similarly, although only ${ }^{154} \mathrm{Eu}$ is reported, ${ }^{155} \mathrm{Eu}$ was also measured and yielded matching results. Detailed results for all isotopes measured in the DLBL solutions can be found in the compact PIE reports (Table 23).

Table 11. Fractional inventory of fission products in the DLBL solutions.

\begin{tabular}{|c|c|c|c|c|c|c|c|}
\hline Compact & ${ }^{110 \mathrm{~m}} \mathrm{Ag}$ & ${ }^{144} \mathrm{Ce}$ & ${ }^{134} \mathrm{Cs}$ & ${ }^{154} \mathrm{Eu}$ & ${ }^{105} \mathrm{Pd}$ & ${ }^{90} \mathrm{Sr}$ & ${ }^{238} \mathrm{U}$ \\
\hline $6-3-2$ & $2.2 \mathrm{E}-4$ & $1.7 \mathrm{E}-4$ & $7.3 \mathrm{E}-5$ & $5.9 \mathrm{E}-3$ & - & $4.3 \mathrm{E}-4$ & $2.8 \mathrm{E}-4$ \\
\hline $6-1-1$ & $1.7 \mathrm{E}-1$ & $6.9 \mathrm{E}-4$ & $2.1 \mathrm{E}-5$ & $1.5 \mathrm{E}-2$ & $1.1 \mathrm{E}-2$ & $5.9 \mathrm{E}-4$ & $<1 \mathrm{E}-4$ \\
\hline $3-2-1$ & $6.9 \mathrm{E}-3$ & $<4 \mathrm{E}-6$ & $<3 \mathrm{E}-6$ & $7.8 \mathrm{E}-4$ & - & $1.5 \mathrm{E}-6$ & $5.0 \mathrm{E}-6$ \\
\hline $5-2-3$ & $3.3 \mathrm{E}-3$ & $1.5 \mathrm{E}-3$ & $4.4 \mathrm{E}-5$ & $6.0 \mathrm{E}-3$ & $3.2 \mathrm{E}-2$ & $3.1 \mathrm{E}-3$ & $6.5 \mathrm{E}-5$ \\
\hline $5-2-1$ & $3.9 \mathrm{E}-3$ & $1.6 \mathrm{E}-3$ & $4.8 \mathrm{E}-5$ & $5.8 \mathrm{E}-3$ & $3.0 \mathrm{E}-2$ & $1.9 \mathrm{E}-3$ & $8.2 \mathrm{E}-5$ \\
\hline $5-3-1$ & $9.1 \mathrm{E}-3$ & $3.4 \mathrm{E}-4$ & $2.5 \mathrm{E}-6$ & $1.2 \mathrm{E}-3$ & $5.4 \mathrm{E}-3$ & $1.9 \mathrm{E}-4$ & $2.4 \mathrm{E}-5$ \\
\hline $4-4-2$ & $2.3 \mathrm{E}-2$ & $1.3 \mathrm{E}-5$ & $1.2 \mathrm{E}-5$ & $5.9 \mathrm{E}-4$ & $1.1 \mathrm{E}-2$ & $1.6 \mathrm{E}-5$ & $6.3 \mathrm{E}-5$ \\
\hline $4-1-1$ & $3.3 \mathrm{E}-2$ & $6.6 \mathrm{E}-7$ & $<4 \mathrm{E}-7$ & $2.4 \mathrm{E}-4$ & - & $1.7 \mathrm{E}-6$ & $1.3 \mathrm{E}-5$ \\
\hline $1-3-1$ & $3.6 \mathrm{E}-3$ & $1.5 \mathrm{E}-4$ & $5.4 \mathrm{E}-6$ & $6.3 \mathrm{E}-3$ & $8.6 \mathrm{E}-3$ & $2.6 \mathrm{E}-3$ & $2.0 \mathrm{E}-5$ \\
\hline
\end{tabular}

Shaded rows indicate compacts known to have one or more particles with failed SiC. Note that a fraction of $2.4 \mathrm{E}-4$ corresponds to the equivalent inventory of a single particle.

Three of the compacts in Table 11 were found to have one or more particles with failed SiC, as discussed in Section 5. These compacts are shaded in the table. In the case of Compacts 5-2-3 and 5-2-1, the particles with failed $\mathrm{SiC}$ were first identified using particle gamma counting following the pre-burn leaching steps and removed from the population prior to burn-leach analysis. As a result, the kernels of these particles were not leached during that analysis. Compact 6-3-2 contained a single particle with failed $\mathrm{SiC}$, and this particle remained in the population when burn-leach was performed. As a result, the contents of this kernel were dissolved in the burn-leach solutions and are included in the totals in Table 11 (note the inventory of ${ }^{238} \mathrm{U}$ for Compact 6-3-2, which is close to the equivalent fraction of a single particle, $2.4 \times 10^{-4}$, indicating that the kernel was dissolved in the leach solution). Therefore, the values in this table for Compact 6-3-2 that are at or below a value of approximately $2.4 \times 10^{-4}$ (including ${ }^{110 \mathrm{~m}} \mathrm{Ag}$, ${ }^{144} \mathrm{Ce}$, and ${ }^{134} \mathrm{Cs}$ ) are not a reliable measure of the inventory retained in this compact outside of the SiC layer because of the additional contribution from the kernel leached during the post-burn leach. 
The data in Table 10 and Table 11 are summarized graphically in Figure 9, which indicates the range of fractional fission product inventory retained in the compacts outside the $\mathrm{SiC}$ layer (red columns) and released from the 12 compacts in each capsule (blue columns). In Figure 9, the separate upper data ranges for ${ }^{134} \mathrm{Cs}$ (circled in the figure) are attributed to compacts or capsules containing particles with failed SiC layers, while the lower data ranges are due to fuel with only intact $\mathrm{SiC}$ (discussed further below). The cross-hatched regions of several of the data columns indicate that the measured inventories on some capsule components were below the detection limit of the technique; therefore, the sum of contributions from all components represents a conservative upper bound for the total inventory in several of the capsules (details of the measured values of specific isotopes on each capsule component are in Demkowicz et al. 2013).

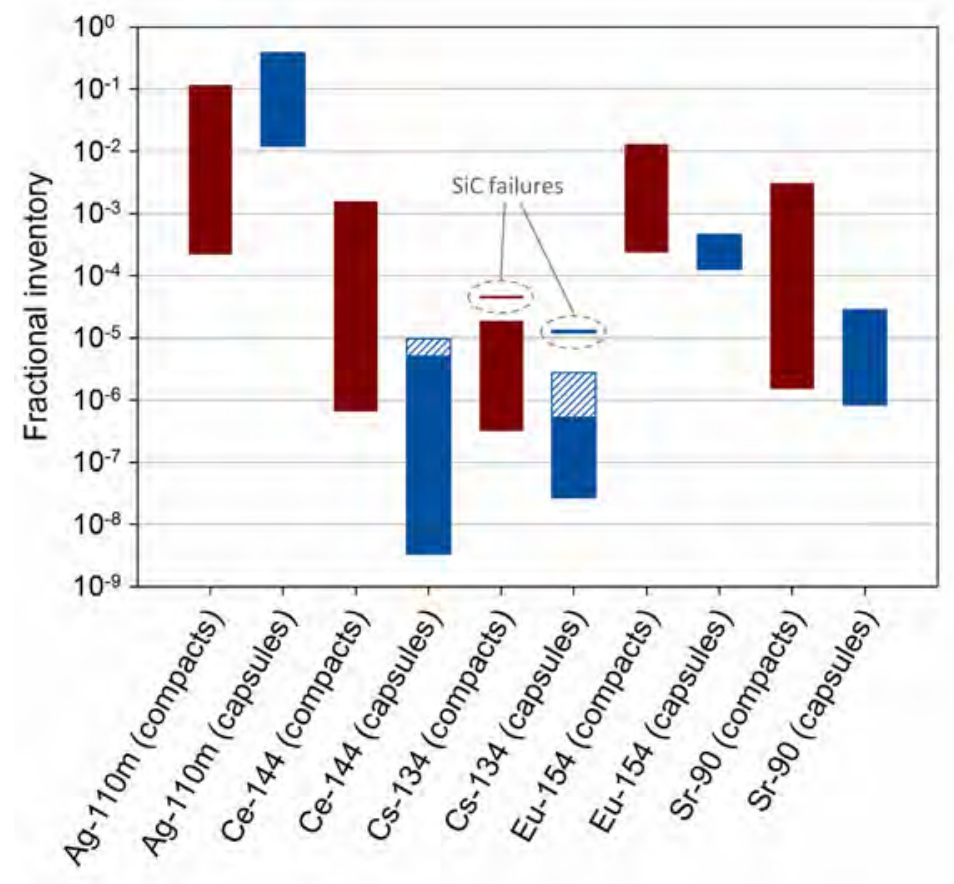

Figure 9. The range of inventory fractions found retained in irradiated compacts outside of the $\mathrm{SiC}$ layer (red columns) and on the capsule components (blue columns). The portions of the data circled and labeled as "SiC failures" are related to the presence of particles with failed SiC layers, as discussed in the text. The cross-hatched regions indicate values that correspond to measured inventories below the detection limit, which represent a conservative upper-bound on the range.

The estimated fraction of ${ }^{110 \mathrm{~m}} \mathrm{Ag}$ retained in 56 of the 72 AGR-1 compacts at the end of irradiation is shown in Figure 10. This was determined from the fuel compact gamma scanning data, and is simply the ratio of the total measured inventory to the predicted inventory from physics simulations. The data are plotted as a function of the vertical position in the AGR-1 test train, with the top of the test train at the left, and compacts in each of the three fuel stacks plotted separately. Note that the fraction slightly exceeds 1.0 for several compacts in Capsules 2, 3, and 4 (the maximum value is 1.09 for Compact 2-4-3). This could be due to uncertainties in the gamma spectra analysis (total uncertainty in the final values is estimated to be approximately $5 \%$ ), a small bias in the predicted ${ }^{110 \mathrm{~m}} \mathrm{Ag}$ inventories from the physics simulation (in this case the implication is that predicted values could be biased low), or a combination of both. A total ${ }^{110 \mathrm{~m}} \mathrm{Ag}$ mass balance was also performed, which summed the inventory found in (1) the compacts and (2) all of the capsule components for each capsule, and the total was compared to the predicted total for each capsule. The agreement between the measured and predicted totals was 
reasonably good, with the total measured inventory ranging from 76 to $108 \%$ of the predicted value for the six capsules (details in Demkowicz et al. 2013).

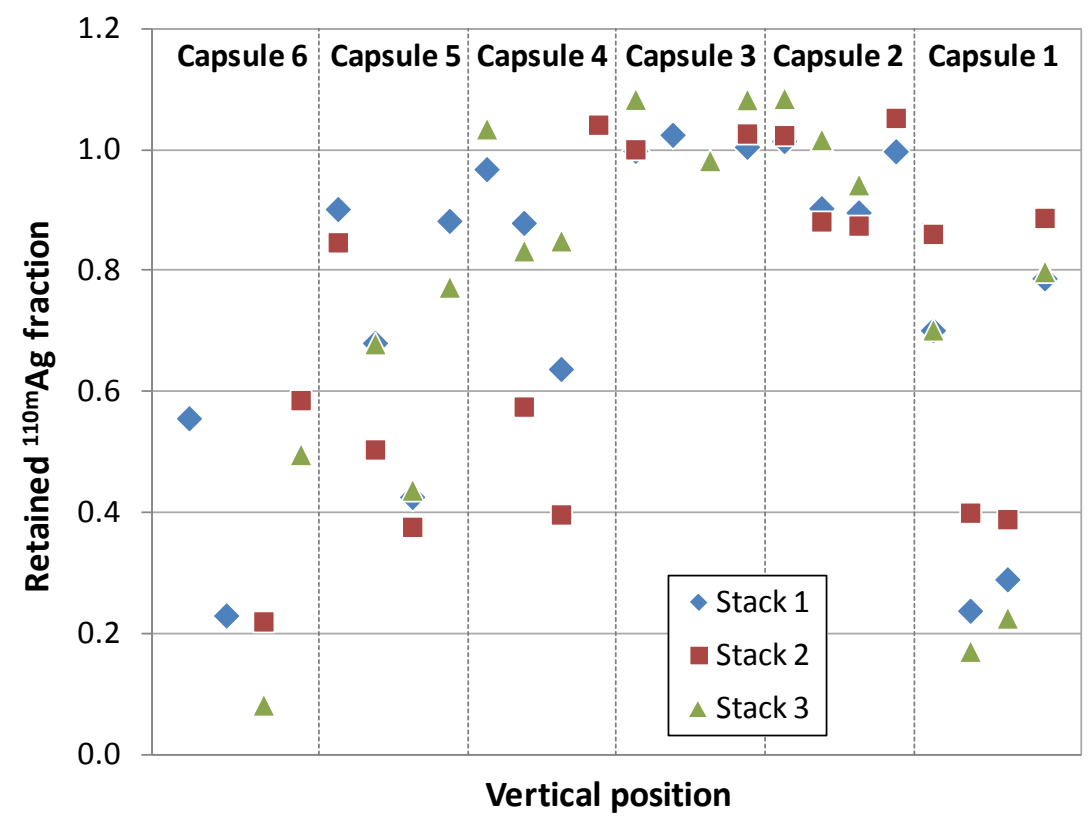

Figure 10. Fraction of retained ${ }^{110 \mathrm{~m}} \mathrm{Ag}$ inventory in 56 of the 72 AGR-1 fuel compacts after irradiation. Data are plotted as a function of vertical position in the experiment (top of the experiment at the left) and by the stack number.

The fraction of ${ }^{110 \mathrm{~m}} \mathrm{Ag}$ retained in individual particles often varied considerably within a single compact. The distributions of the ${ }^{110 \mathrm{~m}} \mathrm{Ag}$ fraction retained in particles from several compacts are shown in Figure 11 as examples. In some cases (e.g., Compact 3-2-1), there was a relatively high degree of silver retention in the sample of particles analyzed (mean of the distribution is near 1.0). In other cases (e.g., Compact 5-2-3), the distribution was extremely broad, with a portion of the particles exhibiting almost complete release of silver during the irradiation (particles plotted in the zero bin for Compact 5-2-3 in Figure 11 had activities below a quantification limit of $\sim 0.08$ ). The presence of particles in these distributions with estimated retained ${ }^{110 \mathrm{~m}} \mathrm{Ag}$ fractions as high as $\sim 1.2$ is believed to be due in part to an appreciable variation in the ${ }^{110 \mathrm{~m}} \mathrm{Ag}$ inventory generated in particles based on their original location within the fuel compacts.

Based on the particle gamma counting data, the average fraction of ${ }^{110 \mathrm{~m}} \mathrm{Ag}$ retained in the subset of particles from each compact was determined, and is presented in Table 12. These values represent an estimate for the fraction of ${ }^{110 \mathrm{~m}} \mathrm{Ag}$ retained within the entire population of particles for each compact. For several of the compacts, a number of gamma counted particles did not have detectable ${ }^{110 \mathrm{~m}} \mathrm{Ag}$ activity. In these cases, a minimum detection limit was determined, and was used as an upper bound on the activity of ${ }^{110 \mathrm{~m}} \mathrm{Ag}$ in the particle, while a value of zero was used as the lower bound. The ranges provided in Table 12 for some of the compacts use these two bounding values to account for the unknown activity in these particles. 

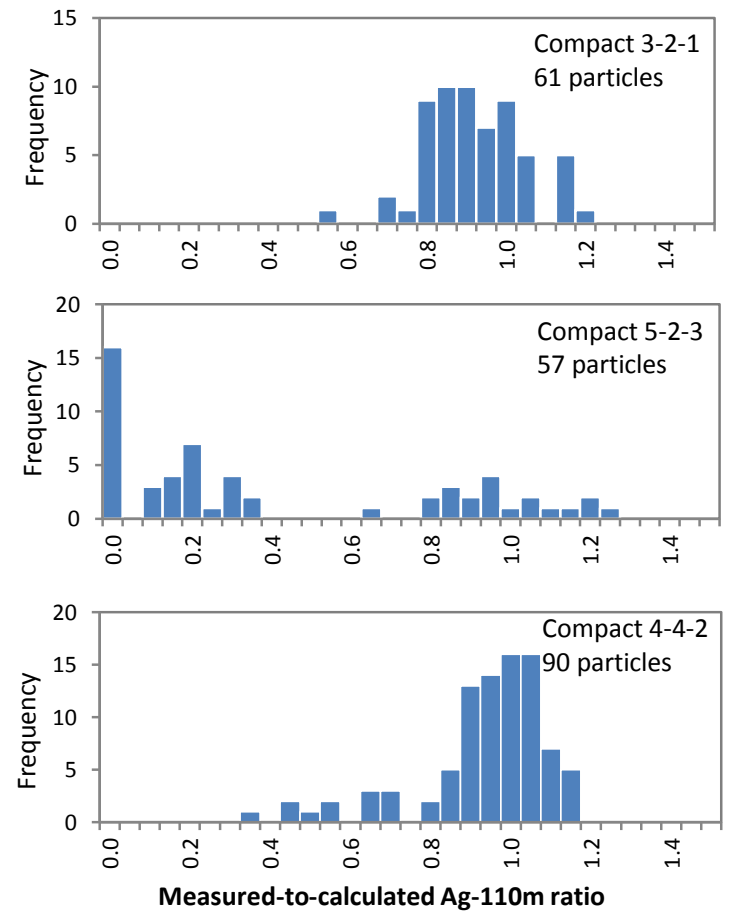

Figure 11. Distributions for the ${ }^{110 \mathrm{~m}} \mathrm{Ag}$ measured-to-calculated ratio in particles from three AGR-1 compacts.

Table 12. Average fraction of ${ }^{110 \mathrm{~m}} \mathrm{Ag}$ retained in a sample of particles taken from the irradiated AGR-1 compacts.

\begin{tabular}{|c|c|}
\hline Compact & Average Retained Fraction of ${ }^{110 \mathrm{~m}} \mathrm{Ag}$ \\
\hline $6-3-2$ & $0.35-0.51$ \\
\hline $6-1-1$ & $0.39-0.45$ \\
\hline $3-2-1$ & 0.92 \\
\hline $5-2-3$ & $0.43-0.45$ \\
\hline $5-2-1$ & $0.30-0.45$ \\
\hline $5-3-1$ & $0.47-0.58$ \\
\hline $4-4-2$ & 0.93 \\
\hline $4-1-1$ & 1.02 \\
\hline $1-3-1$ & $0.11-0.28$ \\
\hline
\end{tabular}

In contrast to the varied and broad range in silver retention behavior observed in individual particles, IMGA measurement of other radioisotopes showed consistent, high levels of retention. For example, Figure 12 shows the inventory distribution for ${ }^{144} \mathrm{Ce}$ and ${ }^{154} \mathrm{Eu}$ in Compact 4-4-2, which had a sub-population of particles with low silver retention (Figure 11). Both distributions in Figure 12 have small standard deviations and there was no evidence of particles with retention behavior outside the norm. The average ${ }^{144} \mathrm{Ce}$ retention was very close to a measured-to-calculated value of $\mathrm{M} / \mathrm{C}=1$, indicating that the particles retained cerium well. The ${ }^{154} \mathrm{Eu}$ inventory is centered around $\mathrm{M} / \mathrm{C}=0.86$; however, this does not indicate that there was a significant fraction of europium released from the particles because it is known that the calculated inventory for ${ }^{154} \mathrm{Eu}$ was overestimated by the physics calculations (see Section 3.3). 

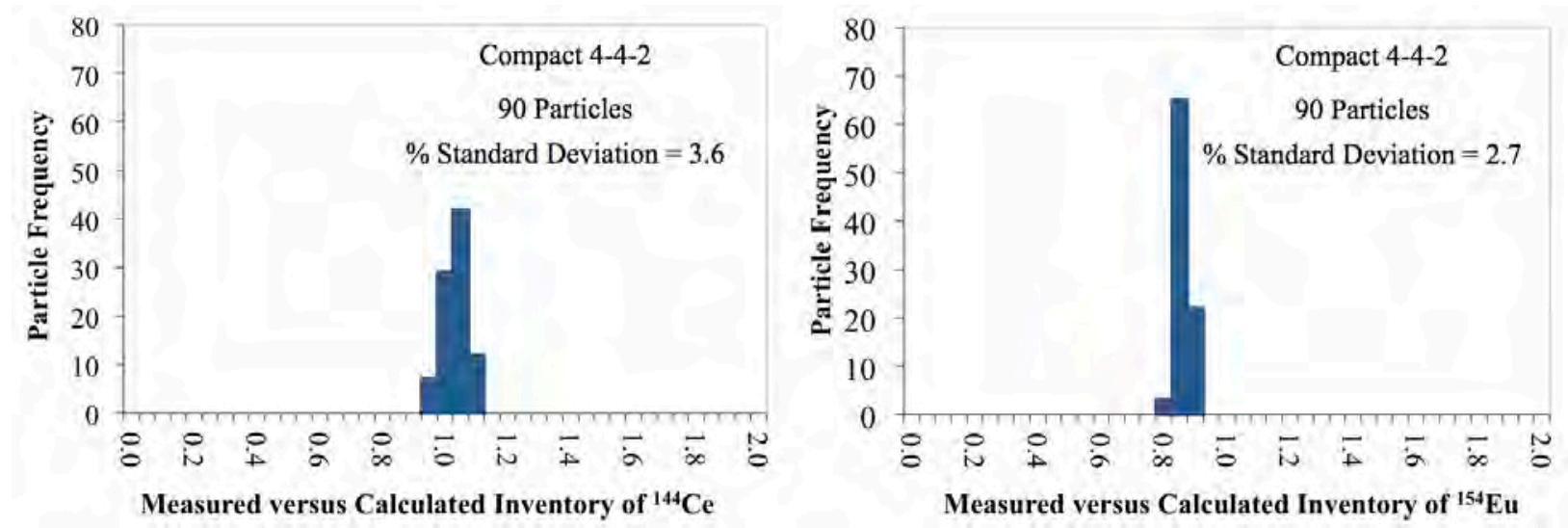

Figure 12. Distributions for the ${ }^{134} \mathrm{Ce}$ and ${ }^{154} \mathrm{Eu}$ measured-to-calculated ratio in particles from Compact 4-4-2.

\subsubsection{Discussion}

3.2.3.1 Cesium. Experience with TRISO fuel has demonstrated that the SiC layer provides the primary containment of cesium in the particles; therefore, cesium release is an effective indicator of $\mathrm{SiC}$ failure (Schenk et al. 1990; Nickel et al. 2002). The total fractional release of ${ }^{134} \mathrm{Cs}$ from the AGR-1 compacts was $<3 \times 10^{-6}$ in Capsules 1-4 (Table 10, but notably higher in Capsules 5 and $6\left(\sim 10^{-5}\right)$.

Detailed spatial gamma spectrometry of the AGR-1 graphite fuel holders initially identified specific compacts in Capsules 5 and 6 that released higher-than-average quantities of cesium during irradiation (Harp et al. 2012). The identified compacts were the focus of detailed examination to locate and characterize any particles containing a failed $\mathrm{SiC}$ layer that could be responsible for the cesium release (see Section 5). The results of this analysis have shown that three AGR-1 compacts (two in Capsule 5 and one in Capsule 6) contained particles with failed $\mathrm{SiC}$ and were responsible for a significant portion of the total cesium that was released in those capsules. As discussed in Section 5, Compact 5-2-3 contained two such particles while Compact 5-2-1 contained one. All three of these particles were located using the IMGA and detailed analysis has been performed. The level of ${ }^{134} \mathrm{Cs}$ fractional release from these particles ranged from 0.38 to 0.65 , which shows that, while $\mathrm{SiC}$ is the most effective cesium barrier in the TRISO particle, it is not the only defense against cesium release. Other analyzed radioisotopes $\left({ }^{95} \mathrm{Zr},{ }^{106} \mathrm{Ru},{ }^{125} \mathrm{Sb}\right.$, ${ }^{144} \mathrm{Ce}$, and ${ }^{154} \mathrm{Eu}$ ) were retained in these three particles within the normal distribution measured by the IMGA on randomly selected particles with intact $\mathrm{SiC}$. A single particle with failed $\mathrm{SiC}$ was identified in Compact 6-3-2; this particle was identified during DLBL analysis, as evidenced by the level of uranium in the burn-leach solutions (see Table 11), which was equivalent to the inventory in a single kernel.

Based on these results, the total number of particles that experienced failed SiC during the AGR-1 irradiation was determined to be four out of approximately $2.98 \times 10^{5}$ particles in the irradiation test, resulting in an in-pile SiC failure fraction of $1.3 \times 10^{-5}\left(\leq 3.1 \times 10^{-5}\right.$ at $95 \%$ confidence).

Analysis of the AGR-1 cesium data indicates that the majority of cesium released from the fuel compacts in Capsules 5 and 6 originated from the particles with failed SiC. The AGR-1 data also indicate that cesium release from compacts is extremely low in the absence of failed $\mathrm{SiC}\left(<3 \times 10^{-6}\right.$ fractional release from the compacts, based on the data from Capsules 1-4). It is concluded that cesium release from the compacts is primarily a function of the number of $\mathrm{SiC}$ failures, and detailed study of these particles has been undertaken to better understand the causes of in-pile $\mathrm{SiC}$ failure. 
The level of ${ }^{134} \mathrm{Cs}$ retained outside of the $\mathrm{SiC}$ layer in the compacts (Table 11), was on average slightly higher than the level released from the compacts (see comparison of ${ }^{134} \mathrm{Cs}$ data ranges in Figure 9). This indicates that there is a certain degree of cesium retention within the compact matrix or OPyC layer. Note that the level of ${ }^{134} \mathrm{Cs}$ released from the compacts to the capsule components in Capsules 5 and 6, and the level found outside of the SiC layer in Compacts 5-2-3 and 5-2-1, have been plotted separately in Figure 9, since these levels are due to release from particles with failed SiC, while the values for the remaining capsules and compacts represent release from intact $\mathrm{SiC}$ (with possible contributions from hot cell contamination and uranium contamination in the matrix of the as-fabricated compacts).

3.2.3.2 Silver. The relatively high fractional release of silver is a well-known characteristic of TRISO fuel (Amian and Stöver 1983; Nabielek et al. 1977). This behavior results from a relatively high rate of transport through $\mathrm{SiC}$ and is a strong function of fuel temperature, although other factors, such as the $\mathrm{SiC}$ microstructure, likely play a role as well.

Silver release from the AGR-1 particles and compacts was significant in many cases, and exhibited considerable variation. At the capsule level, ${ }^{110 \mathrm{~m}} \mathrm{Ag}$ release fractions ranged from 1.2 to $38 \%$ (Table 10 , Figure 9). Release fractions from individual compacts ranged from approximately $0 \%$ to greater than $90 \%$ (Figure 10). Within a single compact, silver release from individual particles could also vary considerably, often spanning a range that extended from 100\% retention to near $100 \%$ release, as demonstrated in Figure 11.

The large range of silver release fractions observed for the AGR-1 particles and compacts is believed to be primarily driven by the temperature of the fuel during irradiation. However, the effects of temperature-related phenomena are difficult to assess due to the complex nature of the temperature variations within the fuel compacts as the irradiation progressed. In the case of compacts with high ${ }^{110 \mathrm{~m}} \mathrm{Ag}$ release, temperatures often achieved relatively high levels for significant portions of the irradiation. For example, computational modeling of temperatures in the AGR-1 fuel (Hawkes 2012) indicates that in Compact 6-2-3, which exhibited an estimated ${ }^{110 \mathrm{~m}} \mathrm{Ag}$ release of approximately $90 \%$ during the irradiation (Figure 10), roughly half of the fuel particles were at temperatures in excess of $1300^{\circ} \mathrm{C}$ for approximately 100 days.

Another complication encountered when interpreting the thermal history of the fuel compacts is the often significant spatial temperature distributions within individual compacts. Calculation of temperature within the compacts (Hawkes 2012) indicates that the temperature gradient within an individual compact could often exceed $300^{\circ} \mathrm{C}$ at any point in time, and this could certainly have a profound effect on the distribution of silver release among particles, as demonstrated empirically in the distributions provided in Figure 11. Computational modeling of the silver release from compacts, which partially accounts for these temperature variations by using the calculated daily volume-average temperatures for each compact, has resulted in reasonable agreement with the empirical data in Figure 10 (Collin et al. 2014).

Nonetheless, a key component of the AGR-1 PIE has been to examine various particles based on their observed ${ }^{110 \mathrm{~m}} \mathrm{Ag}$ retention (from particle gamma counting data) in an attempt to correlate silver retention behavior with $\mathrm{SiC}$ layer characteristics, including grain size, grain boundary characteristics, observable $\mathrm{SiC}$ defects (including as-fabricated defects such as carbon soot inclusions), and coating degradation or fractures related to irradiation. The analysis has included non-destructive x-ray imaging, optical microscopy, scanning electron microscopy, and other advanced analytical techniques including transmission electron microscopy, elemental analysis, and atom probe tomography. Section 3.4 presents results from some of these analyses. To date, no clear correlation between $\mathrm{SiC}$ microstructure and the level of ${ }^{110 \mathrm{~m}} \mathrm{Ag}$ retention in the particles has been observed, although statistical data sets for some of these analyses are still relatively small. Therefore, the current conclusion is that these variations in ${ }^{110 \mathrm{~m}} \mathrm{Ag}$ release fraction are driven primarily by particle-to-particle temperature variations. 
3.2.3.3 Strontium. The strontium inventory retained in the irradiated compacts outside the SiC layer varied considerably (Figure 9). The upper end of this range $\left(\sim 3 \times 10^{-3}\right)$ is considerably higher than the equivalent inventory from a single particle $\left(2.4 \times 10^{-4}\right)$; therefore, this range indicates that there was appreciable strontium release through intact particle coatings in certain compacts. The fractional inventory found on the capsule components - representing the release from the compacts - was between approximately $8 \times 10^{-7}$ and $3 \times 10^{-5}$. Comparison of the fraction found outside of the SiC layer in the compacts with the fraction released from the compacts to the capsules (Figure 9) indicates that strontium is retained to a significant degree within the surrounding carbonaceous phases of the compact (matrix or OPyC layer).

3.2.3.4 Europium. The europium release behavior was similar to that of strontium, although with the maximum fractional inventory retained in the compacts outside of the SiC layer and the inventory released from the compacts approximately one order of magnitude higher relative to strontium (Figure 9). Similar to strontium, these levels (as high as $\sim 10^{-2}$ retained outside of the SiC layer in the compacts and $\sim 5 \times 10^{-4}$ released from the compacts) indicate appreciable release of europium through intact coating layers. As with strontium, a comparison of the fraction found outside of the $\mathrm{SiC}$ layer in the compacts with the fraction released from the compacts indicates that europium is retained to a significant degree within the carbonaceous phases of the compact (matrix or OPyC layer). Particle gamma-counting data did not show any indication for a subpopulation of particles that released more europium than the average.

3.2.3.5 Cerium. Cerium behavior was qualitatively similar to that of strontium and europium. The levels outside of the $\mathrm{SiC}$ layers in certain compacts (as high as $1.6 \times 10^{-3}$ ) indicate appreciable release through intact coatings, and the much higher fraction found in the compacts relative to that released from the compacts indicated significant retention in the carbonaceous phases of the compacts. The overall fractional inventory retained in the compacts outside the SiC layer was roughly similar to the corresponding values for strontium. While the maximum fractional release from compacts was similar to that of strontium, in some capsules the release from compacts was much lower (Figure 9).

3.2.3.6 Palladium. While there are no isotopes of palladium of consequence in terms of radiological hazard, the behavior of palladium in TRISO fuel is of particular interest because of the potential role it can play in $\mathrm{SiC}$ layer degradation. The levels of palladium found in the compacts outside of the SiC layer were relatively high (ranging from approximately 0.5 to $3 \%$, see Table 11 ), indicating appreciable release through intact coatings. However, significant $\mathrm{SiC}$ degradation was only observed in particles with failed $\mathrm{SiC}$, thus palladium transport through $\mathrm{SiC}$ was not detrimental to the $\mathrm{SiC}$ integrity. Attempts at quantification of palladium on capsule components proved to be largely unsuccessful (as described in Demkowicz et al. 2013); therefore, the level of release from the compacts is not known. A key facet of the microanalysis of the irradiated AGR-1 fuel particles was characterization of palladium in the coating layers to understand the transport behavior (particularly interaction with and transport through the SiC layer) and determine the extent to which palladium may play a role in the release of other fission products from the TRISO particles (especially silver). Palladium corrosion was found to be a key contributor to the formation of $\mathrm{SiC}$ failures in particles that released cesium during the AGR-1 irradiation and post-irradiation safety testing. The correlation between the distribution of palladium in $\mathrm{SiC}$ and the release of ${ }^{110 \mathrm{~m}} \mathrm{Ag}$ is currently being studied. These effects are discussed below. 


\subsection{Burnup Analysis and Comparison of Isotopic Inventories with Predictions}

\subsubsection{Burnup Measurement}

Measured burnup data is needed to validate the models used in physics simulations of the AGR-1 experiment (Sterbentz 2013). Experimental evaluation of burnup was performed by two separate techniques. Gamma spectrometry was initially used to nondestructively evaluate the burnup of all 72 compacts. Burnup evaluation based on gamma spectrometry was performed by two methods. The first method involved relating the total activity of a particular fission product $\left({ }^{137} \mathrm{Cs}\right)$ in a compact to the compact average burnup, and the second method used the activity ratio of a shielded and direct fission product $\left({ }^{134} \mathrm{Cs}\right.$ and $\left.{ }^{137} \mathrm{Cs}\right)$ to determine both compact average burnup and local burnup in a small axial region of the compact. Destructive chemical analysis by ICP-MS was also performed on four compacts that were representative of the expected range of fuel burnups in the experiment, to compare with the burnup values determined by gamma spectrometry. The results of both experimental techniques were compared to detailed depletion simulations (Sterbentz 2013). The gamma scans of the compacts are described briefly in Section 3.2.1.2 and detailed in Harp 2014. Details of the burnup measurements from all of the techniques can be found in Harp et al. 2014.

Activities derived from gamma spectrometry measurements were converted to burnup via a relationship that was derived from simulations (Sterbentz 2013) and related activity or activity ratio to burnup. Both the direct ${ }^{137} \mathrm{Cs}$ burnup evaluation and the ${ }^{134} \mathrm{Cs} /{ }^{137} \mathrm{Cs}$ ratio burnup evaluation agreed well with simulations. Some small deviations such as slight differences in Stack 1 and Stack 3 burnup were observed in the experimental data but not the simulation data. Using only ${ }^{137} \mathrm{Cs}$ as a burnup indicator, the peak measured burnup is $20.1 \%$ FIMA for Compact 3-2-3, and the minimum measured burnup is $10.1 \%$ FIMA for Compact 6-4-2. Using the ${ }^{134} \mathrm{Cs} /{ }^{137} \mathrm{Cs}$ ratio method, the minimum measured burnup is $10.7 \%$ FIMA for Compact 6-4-2, and the maximum burnup is 20.0\% FIMA for Compact 3-1-3. For reference, in the simulations the highest burnups were 19.56\% FIMA for Compact 3-4-3 and 19.53\% FIMA for Compact 3-1-3, and the minimum burnup was 11.30\% FIMA for Compact 6-4-2. The numeric burnup values for all 72 compacts by both methods using gamma spectrometry data can be found in Harp 2014.

The ${ }^{134} \mathrm{Cs} /{ }^{137} \mathrm{Cs}$ ratio burnup evaluation can also be used to evaluate the local burnup of different compacts in the area viewed by the gamma scanning system (typically a $0.254-\mathrm{cm}$ axial slice of a compact). The data indicate that burnup could exhibit significant axial variation over the $\sim 25-\mathrm{mm}$ compact length, with the variation exceeding $2 \%$ FIMA in certain instances, particularly for compacts at the axial ends of a capsule. For example, Compact 5-1-2 has a minimum measured local burnup of $15.0 \%$ FIMA and a maximum measured local burnup of 17.2\% FIMA. The use of this local burnup monitor is best illustrated by Figure 9 in Harp et al. 2014.

Determination of burnup from mass spectrometry data first involved dissolution of a small number of kernels from each compact examined. The method used to dissolve the actinides and fission products from the kernels for burnup analysis is described in the individual compact reports (Demkowicz et al. $2012,2015 b, 2015 c, 2015 d)$. Significant effort was put into optimizing the dissolution methodology to ensure full $\mathrm{Pu}$ recovery along with recovering $\mathrm{U}$, the lanthanide fission products, and other minor actinides. Regardless of the dissolution method, the burnup was calculated from the resulting mass spectrometry data in the same way. Burnup was calculated using the measured mass of a specific fission product in the fuel, the cumulative fission yield of that specific fission product, and the total mass of actinides present in the sample (Harp et al. 2014). This method is sometimes referred to as the "Fission Product Monitor - Residual Heavy Atom" technique (Maeck et al. 1973). 
There are six isotopes that work reliably for the ICP-MS technique in the AGR-1 fuel: ${ }^{139} \mathrm{La},{ }^{140} \mathrm{Ce}$, ${ }^{142} \mathrm{Ce},{ }^{141} \mathrm{Pr},{ }^{145} \mathrm{Nd}$, and ${ }^{146} \mathrm{Nd}$. These fission products are all lanthanides that will readily oxidize during the oxidation step and readily dissolve in nitric acid. The differences between ${ }^{235} \mathrm{U}$ yield and ${ }^{239} \mathrm{Pu}$ yield are fairly small for these isotopes as well. These isotopes are nonradioactive and have relatively small neutron absorption cross section with the exception of ${ }^{145} \mathrm{Nd}$. Because of its cross section, the number of ${ }^{145} \mathrm{Nd}$ and ${ }^{146} \mathrm{Nd}$ atoms in the samples and their respective yields are summed in the calculation of burnup. In this calculation, the burnup measurement for each sample of particles was found by taking the average of the individual isotope results. The burnup for a compact was then determined from the average of a set of burnup measurements from the separate particle samples.

Burnup values for each compact evaluated by mass spectrometry, both gamma spectrometry techniques, and simulation are shown in Table 13. The agreement between the three experimental measurements and the simulation is quite good. For all four compacts, the maximum range in the four burnup values is approximately $6 \%$ or less. The agreement between the mass spectrometric values and those derived from gamma spectrometry for these four compacts provides a level of confidence in the gamma spectrometry-based measurements on the remaining compacts in the AGR-1 experiment. In addition, the agreement between all experimental values and the simulations validates the AGR-1 physics model.

Table 13. Mass spectrometry burnup data compared to other techniques in \% FIMA.

\begin{tabular}{|c|c|c|c|c|}
\hline Compact & Mass Spectrometry & $\begin{array}{c}\text { Gamma Spectrometry } \\
\text { Direct }\end{array}$ & $\begin{array}{c}\text { Gamma Spectrometry } \\
\text { Ratio }\end{array}$ & Simulation \\
\hline $6-3-2$ & $10.7( \pm 0.5) \%$ & $10.7( \pm 0.5) \%$ & $11.0( \pm 0.3) \%$ & $11.31 \%$ \\
\hline $3-2-1$ & $19.3( \pm 1.0) \%$ & $18.2( \pm 0.9) \%$ & $18.6( \pm 0.6) \%$ & $18.98 \%$ \\
\hline $5-3-1$ & $16.3( \pm 0.8) \%$ & $16.9( \pm 0.8) \%$ & $15.9( \pm 0.5) \%$ & $16.88 \%$ \\
\hline $1-3-1$ & $16.3( \pm 0.8) \%$ & $16.0( \pm 0.8) \%$ & $15.6( \pm 0.5) \%$ & $15.98 \%$ \\
\hline
\end{tabular}

\subsubsection{Comparison of Measured versus Calculated Inventories}

3.3.2.1 Uranium and Plutonium. It is also constructive for the purposes of evaluating the AGR-1 physics simulations to compare the actinide mass of each isotope measured by ICP-MS to the mass predicted by simulation. Each burnup sample included 20 particles randomly selected from a compact. The particles were crushed to expose the kernels, oxidized in air, and leached in nitric acid or a nitric acid-hydrofluoric acid mixture. The solutions were then analyzed with ICP-MS. The expected mass of 20 TRISO particles for several different actinide isotopes was determined based on Sterbentz 2013, and compared to the ICP-MS results. The predicted mass per kernel was determined by taking the total predicted mass in the compact from Sterbentz 2013 and dividing by the estimated number of particles in the compact $(\sim 4,150)$. Since the mass of the individual kernels used for the measurement was not known, it was assumed that each kernel had average mass. The comparison of $\mathrm{C} / \mathrm{E}$ values for each of the samples is detailed in the individual compact reports for Compacts 3-2-1, 5-3-1, and 1-3-1 (Demkowicz 2015b, Demkowicz 2015c, Demkowicz 2015d). Based on the C/E values for uranium and plutonium, the specific procedure for oxidation and leaching of the kernels evolved during analysis of samples from the four compacts in an attempt to improve recovery of the actinides and achieve better agreement between calculated and experimentally derived values. Details of the procedure used for each sample from each compact can be found in the individual compact PIE reports.

For Compact 6-3-2, C/E values for uranium isotopes were close to 1.0 suggesting good $\mathrm{U}$ recovery and good agreement with simulation. However, the $\mathrm{Pu} C / \mathrm{E}$ values were 34 to $43 \%$ overpredicted by simulation or under-recovered by the dissolution technique. 
For Compact 3-2-1, the uranium isotopes, ${ }^{236} \mathrm{U}$ and ${ }^{238} \mathrm{U}$ were in good agreement, which suggests uranium was recovered well. However, the $\mathrm{C} / \mathrm{E}$ ratios for ${ }^{235} \mathrm{U}$ were relatively high $(\mathrm{C} / \mathrm{E} \approx 1.2)$, suggesting that the ${ }^{235} \mathrm{U}$ inventory at end of irradiation was likely overpredicted by simulation. The plutonium $\mathrm{C} / \mathrm{E}$ values and other minor actinide numbers also showed a discrepancy between the simulations and the experimental values; the simulations predict approximately 34 to $58 \%$ more Pu than was measured experimentally.

In the dissolution of kernels from Compact 5-3-1, the $\mathrm{C} / \mathrm{E}$ data indicate that the addition of hydrofluoric acid (HF) appears to have improved Pu recovery by approximately 15 to $20 \%$ when comparing the amount of recovered $\mathrm{Pu}$ to the expected $\mathrm{Pu}$ content from simulations. The ICP-MS results for the three major $\mathrm{U}$ isotopes in the fuel agreed well with the simulations. For ${ }^{239} \mathrm{Pu}$ and ${ }^{240} \mathrm{Pu}$ there was on average an approximately 25 to $30 \%$ over prediction of Pu content in the kernels by the simulations when HF was added to the leach, whereas the over prediction was in the range of $43-49 \%$ without HF.

For Compact 1-3-1, a more extensive effort was made to explore the optimum approach for sample preparation of the ICP-MS solutions. Nine sets of 20 burned-back particles were randomly selected and three dissolution methods were explored. The comparison of calculated to experimental values for each of the samples is detailed in (Demkowicz 2015d).

Based on the Compact 1-3-1 results, plutonium $\mathrm{C} / \mathrm{E}$ values were closest to unity using the following technique for processing the kernels. The crushed particles were oxidized in air at $750^{\circ} \mathrm{C}$ for 24 hours in an air atmosphere muffle furnace. The particles were leached in $8 \mathrm{M}$ nitric acid with three drops of HF added and heated near boiling for approximately 1 hour. The Pu recovery values for the preferred method suggest an over prediction of Pu content in the kernels in the range of 10 to $35 \%$. When considering all the mass spectrometry burnup evaluations, this dissolution technique appears to have performed the best and is the preferred method for future burnup measurements.

3.3.2.2 Fission Products. In addition to actinide activity, the decay-corrected activity of different gamma-emitting fission products was compared to simulations. When the AGR-1 compacts were examined by gamma scanning, total activity for each compact and each isotope of interest was collected by summing the slice activities derived from spectra that corresponded to a certain AGR-1 compact (Harp et al. 2014). Detailed tables containing all the measured activities are available in (Harp 2014). In Figure 13, the measured activities of several isotopes in the AGR-1 compacts are compared with the calculated activities from Sterbentz (2013). The average calculated-to-experimental (C/E) activity ratios ${ }^{2}$ for all compacts are given in Table 14 for several isotopes measured by gamma scanning. The $\mathrm{C} / \mathrm{E}$ ratio for ${ }^{137} \mathrm{Cs}$ is very close to unity, indicating that its behavior was captured very well by simulation and that it is a reliable link between measured activity and burnup. The $\mathrm{C} / \mathrm{E}$ ratios of ${ }^{134} \mathrm{Cs}$ and ${ }^{144} \mathrm{Ce}^{3}$ are also close to unity, indicating a good agreement between the measured and predicted activities. The average $\mathrm{C} / \mathrm{E}$ values for ${ }^{154} \mathrm{Eu}$ and ${ }^{125} \mathrm{Sb}$ indicate a bias between the simulation and the measurement. The biases shown between simulation and experiment in these data are important to take into account when converting measured fission product inventories (from analyses such as DLBL, particle gamma counting, and safety testing, for example) into a fraction of the predicted inventory in a specific sample. The important conclusion is that while predicted values were used in all cases to determine the fractions, in some cases these fractions will have a small bias because of the bias in the predicted values. Measured ${ }^{106} \mathrm{Ru}$ activities were reasonably close to the predicted values. Unfortunately the inventory of non-gamma-emitting fission products (such as Pd isotopes and ${ }^{90} \mathrm{Sr}$ ) cannot be evaluated in this way; therefore, the bias between measured and predicted inventories was not determined.

2 The measured-to-calculated $(\mathrm{M} / \mathrm{C})$ inventory ratio, discussed in other sections of this report, is simply the reciprocal of the $\mathrm{C} / \mathrm{E}$ ratio.

3 The measured activity of ${ }^{144} \mathrm{Pr}$ was used instead of the activity measured using direct gamma emissions from ${ }^{144} \mathrm{Ce} .{ }^{144} \mathrm{Pr}$ is the daughter of the longer-lived ${ }^{144} \mathrm{Ce}$ and is in secular equilibrium with ${ }^{144} \mathrm{Ce}$. 


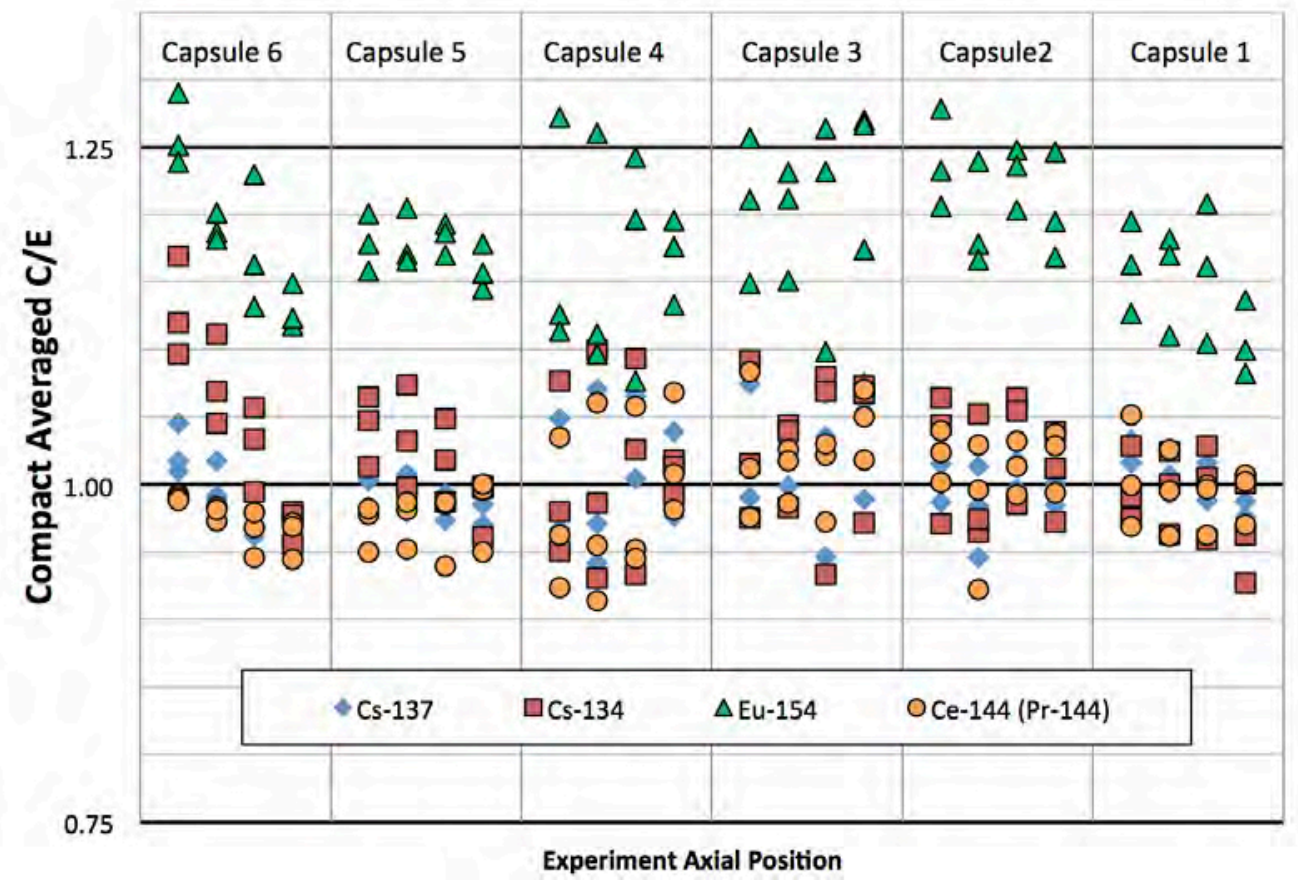

Figure 13. Calculated to Experimental $(\mathrm{C} / \mathrm{E})$ activity ratio for several different fission products for each fuel compact in the AGR-1 test train. Fuel compacts are plotted by vertical position in the AGR-1 test train, with the top of the test train at the left and the bottom at the right. There are three compacts at each axial location.

Table 14. Experimentally determined average $\mathrm{C} / \mathrm{E}$ values and corresponding $\mathrm{M} / \mathrm{C}$ for all AGR-1 compacts for several isotopes. $\mathrm{M} / \mathrm{C}$ values are equal to $1 /[\mathrm{C} / \mathrm{E}]$.

\begin{tabular}{|c|c|c|}
\hline Isotope & $\mathrm{C} / \mathrm{E}$ & $\mathrm{M} / \mathrm{C}$ \\
\hline${ }^{144} \mathrm{Ce}$ & $1.00(0.04)$ & $1.00(0.04)$ \\
\hline${ }^{134} \mathrm{Cs}$ & $1.03(0.05)$ & $0.97(0.05)$ \\
\hline${ }^{137} \mathrm{Cs}$ & $1.01(0.03)$ & $0.99(0.03)$ \\
\hline${ }^{154} \mathrm{Eu}$ & $1.21(0.05)$ & $0.83(0.04)$ \\
\hline${ }^{106} \mathrm{Ru}$ & $1.04(0.04)$ & $0.96(0.04)$ \\
\hline${ }^{125} \mathrm{Sb}$ & $1.44(0.09)$ & $0.70(0.04)$ \\
\hline
\end{tabular}




\subsection{Microstructure Evolution and Fission Product Distribution}

\subsubsection{Kernel and Coating Morphology Evolution}

A large number of particles from 15 different AGR-1 compacts have been analyzed microscopically to statistically study changes in kernel and coating morphology induced by irradiation. This includes characterization of almost 1000 particles in cross sections of six fuel compacts, where internal features of each particle were exposed at a single random depth (Ploger et al. 2012a, Hunn, Savage, and Kehn 2012, Ploger et al. 2014), and over 300 loose particles randomly selected from three compacts that were mounted in planar arrays and examined at multiple elevations for enhanced perspective (Demkowicz et al. 2015a, Demkowicz et al. 2015c, Demkowicz et al. 2015d, Bower et al. 2015). Based on these studies, characteristic particle morphologies have been identified, and particles were classified according to these morphological types to obtain statistics on particle behavior. The statistics presented in this section with regard to the percentage of particles observed with the various morphologies are based on these cross-sectional analyses. Nondestructive x-ray analyses to obtain full three-dimensional insights on a smaller number of select AGR-1 particles have also been performed (Hunn et al. 2012a; Hunn et al. 2013a Hunn et al. 2014b), and were used to provide further information on the morphological evolution of particles during irradiation.

3.4.1.1 Morphological Changes during Irradiation. The morphology most commonly observed within irradiated AGR-1 particles is displayed in Figure 14. The most conspicuous feature is the radial gap that formed as the buffer shrank away from the IPyC layer during irradiation. However, buffer densification was not complete, because considerably more porosity can be seen in the irradiated buffer than in the dense IPyC and OPyC layers. Approximately $60 \%$ of the particles exhibited complete buffer-IPyC delamination in the planes examined, although thin strips of buffer often remained intermittently attached to the IPyC interior. Only $4 \%$ of the particles revealed intact buffer-IPyC bonding along the entire interface (with the buffer shrinking away from the kernel). In the remaining $36 \%$ of the particles observed, the radial gap was locally interrupted by residual bonding along the buffer-IPyC interface (a somewhat higher percentage was observed in particles examined at multiple levels with better detection of local bonding).

Buffer fracturing was observed in some particles, regardless of the behavior of the buffer-IPyC interface. On average, fractured buffers were found in approximately $22 \%$ of the irradiated AGR-1 particles. However, on a relative basis fractured buffers were approximately three times more likely in particles with partial buffer-IPyC bonding, such as in Figure 15, than in particles with either complete delamination or full bonding. 


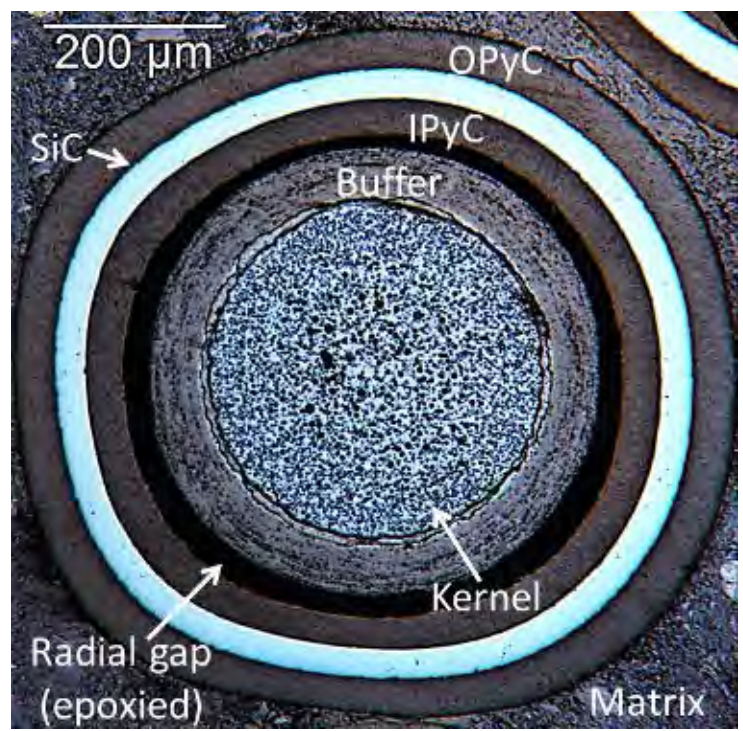

Figure 14. Irradiated AGR-1 Baseline fuel particle with continuous radial gap from inward shrinkage of the buffer layer.

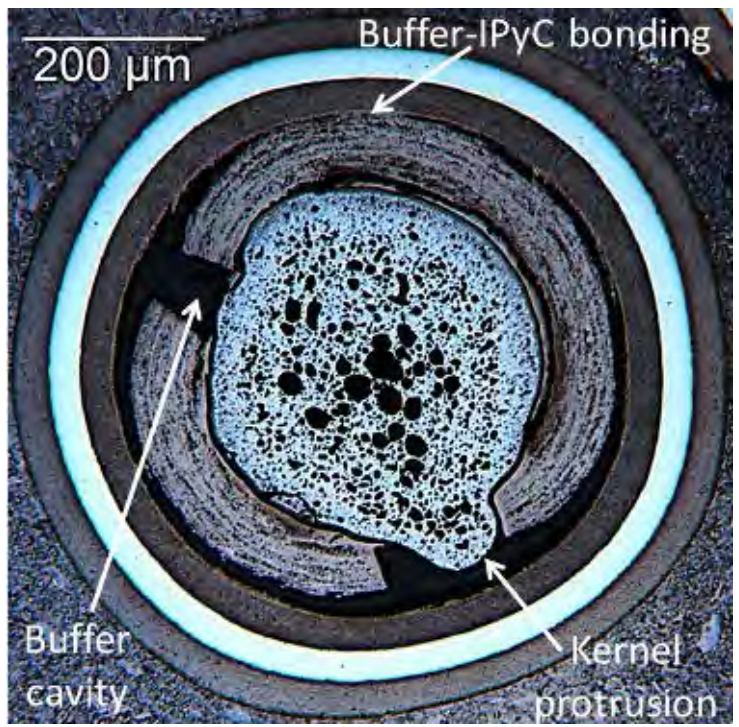

Figure 15. Irradiated AGR-1 Baseline fuel particle with local buffer-IPyC bonding, buffer fracturing, and protruding kernel.

The kernel frequently protruded into a cavity where the buffer split apart, occasionally approaching the IPyC interior without obviously damaging it. Protrusion was typically more extensive on one side, as in the Figure 15 example, presumably where a cavity first opened. This behavior indicates that intact, inwardly shrinking buffers possessed some mechanical strength and constrained kernel growth. Kernels seemed to expand more in the rare particles with no buffer-IPyC delamination due to the outward densification of the buffer. Larger pores tended to be found in kernels with less constrained growth, especially toward the kernel center, as in Figure 15. 
Despite kernel protrusions, no instances of kernel migration (commonly referred to as the "amoeba effect") were observed in cross sectioned AGR-1 particles. As seen historically in irradiation testing of uranium dioxide and uranium carbide particles, these kernels can migrate up the temperature gradient into the coating layers (Lindemer and Pearson 1977). The absence of kernel migration demonstrates that the UCO kernel chemistry effectively reduced the oxygen partial pressure during the AGR-1 experiment.

3.4.1.2 Fractures among TRISO Layers. Fractures in TRISO layers became progressively less frequent moving outward from the buffer, where $22 \%$ of 1288 total particles analyzed exhibited fracture, to the OPyC layer, where zero fractures were discovered in any of the particles examined in cross-section or x-ray imaging. Fractures through the IPyC layer were found in 3\% of the cross-sectioned AGR-1 particles. However, Variant 1 fuel, with an intentionally lower average IPyC density of $1.85 \mathrm{~g} / \mathrm{cm}^{3}$ (Table 2), contained IPyC fractures in $8.1 \%$ of the particles compared to an average frequency of $1.8 \%$ in particles of all of other fuel types, with a higher average IPyC density of $1.9 \mathrm{~g} / \mathrm{cm}^{3}$. Zero fractures through the entire $\mathrm{SiC}$ layer were observed by optical microscopy of randomly selected particles, but partial thickness cracks were detected in $0.4 \%$ of the SiC layers. Note that fractures or degradation that penetrated the entire SiC layer has only been observed in AGR-1 particles determined to have released cesium during the irradiation and specifically identified and selected for microanalysis with IMGA (see Section 5).

Fractured TRISO layers exhibited important relationships. In particles where the buffer-IPyC interface was entirely bonded, the buffers that fractured likely did so as the inner surface of the outwardly densifying buffer came into tension. These fractures propagated directly through the IPyC layer in all eight particles observed, as illustrated in Figure 16. IPyC-SiC debonding was seen at the "spearhead" tips in six of these cases. In four of these six cases, the IPyC-SiC separation induced tangential SiC cracks, although these cracks curved back toward the $\mathrm{SiC}$ interior and were not observed to penetrate the $\mathrm{SiC}$ layer. In contrast, buffers that shrank inwardly onto the kernel and that fractured after delaminating from the IPyC interior could not locally concentrate stress in the IPyC; zero IPyC fractures and SiC cracks were found in the 98 particles observed with complete buffer-IPyC debonding in the plane of polish. Thus, complete delamination along the buffer-IPyC interface appears advantageous.

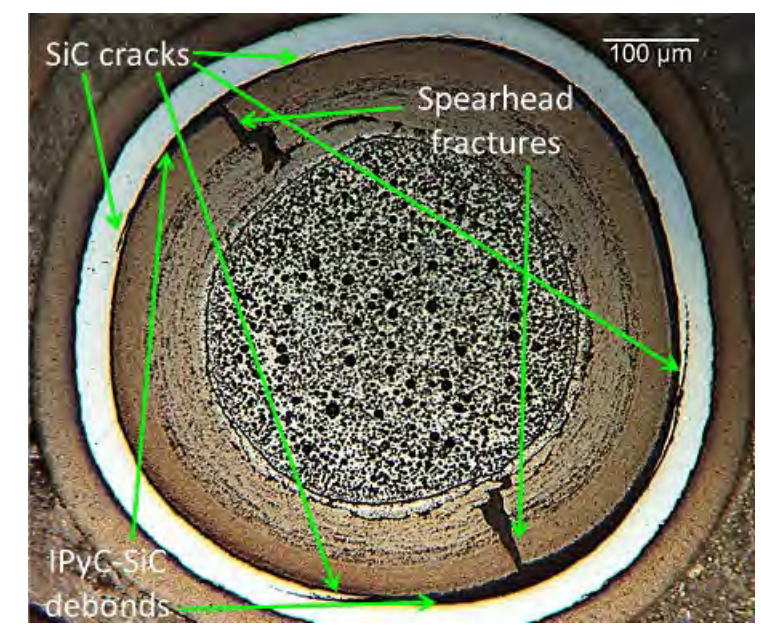

Figure 16. Irradiated AGR-1 Variant 1 particle, showing aligned buffer-IPyC fractures, IPyC-SiC debonds, and $\mathrm{SiC}$ crack formation. 
Partial buffer-IPyC delamination did not always protect the IPyC layer from effects of buffer fracture. IPyC fractures were observed in 26 of the 183 particles with both partial delamination and buffer fracturing, and half of these particles revealed IPyC-SiC debonds, as well. However, the buffer fractures and IPyC fractures in such particles were generally not aligned, and the stress patterns when IPyC fractures initiated were often difficult to deduce from end-state configurations. Furthermore, the majority of these IPyC fractures again occurred in Variant 1 fuel particles where the lower-density IPyC layer complicated generalization across all AGR-1 fuel types.

Four Variant 1 particles contained IPyC fractures without evident buffer fracture and two of these also had IPyC-SiC debonds. One even revealed $\mathrm{SiC}$ cracks in all six levels examined. As suggested by Figure 17, buffer shrinkage resulted in delamination along the IPyC interface. It is possible that delamination then ceased when positions of strong local bonding were reached. Additional buffer shrinkage then induced fractures through the apparently weak IPyC layer and pulled the IPyC inward, away from the $\mathrm{SiC}$. The IPyC and $\mathrm{SiC}$ then continued to delaminate until tangential $\mathrm{SiC}$ cracks were initiated. These $\mathrm{SiC}$ cracks curved inward and did not compromise this key barrier to fission product migration.

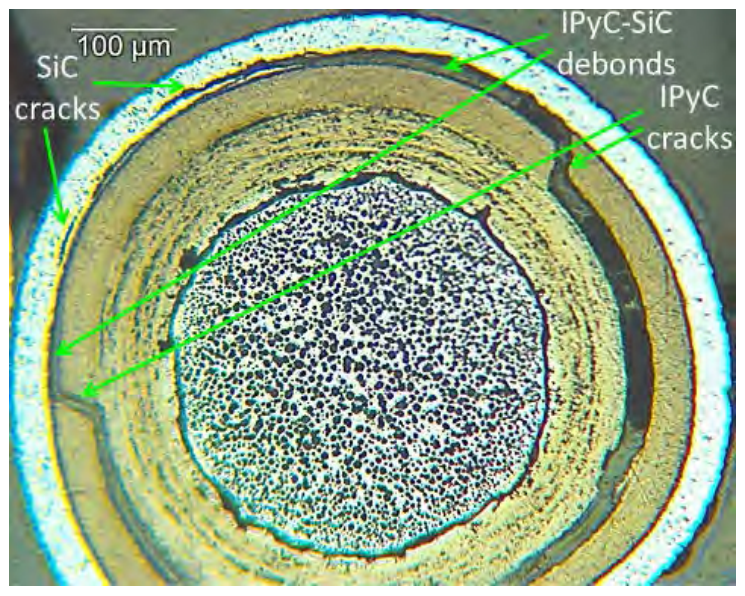

Figure 17. Irradiated AGR-1 Variant 1 particle, showing IPyC fracturing, IPyC-SiC delamination, and $\mathrm{SiC}$ crack formation without evidence of buffer fracture.

Detailed analysis of particles that have experienced a failure of the $\mathrm{SiC}$ layer - both during irradiation and during post-irradiation safety testing - has indicated that fracture of the IPyC and delamination at the $\mathrm{IPyC}-\mathrm{SiC}$ interface were the most frequently observed coating morphologies, with $\mathrm{SiC}$ damage occurring in the region where the $\mathrm{SiC}$ had been exposed and palladium was allowed to concentrate (Hunn et al. 2014d). This is discussed in further detail in Section 5. Thus, one of the key findings of this study is that complete and rapid delamination at the buffer-IPyC interface is preferred to avoid subsequent consequences of IPyC fracturing and IPyC-SiC delamination, which apparently can be a precursor to $\mathrm{SiC}$ failure.

Further details on characterization of particles in full compact cross sections are presented in Ploger et al. 2012a and Ploger et al. 2014. Details of results from particle ensembles examined in cross section at multiple polish planes can be found in Demkowicz et al. 2015c, Demkowicz et al. 2015d, Bower et al. 2015. Additional observations on particle morphology evolution based on examination of cross sections with optical microscopy and x-ray analysis can be found in the individual compact PIE reports (see Table 23). 
3.4.1.3 Particle Behavior Dependence on Irradiation Conditions. One of the original objectives of compact cross-section analysis was to explore the effects of irradiation conditions on particle morphology by examining particles in-situ, since the specific location of the particles within the compacts would be related to parameters such as burnup and temperature. Based on qualitative examination of coating behavior (e.g., buffer-IPyC delamination and coating fracture) and measurements of particle properties from micrographs for several of the compacts analyzed (including percent porosity and pore size in the kernels), no clear correlation with burnup or temperature was found for any of these characteristics. This includes an apparent absence of a correlation for compacts with different irradiation conditions, as well as a lack of trends among particles in individual cross sections, where both temperature and burnup would be expected to vary both axially and radially in the compact (Demkowicz et al. 2013).

\subsubsection{Fission Product Behavior}

3.4.2.1 Basic Electron Microscopy (SEM with EDS and WDS). This section summarizes the results from scanning electron microscope (SEM) examination of particles from two Baseline compacts (6-3-2 and 6-1-1), three Variant 3 compacts (4-1-1, 1-3-1, and 4-4-2) and three Variant 1 compacts (5-3-1, 5-2-1, and 5-2-3) (Hunn et al. 2012a; Hunn et al. 2013a; Hunn et al. 2014b; Van Rooyen et al. 2012a; Van Rooyen et al. 2014b; Van Rooyen et al. 2015c). The SEM analysis of as-irradiated particles provided key insights on the distribution and transport of fission products in the TRISO layers and over the entire particle cross section after irradiation. Particle selection was often based on the $\mathrm{M} / \mathrm{C}^{110 \mathrm{~m}} \mathrm{Ag}$ inventory ratio from gamma counting data (as described in Section 3.2.1.4). This allowed for comparison of the fission product distribution with $\mathrm{Ag}$ retention. SEM analysis was performed at both INL and ORNL. The SEM used for examination at INL is a JEOL-7000F equipped with wavelength dispersive spectroscopy (WDS) and energy dispersive spectroscopy (EDS) detectors. The SEM was operated between 10 and $30 \mathrm{kV}$. The SEM used for examination at ORNL is a JEOL JSM-6390L fitted with an Oxford INCA Energy 250 EDS system (or Oxford X-Max 50Silicon Drift Detector EDS system with AZtec acquisition software) and Oxford INCA Wave 500 WDS system. The ORNL SEM system was designed to operate either in the CCCTF hot cell or in the adjacent radiological control area. SEM imaging was conducted by secondary electron imaging (SEI) for surface sensitive analysis and with backscattered electron composition (BEC), which provided contrast as a function of atomic number $(Z)$. The Z-contrast imaging was ideal for imaging high-Z metallic fission products ${ }^{4}$ and actinides clustered within the lower-Z TRISO layers as they appeared bright and could be targeted for elemental analysis with EDS and WDS.

Analysis of particles from Compact 6-3-2 (the first particles to be examined at INL in 2011) focused on refining the SEM analysis techniques necessary to achieve the microstructural characterization objectives and to identify specific areas or features of interest (Van Rooyen et al. 2012a). SEM examination typically included fission product identification, chemical attack of the $\mathrm{SiC}$ layer, $\mathrm{SiC}$ microstructural characteristics focusing on the IPyC-SiC interlayer, and fuel kernel microstructure. Numerous clusters of fission product precipitates were observed in the coating layers during initial SEM characterization of the cross sections, but compositional quantification was problematic using SEM analytical tools (standardless EDS and WDS) due to the relatively small size of the precipitates and x-ray energy overlaps of constituents in the clusters.

4 In this report, the term "fission product" is used in a general sense to refer to all the isotopes generated from fission processes. These include direct fission products and those generated by neutron activation of direct fission products, as well as the relevant daughter isotopes. Note that uranium was often observed concurrently with various fission products in the coating layers, and is often grouped in this term in this discussion. 
Common features were observed in particles from all as-irradiated compacts that were examined. These features included fission products piled up at the IPyC-SiC interface and fission product clusters embedded in the SiC layer (Hunn et al. 2012a; Hunn et al. 2013a; Hunn et al. 2014b). Figure 18 shows the location of these features for a very low-Ag-retention particle $\left({ }^{110 \mathrm{~m}} \mathrm{Ag} \mathrm{M} / \mathrm{C} \leq 0.09\right)$ from Compact 5-2-3. The embedded fission product features ranged in size from micron to submicron in scale while the frequency and distribution of the embedded fission product clusters in the SiC layer varied from particle to particle. EDS and WDS analysis indicated the fission product features were composed of both fission product and actinide species. Palladium was the most prevalent fission product in the SiC and easy to identify in almost every cluster, while some also generated measurable signatures indicating significant U content (Hunn et al. 2012a; Hunn et al. 2014b). Pileup of Cs, Pd and U at the IPyC-SiC interlayer was commonly observed and is further demonstrated in the WDS mapping in Figure 19 for particle AGR1531-038 (Van Rooyen et al. 2015c). Other elements were observed in select fission product features, primarily at the IPyC-SiC interface; these elements included $\mathrm{Ba}, \mathrm{Ce}, \mathrm{Cs}, \mathrm{Nd}, \mathrm{O}$, and $\mathrm{Zr}$. Of these elements, $\mathrm{Ce}, \mathrm{Cs}$, and $\mathrm{Nd}$ were confirmed by WDS analysis. The automated standardless EDS routine also identified $\mathrm{Ag}, \mathrm{Cd}, \mathrm{Pu}$, and $\mathrm{Sr}$; however, the characteristic X-ray peaks of these elements were not directly observed due to peak overlap with the dominant species in the material system (Hunn et al. 2012a; Hunn et al. 2014b).

Silver is a fission product of primary interest, as the retention behavior varies greatly among individual particles. Identification of $\mathrm{Ag}$ across the particle cross sections can provide potential insight to $\mathrm{Ag}$ transport within a particle, which is ultimately related to $\mathrm{Ag}$ release. The detection of low concentrations of $\mathrm{Ag}$ in the presence of $\mathrm{U}$ and $\mathrm{Pd}$ is a particular challenge as the major $\mathrm{Ag}$ characteristic $\mathrm{x}$-ray peaks with energies below $\sim 20 \mathrm{keV}$ overlap with the relatively-high-intensity characteristic x-ray peaks from $\mathrm{U}$ and $\mathrm{Pd}$. This peak overlap makes direct identification of $\mathrm{Ag}$ in the Pd-U system using EDS difficult. Detection of Ag using higher energy detectors in the range of 20 to $40 \mathrm{keV}$ could avoid problems with overlap between $\mathrm{U}, \mathrm{Pd}$, and $\mathrm{Ag}$ (e.g., the $\mathrm{Ag} \mathrm{K}_{\alpha 1}$ peak at $22.163 \mathrm{keV}$ ), but the small concentrations associated with the fission product features are limited by detector sensitivity issues coupled with lower detector efficiency at higher x-ray energies. Additionally, the contribution of Si or C to the feature composition could not be accurately determined as the SEM interaction volume contained significant contributions from the surrounding $\mathrm{SiC}$ matrix. Advanced electron microanalysis techniques discussed in Section 3.4.2.2, with improved chemical sensitivity and increased spatial resolution, were explored to help identify and quantify fission product features to complement the large-area SEM analysis. 


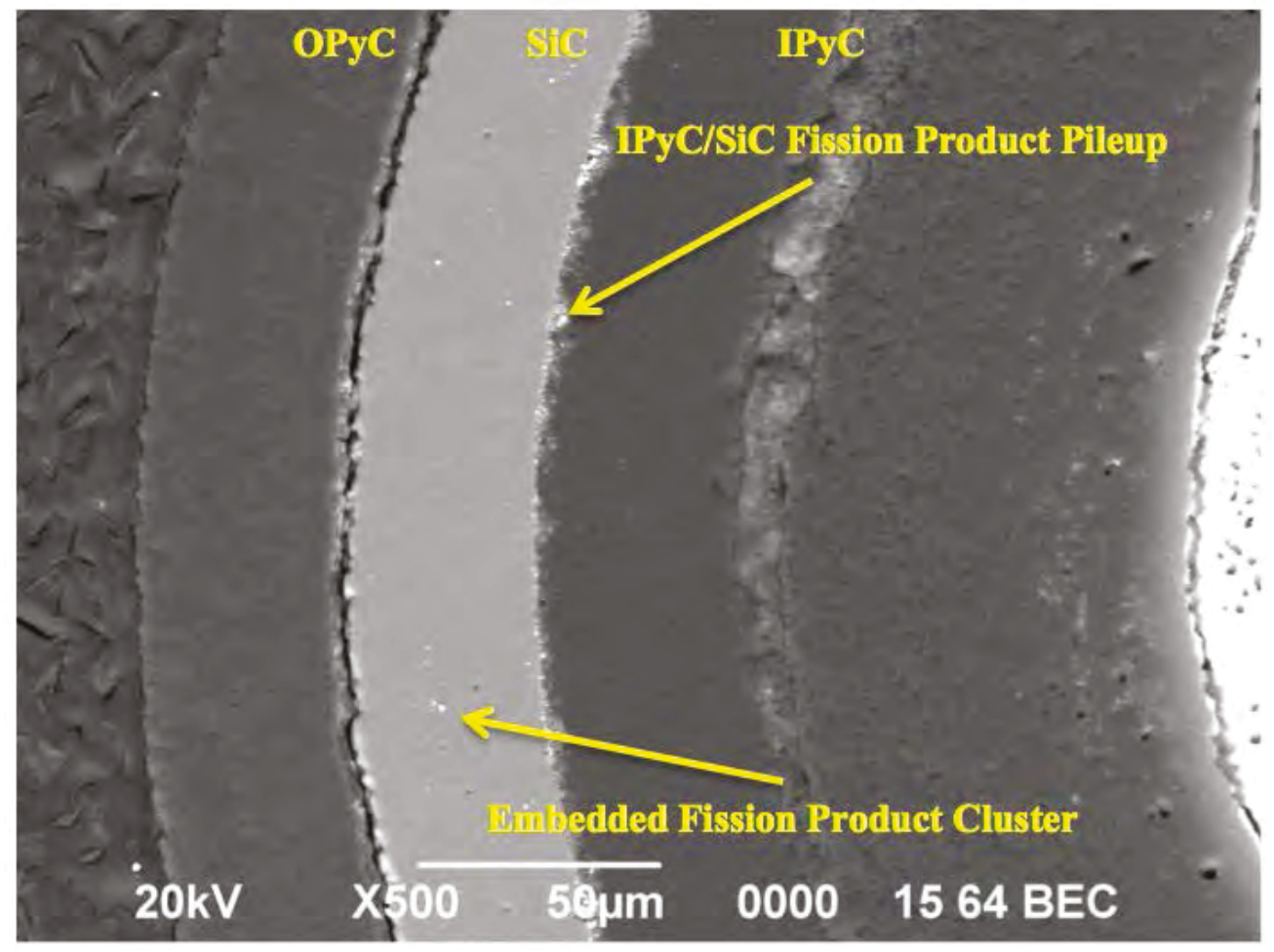

Figure 18. BEC micrograph of the TRISO layers from a Compact 5-2-3 particle with very low Ag retention $(\mathrm{M} / \mathrm{C} \leq 0.09)$, bright areas at the $\mathrm{IPyC}-\mathrm{SiC}$ interface and in the $\mathrm{SiC}$ layer are associated with segregated fission product features.

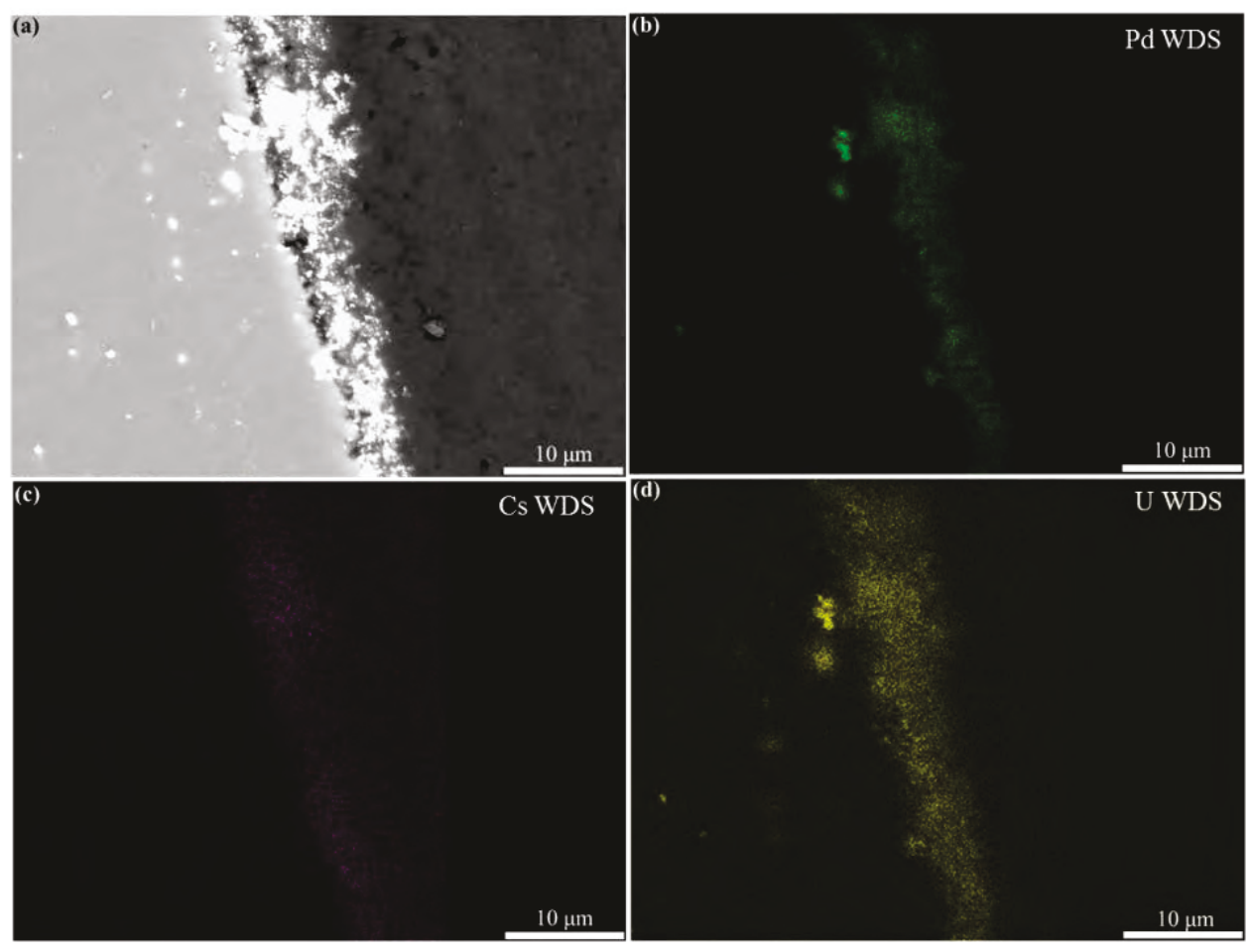

Figure 19. SEM micrograph showing $\mathrm{Pd} / \mathrm{Cs} / \mathrm{U}$ rich fission product features at the $\mathrm{IPyC}-\mathrm{SiC}$ interface in AGR1-531-038, confirmed by WDS maps of Pd, Cs and U. 
A subset of particles from Compacts 5-2-1 (five particles) and 5-2-3 (four particles) with a broad range in $\mathrm{Ag}$ retention behavior were analyzed. These particles had ${ }^{110 \mathrm{~m}} \mathrm{Ag} \mathrm{M} / \mathrm{C}$ ranging from $\leq 0.22$ to 1.39. A comparison of particles exhibiting high and low Ag retention from Compact 5-2-1 is shown in Figure 20. The Ag retention behavior comparison indicated that particles with low Ag retention contained a higher frequency of fission product clusters at greater depths in the $\mathrm{SiC}$ layer compared to high retention particles (Hunn et al. 2014b). EDS analysis of the fission product pileup features and embedded fission product features indicated a correlation in composition distribution with Ag retention behavior. A greater frequency of Pd-U features at the IPyC-SiC interface and in the inner half of the SiC layer was observed for low-Ag-retention particles compared to high-retention particles. Low retention particles also had fission product clusters in the outer half of the $\mathrm{SiC}$ that appeared to be predominately $\mathrm{Pd}$, having little or no detectable EDS signal from U (Hunn et al. 2014b). The observed correlation of fission product feature distribution with Ag retention performance suggest the in-reactor variables, which influence both phenomena are related, with the most likely variable being in-reactor temperature effects.

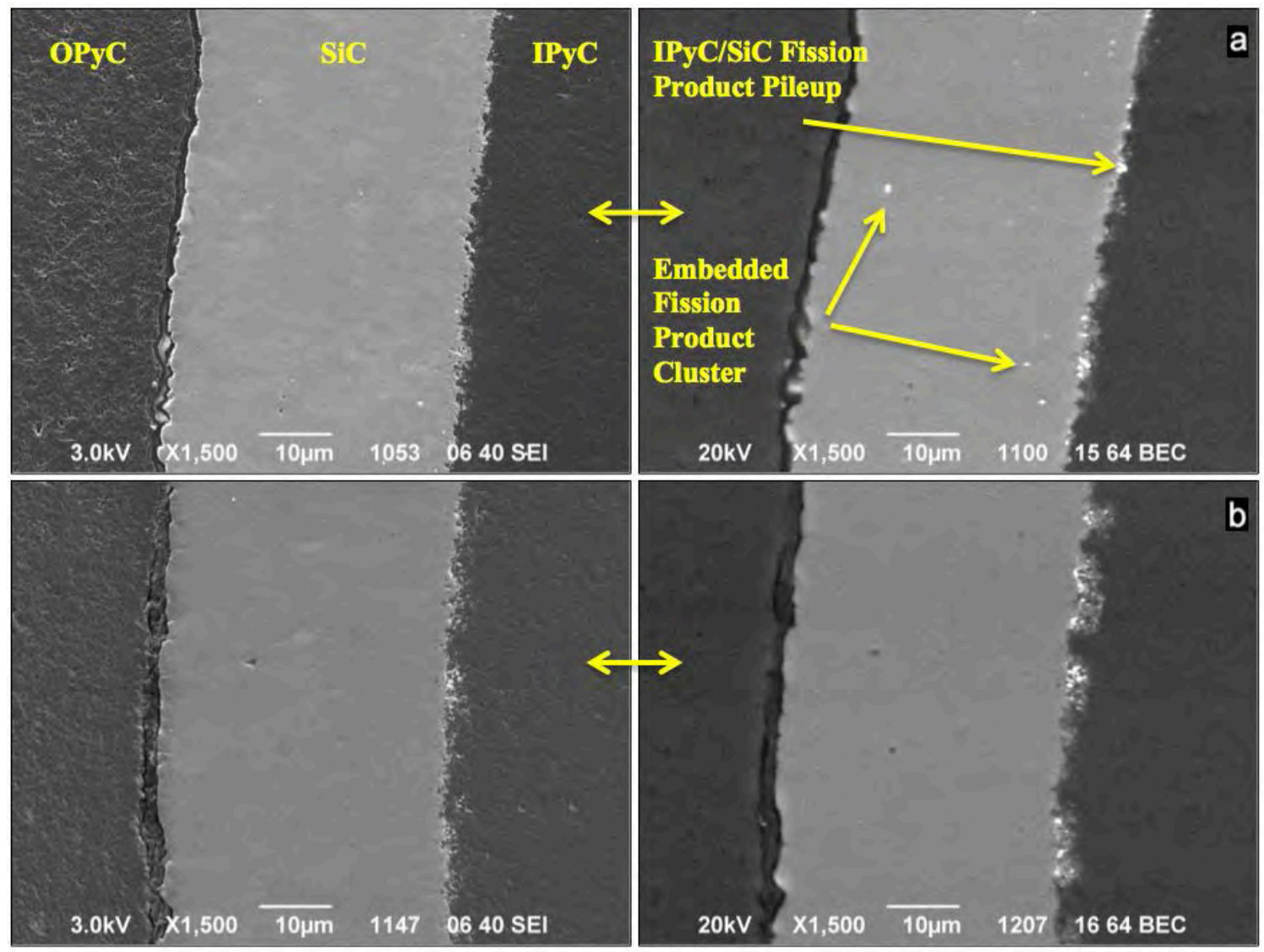

Figure 20. SEI/BEC-paired images of Compact 5-2-1, (a) very low Ag retention particle $(\mathrm{M} / \mathrm{C} \leq 0.25)$ and (b) high $\mathrm{Ag}$ retention particle $(\mathrm{M} / \mathrm{C}=1.03)$. Areas of bright contrast in $\mathrm{BEC}$ micrograph indicate isolated fission product features. 
Scanning electron microscopy image montages of the IPyC-SiC interface around the entire circumference of several particle cross sections were acquired to examine the fission product feature distributions along the interface as well as the local interfacial microstructure. Particles were examined that had ${ }^{110 \mathrm{~m}} \mathrm{Ag} \mathrm{M} / \mathrm{C}$ ratios at the low and high end of the distributions for each compact, often corresponding to a large variation in the level of $\mathrm{Ag}$ retention. Insights on variations of feature distribution as a function of $\mathrm{Ag}$ retention behavior, as well as possible variations in the IPyC-SiC interface integrity, may provide a better understanding of fission product release. Montages were prepared for five coated particles from two Variant 3 compacts (4-1-1 and 1-3-1), three coated particles from a Baseline compact (6-3-2), and two coated particles from a Variant 1 compact (5-3-1). Details of how these montages were produced and the specific results are described in Van Rooyen et al. 2012a, Van Rooyen et al. 2014b, and Van Rooyen et al. 2015c. A typical example of such an SEM montage is shown in Figure 21.

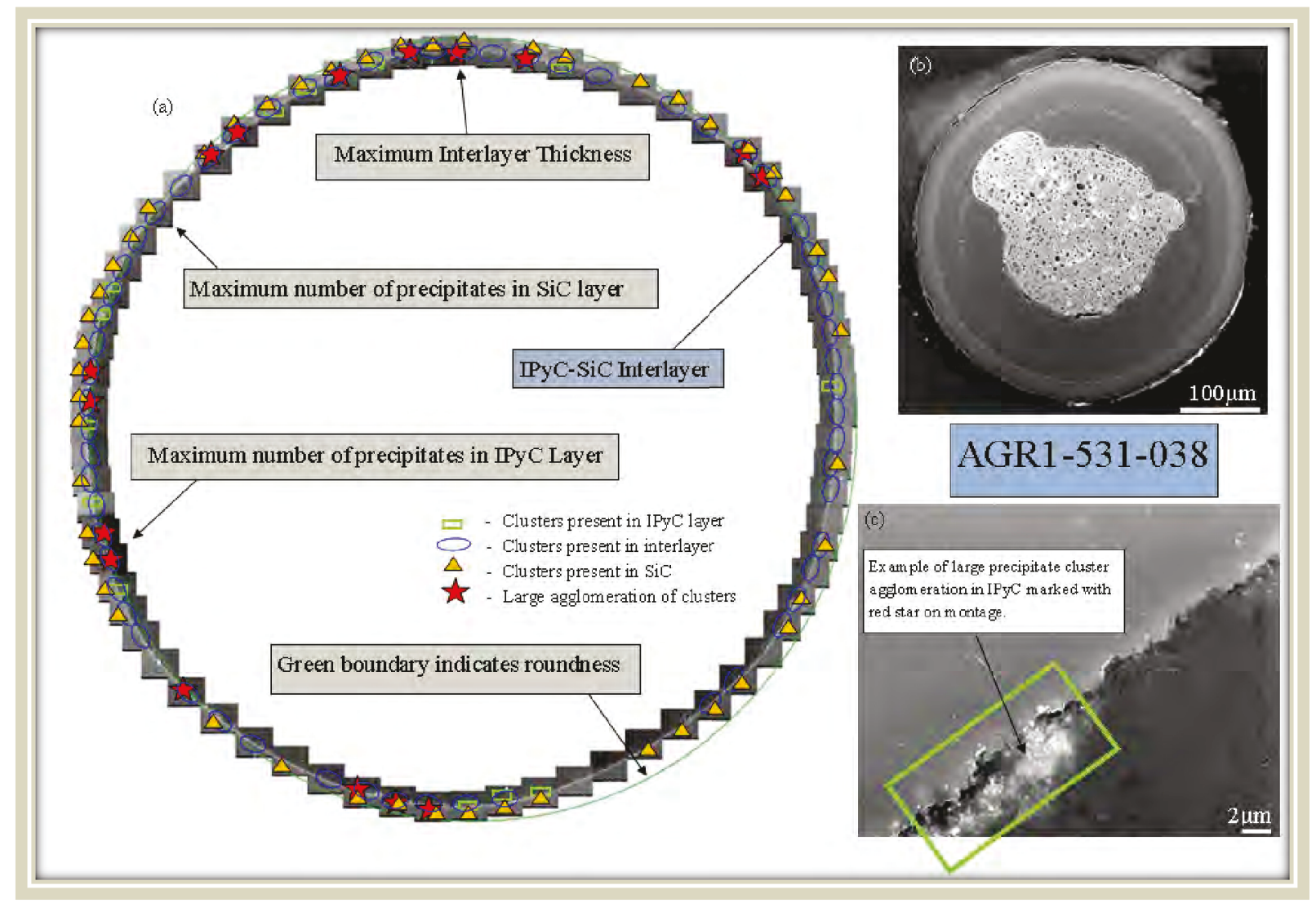

Figure 21. SEM images of particle AGR1-531-038 showing (a) an image montage representing the distribution of precipitate clusters, (b) an optical micrograph of the particle cross section, and (c) a representative SEM image of the IPyC-SiC interface.

The IPyC-SiC interfacial montage analysis indicated a particle-to-particle interlayer thickness variation, with the interlayer thickness ranging typically from 2 to $3 \mu \mathrm{m}$. However, the average interlayer thicknesses of the particles from two Variant 3 compacts (Compacts 4-1-1 and 1-3-1) exhibited the largest interlayer thickness values, with coated particle AGR1-411-021 exhibiting the largest interlayer thickness (maximum thickness of $6.58 \mu \mathrm{m}$ ). Voids were observed in the IPyC layer near the IPyC-SiC interface in most of the samples analyzed. However, these voids were not observed during the SEM analysis of Baseline Compact 6-3-2 and iterative polishing with very-fine polishing films on other specimens has demonstrated that these voids are most often an artifact of the grinding and polishing process used to prepare the cross sections for imaging. (Comparatively, more voids in the IPyC layer were observed in the 
particles from the safety-tested Compact 4-3-3; see Section 4.8.2.3 for more detail on the SEM examination on this compact). The montage analysis indicated that no significant corrosion of the $\mathrm{SiC}$ layer from fission product pileup was present in typical particles; however, variations in the fission product distributions at the IPyC-SiC interface were observed. Notably, large variations in the frequency of fission product features located at the IPyC-SiC interface were observed between particles from the same compact for both Variant 1 and Variant 3 fuel particles. Particle AGR1-531-031 contained the most precipitates in the $\mathrm{SiC}$ layer in the IPyC-SiC interlayer images. Additionally, more fission product clusters were identified in the SiC layer in particles from the Variant 3 compact (1-3-1) compared with the Variant 1 compact (5-3-1). Trend analysis shows precipitates were randomly distributed along the perimeter of the IPyC-SiC interlayer with a slight association with kernel protrusion and buffer fractures. A slightly higher concentration of fission product clusters was found in the region where the kernel is slightly closer to the IPyC-SiC interlayer. This trend was more prominent for particle AGR1-531-038 (Figure 21).

In summary SEM analysis of as-irradiated particles provided an understanding of the redistribution of fission products and actinides among the individual TRISO layers over an entire particle cross section. The analysis indicated particle-to-particle variations in fission product distribution in the $\mathrm{SiC}$ layer and at the IPyC-SiC interface. Particle-to-particle and compact-to-compact variations in the IPyC-SiC interlayer structure (thickness and void distribution) were also noted. Correlation in the fission product distribution in the $\mathrm{SiC}$ layer was also noted for particles with varying Ag retention behaviors.

\subsubsection{Advanced Electron Microscopy and Microanalysis}

\section{Background}

The results obtained with SEM/EDS/WDS analysis (Section 3.4.2.1) led to the exploration of other more advanced analytical and microscopic techniques to characterize fission product behavior in the particles. As most of these advanced techniques have not been used previously to characterize irradiated TRISO-coated particles or irradiated SiC, the level of effort to establish facilities, pathways and develop methods to perform the analysis was high. In addition to AGR-1 fuel performance data, these tests have also yielded important operational experience related to these methods and the additional support activities necessary to perform this work. Detailed results have been presented in separate topical reports and/or conference or journal papers. Publications and presentations completed to date (or in progress) are also provided in Table 15, which also includes an overview of the entire matrix of advanced electron microscopic examination techniques developed and implemented on AGR-1 particles since 2012. This section summarizes results obtained from the various techniques. 
Table 15. Status summary of advanced microscopy activities for the AGR-1 PIE.

\begin{tabular}{|c|c|c|c|c|c|c|c|c|}
\hline Technique $^{1}$ & $\begin{array}{c}\text { Compact } \\
6-3-2\end{array}$ & $\begin{array}{c}\text { Compact } \\
4-1-1\end{array}$ & $\begin{array}{c}\text { Compact } \\
5-3-1 \\
\end{array}$ & $\begin{array}{c}\text { Compact } \\
1-3-1\end{array}$ & $\begin{array}{c}\text { Compact } \\
4-3-3\end{array}$ & $\begin{array}{c}\text { Compact } \\
5-2-3\end{array}$ & Unirradiated Particles & References \\
\hline \multicolumn{8}{|c|}{ Advanced Microscopy } & $\begin{array}{l}\text { Van Rooyen et al. 2015a } \\
\text { Van Rooyen et al. 2013 } \\
\text { Van Rooyen et al. 2013a }\end{array}$ \\
\hline Basic TEM & Complete & Complete & -- & -- & -- & -- & Complete & $\begin{array}{l}\text { Van Rooyen et al. 2012a } \\
\text { Van Rooyen et al. 2012b } \\
\text { Van Rooyen et al. 2014b }\end{array}$ \\
\hline EPMA & -- & -- & -- & -- & Planned & Complete & Complete & \\
\hline \multirow[t]{3}{*}{ STEM } & Complete & Complete & Complete & Complete & In progress & Complete & -- & $\begin{array}{l}\text { Lillo and Van Rooyen 2015a } \\
\text { Lillo and Van Rooyen } 2014 \\
\text { Wen et al. } 2015 \\
\text { Wen et al. } 2015 \mathrm{a} \\
\text { Van Rooyen et al. 2014d } \\
\text { Included in Demkowicz et.al. 2015g } \\
\text { Wen et al. 2015b } \\
\text { Wen et al. 2015c }\end{array}$ \\
\hline & Complete $^{2}$ & -- & -- & -- & -- & -- & -- & Leng et al. 2015 \\
\hline & Planned $^{3}$ & -- & -- & -- & -- & Complete ${ }^{3}$ & -- & \\
\hline $\begin{array}{l}\text { EELS, } \\
\text { EFTEM }\end{array}$ & Complete $^{2,4}$ & -- & -- & -- & -- & -- & -- & Included in Van Rooyen et al. 2013 \\
\hline APT & Complete $^{2}$ & -- & -- & -- & -- & -- & -- & Included in Van Rooyen et al. 2013 \\
\hline \multirow{2}{*}{ HRTEM } & \multirow{2}{*}{--} & \multirow{2}{*}{ Complete } & \multirow{2}{*}{--} & \multirow{2}{*}{$\begin{array}{c}\text { In } \\
\text { progress }\end{array}$} & \multirow{2}{*}{--} & \multirow{2}{*}{--} & \multirow[b]{2}{*}{--} & Van Rooyen et al. 2014a \\
\hline & & & & & & & & Van Rooyen et al. 2015b \\
\hline EBSD & Complete & Complete & -- & -- & -- & -- & Complete & Included in Van Rooyen et al. 2013 \\
\hline TKD & Complete & Complete & -- & -- & -- & -- & -- & $\begin{array}{l}\text { Included in Van Rooyen et al. } 2013 \\
\text { Van Rooyen et al. 2014c }\end{array}$ \\
\hline \multirow{2}{*}{$\begin{array}{c}\text { PED } \\
\text { (ASTAR) }\end{array}$} & \multirow[t]{2}{*}{ Complete $^{2}$} & \multirow[t]{2}{*}{--} & \multirow[t]{2}{*}{ Complete } & \multirow[t]{2}{*}{ Complete } & \multirow[t]{2}{*}{--} & \multirow[t]{2}{*}{--} & \multirow[t]{2}{*}{ Complete $^{2}$} & $\begin{array}{l}\text { Lillo and Van Rooyen 2015b } \\
\text { Lillo and Van Rooyen 2015c }\end{array}$ \\
\hline & & & & & & & & Lillo et al. 2015c \\
\hline STEM & Planned & & & & & Complete & & \\
\hline
\end{tabular}

1 APT (Atom Probe Tomography); EBSD ( Electron Back Scatter Diffraction); EELS (Electron Energy Loss Spectroscopy); EFTEM (Energy Filtered Transmission Electron Microscopy); EPMA (Electron Probe Micro-Analysis); HRTEM (High Resolution Transmission Electron Microscopy); PED (Precession Electron Diffraction); STEM

(Scanning Transmission Electron Microscopy); TEM (Transmission Electron Microscopy); TKD (Transmission Kikuchi Diffraction);

2 Work performed with funding from a National Scientific User Facility Rapid Turnaround Experiment project.

3 Examination performed specifically on the UCO kernels

4 Application for funding from a National Scientific User Facility Rapid Turnaround Experiment project to support additional scope has been awarded $4^{\text {th }}$ quarter in 2015. 


\section{Basic Transmission Electron Microscopy (TEM)}

Initially, a basic TEM examination was performed on selected samples to provide information on microstructure and chemical composition of the precipitates identified during SEM examination. It was found that the basic TEM examinations could not adequately quantify the chemical composition of precipitates. However, this earlier work did provide an initial indication of the composition of micron-sized precipitates; additionally, some knowledge on the microstructural changes in the coating layers due to irradiation was obtained. TEM specimens were prepared using the focused ion beam (FIB) to mill small rectangular lamellae (approximate dimensions $10 \mu \mathrm{m} \times 10 \mu \mathrm{m} \times 0.1 \mu \mathrm{m}$ thick) from particle cross sections. TEM was performed with a JEOL 2010 TEM operating at $200 \mathrm{kV}$ and typical magnifications of 5,000 to 100,000x. This microscope is equipped with a $136 \mathrm{eV}$ Oxford EDS detector. Bright field and dark field images were produced in key regions of the samples, focusing on key microstructural features. A double tilt holder was used to tilt the sample to key zone patterns and 2-beam conditions to better characterize the microstructure. Zone patterns helped identify if the sample was crystalline and to characterize the crystal structure. Two-beam conditions were used to image existing defects. Over- and under-focus imaging was used to image cavities in the material. Detailed TEM analysis was completed on irradiated particles AGR1-632-030 (1 lamella), AGR1-632-034 (2 lamellae), AGR1-632-035 (2 lamellae), and AGR1-411-030 (5 lamellae). During the interpretation and detailed analysis stages, it was decided not to continue with this work as the confirmation and quantification of the chemical composition of the precipitates was found to be inadequate and could only be verified once the advanced analysis using electron energy loss spectroscopy (EELS) and atom probe tomography (APT) were completed. A summary of TEM results from the Compact 6-3-2 and 4-1-1 particles analyzed is given below.

Precipitates observed in Compact 6-3-2 particles could be crystallographically indexed as $\mathrm{UPd}_{2} \mathrm{Si}_{2}$ (International Centre for Diffraction Data card 00-047-1029); however, the EDS data suggest significant compositional variations and none of the EDS analyses indicate stoichiometric $\mathrm{UPd}_{2} \mathrm{Si}_{2}$. A Cs-rich precipitate was observed in a crack in particle AGR1-632-035, but no Cs was observed in the SiC grain structure itself. Polytype 2H SiC was also identified in lamella AGR1-632-030-1a. Additionally, spherical cavities were found concentrated alongside grain boundaries near a Pd-rich precipitate (Figure 22).

5 Specific particles are identified by the nomenclature "AGR1-XYZ-nnn", where $X Y Z$ refers to the compact ID and $n n n$ refers to the particle number assigned during gamma counting (further details available in specific compact PIE reports). Specific lamella identifiers are appended to this particle ID. 


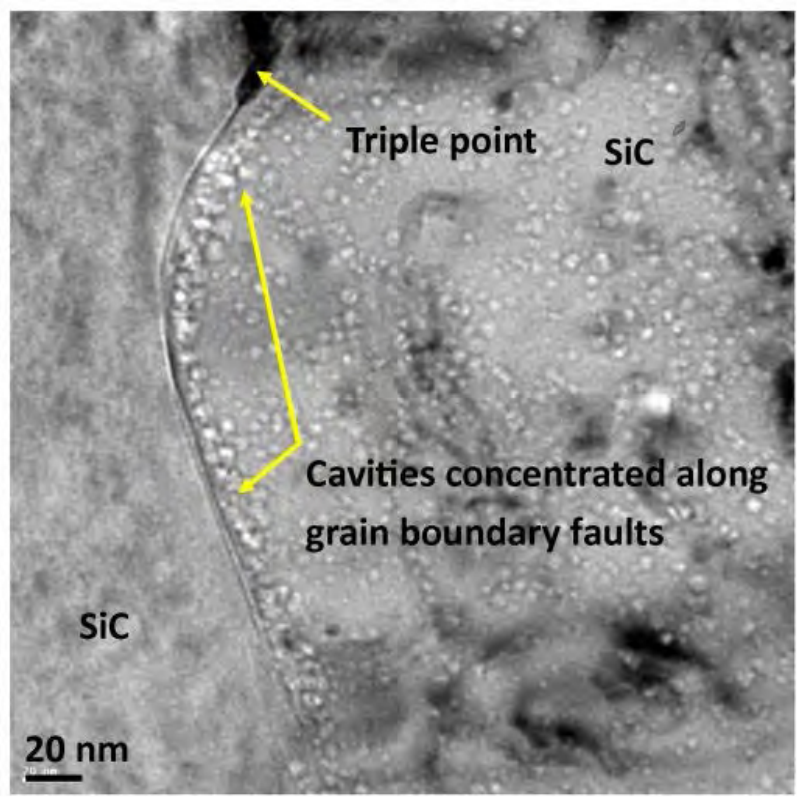

Figure 22. Spherical cavities concentrated alongside $\mathrm{SiC}$ grain boundaries near a Pd-rich precipitate in the triple point (image is adapted from Van Rooyen et al. 2014b).

The TEM-EDS analysis on the micron-sized precipitates observed in particles from Compact 4-1-1 showed Pd-rich precipitates with no U or Ag detected. This is in contrast with the EDS analysis previously performed on micron-sized precipitates in Compact 6-3-2 particles, where U was identified. Selected area diffraction (SAD) measurements showed no correspondence to those of $\mathrm{UPd}_{2} \mathrm{Si}_{2}$ as previously found in the Compact 6-3-2 specimens investigated. From both the qualitative EDS analysis and the SAD patterns, the precipitates are different between these two compacts. Slight indications of debonding at localized areas at the IPyC-SiC interface are noted. No indications of debonding were observed for the Compact6-3-2 specimens. Cs precipitates were found in a porous region of the buffer area in particle AGR1-411-030.

\section{Electron Probe Micro-Analyzer (EPMA)}

One particle (AGR1-523-SP01) mounted by ORNL in a mini-met mount was analyzed using the electron probe microanalyzer (EPMA) at INL. This particle is one of three that experienced SiC failure in-pile and were recovered for subsequent analysis (see Section 5). Additional details of this particle and the cross section prepared at ORNL are provided in Hunn et al. 2014b. Figure 23 and Figure 24 show preliminary data obtained during initial measurements, with more detailed results provided in Van Rooyen et al. 2015a. Optimization of scanning and mapping conditions had not yet been performed at the time of this analysis; therefore, this information is considered semiquantitative. Figure 23 shows the EPMA map results obtained from a beam scan with a step size of $0.3 \mu \mathrm{m}(256 \times 256$ pixels $)$. Figure 24 shows selected results from a line scan from the center of the kernel to the $\mathrm{SiC}$ layer. Iodine and $\mathrm{Cs}$ pile-up at the $\mathrm{SiC}$ layer is visible, with no $\mathrm{Ag}$ or Cd detected. Palladium was detected at the $\mathrm{SiC}-\mathrm{IPyC}$ interlayer.

Further EPMA analysis on AGR-1 particles was prevented by relocation of the instrument to a new facility at MFC. Once the instrument is again operational, it will be available for analysis of particles from AGR-1 and subsequent irradiation experiments. 


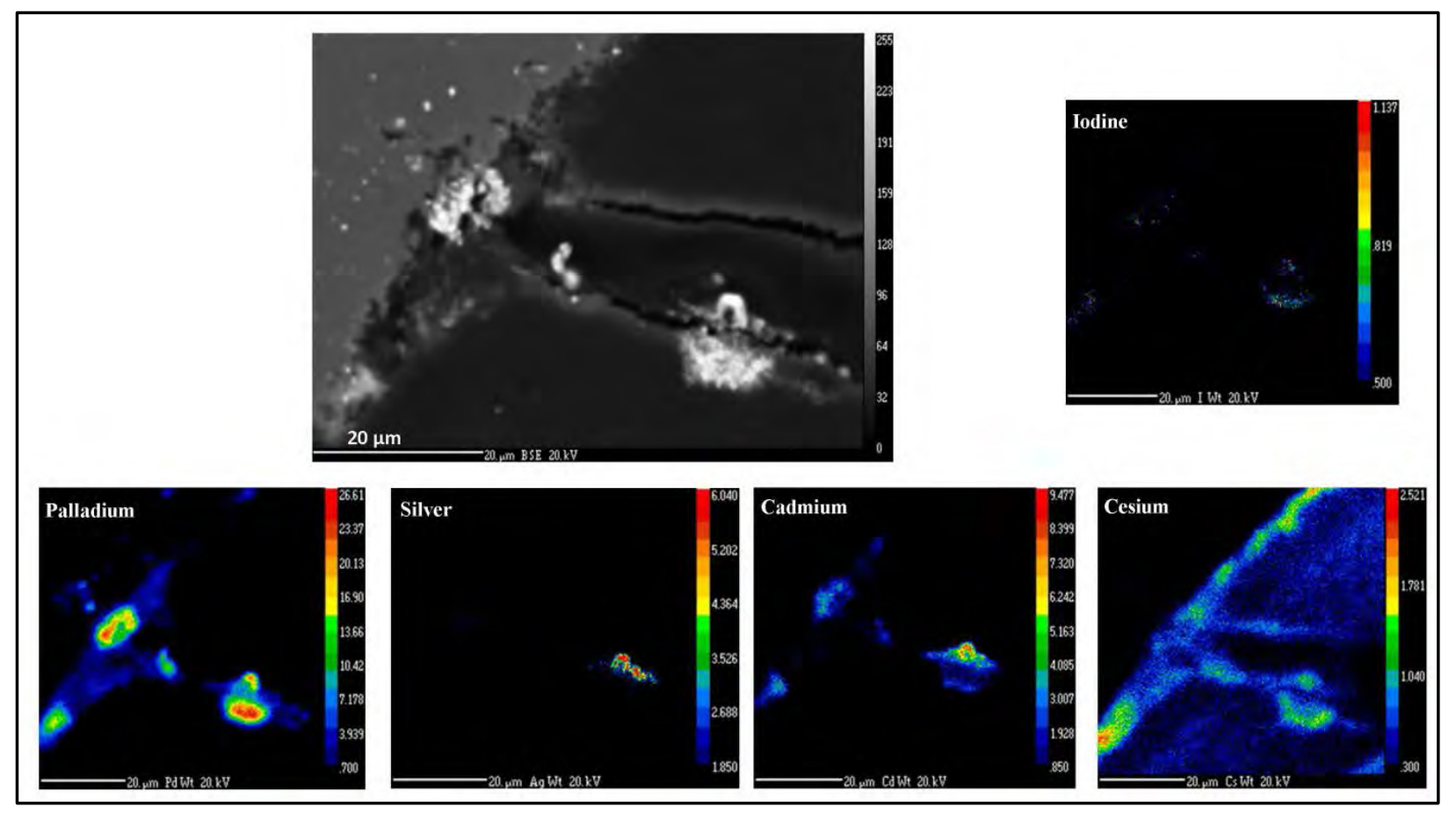

Figure 23. EPMA elemental maps at the tip of a crack in the IPyC layer of particle AGR1-523-SP01. Maps were corrected for peak overlaps. Detection limits were computed for x-ray images. Each image was scaled so that the lower end of the color scale is the detection limit in weight percent.

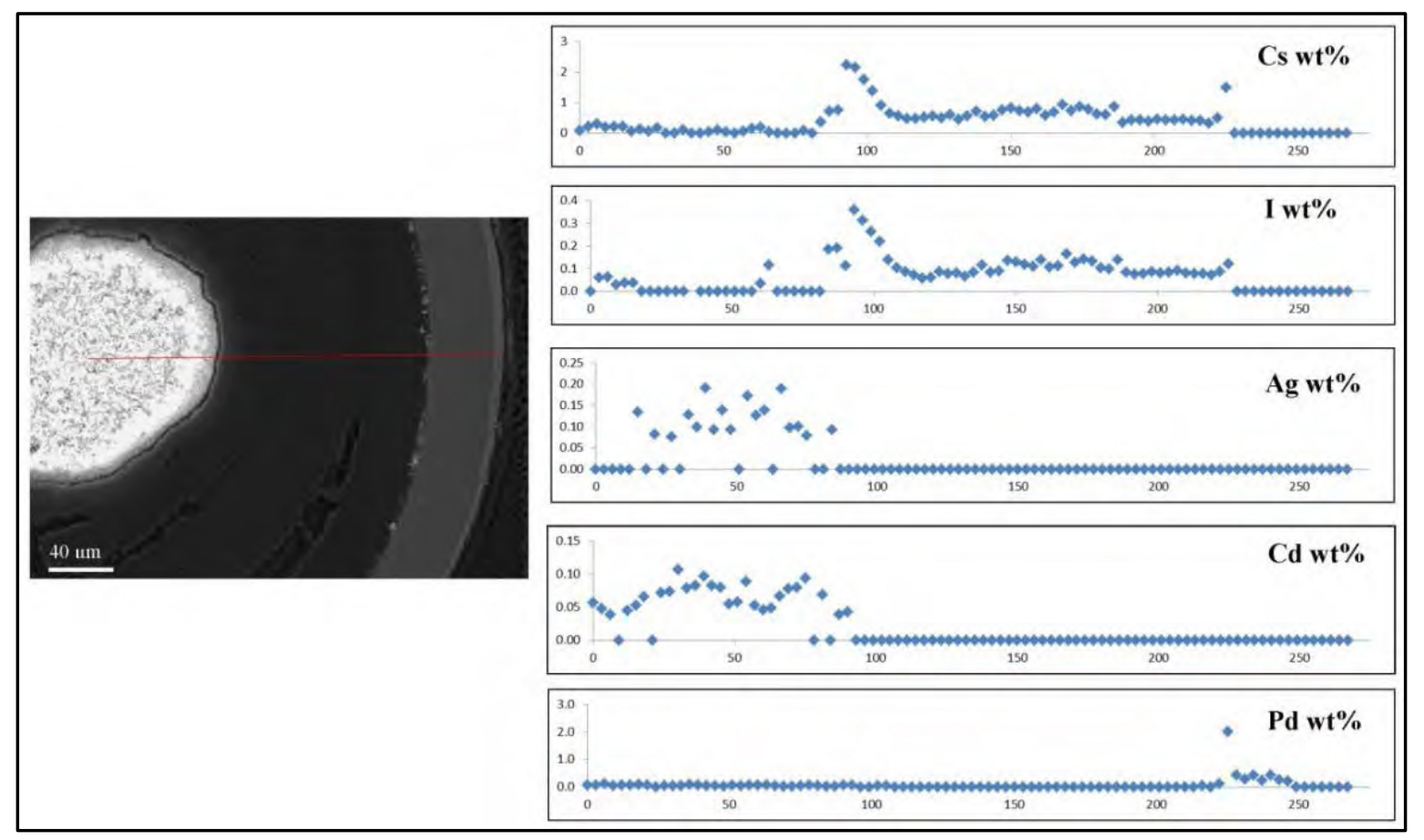

Figure 24. Results of an EPMA line scan on a cross section of particle AGR1-523-SP01. The red line indicates the path of quantitative radial traverse (analytical conditions $20 \mathrm{kV}, 200 \mathrm{nA}, 30$ seconds peaks, 10 seconds background). 


\section{Advanced techniques in Center for Advanced Energy Studies (CAES)}

One of the biggest challenges in pursuing advanced microscopy techniques to characterize the AGR-1 fuel was to find a suitable facility that is licensed to work with irradiated materials and that also houses instrumentation that could meet the resolution requirements. The Center for Advanced Energy Studies (CAES) facility at INL provided the AGR-1 electron microscopy team the opportunity to explore the advanced techniques of scanning transmission electron microscopy (STEM), EELS, energy filtered transmission electron microscopy (EFTEM) and APT for the irradiated TRISO particles. Based on early success in analyzing the first specimens, it was decided to expand the STEM examinations on coated particles from other compacts and on lamellae extracted from particle cross sections and traversing the entire SiC layer thickness. STEM lamellae were prepared at the Electron Microscopy Laboratory (EML) at the MFC using the dual-beam Quanta 3D field emission gun (FEG) FIB.

\section{STEM, STEM-EDS, EELS and EFTEM analysis}

The STEM, EELS, and EFTEM analyses were conducted with an FEI Tecnai G2 F30 STEM at the Microscopy and Characterization Suite (MaCS) in CAES. This advanced microscopy work was completed on irradiated particles AGR1-632-034 (2 lamellae), AGR1-632-035 (1 lamellae), AGR1-131-066 (4 lamellae), AGR1-131-099 (5 lamella), AGR1-531-031 (4 lamellae), AGR1-531-038 (4 lamellae) and AGR1-523-SP01 (10 lamellae). STEM analysis on lamellae from particle AGR1-433-04 has not been completed and is scheduled for later in FY 2015 and FY 2016. The integrated comparative analysis will take place later this year and will be reported separately.

The electron microscopy team used STEM, EELS, and EFTEM to identify for the first time the physical location and elemental distribution of fission products at the micro- and nano-scale in the SiC and IPyC layers of irradiated TRISO fuel. The STEM examination provided evidence of nano-sized silver precipitates at triple-points (Figure 25a) and grain boundaries in the $\mathrm{SiC}$ on the edge of the SiC-IPyC interface. Cadmium was also found to be present in the triple junctions (Figure 25b). This was the first finding of this nature in international TRISO research. No Pd was observed in the triple junction; Pd and $\mathrm{U}$ were identified in the $\mathrm{SiC}$ matrix adjacent to this triple junction. This work also resulted in the first observation of a Pd-Ag precipitate inside a neutron-irradiated $\mathrm{SiC}$ grain, and identified in lamella AGR1-632-035-6b (Figure 26a and b). Most nano-precipitates found inside the SiC grains were Pd-rich with no silver detected (Figure 26c). 


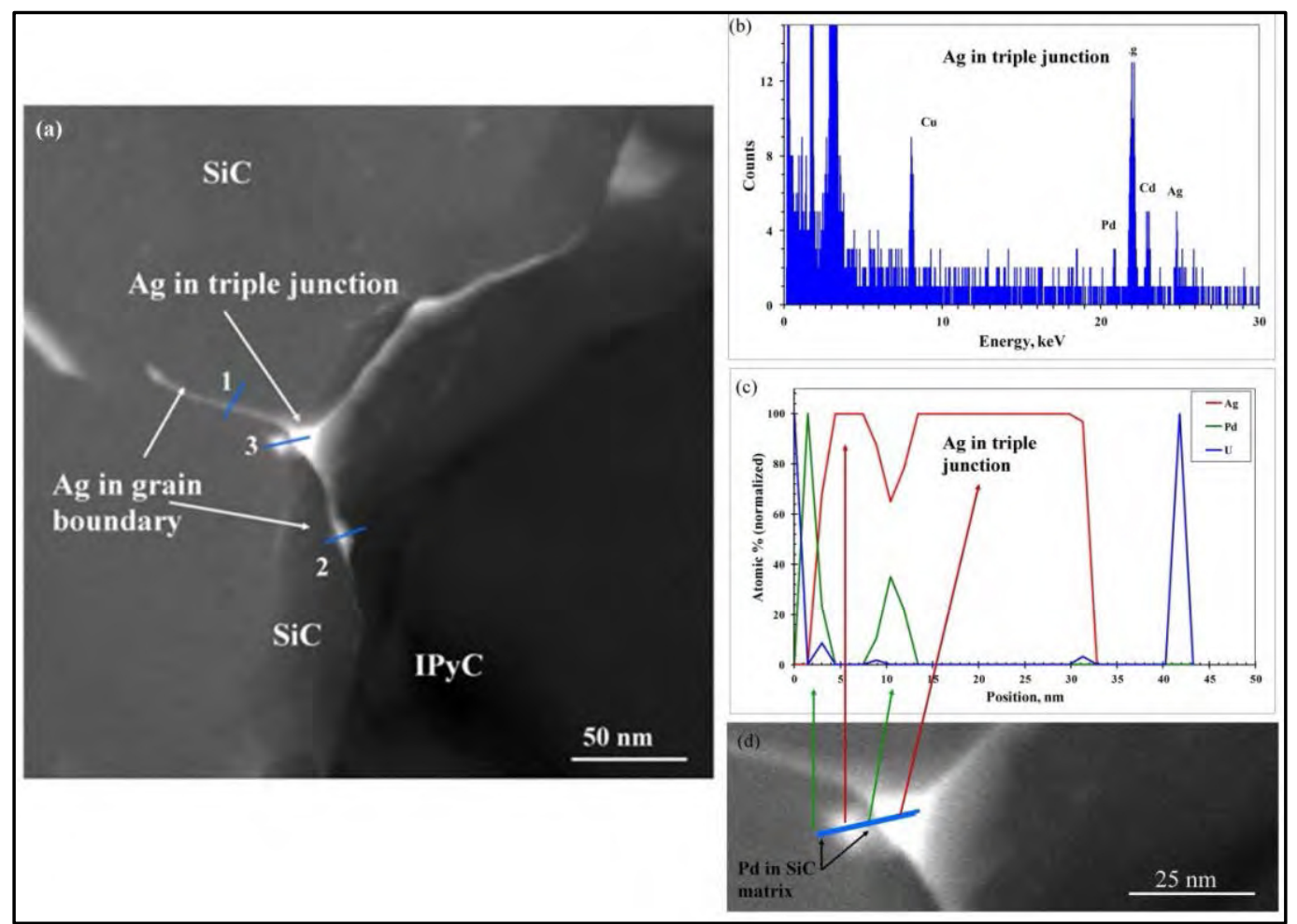

Figure 25. Image showing (a) a high-angle annular dark field (HAADF) STEM image of grain boundaries containing silver (labeled 1 and 2) and a triple junction (labeled 3) at the edge of the $\mathrm{SiC}$ adjacent to the IPyC from lamella AGR1-632-035-6b . Image showing (b) the EDS spectrum identifying the Ag Kal peak at $22.163 \mathrm{keV}$ and the presence of $\mathrm{Cd}$ in the center of the triple junction shown in (a) (Cu is an artifact from the grid holder), (c) the EDS line scan profile through the triple junction indicating the presence of Ag, and (d) higher magnification of Area 3 in (a). Although no Pd was observed in the triple junction, $\mathrm{Pd}$ and $\mathrm{U}$ were identified in the $\mathrm{SiC}$ matrix adjacent to this triple junction (Van Rooyen et al. 2014d).

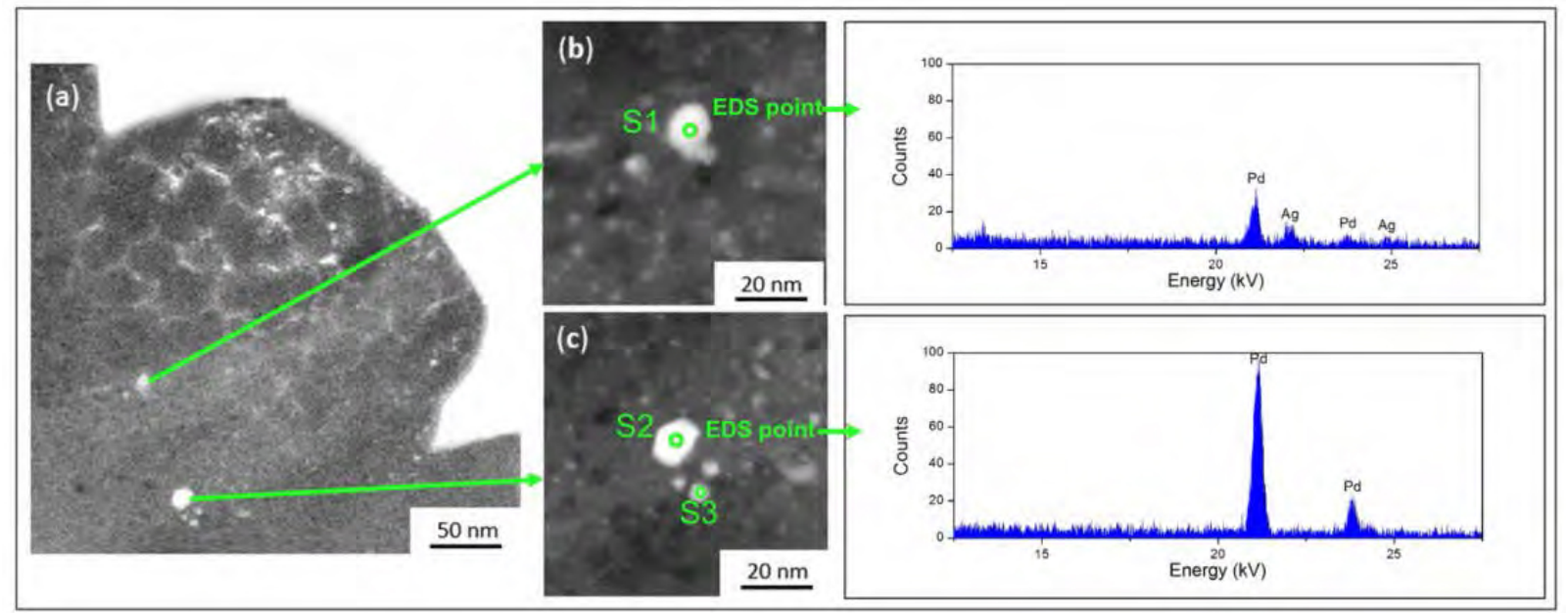

Figure 26. (a) Different types of nano-precipitates identified inside a SiC grain, (b) EDS spectrum indicates $\mathrm{S} 1$ is a Pd-Ag precipitate and (c) EDS spectrum indicates S2 is a Pd-rich precipitate (Leng et al. 2015). 
An Ag-Pd-Cd precipitate was identified at a stacking fault inside a $\mathrm{SiC}$ grain in particle AGR1-532-SP01, lamella 10 (Figure 27). This study confirmed with STEM, TEM, STEM-EDS, and inverse fast Fourier transformation (FFT) that the precipitate is indeed at a stacking fault and not at a grain boundary.

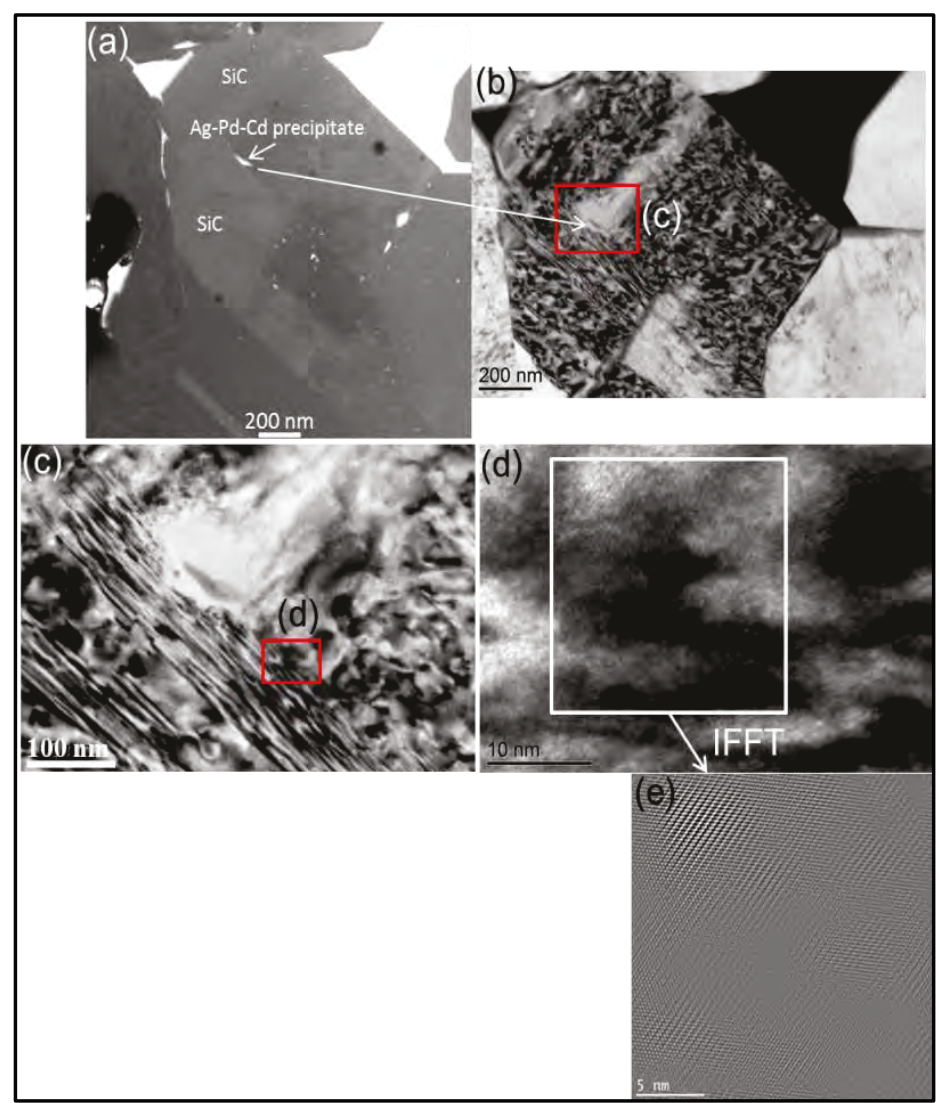

Figure 27. An Ag-Pd-Cd precipitate at a stacking fault inside a SiC grain of particle AGR1-532-SP01. (a) STEM image showing the location of the Ag-Pd-Cd precipitate, whose composition was determined by EDS; (b) TEM image corresponding to (a); (c) a magnification of the red rectangle in (b); (d) a magnification of the red rectangle in (c), where stacking faults are present; (e) inverse FFT of the white square in (d), where the continuous lattice fringes indicate absence of grain boundary and confirm the presence of stacking faults (Wen et al. 2015c).

For lamella AGR1-632-035-6b (Baseline fuel type), uranium was never detected in precipitates in the coating layers when silver was present and vice versa. Also, uranium was never found alone; it was always associated with palladium. In contrast, for Variant 3 fuel particle AGR1-131-099, U was found separately in the SiC layer. Additionally, almost all precipitates at the IPyC-SiC interface in particle AGR1-131-099 contain U, which is also different compared with particle AGR1-632-035. This will need to be further explored to determine the effect of temperature and burnup. This may be achieved by the full integration of the STEM-EDS results of the AGR-1 particles examined, as these particles represent various irradiation histories (Van Rooyen et al 2015a). Figure 28 provides an overview of the precipitate type distribution found in particle AGR1-131-099. Cd was detected in the precipitates from the IPyC-SiC interface up to approximately the middle of the $\mathrm{SiC}$ (Wen et al. 2015a). STEM examination showed fission product networks up to the outer edge of the $\mathrm{SiC}$ layer. See Figure 29 for a typical example of these networks for lamella AGR1-632-035-6b. 


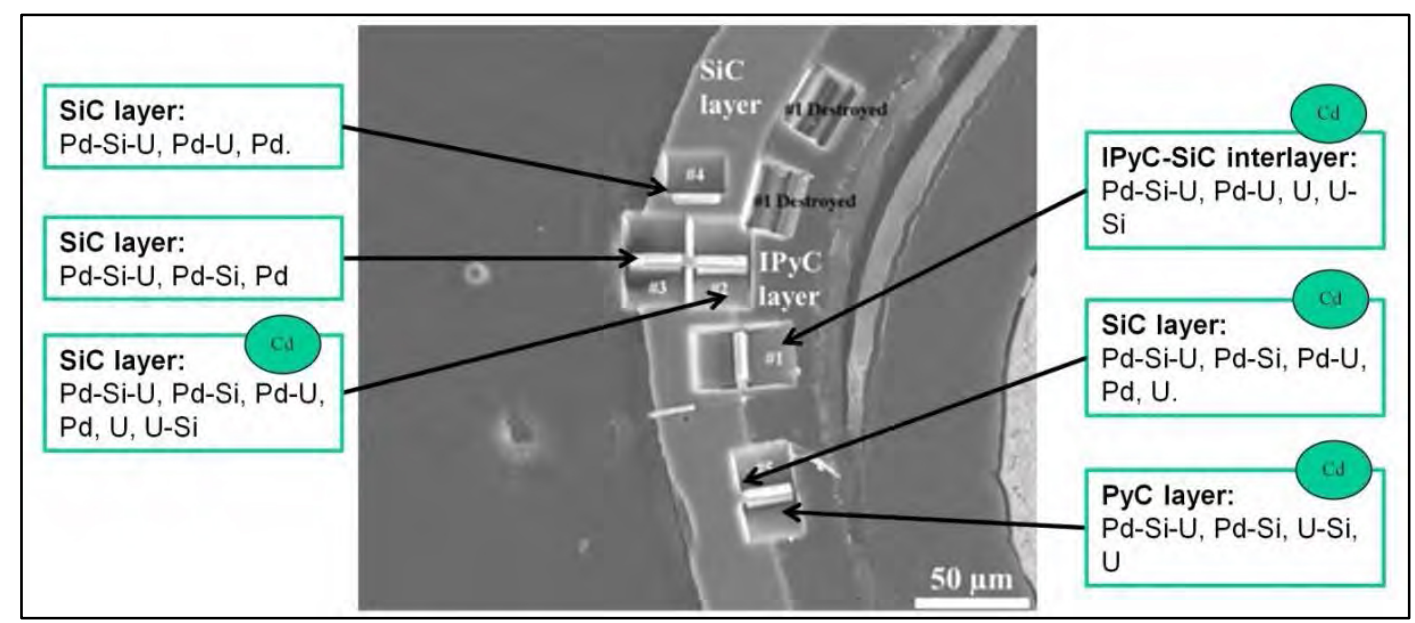

Figure 28. An overview of the precipitate type distribution found in particle AGR1-131-099 (figure adapted from Wen et al. 2015a). The predominant precipitate composition is shown for each area; additionally, small levels of $\mathrm{Cd}$ (denoted in green circles) were detected in the precipitates from the IPyC-SiC interface up to approximately the middle of the $\mathrm{SiC}$.

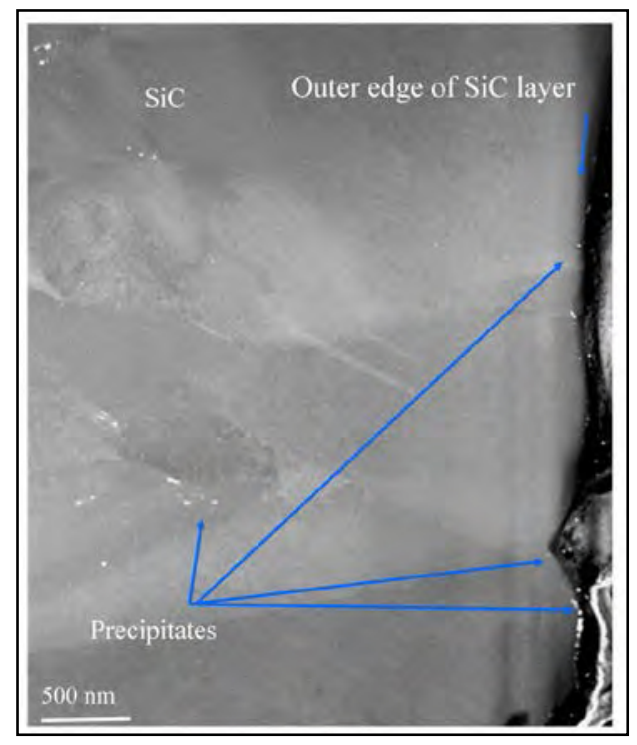

Figure 29. STEM micrograph showing evidence of a nano network of fission products at the outer edge of the $\mathrm{SiC}$ from particle AGR1-632-035-6b.

In the strategy to identify silver, another analytical tool, EELS, was considered. This work was completed as part of a NSUF rapid turnaround experiment (NSUF-RTE) awarded in March 2013 in collaboration with the University of Wisconsin-Madison. Although Ag and Pd were detected using EELS measurements (Figure 30), the concentrations were not well-quantified due to the close proximity of their edge energies. It was decided that attention will be placed on APT for more accurate three-dimensional (3-D) quantification. EELS analysis is still a possibility to be further explored (Van Rooyen et al. 2013). 


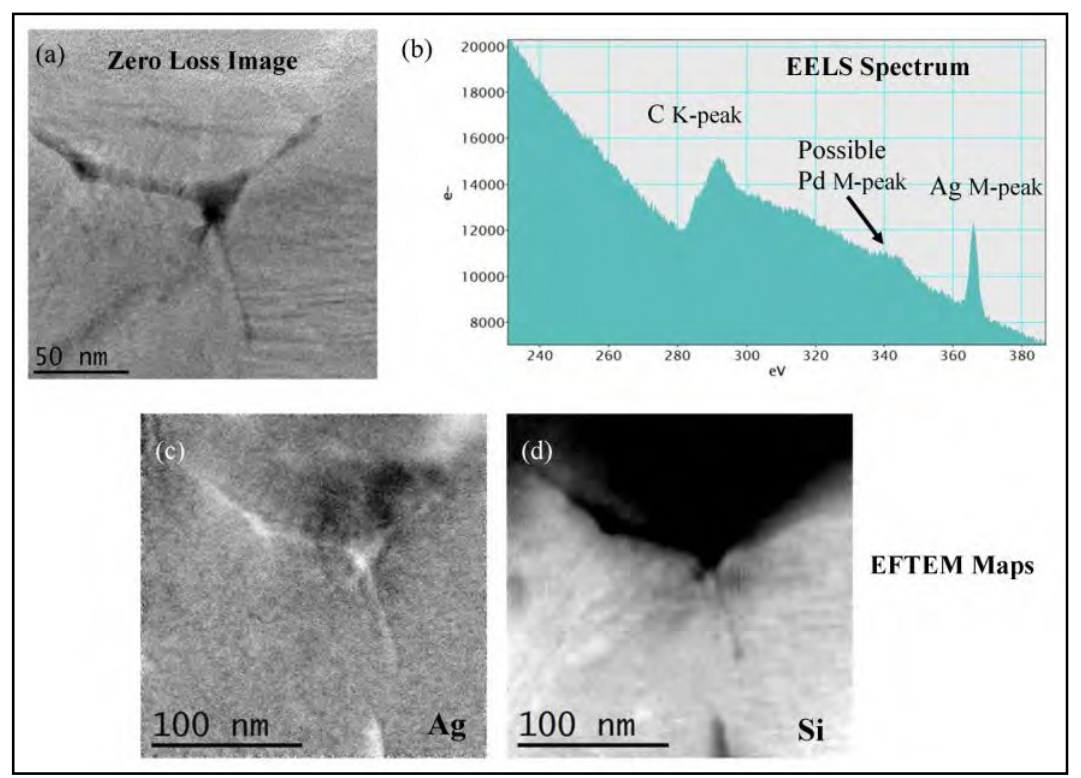

Figure 30. Zero-loss image of the second phase at triple junction (a) and corresponding EELS spectrum obtained at this area (b); EFTEM elemental maps of Ag and Si at this area (c) and (d), respectively (Van Rooyen et al. 2013).

\section{Atom Probe Tomography (APT)}

The first APT probe tips were prepared from particle AGR1-632-035 using the FIB at EML during July 2013. Due to the brittle nature of irradiated SiC, and the small size of the fission product precipitates of interest, APT measurements to date on irradiated material have been unsuccessful in isolating and analyzing the precipitates. APT analysis was successfully performed on unirriadiated SiC tips prepared with the FIB to aid in the optimization of APT parameters for examining irradiated material. Two large datasets up to $300 \mathrm{~nm}$ in depth, which contained up to 15 million atoms, were acquired. Some further work is still needed to prevent the formation of an amorphous layer during FIB sample preparation, which complicates APT measurements. Further work is also needed to prepare a smooth profile of the tips. The most successful measurements were obtained at a temperature of $90 \mathrm{~K}$ and laser energy of 90-100 pJ. New APT tips from irradiated SiC were prepared based on the lessons learned from work completed over the past 2 years and are scheduled for analysis later in 2015. Development work on APT is a collaborative effort with the University of Wisconsin-Madison and Boise State University and is partially funded by NSUF-RTE.

\section{High Resolution Transmission Electron Microscope (HRTEM)}

HRTEM examination was performed on selected lamella from only two particles (AGR1-411-030 and AGR1-131-99). The main objective of this examination was to obtain very high resolution images at the atomic level with corresponding EDS analysis to provide information on the structure and composition of fission products. 
FIB lamellae Positions 1b and 2 from particle AGR1-411-030 were examined in June 2013 at the Nelson Mandela Metropolitan University (NMMU), South Africa, using a double Cs-corrected JEOL ARM 200F operated at $200 \mathrm{kV}$ with $0.11 \mathrm{~nm}$ and $0.08 \mathrm{~nm}$ TEM and STEM resolution, respectively. Preliminary HR(S)TEM analysis of particle AGR1-131-99, lamellae 1 and 5, was performed in May 2015 and July 2015 at LANL, using a FEI Titan 80-300TM with $0.07 \mathrm{~nm}$ and $0.20 \mathrm{~nm}$ TEM and STEM resolution, respectively. This initial work was performed to establish a U.S.-based facility in lieu of the successful research conducted in 2013 at the NMMU electron microscopy facility. The preliminary electron microscopy performed at LANL showed promise although the resolution is not close to that obtained using the NMMU TEM, which is equipped with two CEOS spherical aberration correctors.

During analysis of AGR1-411-030 lamellae 1b and 2, Ag was not found separately, but always found in co-existence with $\mathrm{Cd}$ and $\mathrm{Pd}$ at grain boundaries and triple points (Figure 31). Pd precipitates were found at stacking faults (Figure 32). This was the first image of Pd located at stacking faults in irradiated $\mathrm{SiC}$ and provides initial insight into the movement of atoms within the $\mathrm{SiC}$ structure. A small indication of phosphorus was also detected inside the $\mathrm{SiC}$ grain. This is the first finding of phosphorus in the $\mathrm{SiC}$ layer of neutron-irradiated TRISO coated particles (Van Rooyen et al. 2015b).

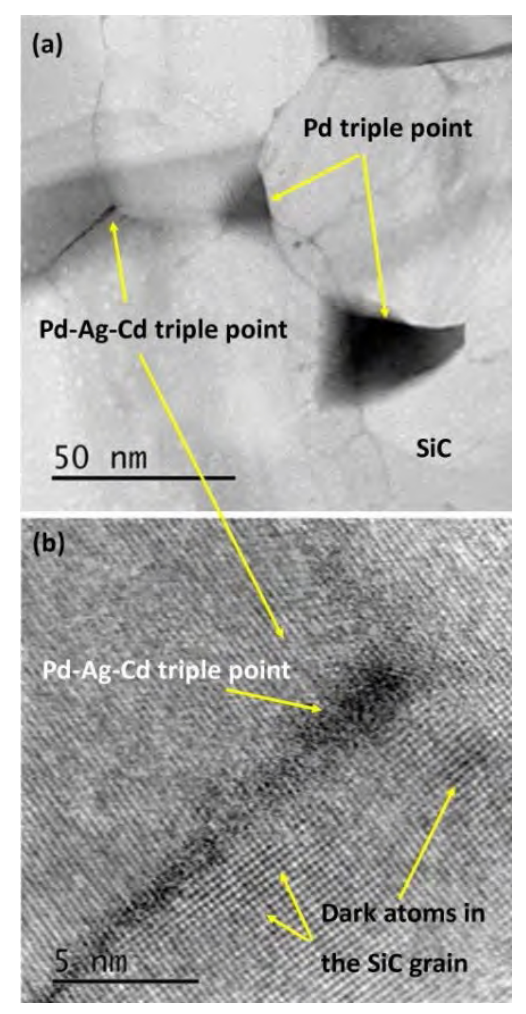

Figure 31. Bright field (BF) STEM image (a) of a triple point containing Pd, Ag, and Cd, with the corresponding high-resolution BF STEM image (b), where fission product atoms (dark spots) are also visible deeper in the $\mathrm{SiC}$ grain (Van Rooyen et al. 2014a). 


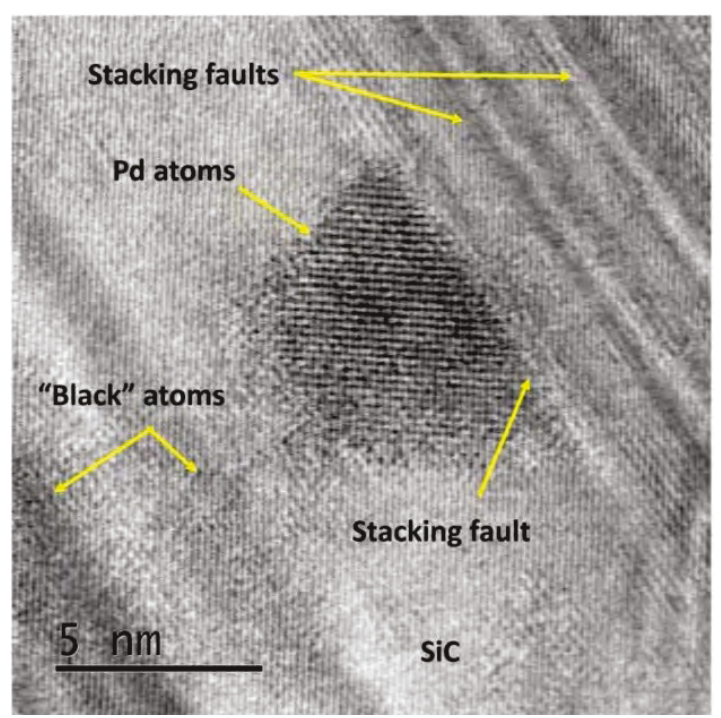

Figure 32. High resolution BF STEM image of a Pd precipitate ( $\mathrm{Pd}$ atoms are indicated by the arrow in the figure), which accumulated at a stacking fault in a SiC grain. Some black atoms (dark spots representing fission product atoms) are also visible in the SiC grain (Van Rooyen et al. 2014a).

Multi and single-phased precipitates were identified in both the IPyC layer of particle AGR1-131099, lamella 1 and 5 (Figure 33) as well as in the SiC layer (Figure 34), based on the elemental composition (crystallographic examination also confirmed this finding). The interface between $\mathrm{SiC}$ and a fission product precipitate was well-defined and free of porosity (Figure 35). From the change in tilt of the atomic layers across this interface, it appears that the secondary phase is not aligned to the SiC in any well-defined manner.
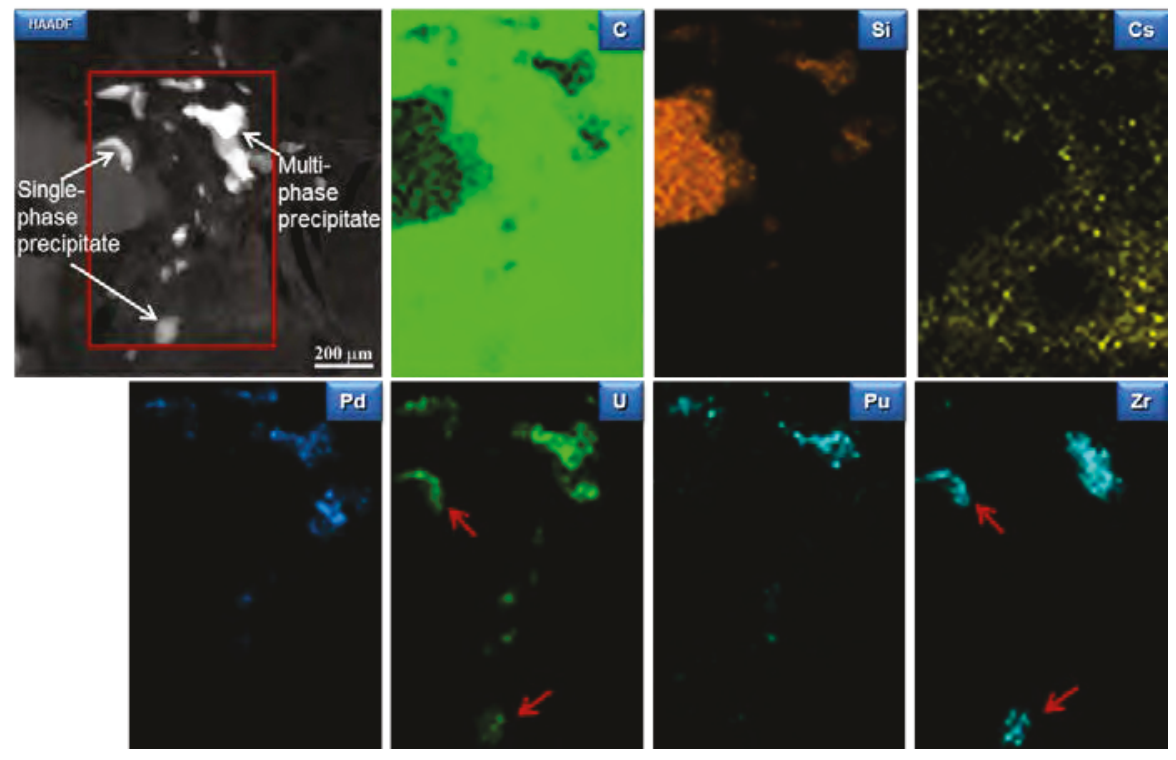

Figure 33. HRSTEM image and EDS mapping of a small area containing precipitates in the IPyC layer of particle AGR1-131-099 close to the IPyC-SiC interface. Both single and multiphase precipitates are shown. The red arrows indicate the single phase precipitate. 


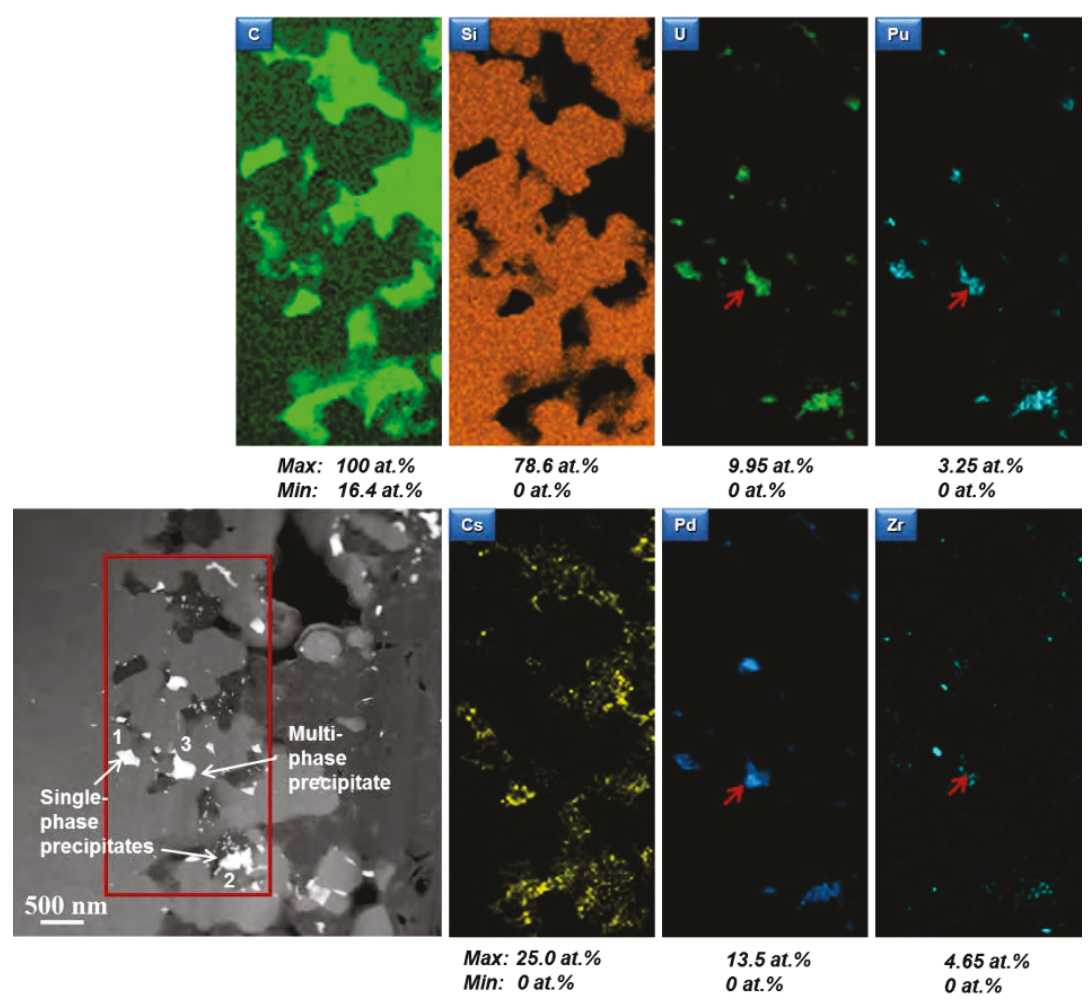

Figure 34. HRSTEM image and EDS mapping of an area containing precipitates in the SiC layer of particle AGR1-131-099 close to the IPyC-SiC interface. Both single and multiphase precipitates are shown. The red arrows indicate the multi-phase precipitate.

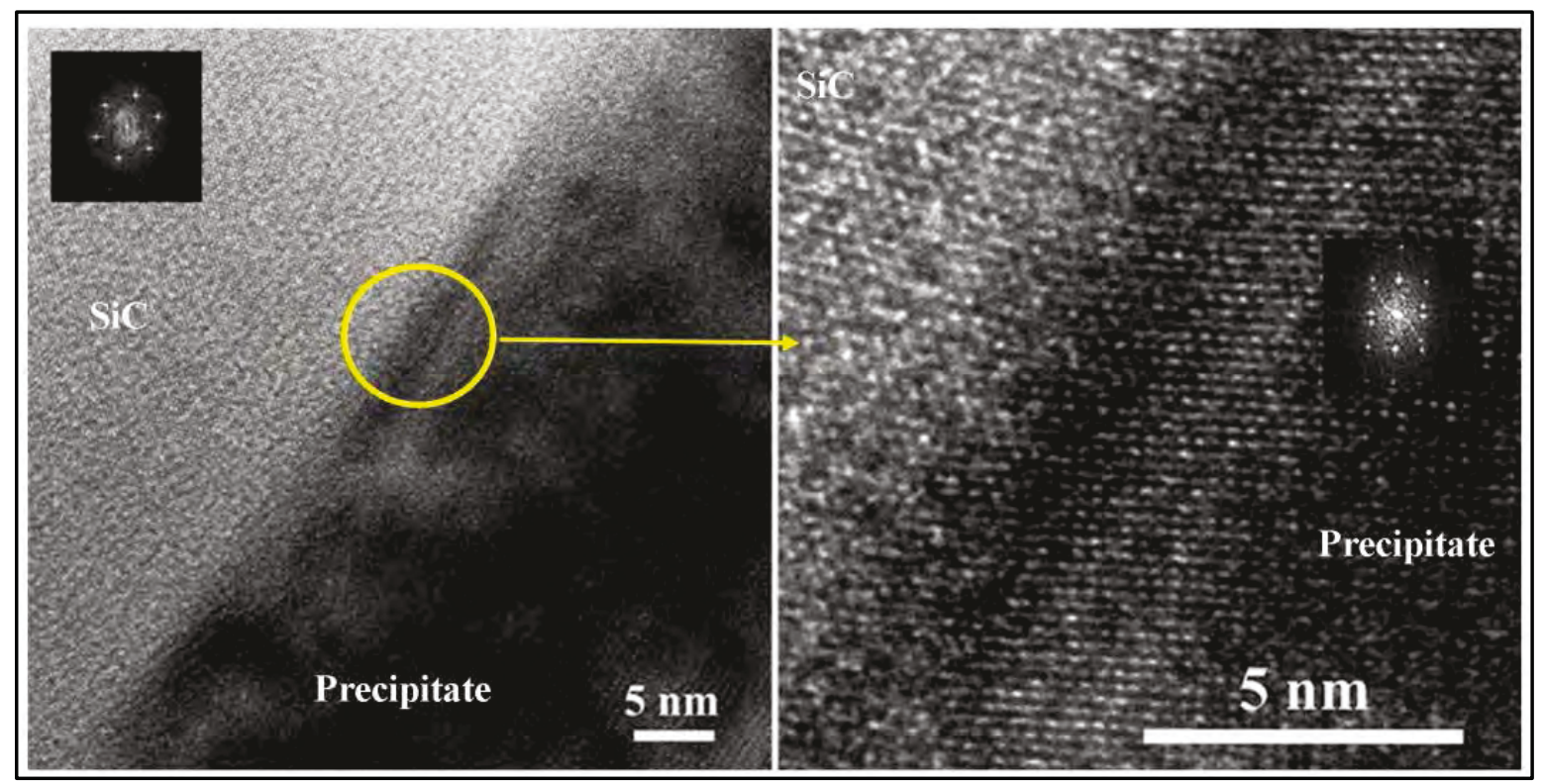

Figure 35. HRTEM images of the interface between a fission product precipitate and the $\mathrm{SiC}$ matrix in particle AGR1-131-099 lamella 1. 


\section{Techniques to Determine Crystallographic Information (EBSD, TKD, PED)}

To elucidate the influence of grain boundary character on fission product migration in $\mathrm{SiC}$, it is necessary to employ techniques that can determine the misorientation across individual grain boundaries, including grain boundaries that contain fission products as well as those that do not contain fission products. While SEM-based EBSD can determine grain boundary misorientation, it is not possible to identify nano-sized fission product precipitates on the grain boundaries or identify the composition of these precipitates. Methods to determine grain orientations, and subsequently grain boundary misorientations, in the TEM based on Kikuchi bands are relatively slow, although the Kikuchi bands are often sufficiently prominent to allow analysis of the orientation.

Transmission Kikuchi diffraction (TKD) or t-EBSD is an SEM method for measuring crystallographic properties in materials, similar to conventional EBSD, but with an order of magnitude improvement in spatial resolution. The resolution is better because of the forward-direction scattering that excites the electrons near the exit surface, where they have a chance for Kikuchi scattering. Forward scattering is, of course, favored in conventional EBSD as well, but to form a pattern, backscatter detection out of the beam entry surface is also required, and the backscatter signal is less compared to the transmission case. Another advantage of the forward-scatter TKD geometry is that because low-angle elastic scattering is favored over high-angle scattering, there is less beam-spreading in thin specimens by the time the important Kikuchi events occur. In addition, the interaction volume is considerably smaller.

Recently, techniques based on precession electron diffraction (PED) have advanced to the point where automated PED pattern collection and analysis has become possible. PED allows the resulting diffraction pattern to be matched with one in a PED pattern database consisting of simulated diffraction patterns generated at various orientations. The advantage of PED is that it utilizes a very small electron beam spot size ( $\sim 5 \mathrm{~nm}$ or less) and the interaction volume is on the order of the beam size since the sample is very thin. Both enable a very small step size and high spatial resolution, allowing orientation analysis at the nano-level. Therefore, it would appear that PED techniques are well-suited for analysis of the nano-sized grain boundary fission product precipitates.

Figure 36 shows a schematic overview of the work done as part of AGR-1 PIE along with complementary projects and other funding sources. Although the initial focus was to obtain crystallographic information from conventional EBSD patterns, technical difficulties and operational hold-ups led to the search for alternative approaches. Initial EBSD measurements on irradiated particles AGR1-632-034, AGR1-632-035, and AGR-141-030 were not successful and were followed with TKD measurements in collaboration with NMMU and Bruker Germany on lamellae from an unirradiated TRISO particle and irradiated particle AGR1-411-030. These TKD measurements provided quantitative data on crystallographic parameters, but it was found that the resolution was not sufficient to resolve the specific nano precipitates, which contain Ag. PED measurements were successfully collected on unirradiated SiC (3 lamellae) and particles AGR1-632-035 (4 lamellae), AGR1-131-066 (3 lamellae), AGR1-131-099 (2 lamella), AGR1-531-031 (3 lamellae), AGR1-531-038 (4 lamellae) and AGR1-523-SP01 (4 lamellae). The highlights of the initial PED measurements are discussed below. PED measurements on AGR1-433-04 lamellae have not been completed and are scheduled for FY 2016. 


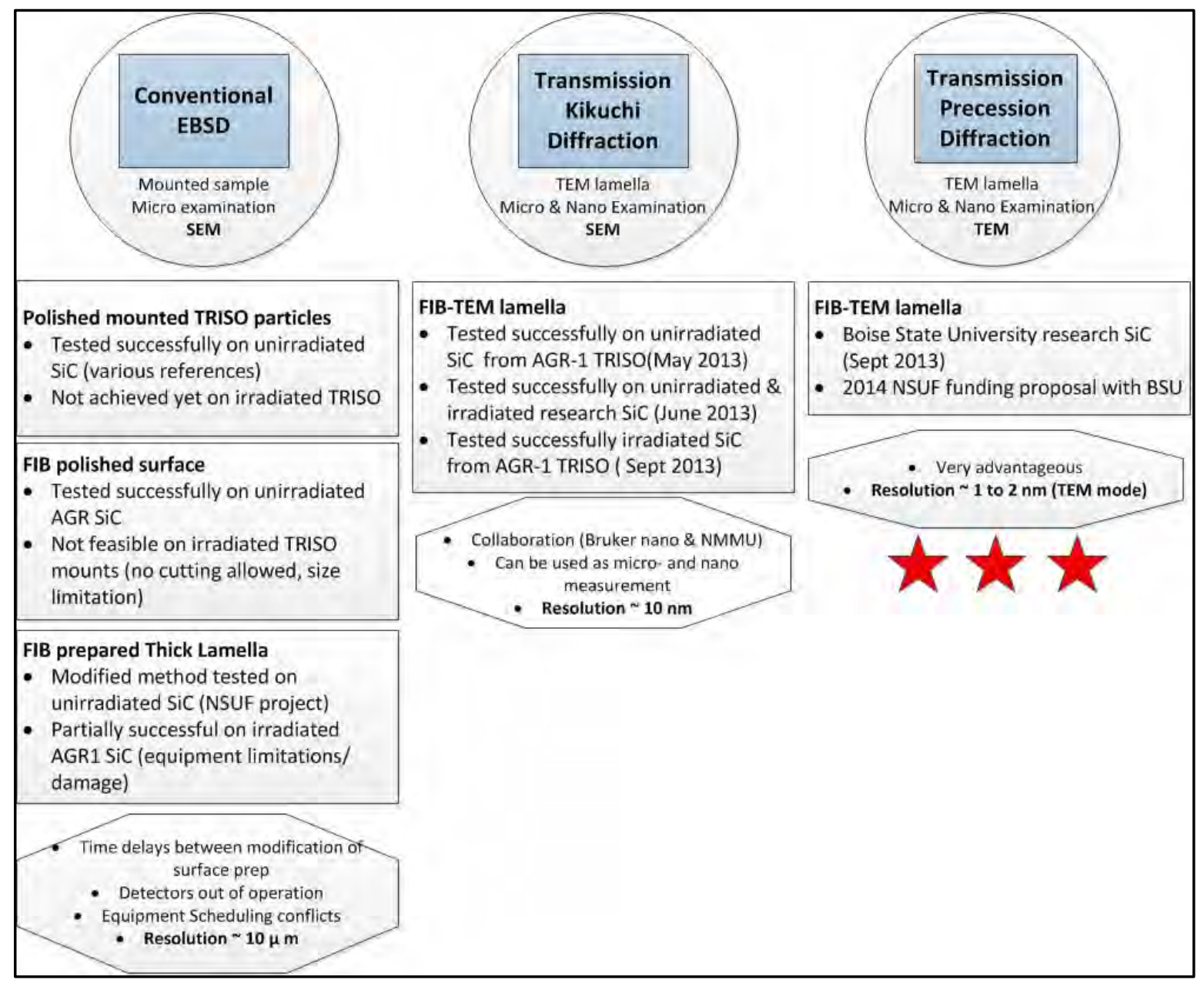

Figure 36. Schematic overview of the work done as part of AGR-1 PIE with complementary projects and other funding sources to assess crystallographic data on the $\mathrm{SiC}$ layer of particles and determine grain boundary misorientation (stars indicating the most successful results obtained at present).

In general, it was determined that the lamella thickness produced using the standard FIB fabrication process, is sufficient to provide reliable PED measurements. Thicker lamellae $(\sim 120 \mathrm{~nm})$ produce higher quality orientation data (Lillo et al. 2015a). PED data has been collected on FIB lamellae from coated particle AGR1-632-035 in every area previously analyzed with STEM and EDS, enabling examination of the crystallographic relationships on approximately 929 grain boundaries. Of these, only 179 boundaries and triple junctions contained fission products and transuranic elements. The distributions of grain boundary types in the SiC layer of particle AGR1-632-035 at inner, center, and outer areas, exhibit a prevalence of high-angle $\left(>15^{\circ}\right)$ and coincident site lattice (CSL)-related grain boundaries (Figure 37).

While the majority of grain boundaries are twin boundaries with a 60-degree misorientation angle, there are significantly fewer twins in the inner region, where growth of the $\mathrm{SiC}$ layer began, compared to the outer region. The fraction of CSL-related grain boundaries increased from the inner to the outer area, while the fraction of random high-angle grain boundaries decreased. Fission products are found predominantly on random, high angle grain boundaries but were also found on low-angle and CSL-related grain boundaries to a limited degree. Ag precipitates occurred only at random high-angle boundaries and never low-angle or CSL boundaries. Ag and Pd were observed co-existing on CSL-related boundaries in addition to random, high-angle boundaries. They were never observed together on low-angle boundaries. 


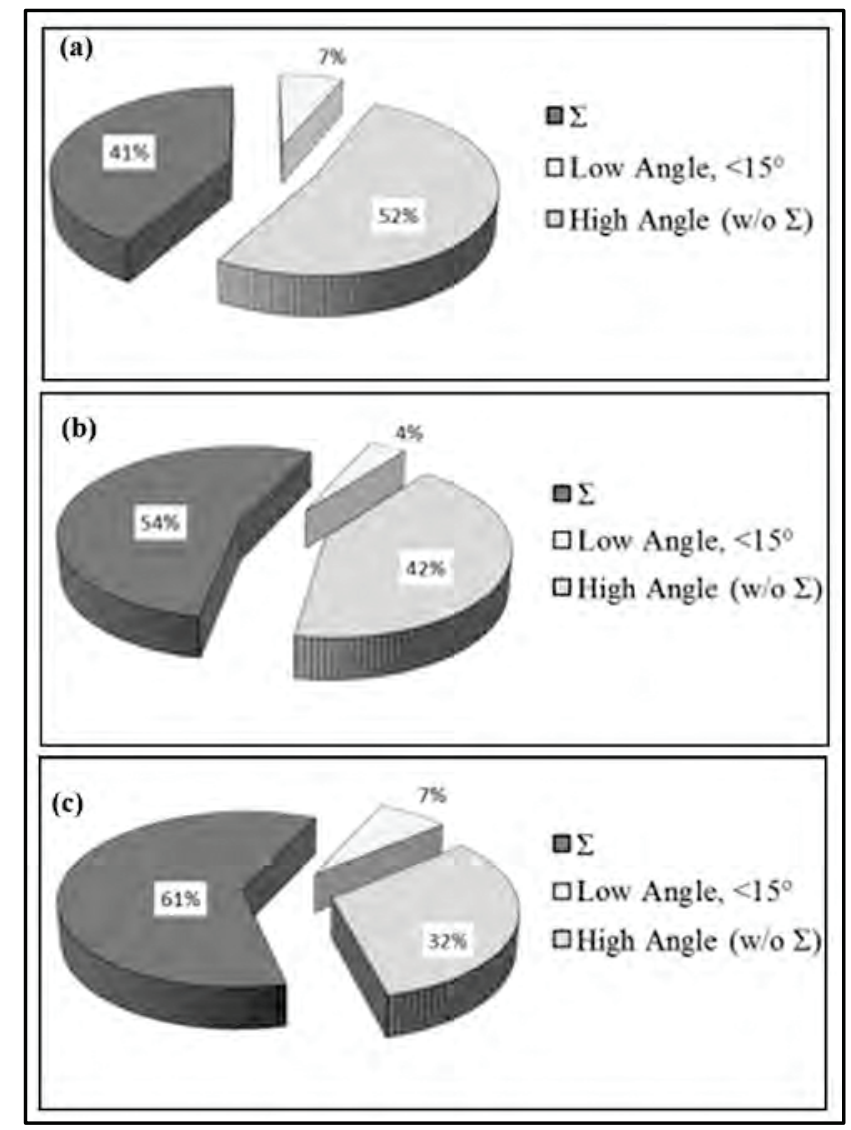

Figure 37. Distribution of grain boundary types for (a) inner, (b) center, and (c) outer areas in the SiC layer of an irradiated TRISO particle (AGR1-632-035) (adapted from Lillo et al. 2015b).

Three areas from particle AGR1-131-066 were analyzed, which included 45 grain boundaries that contained fission products, including 38 with Pd and 7 with Pd-U precipitates. The Pd precipitates occurred on all three grain boundary types with precipitates favoring random, high-angle grain boundaries, while the Pd-U precipitates do not occur on low-angle grain boundaries (Figure 38).

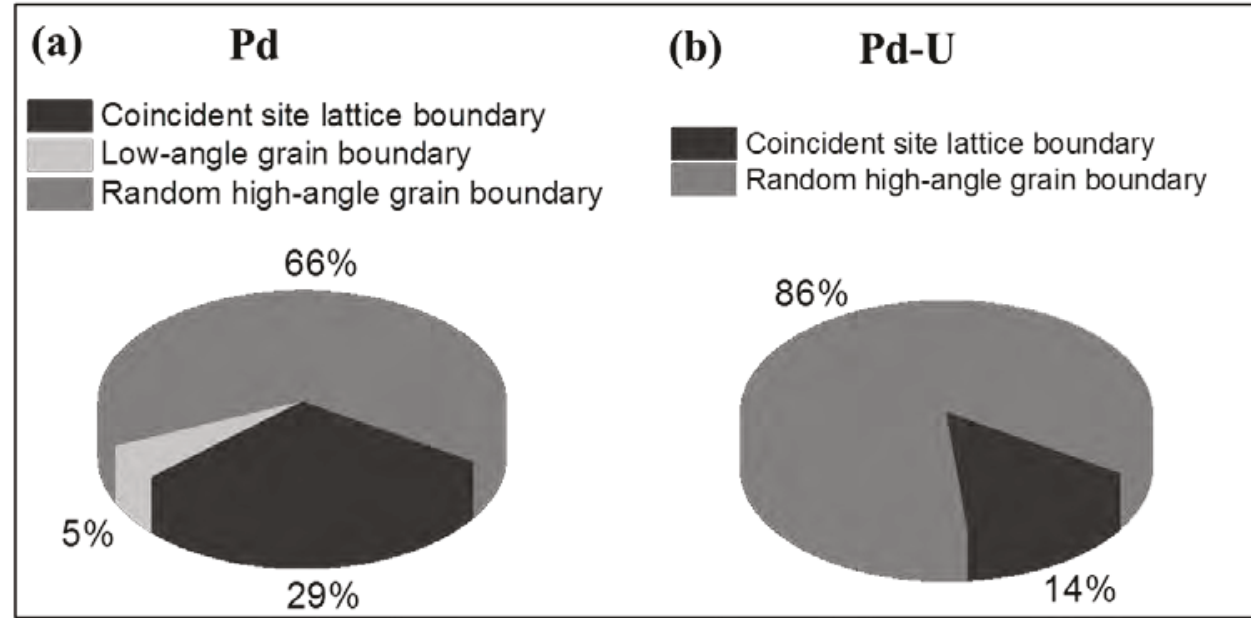

Figure 38. Distribution of grain boundary types for grain boundaries containing specific fission products in three inner areas in the SiC layer of particle AGR1-131-066: (a) grain boundaries containing Pd precipitate; (b) grain boundaries containing Pd-U precipitates. 


\section{Summary Conclusions from Advanced Microscopy Work}

Significant success was achieved during the AGR-1 advanced microscopy campaign, summarized as follows:

- $\quad$ The STEM, TEM, HRTEM, EBSD, TKD, APT, EELS, and PED results are the first-of-a-kind for the $\mathrm{SiC}$ layer of irradiated TRISO-coated particles reported in open literature.

- Pioneered innovative nano-crystallographic measurements on neutron-irradiated SiC through successful demonstration of the first application of PED in conjunction with fission products in irradiated fuels.

- STEM examination provided the first-of-a-kind results indicating silver-containing, nano-sized triple points and grain boundaries. This provides significant knowledge for silver transport mechanistic studies, which has been the topic of international research for the past 40 years.

- The HRTEM analysis provided the first image at the atomic level of $\mathrm{Ag}$ and $\mathrm{Pd}$ atoms on the grain boundaries of irradiated $\mathrm{SiC}$. This also provided insight into the co-existing nature of $\mathrm{Pd}$ and $\mathrm{Ag}$ in the same grain boundary.

- Fission product precipitates can consist of multi-phases or single phases.

- Cs was very rarely found in intact SiC layers, and was only once identified during an HRTEM investigation. However, $\mathrm{Cs}$ was detected in the $\mathrm{SiC}$ layer adjacent to a crack tip.

- Ag was identified inside a SiC grain in two different compacts (Baseline and Variant 3) in contrast to the prominent presence of $\mathrm{Ag}$ in $\mathrm{SiC}$ grain boundaries and/or triple points.

- The preferential location of fission products in grain boundaries based on the grain boundary character were obtained for Baseline fuel Compact 6-3-2 particles.

- Preliminary comparative STEM analysis showed differences in precipitate compositions between Baseline and Variant 3 fuels. For lamella AGR1-632-035-6b (Baseline fuel type), uranium was never detected in precipitates in the coating layers when silver was present and vice versa. Also, uranium was never found alone; it was always associated with palladium. In contrast, for Variant 3 fuel particle AGR1-131-099, U was found separately in the SiC layer.

\section{HIGH-TEMPERATURE FUEL PERFORMANCE \\ 4.1 Introduction}

Post-irradiation, elevated-temperature performance tests were conducted at both INL and ORNL to explore the fission product release characteristics of UCO fuel at temperatures that may be reached during a depressurized conduction cool-down event. The first test was conducted at $1600^{\circ} \mathrm{C}$ in a pure helium atmosphere (Baldwin et al. 2012) and subsequent tests were conducted at 1600,1700 , and $1800^{\circ} \mathrm{C}$. Tests at $1600^{\circ} \mathrm{C}$ were designed to test fuel performance at the maximum temperature that might be reached in the absence of normal-operation pressurized-gas cooling, while 1700 and $1800^{\circ} \mathrm{C}$ tests were performed to explore the safety margin and further understand temperature-dependent fission product release and microstructural changes in the fuel. Two additional special tests were conducted at ORNL, one on 75 loose particles deconsolidated from Compact 4-4-2 to obtain additional information on fission product release at $1800^{\circ} \mathrm{C}$ and the other at multiple temperatures to study silver release. A third special test will be conducted at INL where three compacts will be heated simultaneously using a temperature profile more representative of an actual conduction cool-down event. Table 16 and Table 17 list the compacts and safety test temperatures studied. Table 18 details the compact irradiation conditions. 
Table 16. Summary of safety tests in ORNL CCCTF.

\begin{tabular}{|c|c|c|c|c|c|}
\hline $\begin{array}{c}\text { ORNL } \\
\text { Test }\end{array}$ & $\begin{array}{l}\text { Compact } \\
\text { ID }\end{array}$ & Composite & $\begin{array}{l}\text { Safety Test } \\
\text { Temperature }\end{array}$ & $\begin{array}{c}\text { Safety Test } \\
\text { Summary Report }\end{array}$ & PIE Summary Report \\
\hline 1 & $6-4-3$ & Baseline & $1600^{\circ} \mathrm{C}$ & Baldwin et al. 2012 & \multirow{2}{*}{ Hunn et al. 2012b } \\
\hline 2 & $3-3-2$ & Baseline & $1600^{\circ} \mathrm{C}$ & \multirow{3}{*}{ Hunn et al. 2012e } & \\
\hline 3 & $3-2-2$ & Baseline & $1600^{\circ} \mathrm{C}$ & & Hunn et al. 2012c \\
\hline 4 & $6-2-1$ & Baseline & $1600^{\circ} \mathrm{C}$ & & \multirow{3}{*}{ Hunn et al. 2013b } \\
\hline 5 & $3-3-1$ & Baseline & $1700^{\circ} \mathrm{C}$ & Hunn et al. 2012d & \\
\hline 7 & $4-4-1$ & Variant 3 & $1800^{\circ} \mathrm{C}$ & \multirow{3}{*}{ Hunn et al. 2013c } & \\
\hline 6 & $4-1-2$ & Variant 3 & $1600^{\circ} \mathrm{C}$ & & \multirow{2}{*}{ Hunn et al. 2014c } \\
\hline 8 & $4-4-3$ & Variant 3 & $1700^{\circ} \mathrm{C}$ & & \\
\hline 9 & $5-3-3$ & Variant 1 & $1600^{\circ} \mathrm{C}$ & \multirow{2}{*}{ Hunn et al. 2013d } & \multirow{3}{*}{ Hunn et al. $2014 a$} \\
\hline 10 & $5-1-3$ & Variant 1 & $1800^{\circ} \mathrm{C}$ & & \\
\hline 11 & $3-2-3$ & Baseline & $1800^{\circ} \mathrm{C}$ & Hunn et al. 2014a & \\
\hline 12 & $4-2-2$ & Variant 3 & $1000-1600^{\circ} \mathrm{C}^{\mathrm{a}}$ & Hunn et al. 2014e & Hunn et al. $2015 \mathrm{~b}$ \\
\hline 13 & $4-4-2^{b}$ & Variant 3 & $1800^{\circ} \mathrm{C}$ & Hunn et al. $2014 \mathrm{f}$ & Hunn et al. $2015 \mathrm{c}$ \\
\hline 14 & $5-1-1$ & Variant 1 & $1700^{\circ} \mathrm{C}$ & Hunn et al. 2015a & Hunn et al. 2015a \\
\hline
\end{tabular}

Table 17. Summary of safety tests in INL FACS.

\begin{tabular}{|c|c|c|c|c|c|}
\hline $\begin{array}{l}\text { INL } \\
\text { Test }\end{array}$ & $\begin{array}{l}\text { Compact } \\
\text { ID }\end{array}$ & Composite & $\begin{array}{l}\text { Safety Test } \\
\text { Temperature }\end{array}$ & $\begin{array}{l}\text { Safety Test } \\
\text { Summary }\end{array}$ & PIE Summary \\
\hline 1 & $6-4-1$ & Baseline & $1600^{\circ} \mathrm{C}$ & \multirow{3}{*}{ Demkowicz et al. 2015e } & NA \\
\hline 2 & $4-3-3$ & Variant 3 & $1600^{\circ} \mathrm{C}$ & & Demkowicz et al. $2015 \mathrm{f}$ \\
\hline 3 & $4-3-2$ & Variant 3 & $1800^{\circ} \mathrm{C}$ & & NA \\
\hline \multirow[t]{3}{*}{4} & $1-1-1$ & Variant 3 & \multirow[t]{3}{*}{ up to $1700^{\circ} \mathrm{C}^{\mathrm{a}}$} & \multirow[t]{3}{*}{ (Planned for FY16) } & \multirow{3}{*}{ (Planned for FY16) } \\
\hline & $1-1-3$ & Variant 3 & & & \\
\hline & $1-4-2$ & Variant 3 & & & \\
\hline
\end{tabular}

Table 18. Summary of safety test compact irradiation conditions.

\begin{tabular}{|c|c|c|c|c|c|}
\hline Compact & Fuel type & $\begin{array}{c}\text { TAVA }^{\mathrm{a}} \text { Temp } \\
\left({ }^{\circ} \mathrm{C}\right)^{\mathrm{b}}\end{array}$ & $\begin{array}{c}\text { TA Max } \\
\left({ }^{\circ} \mathrm{C}\right)^{\mathrm{b}}\end{array}$ & $\begin{array}{c}\text { Burnup } \\
(\% \text { FIMA })^{\mathrm{d}}\end{array}$ & $\begin{array}{c}\text { Fast fluence } \\
\left(10^{25} \mathrm{n} / \mathrm{m}^{2}\right)^{\mathrm{d}}\end{array}$ \\
\hline $1-1-1$ & Variant 3 & 1017 & 1114 & 15.19 & 2.81 \\
\hline $1-1-3$ & Variant 3 & 1018 & 1115 & 15.32 & 2.86 \\
\hline $1-4-2$ & Variant 3 & 1045 & 1140 & 14.93 & 3.01 \\
\hline $3-2-2$ & Baseline & 1019 & 1119 & 17.02 & 3.79 \\
\hline $3-2-3$ & Baseline & 1053 & 1145 & 19.12 & 4.28 \\
\hline $3-3-1$ & Baseline & 1051 & 1145 & 19.07 & 4.23 \\
\hline $3-3-2$ & Baseline & 1020 & 1121 & 17.02 & 3.80 \\
\hline $4-1-2$ & Variant 3 & 1042 & 1156 & 17.39 & 3.72 \\
\hline $4-2-2$ & Variant 3 & 1065 & 1159 & 16.64 & 3.73 \\
\hline $4-3-2$ & Variant 3 & 1057 & 1150 & 16.38 & 3.68 \\
\hline
\end{tabular}


Table 18. (continued).

\begin{tabular}{|c|c|c|c|c|c|}
\hline Compact & Fuel type & $\begin{array}{c}\text { TAVA }^{\mathrm{a}} \text { Temp } \\
\left({ }^{\circ} \mathrm{C}\right)^{\mathrm{b}}\end{array}$ & $\begin{array}{c}\text { TA Max }{ }^{\mathrm{c}} \text { Temp } \\
\left({ }^{\circ} \mathrm{C}\right)^{\mathrm{b}}\end{array}$ & $\begin{array}{c}\text { Burnup } \\
(\% \text { FIMA })^{d}\end{array}$ & $\begin{array}{l}\text { Fast fluence } \\
\left(10^{25} \mathrm{n} / \mathrm{m}^{2}\right)^{\mathrm{d}}\end{array}$ \\
\hline 4-3-3 & Variant 3 & 1094 & 1179 & 18.63 & 4.16 \\
\hline 4-4-1 & Variant 3 & 1057 & 1166 & 18.96 & 3.99 \\
\hline $4-4-2$ & Variant 3 & 1024 & 1139 & 16.74 & 3.59 \\
\hline $4-4-3$ & Variant 3 & 1059 & 1168 & 18.99 & 4.06 \\
\hline $5-1-1$ & Variant 1 & 1041 & 1143 & 18.22 & 3.76 \\
\hline $5-1-3$ & Variant 1 & 1042 & 1144 & 18.19 & 3.82 \\
\hline $5-3-3$ & Variant 1 & 1042 & 1123 & 17.01 & 3.65 \\
\hline $6-2-1$ & Baseline & 1135 & 1197 & 14.20 & 2.87 \\
\hline $6-4-1$ & Baseline & 1041 & 1130 & 13.35 & 2.43 \\
\hline $6-4-3$ & Baseline & 1041 & 1130 & 13.35 & 2.46 \\
\hline \multicolumn{6}{|c|}{$\begin{array}{l}\text { a. Time average, volume average temperature } \\
\text { b. Hawkes } 2012 \\
\text { c. Time average maximum temperature } \\
\text { d. Sterbentz } 2013 \text {. }\end{array}$} \\
\hline
\end{tabular}

\subsection{Experimental Methods}

The objectives of these furnace tests were: (1) heat the compact in a pure helium atmosphere, and measure the high-temperature time-dependent release of gaseous and condensable fission products from the compact with the Core Conduction Cooldown Test Facility (CCCTF) at ORNL (Baldwin et al. 2012) and with the Fuel Accident Condition Simulator (FACS) furnace system at INL (Demkowicz et al. 2010), (2) measure the inventory of fission products released from the particles but retained in the compact matrix by DLBL following the furnace test, (3) examine TRISO fuel particles recovered after the deconsolidation to quantify the individual particle retention of specific fission products (including ${ }^{110 \mathrm{~m}} \mathrm{Ag}$, ${ }^{134} \mathrm{Cs},{ }^{137} \mathrm{Cs},{ }^{144} \mathrm{Ce}$, and ${ }^{154} \mathrm{Eu}$ ), and (4) perform microanalysis on selected particles to better understand the correlation between particle microstructure and fission product retention.

The ORNL CCCTF and INL FACS are high-temperature furnaces designed to test the behavior of coated-particle fuel under simulated accident conditions. The CCCTF furnace (Figure 39a) operates within a dedicated hot cell and can be heated up to a maximum temperature of $2000^{\circ} \mathrm{C}$. The test compact is placed inside a graphite holder within a tantalum can that separates it from the surrounding furnace components. High-purity helium (99.9998\%) is used as a sweep gas to purge the interior of the can through a series of liquid-nitrogen-cooled charcoal traps outside the CCCTF cell. The traps adsorb any condensable gases and are continuously monitored with NaI detectors to provide real-time measurement of radioactive fission gas $(\mathrm{Kr}$ and $\mathrm{Xe})$ indicative of diffusive-release or TRISO coating failure. An airlock at the top of the furnace allows for the exchange of a water-cooled cold finger assembly that resides in the upper section of the furnace. The cold finger has a replaceable deposition cup on the end that collects volatile fission products (e.g., $\mathrm{Cs}, \mathrm{Ag}, \mathrm{Pd}, \mathrm{I}, \mathrm{Sr}$, and $\mathrm{Eu}$ ) while it is inside the furnace, thus allowing for periodic measurement of metallic fission product release. 


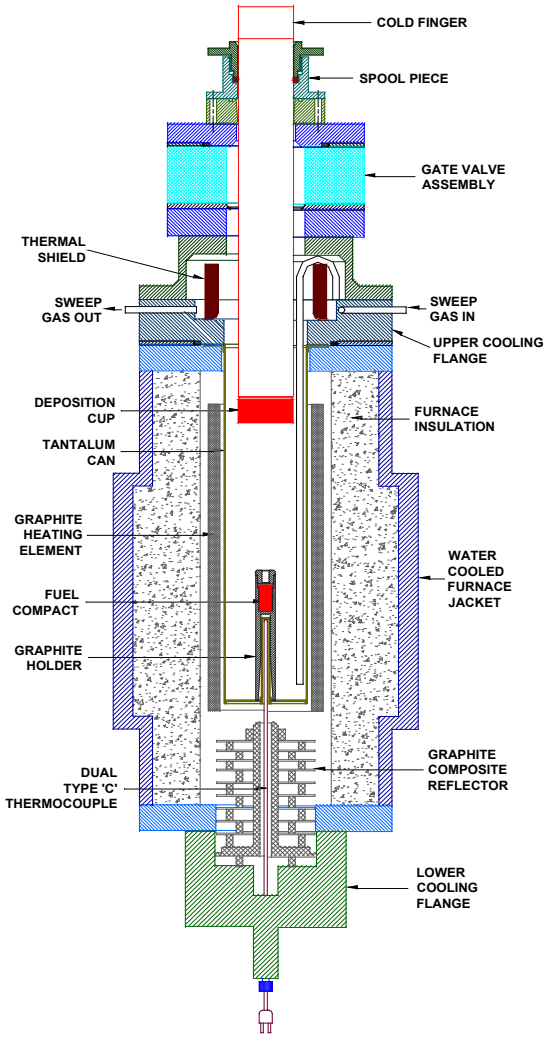

(a)

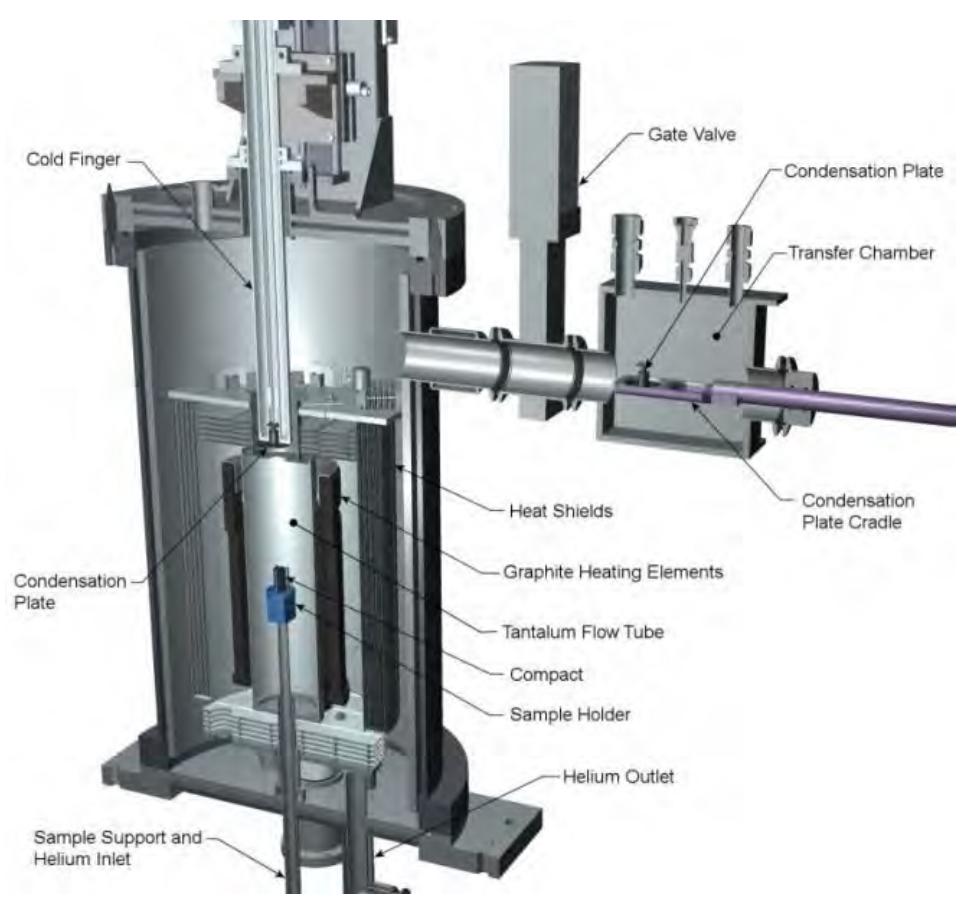

(b)

Figure 39. Schematic of the CCCTF (a) and FACS (b) safety test furnaces.

The INL FACS furnace system has a somewhat different design but performs the same basic functions as the CCCTF. Fission gases released from the fuel to the sweep gas are monitored in real time using dual cryogenic traps fitted with high purity germanium detectors. Condensable fission products are collected on a plate attached to a water-cooled cold finger that can be exchanged periodically and automatically without interrupting the test. A schematic of the furnace system is shown in Figure 39b. While both furnace systems have mostly tantalum parts exposed to the test atmosphere, the CCCTF differs in that it has a graphite fuel holder surrounding the fuel compact that introduces a significant amount of graphite into the test environment. This fuel holder simulates the graphite surrounding the fuel in a prismatic block reactor and can act as a sink for the less-volatile fission products such as Eu and Sr; it has little effect on $\mathrm{Ag}$ and Cs.

The general test program proceeded by ramping the furnace to $400^{\circ} \mathrm{C}$ under flowing helium and holding for 2 hours to bake out water or air that may have been present in the fuel compact and furnace components. Next, the furnace was ramped to $1250^{\circ} \mathrm{C}$ and held for 12 hours to complete the baking process and allow the fuel to come to equilibrium near its irradiation temperature. A deposition cup/plate was usually changed at the end of this period. The furnace was then ramped from $1250^{\circ} \mathrm{C}$ up to the test temperature at a rate of $\sim 50^{\circ} \mathrm{C} /$ hour and a second deposition cup/plate exchange was performed within 1 hour after reaching the test temperature. The next 2-3 cups/plates were changed at around 12-hour intervals and then the intervals were increased to around 24 hour for the remainder of the test. 
During an entire test, the fission gas traps were continuously monitored for ${ }^{85} \mathrm{Kr}$. Unless there was a problem, the trap inventory was allowed to build up during the test; the traps were not emptied until the test was over, at which time the ${ }^{85} \mathrm{Kr}$ in the trap was sometimes removed for optional offline analysis. Dual traps allow the test to continue should one become plugged.

The isotopic inventories deposited on the cups/plates are measured by gamma counting followed by acid leaching for mass spectrometry of stable or long-lived isotopes and to obtain solutions for measuring the beta-emitting ${ }^{90} \mathrm{Sr}$ isotope. The FACS condensation plate collection efficiencies (used to determine compact releases from measured accumulation on the plates) were determined by calibrating with test samples containing various radioisotopes. The CCCTF deposition cup collection efficiencies are separately determined for each test by measuring the isotopic inventories on the other furnace components. The Ta liner and gas inlet tube are gamma counted and leached and the graphite components are ashed and leached; this provides an account of the fission products that escaped the compacts but did not reach the deposition cups.

\subsection{Safety Test Results \\ 4.4 Representative $1600^{\circ} \mathrm{C}$ Safety Tests}

Two $1600^{\circ} \mathrm{C}$ tests are of particular interest since they illustrate the release behavior of cesium, a volatile element with significant reactor safety implications. The results of the Compact 6-2-1 test are shown in Figure 40 and indicate that this compact did not release significant cesium. In contrast, Compact 4-1-2 (Figure 41) released significant cesium during its test due to a SiC failure, as was later verified by compact deconsolidation and identification of the failed particle with IMGA (Hunn et al. 2014d). Test results are plotted as the cumulative fraction released from the compact during the furnace test. The released fraction is the cumulative inventory on the cups/plates divided by the predicted compact inventory at the end of the irradiation. Compact 6-2-1 ${ }^{134} \mathrm{Cs}$ release (a better indicator of trace levels of cesium release than ${ }^{137} \mathrm{Cs}$ because of lower hot cell contamination) was below $5 \times 10^{-6}$, while in the test of Compact 4-1-2, the collected cesium was an appreciable fraction of one particle (one particle is equivalent to a compact fraction of $2.4 \times 10^{-4}$ ). 


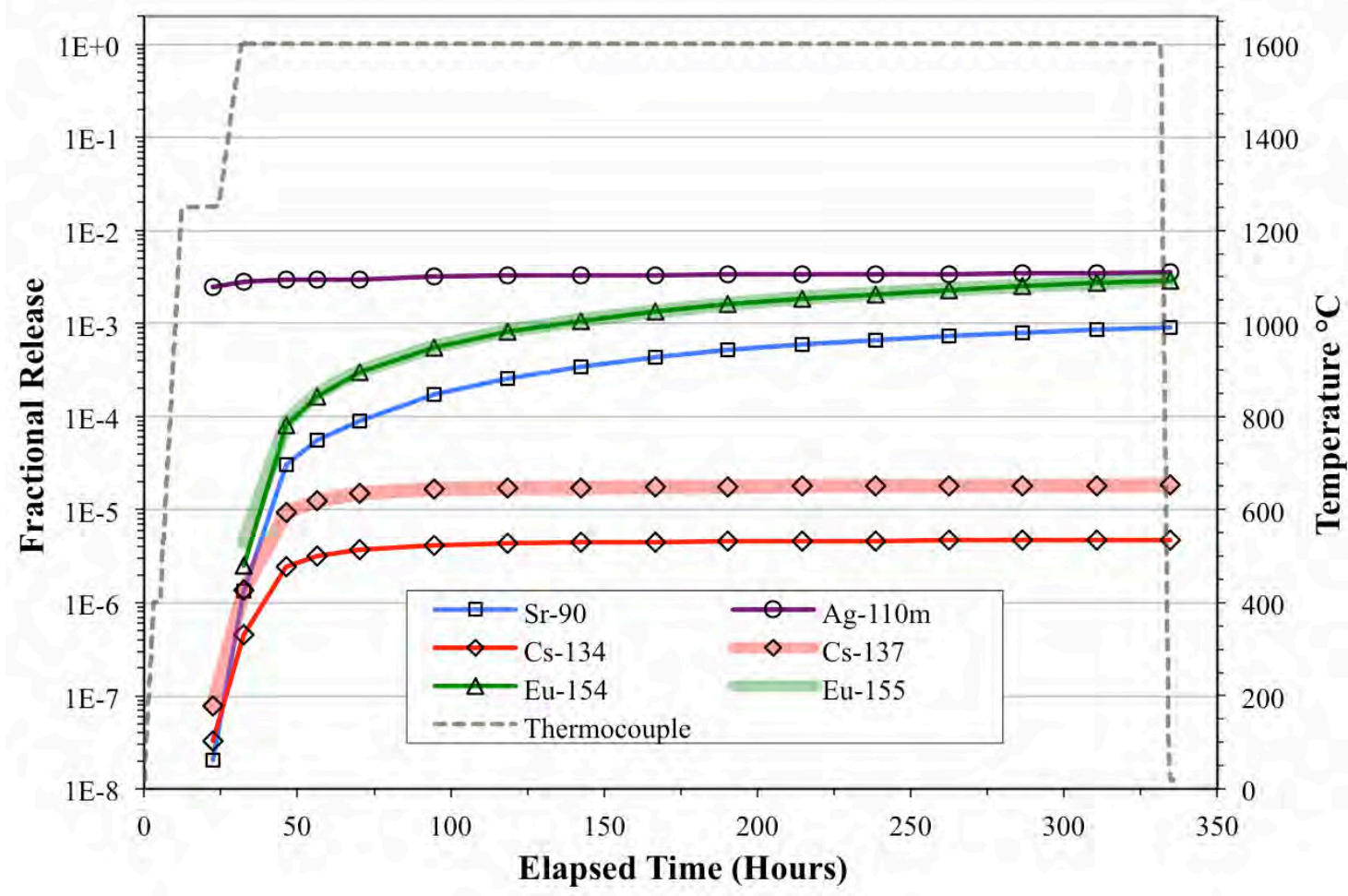

Figure 40. Compact 6-2-1 test results. Cesium release was very low; higher ${ }^{137} \mathrm{Cs}$ accumulation, compared to ${ }^{134} \mathrm{Cs}$, indicates hot cell contamination.

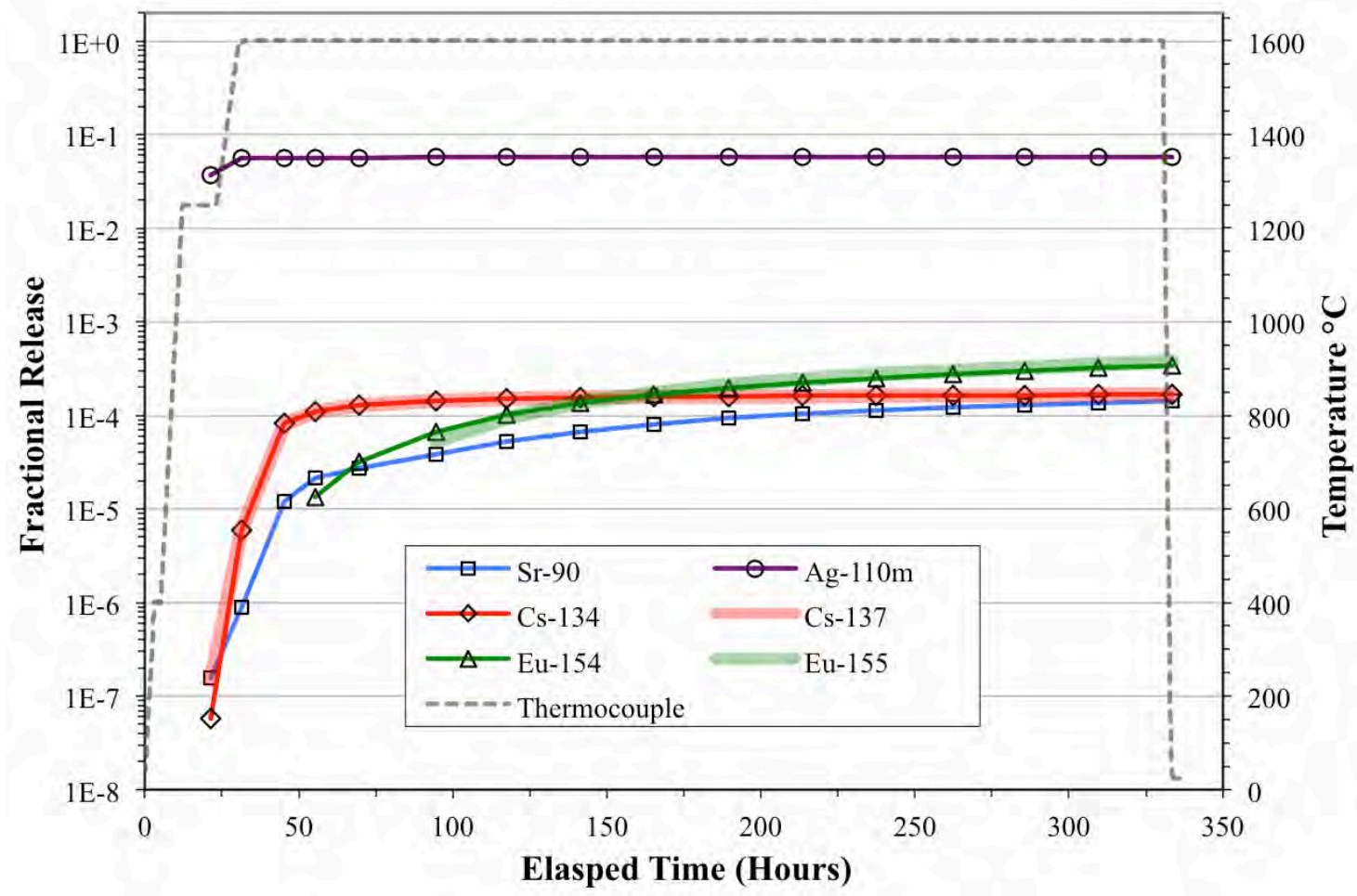

Figure 41. Compact 4-1-2 test results. Cesium release above $10^{-4}$ indicates that this compact contained a particle whose $\mathrm{SiC}$ layer was not intact. 
Neither compact released significant radioactive gas during the furnace tests $\left({ }^{85} \mathrm{Kr}\right.$ was near or below detection levels of the CCCTF gas analysis system - typically $<10^{-6}$ ). This indicates that in Compact 4-1-2, the single particle with the failed $\mathrm{SiC}$ layer maintained at least one intact pyrocarbon layer, which effectively retained fission gases. Additionally, no other particles in either compact had a TRISO failure (failure of all three structural layers). The diffusion of ${ }^{85} \mathrm{Kr}$ through pyrocarbon at $1600^{\circ} \mathrm{C}$ is very low for this time interval.

Figure 40 and Figure 41 also illustrate that the other measured isotopes did not generally track the cesium release behavior. For instance, the ${ }^{110 \mathrm{~m}} \mathrm{Ag},{ }^{154} \mathrm{Eu}$, and ${ }^{90} \mathrm{Sr}$ released from Compact 6-2-1 were equivalent to the inventory in many particles even though the ${ }^{134} \mathrm{Cs}$ release was negligible. This suggests a source of release for these elements independent of $\mathrm{SiC}$ containment failure, as discussed below.

\subsection{Overview of Safety Tests}

Eight runs at $1600^{\circ} \mathrm{C}$, three runs at $1700^{\circ} \mathrm{C}$, and four runs at $1800^{\circ} \mathrm{C}$ were conducted for the AGR-1 program. The results are shown, grouped by isotope, in Figure 42 through Figure 47. Silver and cesium (Figure 44 and Figure 45) demonstrated a relatively rapid release behavior. When releases occurred, either as compacts were heated to the target temperature or when SiC failures occurred early in the testing, cumulative values quickly approached a maximum and then plateaued. This is indicative of fast release from the carbonaceous material outside of intact $\mathrm{SiC}$, rather than slower diffusion through intact SiC. As discussed in Section 3.2.2, it is known from DLBL analysis of as-irradiated compacts that significant amounts of silver were released through intact $\mathrm{SiC}$ during the irradiation test and retained in the surrounding carbon matrix and $\mathrm{OPyC}$. Cumulative silver and cesium releases during safety testing in the absence of $\mathrm{SiC}$ failure were of similar magnitude as was observed in as-irradiated compacts by DLBL. It cannot be determined if the comparatively small gradual accumulation of silver and cesium after the initial rise to test temperature throughout some tests was due to release through intact $\mathrm{SiC}$ or simply from residual inventory in the matrix and OPyC. The less-volatile elements strontium and europium (Figure 43 and Figure 47, respectively) displayed a release behavior with a much longer rise time as compared to silver and cesium. This too appears to be dominated by the inventory of these isotopes trapped in the matrix and $\mathrm{OPyC}$ at the end of irradiation. The slower release rates for europium and strontium are related to slower release from the carbonaceous material in the compacts coupled with slower transport to the furnace collection cups/plates. Results for krypton release (Figure 42) are only shown for those runs that had releases above the detection limits of the collection systems. Complete TRISO failure was evident in only one case (the $1800^{\circ} \mathrm{C} \mathrm{FACS}$ test of Compact 4-3-2); most of the remaining ${ }^{85} \mathrm{Kr}$ release curves represent diffusion through intact OPyC in particles with failed $\mathrm{SiC}$ (the IPyC was also cracked in these cases). Significant ${ }^{85} \mathrm{Kr}$ release from Compact 4-3-2 appears to be from incremental coating failure in three particles; with a sequence of $\mathrm{SiC}$ failure followed by OPyC failure in the first two particles, and only $\mathrm{SiC}$ failure in the third particle near the end of the test (Demkowicz et al. 2015e).

Cumulative ${ }^{134} \mathrm{Cs}$ fractional release (Figure 45) for five out of the eight compacts tested at $1600^{\circ} \mathrm{C}$ was below $10^{-5}$ (corresponding to a few percent of a single particle's inventory). Cesium release at these levels may be from very low levels of cesium in the compact matrix or may be dominated by contributions from hot cell contamination. Significant cesium release during safety testing was connected with failed $\mathrm{SiC}$; the three compacts that released cesium at $1600^{\circ} \mathrm{C}$ each had one particle with failed $\mathrm{SiC}$. The cesium releases from Compacts 4-1-2 and 3-3-2 were investigated in detail to locate the cesium-releasing particles, and both were determined to be related to as-fabricated $\mathrm{SiC}$ defects (Hunn et al. 2014d). At higher temperatures, cesium release generally increased, and failure of the $\mathrm{SiC}$ in individual particles often continued throughout the safety test, rather than just during initial heat up. This is illustrated by the shape of the scaled release curves in Figure 46, which only includes results from compacts that exhibit cesium release consistent with failed SiC. Early single-particle releases resulted in a rapid increase followed by a plateau, while multiple-particle releases distributed over time resulted in a more linear accumulation of cesium. However, the increased cesium release due to SiC failure at higher temperature was modest and no catastrophic avalanche of cesium release was observed. 


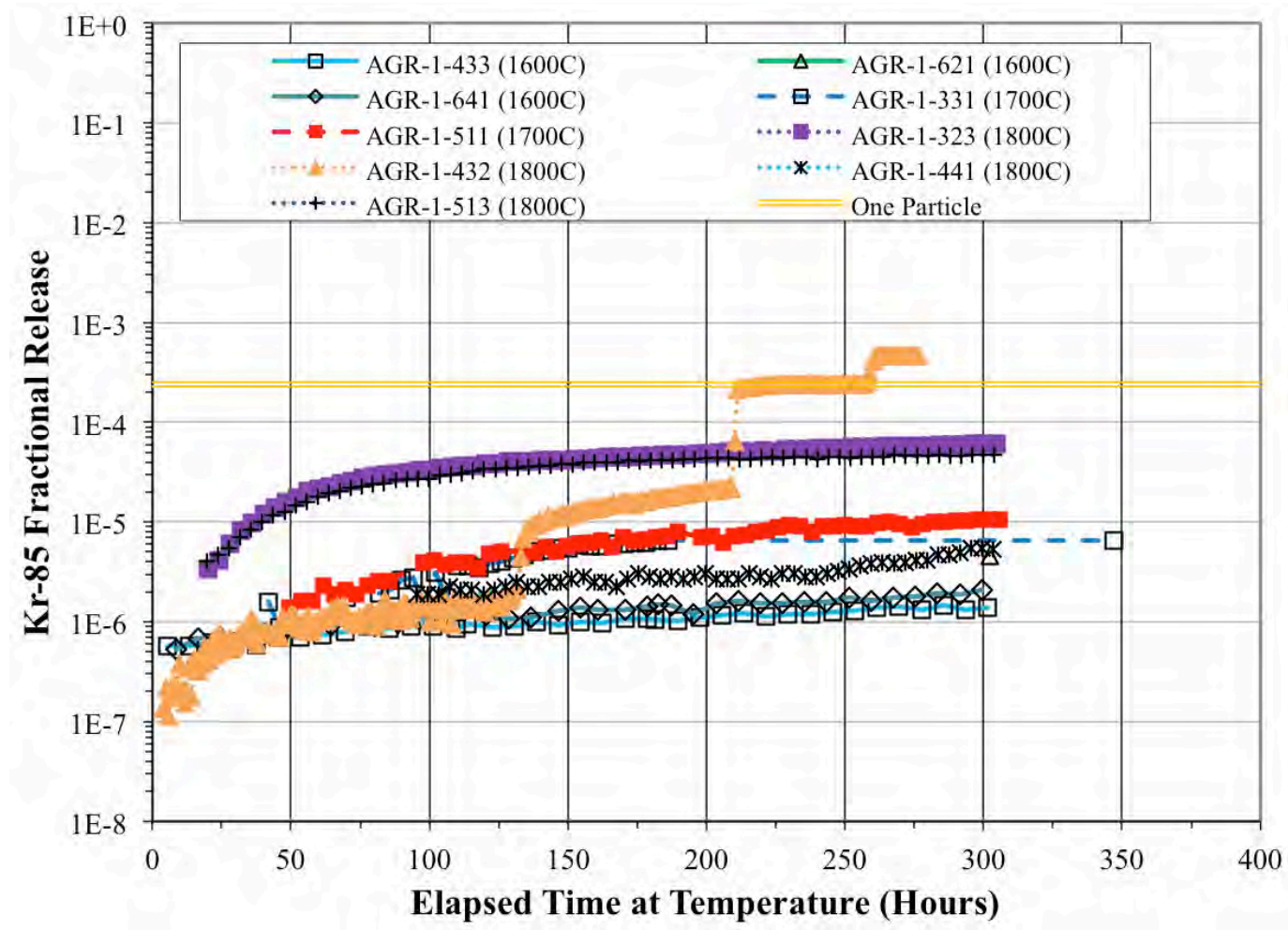

Figure 42. Fractional release of ${ }^{85} \mathrm{Kr}$ during safety testing. Only nine runs had measurable release, and Compact 4-3-2 showed the only TRISO failure.

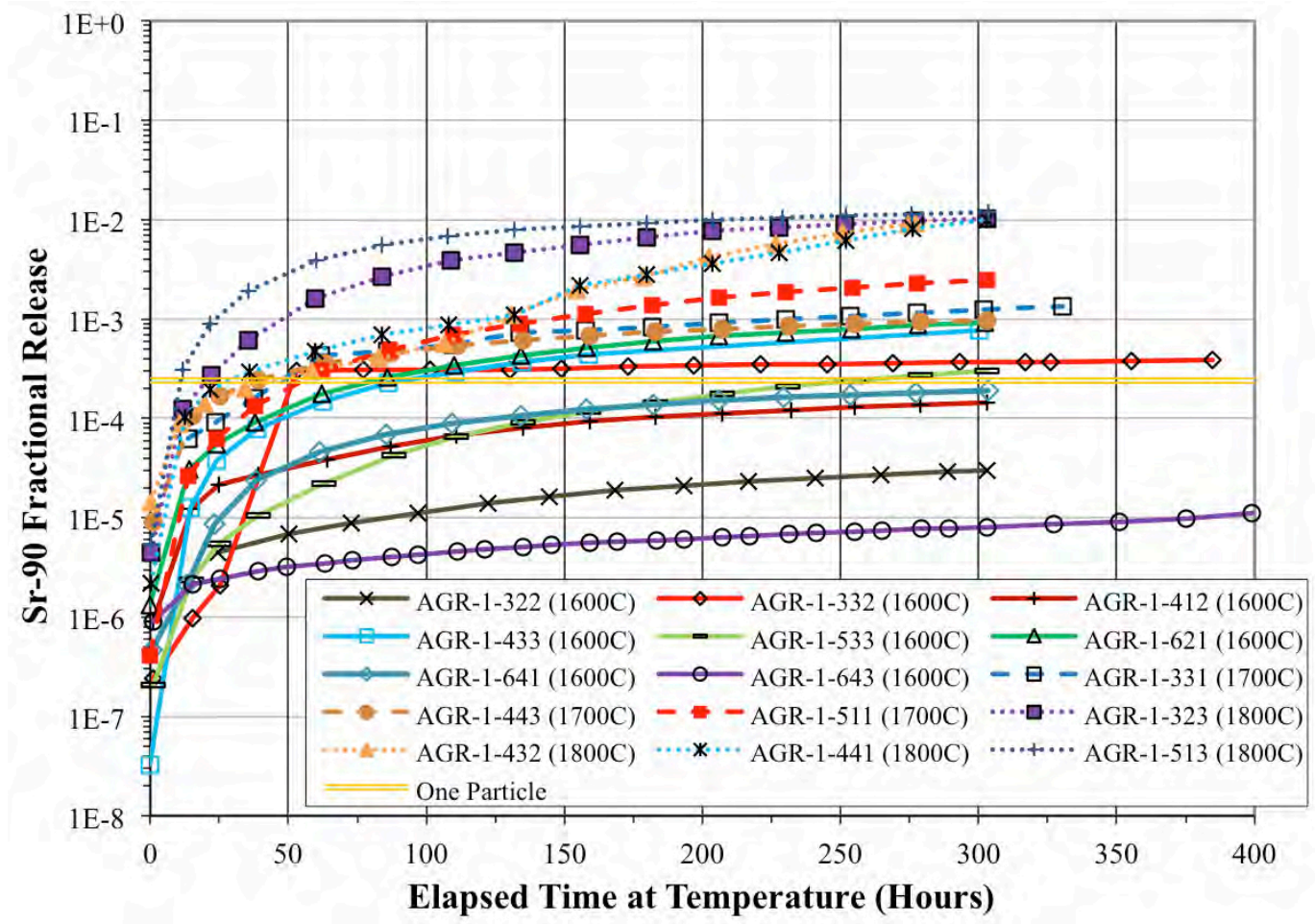

Figure 43. Fractional release of ${ }^{90} \mathrm{Sr}$ during safety testing. Release increased with temperature. 


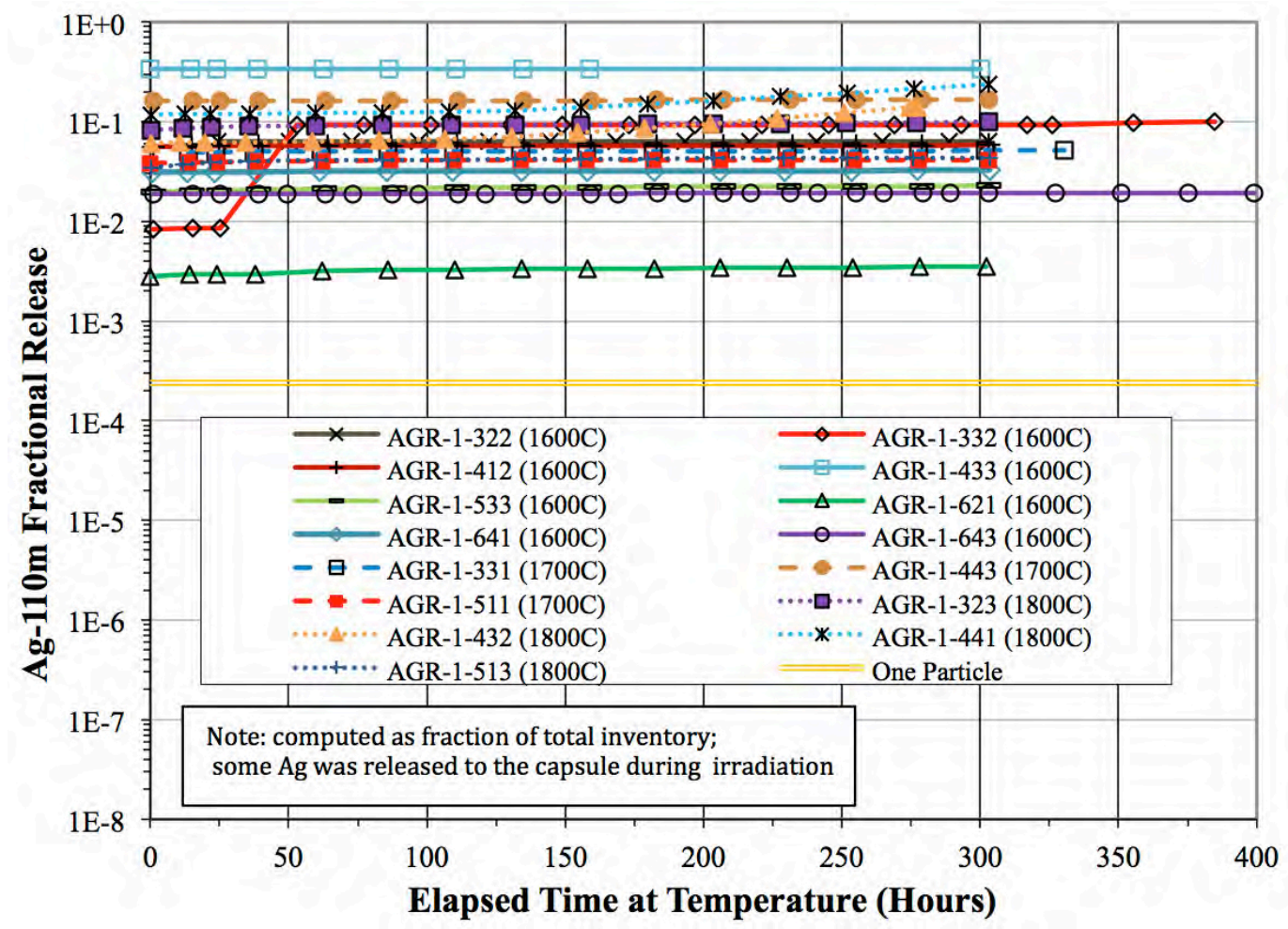

Figure 44. Fractional release of ${ }^{110 \mathrm{~m}} \mathrm{Ag}$ during safety testing. Release peaked very early. Compact 3-3-2 showed secondary release related to thermal cycling of furnace.

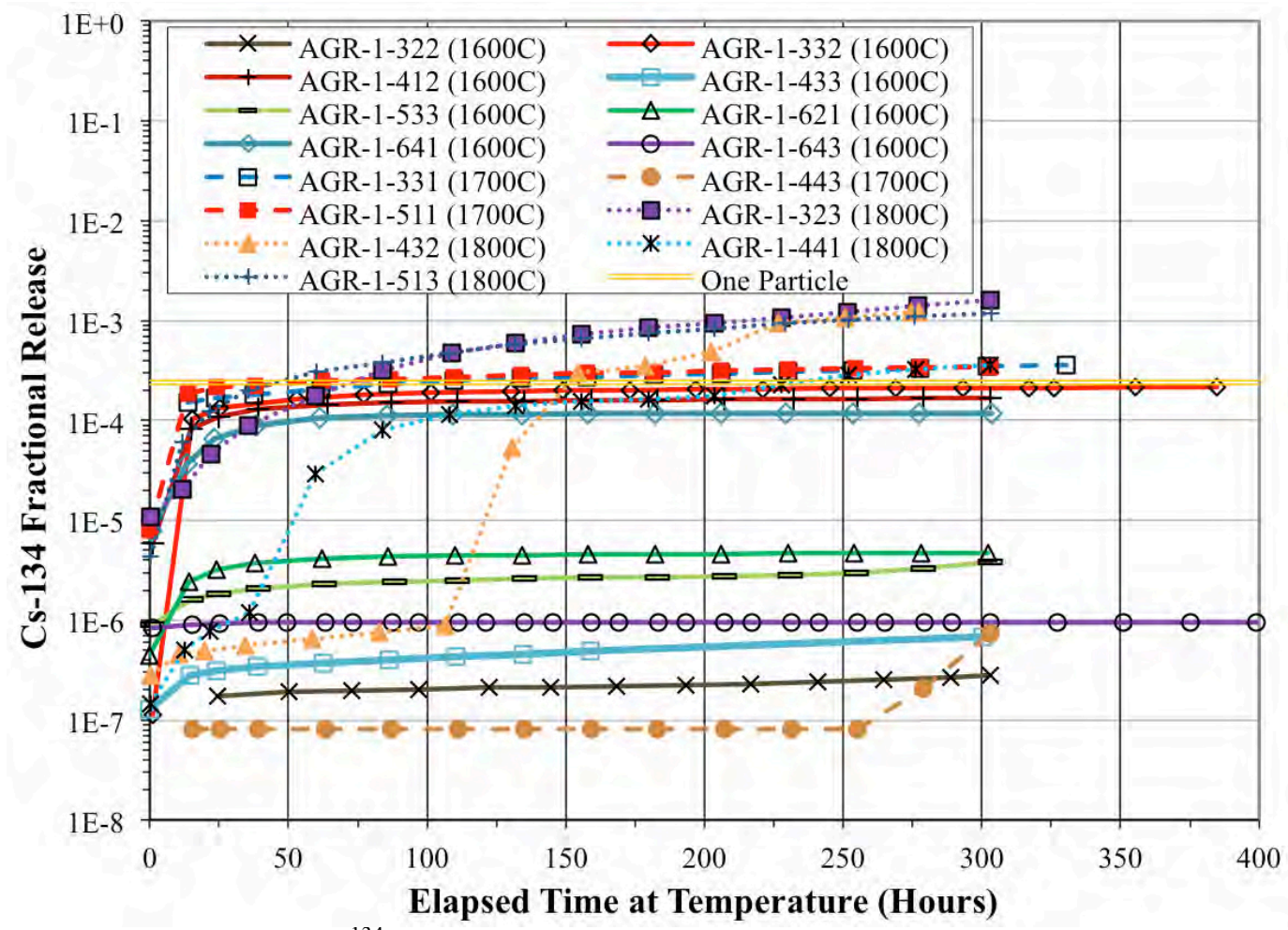

Figure 45. Fractional release of ${ }^{134} \mathrm{Cs}$ during safety testing. Sudden increases were due to SiC failure while either coming up to temperature or later in the run. 


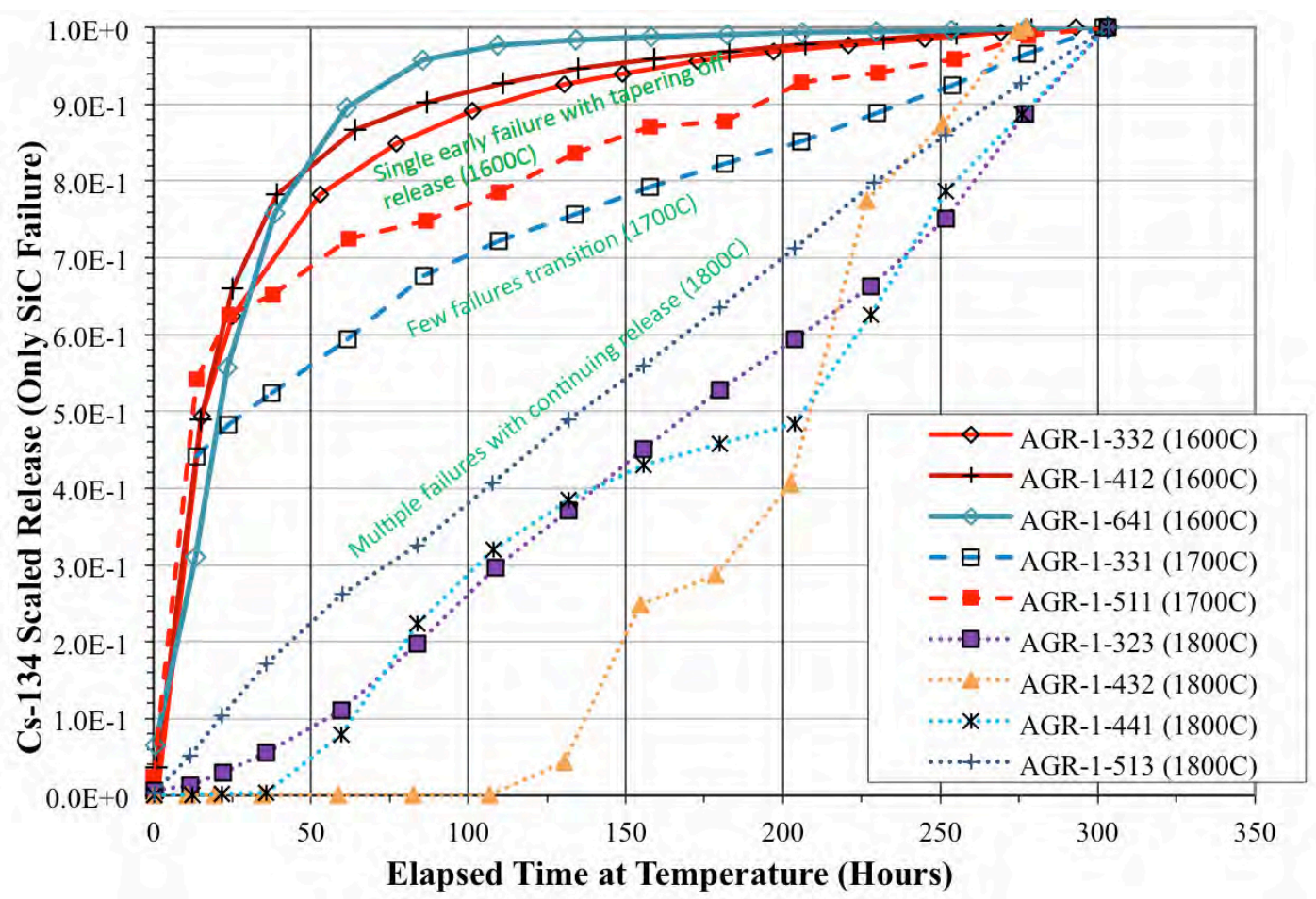

Figure 46. Scaled-release of ${ }^{134} \mathrm{Cs}$ illustrates the release history as a function of test temperature. The number of $\mathrm{SiC}$ failures increased with test temperature.

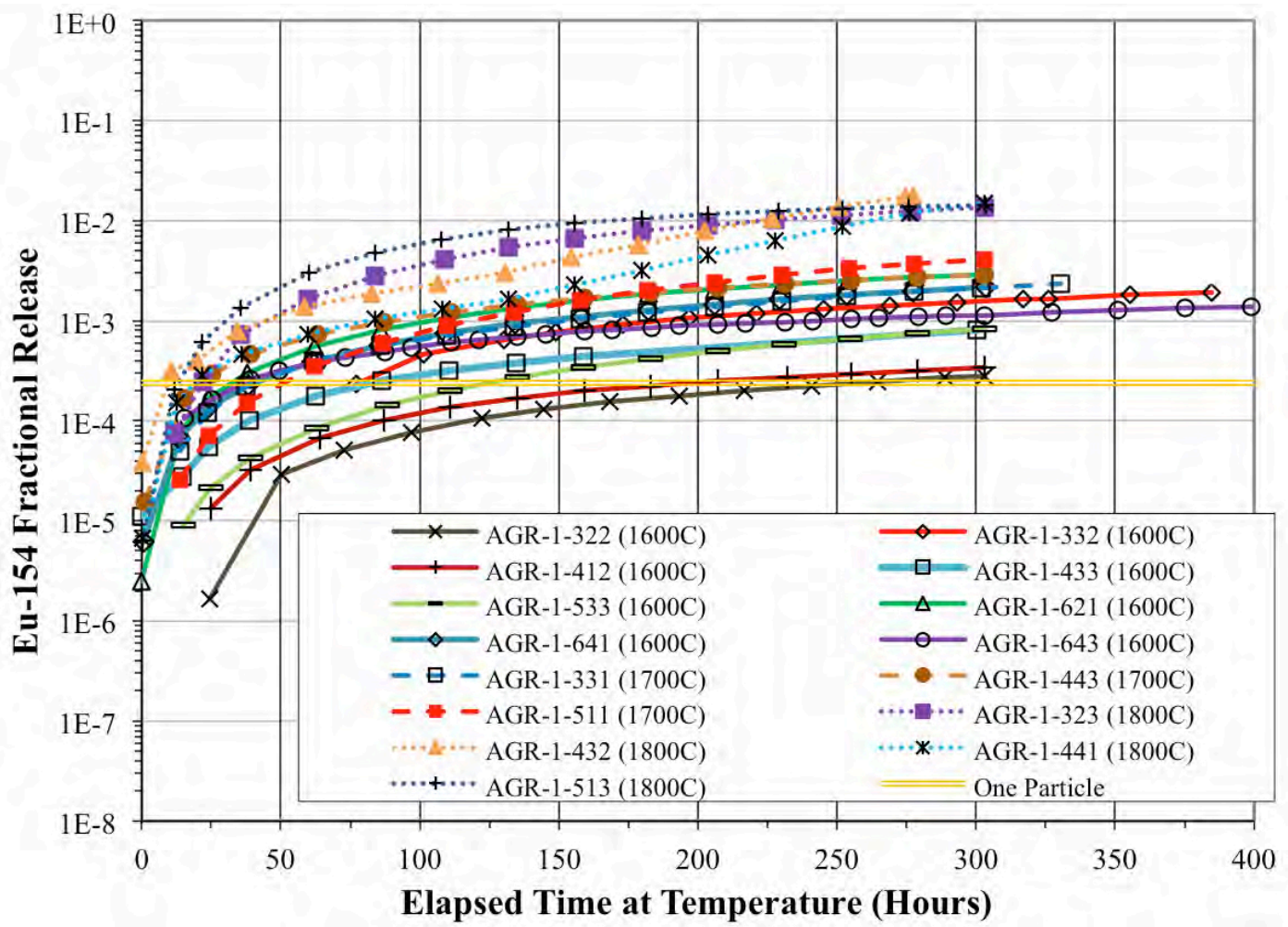

Figure 47. Fractional release of ${ }^{154} \mathrm{Eu}$ during safety testing. Release increased with temperature and exceeded single-particle inventory. 
Silver release was much higher than cesium, with compacts releasing the equivalent of the ${ }^{110 \mathrm{~m}} \mathrm{Ag}$ inventory of 10-1000 particles. Total silver release was not impacted by the presence of particles with failed $\mathrm{SiC}$, nor did it correlate with overall cesium release. It should also be noted that although the plotted release fractions are based on the calculated inventory, many compacts started the safety test with a reduced inventory due to silver release during irradiation (see Section 3.2.2).

In six of the eight $1600^{\circ} \mathrm{C}$ tests, ${ }^{154} \mathrm{Eu}$ releases were equivalent to the inventory of 3-12 particles, even though two of those compacts (Compacts 3-3-2 and 6-4-1) only had single-particle SiC failure and the other four compacts had none. In the remaining two $1600^{\circ} \mathrm{C}$ tests, where each compact released closer to one particle's ${ }^{154} \mathrm{Eu}$ inventory, only Compact 4-1-2 had a $\mathrm{SiC}$ failure. The greatest ${ }^{154} \mathrm{Eu}$ release at $1600^{\circ} \mathrm{C}$ was from Compact 6-2-1, which did not contain any particles with failed SiC. Thus, europium release was not strongly connected with $\mathrm{SiC}$ failure. However, it was strongly connected with safety test temperature, as can be seen from Figure 47. It is not clear whether this trend indicates increased diffusion through the $\mathrm{SiC}$ layer or greater release from the material that accumulated in the matrix and OPyC during irradiation as a result of very long-term in-pile diffusion. Analysis of as-irradiated compacts with DLBL indicated that the amount of europium in the compacts (Figure 9) was comparable to the total released from the compacts during furnace testing and remaining in the compact matrix at the end of the test. Thus, any contribution from diffusive release through the $\mathrm{SiC}$ would be masked.

Strontium release approximately paralleled europium release, but at a lower level (compacts that released more europium also tended to release about the same fraction more strontium). Six compacts exhibited release at $1600^{\circ} \mathrm{C}$ either below or just above one particle's worth of strontium, and three of those (Compacts 3-3-2, 4-1-2, and 6-4-1) had single-particle $\mathrm{SiC}$ failure. Similar to europium, the greatest release at $1600^{\circ} \mathrm{C}$ was from Compact 6-2-1; thus, strontium release also was not obviously coupled to $\mathrm{SiC}$ failure. Recovering and measuring ${ }^{90} \mathrm{Sr}$ from furnace components was difficult, so part of the wider range of releases shown in Figure 43 may be due to incomplete ${ }^{90} \mathrm{Sr}$ recovery or uncertainties in the estimated collection efficiency. Like europium, higher safety test temperatures resulted in greater strontium release.

Post-test furnace component analysis and DLBL showed that europium and strontium were distributed throughout the $\mathrm{OPyC}$, matrix, graphite holder, and tantalum furnace components. This observation, in conjunction with the gradual accumulation on the water-cooled collectors, suggests slow release of europium and strontium from the carbonaceous material (matrix and $\mathrm{OPyC}$ ) rather than large releases from $\mathrm{SiC}$ diffusion during the testing; however, as noted, small diffusive releases through the $\mathrm{SiC}$ cannot be positively ruled out. However, testing at $1800^{\circ} \mathrm{C}$ does offer some evidence that fission product diffusion may be occurring during the heating test.

Two patterns are evident in Figure 48 and Figure 49, which show the 154Eu and 90Sr releases from the four compacts tested at $1800^{\circ} \mathrm{C}$ on a linear scale. As observed in the lower-temperature furnace tests, europium and strontium releases from a given compact tended to track together. Total releases for these four compacts were similar and greater than the $1600^{\circ} \mathrm{C}$ total releases, but the release curves start at a high rate and decrease for Baseline and Variant 1 fuel (Compacts 3-2-3 and 5-1-3, respectively) and do the opposite for the two Variant 3 compacts (implying SiC diffusion in these compacts). Although this behavior has not yet been directly connected to the $\mathrm{SiC}$ microstructure, it is interesting given that the Baseline and Variant $1 \mathrm{SiC}$ layers were deposited using the same deposition conditions (methyltrichlorosilane with hydrogen) and the Variant $3 \mathrm{SiC}$ layers were deposited with the addition of argon gas to produce a finer grain structure (see Section 1.1.1). The $1800^{\circ} \mathrm{C}$ releases were low enough that depletion of the inventory inside the particles would not be significant; therefore, this would not be a reason for the reduction in the release rate from Compacts 3-2-3 and 5-1-3. Interpreting the release patterns in Figure 48 and Figure 49 is complicated by the possible variation in the amount of ${ }^{154} \mathrm{Eu}$ and ${ }^{90} \mathrm{Sr}$ released through intact $\mathrm{SiC}$ and trapped in the compact matrix and $\mathrm{OPyC}$ during irradiation, as it would be available for early release and would be more mobile at this higher temperature. 


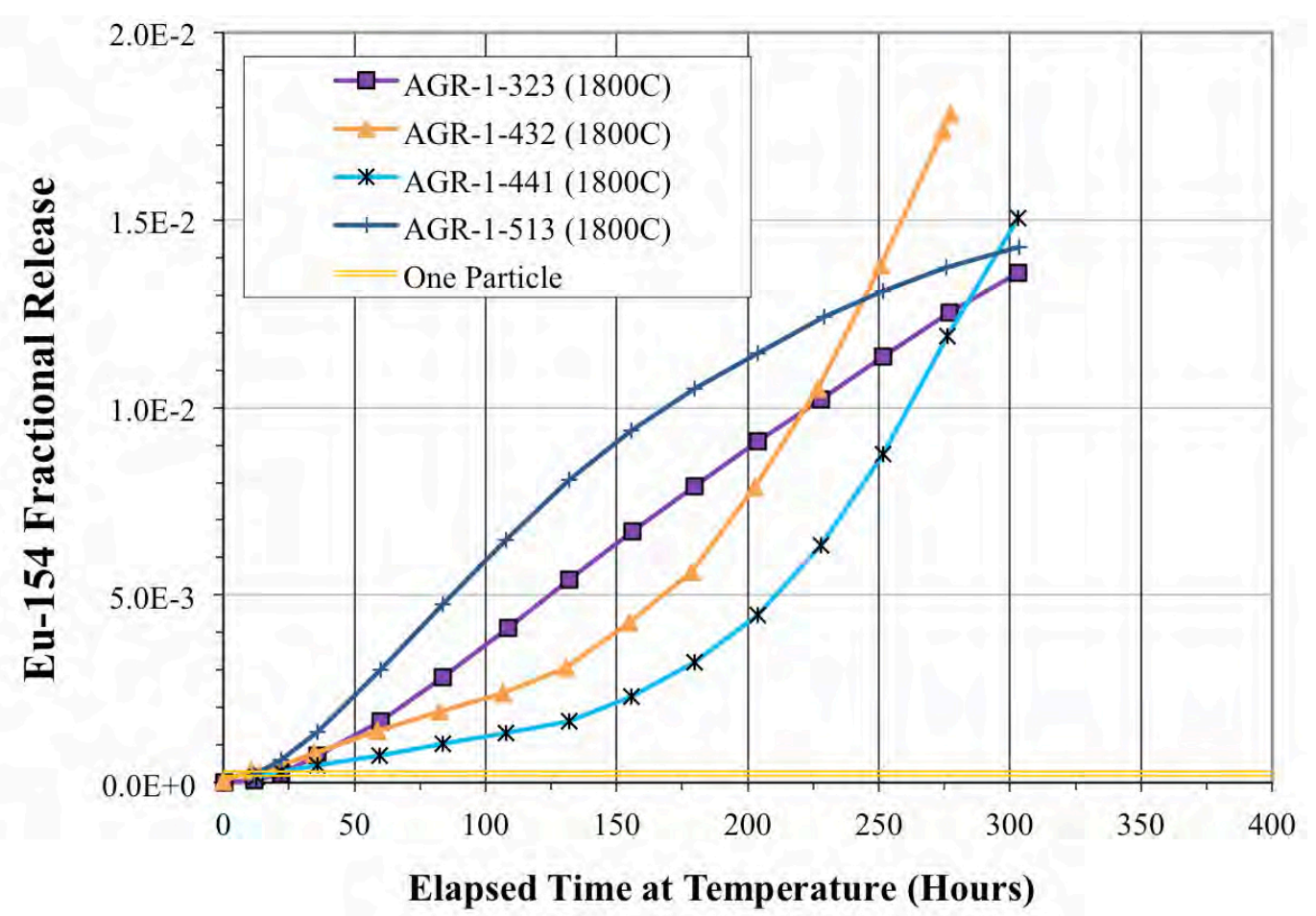

Figure 48. Comparison of the ${ }^{154} \mathrm{Eu}$ release from Baseline and Variant 1 (Compacts 3-2-3 and 5-1-3, respectively) versus Variant 3 Compacts 4-3-2 and 4-4-1; the Variant 3 compact behavior implies a diffusive release.

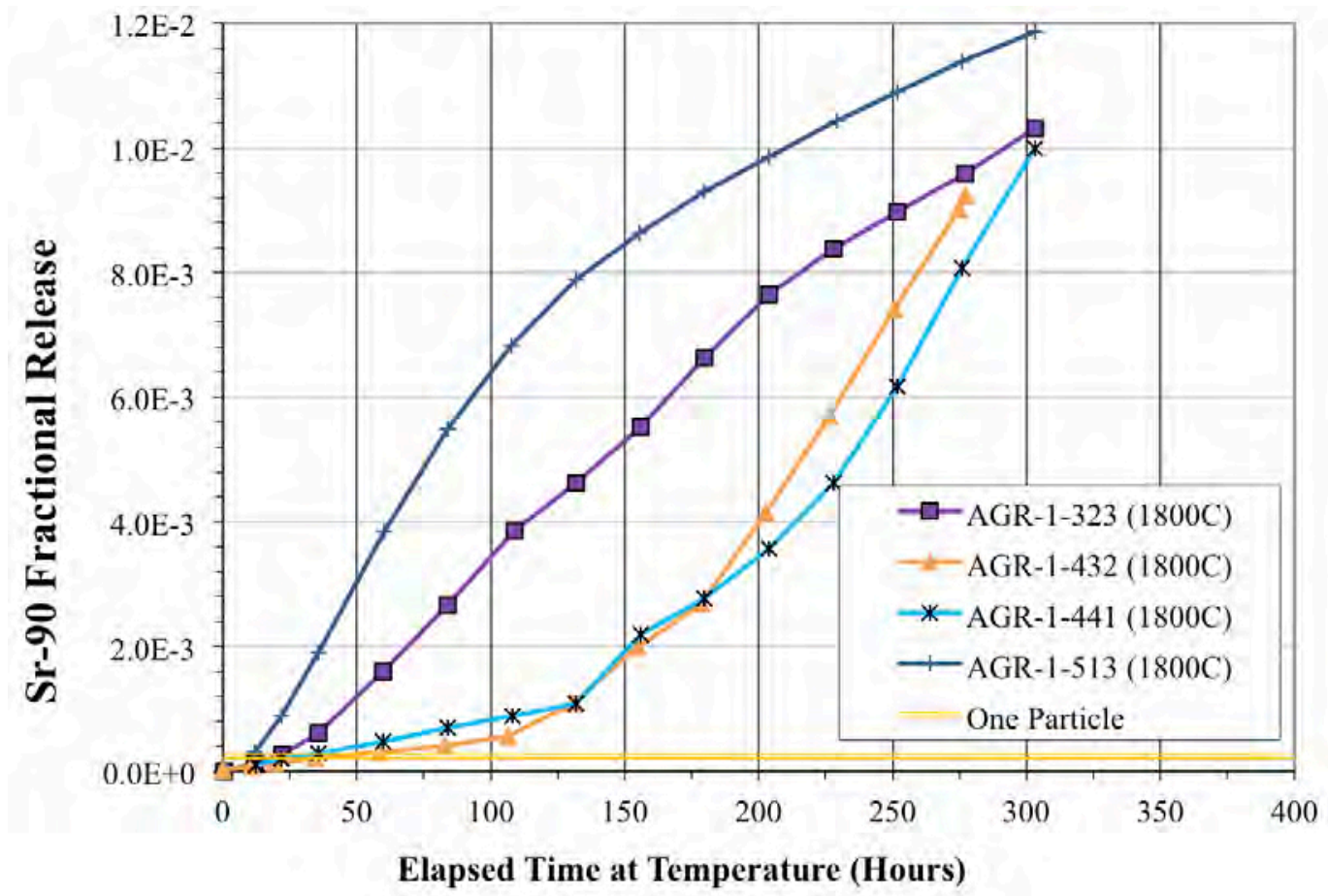

Figure 49. Comparison of the ${ }^{90} \mathrm{Sr}$ release from Baseline and Variant 1 (Compacts $32-3$ and 5-1-3, respectively) versus Variant 3 Compacts 4-3-2 and 4-4-1; this result is consistent with the ${ }^{154} \mathrm{Eu}$ data. 
As illustrated in Figure 50, silver release patterns also showed a difference between the Variant 3 compacts and the compacts with coarser-grained $\mathrm{SiC}$. The increasing release rates in the latter half of the Variant 3 furnace tests imply that diffusive release through intact $\mathrm{SiC}$ may have been occurring at a high enough rate that it was not obscured by contribution from ${ }^{110 \mathrm{~m}} \mathrm{Ag}$ trapped in the OPyC and matrix at the end of irradiation. This again suggests that diffusive behavior at $1800^{\circ} \mathrm{C}$ is significantly higher than at $1600^{\circ} \mathrm{C}$ and that the two $\mathrm{SiC}$ variations may have different behavior at extreme temperatures.

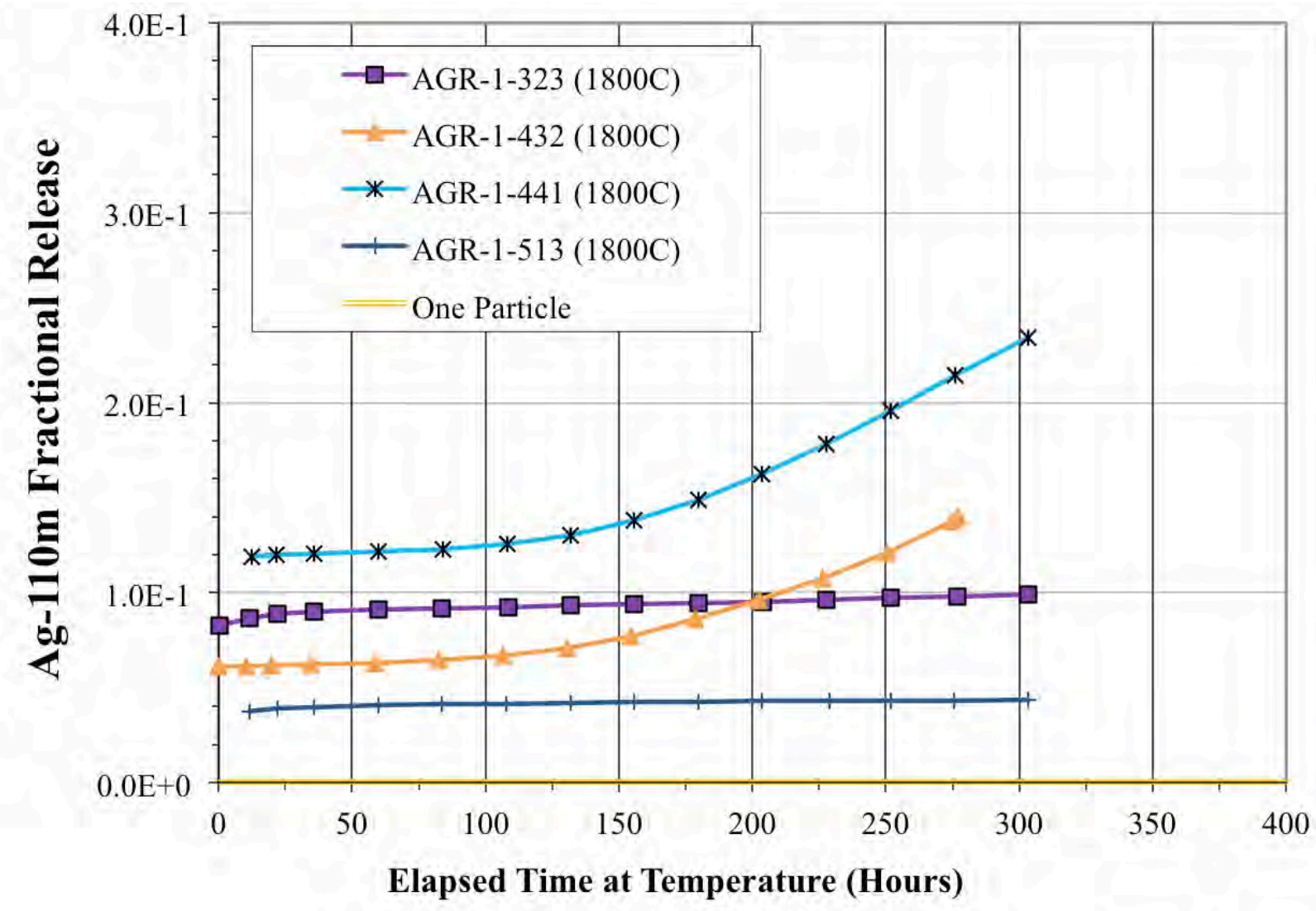

Figure 50. Contrast in silver behavior between Variant 3 (compacts 4-3-2 and 4-4-1) compared to Baseline (Compact 3-2-3) and Variant 1 (Compact 5-1-3). The results are qualitatively similar to Eu and $\mathrm{Sr}$ results.

During the Compact 3-3-2 testing, a furnace malfunction resulted in a sudden temperature drop and the following restart revealed additional silver release even though the silver release had tapered off prior to the malfunction. Subsequent intentional temperature cycling at the end of the test also revealed additional silver release as the temperature cycled between room temperature to $1600^{\circ} \mathrm{C}$. Because of this behavior, an additional test of Compact 4-2-2 was dedicated to study silver release as a function of temperature and thermal cycling. The observed silver collection during this test is shown in Figure 51 (Hunn et. al. 2015b). There was no indication that any particles experienced $\mathrm{SiC}$ failure during this test; the cumulative ${ }^{134} \mathrm{Cs}$ release was less than $0.3 \%$ of one particle's inventory. Therefore, all observed silver can be presumed to have come from previous release of silver during irradiation or thermally driven release through intact $\mathrm{SiC}$. 


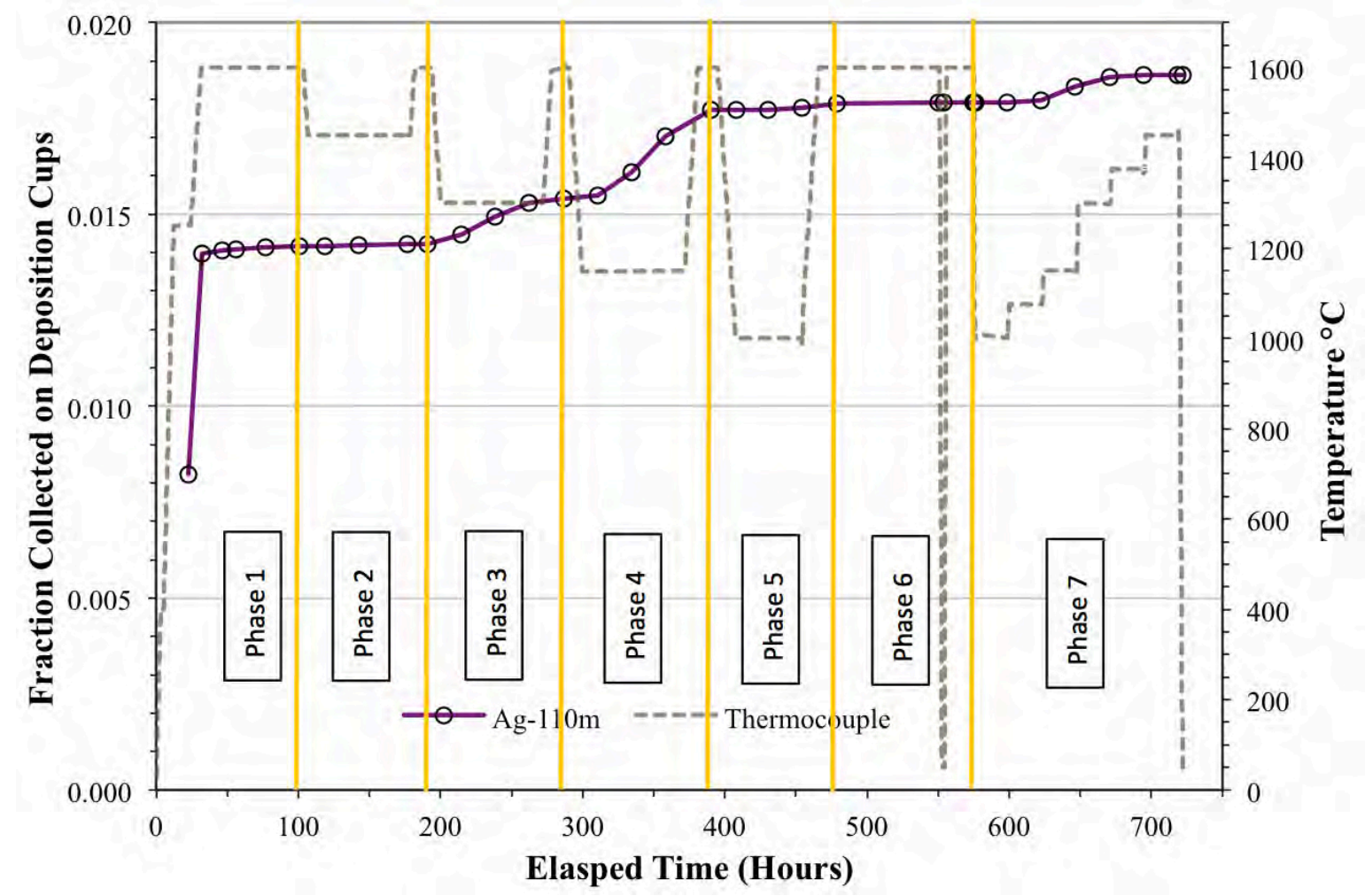

Figure 51. Collection of silver from Compact 4-2-2 during multiple-temperature safety test. The vertical axis shows the amount collected on the deposition cups; because the collection efficiency varied with temperature, this data may not directly scale to compact release.

Compact 4-2-2 was initially heated to a maximum test temperature of $1600^{\circ} \mathrm{C}$ and held for 72 hours. Based on results from previous $1600^{\circ} \mathrm{C}$ tests, this amount of time at $1600^{\circ} \mathrm{C}$ was expected to flush most of the silver out of the compact matrix and $\mathrm{OPyC}$ and deposit it on the deposition cups. Figure 51 shows that $98.7 \%$ of the initial silver release in Phase 1 was detected within the first hour after reaching $1600^{\circ} \mathrm{C}$. Subsequent cups exchanged during this first $1600^{\circ} \mathrm{C}$ hold showed very little additional silver accumulation (only $1.3 \%$ of the total at that point). This agreed with the expectation that silver remaining in the matrix and $\mathrm{OPyC}$ due to release through intact $\mathrm{SiC}$ during irradiation would be released by the initial 72 hour soak at $1600^{\circ} \mathrm{C}$. When the temperature was reduced to $1450^{\circ} \mathrm{C}$ in Phase 2, additional silver collection was negligible. Because the deposition cup collection efficiency at $1450^{\circ} \mathrm{C}$ was not specifically known, the furnace was heated back up to $1600^{\circ} \mathrm{C}$ at the end of Phase 2, where collection efficiency is high, to try to ensure any exposed silver was collected on the last cup in that phase. However, silver accumulation remained negligible, indicating negligible silver was released from the compact at $1450^{\circ} \mathrm{C}$.

In Phase 3, the temperature was dropped to $1300^{\circ} \mathrm{C}$ and significant silver was collected on each cup exchanged during that phase. This was a surprising result, given that silver release had already decreased to negligible levels at higher temperatures. In Phase 4, the process was repeated with an $1150^{\circ} \mathrm{C}$ hold. Again significant additional silver accumulated on the deposition cups (about twice what was detected during the $1300^{\circ} \mathrm{C}$ hold). The increased accumulation of silver during Phases 3 and 4 , after the apparent depletion of silver from the matrix and OPyC during Phases 1 and 2, suggests that additional silver was released through intact $\mathrm{SiC}$ coatings. At the end of Phases 3 and 4, the furnace temperature was raised to $1600^{\circ} \mathrm{C}$, but there was no large increase in silver collection that would indicate that silver released through the $\mathrm{SiC}$ at 1150 and $1300^{\circ} \mathrm{C}$ was significantly held up in the $\mathrm{OPyC}$ or matrix, or trapped elsewhere in the furnace and released to the cup as the temperature was raised. 
Figure 52 shows the average ${ }^{110 \mathrm{~m}} \mathrm{Ag}$ collection rate (fraction collected on each cup divided by the residence time). This shows how the silver collection rate rapidly dropped off after the first hour at $1600^{\circ} \mathrm{C}$ and stayed low through the remainder of Phases 1 and 2.

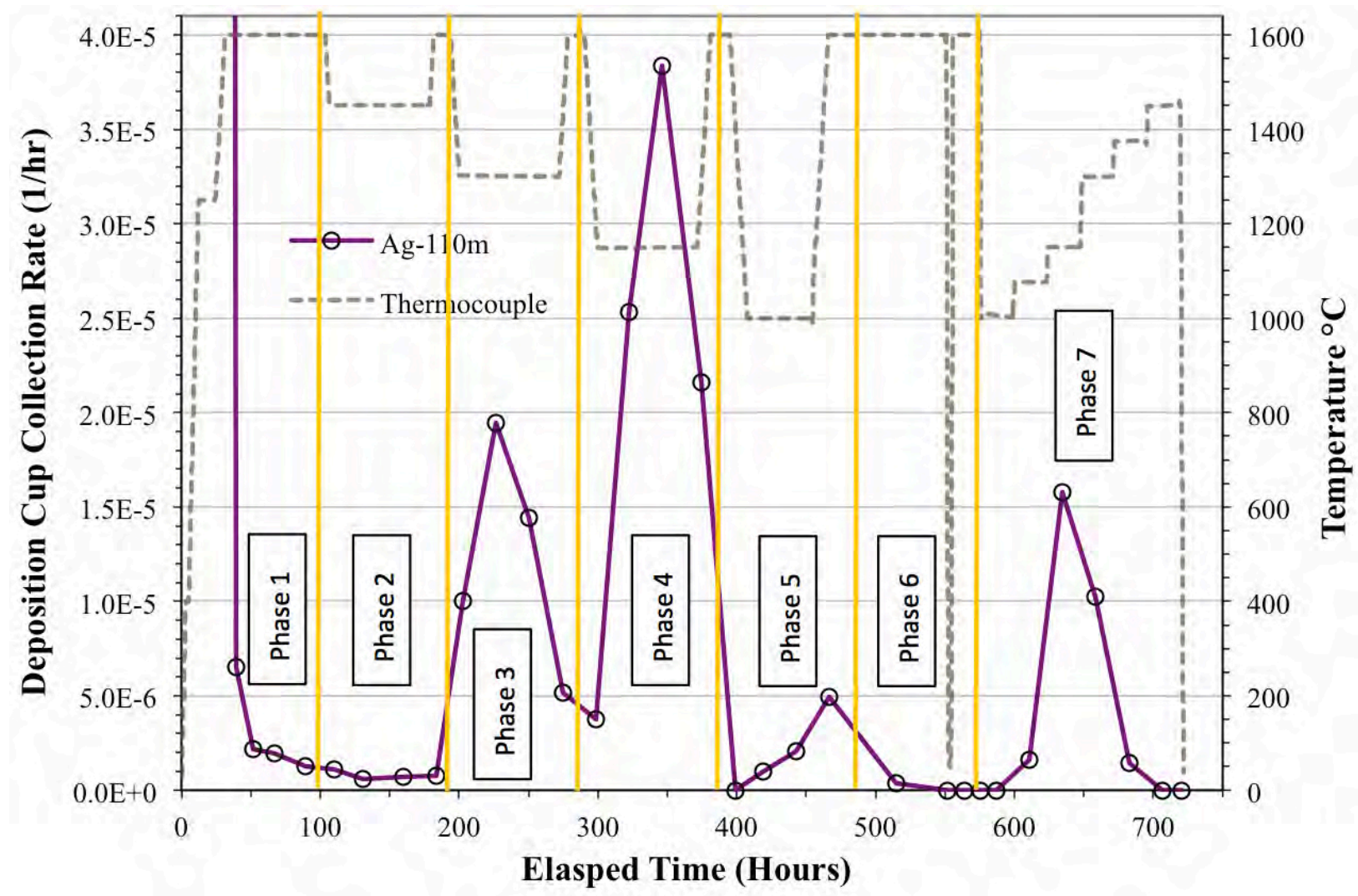

Figure 52. Collection rate of silver from Compact 4-2-2 test. Note the temperature dependence.

At the beginning of Phase 3, the silver collection rate increased dramatically. The first Phase 3 cup only collected about half the silver as the second cup, but this was biased by the fact that the furnace was cooled slowly and was only at $1300^{\circ} \mathrm{C}$ for the latter $58 \%$ of the first collection period. (Collection periods during Phases 1-5 were $\sim 24$ hours each.) The fourth Phase 3 cup had a lower average collection rate than the others because the furnace was only at $1300^{\circ} \mathrm{C}$ for the first $42 \%$ of the fourth collection period. Very little silver was collected on the first Phase 4 cup, partially due to the slow cooldown limiting the dwell time at lower temperature, but also probably due to a slower migration of silver to the deposition cup at $1150^{\circ} \mathrm{C}$ resulting in a delay period before silver released from the particles started collecting on the cups. The average collection rate increased during the second and third collection periods at $1150^{\circ} \mathrm{C}$, eventually reaching a rate almost double that observed at $1300^{\circ} \mathrm{C}$. The fourth Phase 4 cup had a $56 \%$ lower average collection rate than the previous cup, but it was only at $1150^{\circ} \mathrm{C}$ for about $41 \%$ of the collection period, so this seems to indicate the silver release rate remained near its peak until the furnace was heated above $1150^{\circ} \mathrm{C}$ and the rate dropped to that observed at higher tempertures. 
During the Phase 5 hold at $1000^{\circ} \mathrm{C}$, the silver collection rate dropped below that observed at 1300 and $1150^{\circ} \mathrm{C}$, but not as low as observed at 1450 and $1600^{\circ} \mathrm{C}$. The rate continued to increase throughout Phase 5, again indicating a delay in the transport of silver to the deposition cups at the lower test temperatures; this is not surprising since the silver vapor pressure drops exponentially as the melting point $\left(962^{\circ} \mathrm{C}\right)$ is approached. The average collection rate at the end of Phase 5 was probably positively biased by the time spent in the temperature range between 1150 and $1300^{\circ} \mathrm{C}$ during the ramp back to $1600^{\circ} \mathrm{C}$.

Phase 6 involved another 72-hour hold at $1600^{\circ} \mathrm{C}$, during which silver release continued to be negligible, followed by a quick thermal cycle to room temperature and back. No measurable silver release was detected after this thermal cycle. In an attempt to separate the steady state release observed in the earlier test phases from possible transient effects, the ramp rate for this thermal cycle was increased to reduce the dwell time at temperatures around 1150 and $1300^{\circ} \mathrm{C}$. This thermal cycle test was performed to explore the conditions that led to secondary silver release in earlier tests (e.g. the Compact 3-3-2 safety test). In those earlier tests, the ramp rate back to temperature was almost ten times slower; so it appears that the silver release in those earlier test may have also occurred when the compacts were at temperatures around 1150 and $1300^{\circ} \mathrm{C}$.

In Phase 7, the temperature was dropped to $1000^{\circ} \mathrm{C}$ using the same rapid ramp rate, and then stepped back up to $1450^{\circ} \mathrm{C}$ in 24 -hour intervals. Negligible silver was deposited on the cups at 1000 and $1075^{\circ} \mathrm{C}$, silver collection rate peaked at $1150^{\circ} \mathrm{C}$ and remained high at $1300^{\circ} \mathrm{C}$; deposition dropped off again at $1375^{\circ} \mathrm{C}$, and was negligible at $1450^{\circ} \mathrm{C}$. The Phase 7 releases agreed with the earlier results and further refined the temperature range at which silver release appeared to be active.

The other collected isotopes (Eu, Sr, Cs) did not show this behavior; the amount collected was greater with increasing temperatures. This does not necessarily indicate europium and strontium were being released through intact $\mathrm{SiC}$ at $1600^{\circ} \mathrm{C}$, but more likely it indicates a temperature-dependent reduction in the transport rate of europium and strontium from the matrix and $\mathrm{OPyC}$, through the graphite holder, and to the deposition cups.

\subsection{Safety Test Results Summary}

In conclusion, an extensive series of high-temperature, inert-atmosphere testing was undertaken using irradiated compacts from the AGR-1 experiment (Petti et al. 2010). Results from furnace tests on 15 compacts $(\sim 62,000$ particles) were summarized in this section. Three UCO fuel types with minor coating variations in the $\mathrm{IPyC}$ or $\mathrm{SiC}$ were tested from $1600-1800^{\circ} \mathrm{C}$. All compacts performed well at these temperatures for testing periods of $\sim 300$ or more hours; a radar graph summary of the release fractions is shown in Figure 53. Cesium and krypton releases were dominated by a small number of $\mathrm{SiC} / \mathrm{TRISO}$ failures (Section 5.4 presents a summary of coating failure fractions determined for each test temperature). Silver, strontium, and europium appear to come mostly from the matrix inventory accumulated during irradiation, but some diffusion through the $\mathrm{SiC}$ at the higher temperatures is probably occurring. Europium and strontium release from the compacts increased with safety test temperature, and this was related to retention of these elements by the carbonaceous material in the matrix (as well as apparent diffusion through intact $\mathrm{SiC}$ in some compacts at the higher test temperatures). Silver release was relatively independent of test temperature due to the fact that it was not well-retained by the carbonaceous material and rapidly migrated out of the matrix at all test temperatures. 


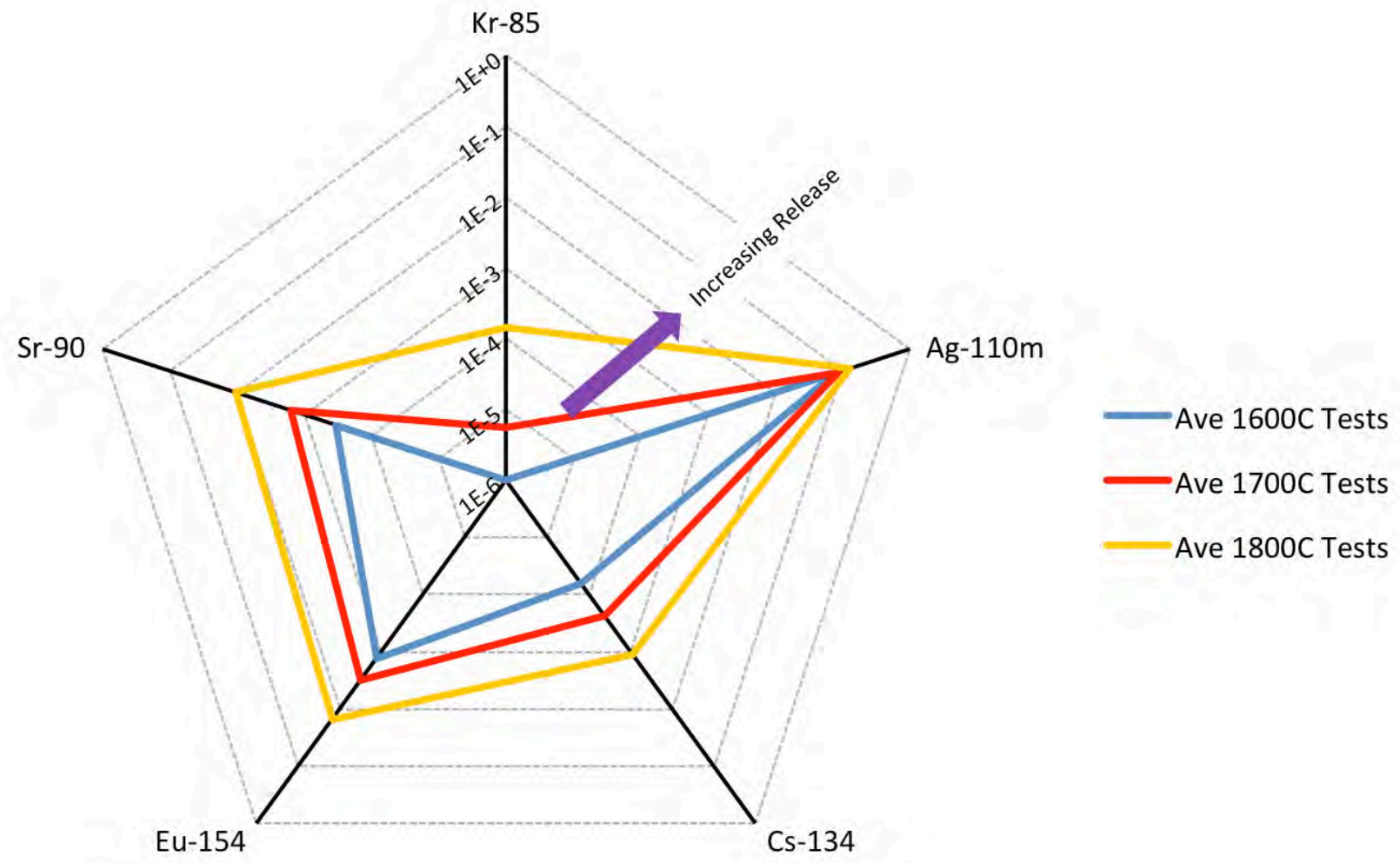

Figure 53. Summary of the average release fractions at the end of the safety tests for the three test temperatures. The general trend was a gradual increasing release with temperature, except for silver, which was almost independent of test temperature. Cesium release was an indicator of SiC failure, and krypton release was related to the same $\mathrm{SiC}$ failure (with highest release from Compact 4-3-2 due to concurrent TRISO failure).

\subsection{Loose particle heating test}

A special test was conducted where 75 particles deconsolidated from Compact 4-4-2 were heated to $1800^{\circ} \mathrm{C}$ for $\sim 650$ hours (Hunn et al. $2015 \mathrm{c}$ ). This test showed an increased release of silver, europium, and strontium after about 150 hours at $1800^{\circ} \mathrm{C}$ (Figure 54). The onset of this same behavior was previously indicated during $1800^{\circ} \mathrm{C}$ safety testing of Compacts 4-4-1 and 4-3-2 (Figure 48, Figure 49, and Figure 50). This release appears to be due to thermally induced diffusion through intact SiC (only five particles in the loose-particle test experienced $\mathrm{SiC}$ failure). At the end of the loose-particle test, the silver release began to decrease, presumably due to depletion of the available silver in the particles. 


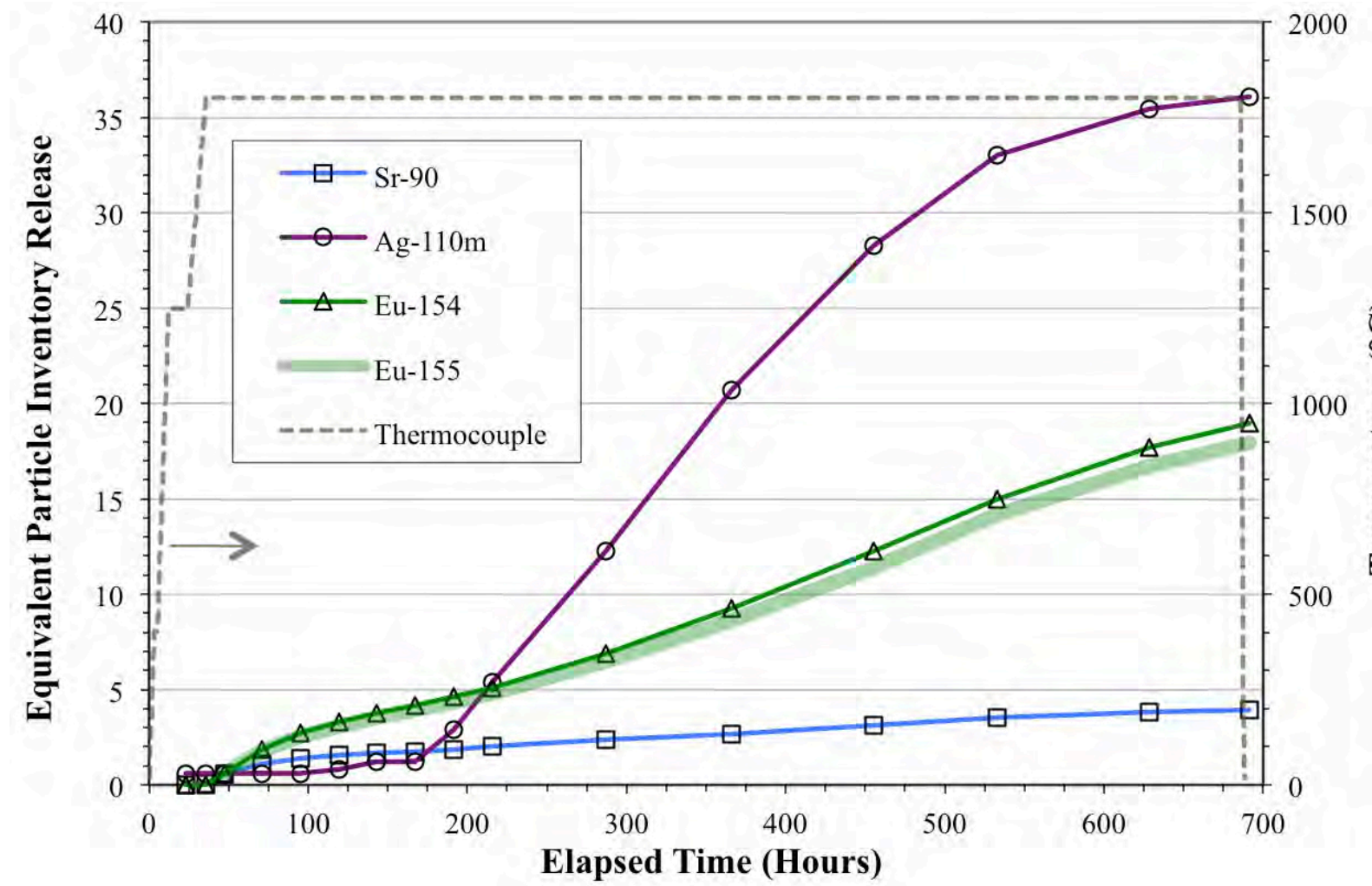

Figure 54. Cumulative release of silver, europium, and strontium from Compact 4-4-2 loose particles at $1800^{\circ} \mathrm{C}$.

Because this test was run on loose particles, it was possible to use IMGA to measure the individual particle inventories before and after the heating test. Prior to initiating the loose-particle test, all particles had measurable ${ }^{110 \mathrm{~m}} \mathrm{Ag}$ inventory; after the test, only six particles retained a measurable inventory (Figure 55). Figure 56 is a plot of the fraction of each of the other measured radioisotopes retained in each particle. Five particles exhibited $0-1 \%$ Cs retention due to full-TRISO failure; these particles also released various amounts of other fission products. The presence of these particles was indicated by significant releases of cesium and krypton that were detected during safety testing, and all five particles were recovered intact and verified to be responsible for the observed cesium release by IMGA. Further analysis of these five particles and discussion about the abnormal TRISO failure, which was presumably related to prior electrolytic deconsolidation and subsequent heating without the surrounding compact matrix, are available in Hunn et al. 2015c. Not counting the five abnormal particles, there was no measurable release of ${ }^{106} \mathrm{Ru},{ }^{134} \mathrm{Cs},{ }^{137} \mathrm{Cs}$, or ${ }^{144} \mathrm{Ce}$ from the remaining 70 particles; the average retention fraction for these isotopes was close to $100 \%$. The average retention fraction for ${ }^{125} \mathrm{Sb}$ was $96 \%$, but this deviation from $100 \%$ may not be significant compared to the measurement uncertainty. However, an average retention fraction for ${ }^{154} \mathrm{Eu}$ of $89 \%$ appears to indicate a measurable release of europium from the particles, in agreement with the indication for measurable diffusive release of europium in Figure 54. (Figure 56 shows this general downward shift in europium activity after the safety test, as well as an increased variability in the retention fraction compared to the other plotted isotopes.) 

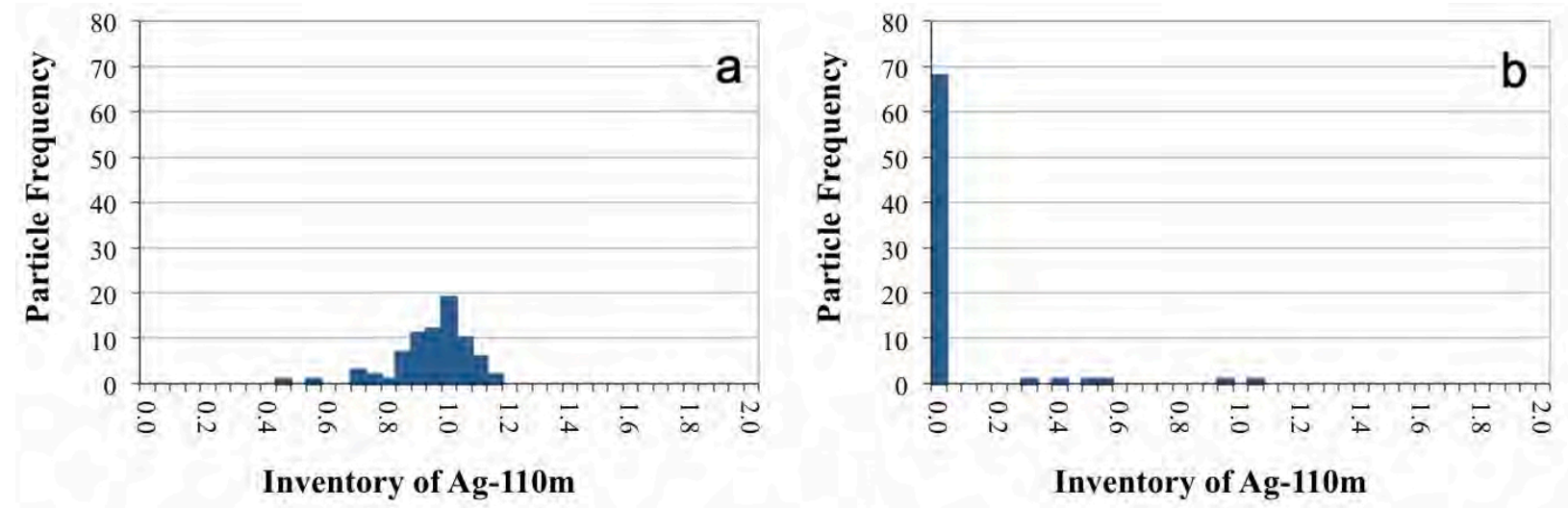

Figure 55. Ratio of measured ${ }^{110 \mathrm{~m}} \mathrm{Ag}$ retained in 75 particles versus calculated inventory, adjusted for variation in fissionable material and burnup with the measured ${ }^{106} \mathrm{Ru}$ activity; (a) as-irradiated and (b) after $1800^{\circ} \mathrm{C}$ heating test (detection limit at the end of the test was $\mathrm{M} / \mathrm{C}<0.21-0.41$ ).

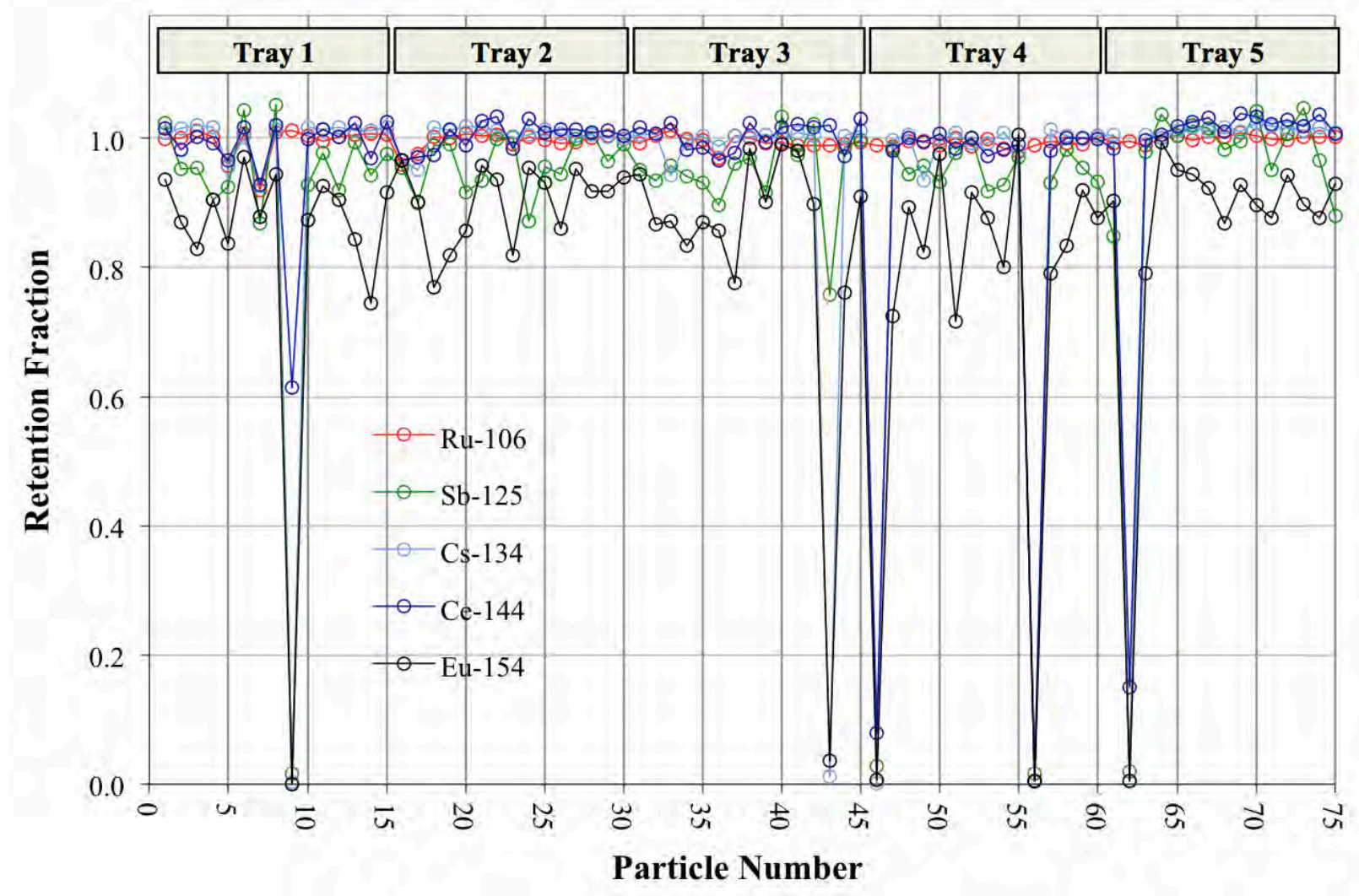

Figure 56. Radioisotope retention fraction of 75 particles after $1800^{\circ} \mathrm{C}$ safety testing.

\subsection{Post-Test Analysis}

\subsubsection{Fission Product Distributions (DLBL, IMGA)}

After safety testing, DLBL and IMGA measurements were performed on many of the safety-tested compacts, using the same methods applied to as-irradiated compacts. Detailed results of these analyses can be found in the post-safety test PIE summary reports for each compact (Table 16 and Table 17).

Table 19 is a summary of the measured inventories of fission products located in the compacts outside of 
the $\mathrm{SiC}$ layer after safety testing; these values can be compared to what was measured by DLBL in the as-irradiated compacts (Table 11). In some compacts, one or more particles were damaged during DLBL analysis, resulting in exposed kernels; this was indicated by elevated uranium levels (shown in red in Table 19). This damage was often related to cracking of the OPyC layer in particles with failed $\mathrm{SiC}$ (see Section 5), where all that protected the kernel from acid leaching was this last intact structural pyrocarbon layer. Samples with exposed kernels also exhibited noticeably elevated levels of other isotopes.

Table 19. Fractional inventory of fission products in the DLBL solutions after safety testing.

\begin{tabular}{|c|c|c|c|c|c|c|c|c|}
\hline Compact & Test ${ }^{\circ} \mathrm{C}$ & ${ }^{110 \mathrm{~m}} \mathrm{Ag}$ & ${ }^{144} \mathrm{Ce}$ & ${ }^{134} \mathrm{Cs}$ & ${ }^{154} \mathrm{Eu}$ & ${ }^{105} \mathrm{Pd}$ & ${ }^{90} \mathrm{Sr}$ & ${ }^{238} \mathrm{U}$ \\
\hline $3-2-2$ & 1600 & $9.2 \mathrm{E}-5$ & $1.0 \mathrm{E}-3$ & $3.3 \mathrm{E}-4$ & $2.0 \mathrm{E}-3$ & $1.3 \mathrm{E}-4$ & $1.0 \mathrm{E}-3$ & $1.1 \mathrm{E}-3$ \\
\hline $3-2-3$ & 1800 & $<2.6 \mathrm{E}-3$ & $1.1 \mathrm{E}-3$ & $6.7 \mathrm{E}-4$ & $1.0 \mathrm{E}-3$ & $1.7 \mathrm{E}-4$ & $9.5 \mathrm{E}-4$ & $8.6 \mathrm{E}-4$ \\
\hline $3-3-1$ & 1700 & $<9.6 \mathrm{E}-4$ & $2.0 \mathrm{E}-4$ & $2.1 \mathrm{E}-4$ & 8.0E-4 & $5.6 \mathrm{E}-5$ & $6.2 \mathrm{E}-4$ & $1.1 \mathrm{E}-4$ \\
\hline $3-3-2$ & 1600 & $<8.8 \mathrm{E}-4$ & 4.9E-4 & $2.8 \mathrm{E}-6$ & $1.5 \mathrm{E}-3$ & $1.3 \mathrm{E}-5$ & $4.5 \mathrm{E}-4$ & $2.5 \mathrm{E}-4$ \\
\hline $4-1-2$ & 1600 & $<3.3 \mathrm{E}-4$ & $6.6 \mathrm{E}-5$ & $3.4 \mathrm{E}-6$ & $3.9 \mathrm{E}-4$ & $2.0 \mathrm{E}-5$ & $1.2 \mathrm{E}-4$ & $1.6 \mathrm{E}-5$ \\
\hline $4-2-2$ & 1600 & $<1.8 \mathrm{E}-3$ & $4.5 \mathrm{E}-5$ & $1.9 \mathrm{E}-5$ & $1.3 \mathrm{E}-3$ & $2.1 \mathrm{E}-5$ & $5.0 \mathrm{E}-4$ & $5.3 \mathrm{E}-5$ \\
\hline $4-4-1$ & 1800 & $<2.1 \mathrm{E}-3$ & $3.3 \mathrm{E}-3$ & $3.4 \mathrm{E}-4$ & $2.0 \mathrm{E}-3$ & $5.5 \mathrm{E}-5$ & $1.1 \mathrm{E}-3$ & $1.2 \mathrm{E}-3$ \\
\hline $4-4-3$ & 1700 & $<4.3 \mathrm{E}-4$ & $6.5 \mathrm{E}-5$ & $2.0 \mathrm{E}-6$ & $1.2 \mathrm{E}-3$ & $<5.9 \mathrm{E}-5$ & $2.8 \mathrm{E}-4$ & $1.6 \mathrm{E}-5$ \\
\hline $5-1-1$ & 1700 & $<6.4 \mathrm{E}-3$ & $1.6 \mathrm{E}-3$ & $5.3 \mathrm{E}-5$ & $3.1 \mathrm{E}-3$ & $1.7 \mathrm{E}-4$ & $3.1 \mathrm{E}-3$ & $2.5 \mathrm{E}-4$ \\
\hline $5-1-3$ & 1800 & $<2.6 \mathrm{E}-3$ & $3.6 \mathrm{E}-3$ & $5.6 \mathrm{E}-4$ & 7.4E-4 & $2.3 \mathrm{E}-4$ & $5.5 \mathrm{E}-4$ & $1.2 \mathrm{E}-3$ \\
\hline $5-3-3$ & 1600 & $5.0 \mathrm{E}-4$ & 4.7E-4 & $2.9 \mathrm{E}-6$ & $1.9 \mathrm{E}-3$ & $1.4 \mathrm{E}-4$ & $6.6 \mathrm{E}-4$ & $2.8 \mathrm{E}-5$ \\
\hline $6-2-1$ & 1600 & $<9.2 \mathrm{E}-4$ & $2.8 \mathrm{E}-4$ & $6.0 \mathrm{E}-8$ & 4.6E-3 & $5.2 \mathrm{E}-5$ & $8.5 \mathrm{E}-4$ & $5.2 \mathrm{E}-5$ \\
\hline $6-4-3$ & 1600 & $5.8 \mathrm{E}-4$ & $8.1 \mathrm{E}-6$ & $3.1 \mathrm{E}-6$ & $1.9 \mathrm{E}-3$ & $<1.9 \mathrm{E}-3$ & $1.8 \mathrm{E}-5$ & $8.0 \mathrm{E}-5$ \\
\hline $4-3-3$ & 1600 & $<3.2 \mathrm{E}-3$ & $6.9 \mathrm{E}-4$ & $9.5 \mathrm{E}-6$ & $9.3 \mathrm{E}-4$ & $4.2 \mathrm{E}-5$ & 4.4E-4 & $2.1 \mathrm{E}-5$ \\
\hline \multicolumn{9}{|c|}{$\begin{array}{l}\text { Values are the summation of fission products leached in two pre-burn leaches and two post-burn leaches. Shaded rows } \\
\text { indicate compacts known to have one or more particles with failed SiC. A fraction of } 2.4 \mathrm{E}-4 \text { corresponds to the equivalent } \\
\text { inventory of a single particle. Uranium values in red indicate particles were damaged and kernels exposed during DLBL, } \\
\text { which also resulted in a noticeable bias for some other isotopes. }\end{array}$} \\
\hline
\end{tabular}

The inventory of ${ }^{110 \mathrm{~m}} \mathrm{Ag}$ remaining in the matrix and $\mathrm{OPyC}$ after safety testing (Table 19) was significantly less than what was typically measured in as-irradiated compacts (Table 11). This agrees with the conclusion based on the rapid release behavior during safety testing that silver in these carbonaceous materials was not well retained at the safety testing temperatures, and whatever not contained by the SiC freely moved out of the heated compact. The same observation also applies to palladium.

For those compacts that did not have exposed kernels due to particles breaking during DLBL, the inventory of ${ }^{134} \mathrm{Cs}$ remaining in the matrix and OPyC after safety testing (Table 19) was very low and similar to what was typically measured in as-irradiated compacts (Table 11). This supports the conclusion that cesium was very well retained by intact $\mathrm{SiC}$. As mentioned above, many of the kernels that were exposed and leached during DLBL were from particles whose SiC layers failed during safety testing. The fact that significant fractions of cesium were detected when these kernels were dissolved in acid indicates that the kernels apparently retained significant fractions of their cesium throughout the safety test, even though the $\mathrm{SiC}$ retention properties were degraded.

It is difficult to draw conclusions from the comparison of europium, strontium, and cerium values reported in Table 19 and Table 11. SiC failure and DLBL damage impacted these values, but measured values in the absence of these effects were in the same range as the additional contribution from exposed kernels. The expected reduction in the measured values after safety testing was not significant enough to resolve given the compact-to-compact variability in the measured values in the as-irradiated compacts. 
With the exception of particles that exhibited $\mathrm{SiC}$ failure, there were no resolvable differences between IMGA-measured ${ }^{106} \mathrm{Ru},{ }^{125} \mathrm{Sb},{ }^{134} \mathrm{Cs},{ }^{144} \mathrm{Ce}$, and ${ }^{154} \mathrm{Eu}$ inventories in safety-tested particles compared to those measured in the as-irradiated condition. Inventory distributions were narrow and centered on the expected full-inventory values (taking into account the bias between predicted and measured values, discussed in Section 3.3.2.2) after safety testing, similar to what was observed in the as-irradiated samples (Figure 12). This result is not surprising, given that general particle release would have to be greater than $\sim 5 \%$ before it could be resolved by IMGA, and the DLBL and furnace release data indicate that if there was any release through intact $\mathrm{SiC}$ during safety testing, it was below this level, even at $1800^{\circ} \mathrm{C}$.

As discussed in Section 3.2.2, silver inventory varied dramatically from compact to compact and often from particle to particle within a single compact (Figure 11). IMGA measurement of the silver distribution in randomly selected particle samples recovered from safety-tested compacts showed a similar character. Because of the large variation before and after safety testing, it is difficult to draw any conclusions from the IMGA results for ${ }^{110 \mathrm{~m}} \mathrm{Ag}$ regarding whether individual particles released silver during safety testing.

\subsubsection{Microstructure Evolution and Fission Product Distribution}

4.8.2.1 X-ray Tomography. X-ray tomography was performed on safety-tested particles from the randomly selected long-count IMGA subsamples discussed in Section 4.8.1 according to the method discussed in (Hunn et al. 2013). X-ray tomography is a nondestructive technique, which allows for 3 -D visualization of the TRISO particle internal structure. Particle selection for x-ray tomography analysis was based on the individual particle's ${ }^{110 \mathrm{~m}} \mathrm{Ag} \mathrm{M} / \mathrm{C}$ inventory fraction. Particles were often selected from the "undetectable" silver subpopulation and the "average" or "above-average" silver subpopulation. This provided an opportunity to compare the TRISO particle's internal structure with the particle's silver retention performance. The interplay between buffer densification/IPyC delamination and internal layer integrity, as well as kernel protrusions and fission product distribution, were areas of interest concerning x-ray tomography analysis of safety-tested particles.

$\mathrm{X}$-ray tomography was conducted on select particles from $1600^{\circ} \mathrm{C}$ safety-tested Compacts 6-4-3, 3-2-2, 6-2-1, 4-1-2, and 5-3-3. Figure 57 shows a comparison of $\mathrm{x}$-ray tomographs between particles with undetectable $(\mathrm{M} / \mathrm{C}<0.22)$ and average $(\mathrm{M} / \mathrm{C}=0.88){ }^{110 \mathrm{~m}} \mathrm{Ag}$ retention from Compact 5-3-3. Both particles in Figure 57 show the typical layer behavior observed in as-irradiated particles and discussed in Section 3.4.1; that is, radiation-induced buffer densification and delamination from the IPyC layer. Figure 57 also identifies localized areas of fission product pileup at the IPyC-SiC interface. Occasionally, local areas of the buffer/IPyC interface did not completely delaminate or small "tendrils" remained after delamination connecting the buffer and IPyC layer. In some cases when the buffer did not delaminate and the buffer/IPyC layer remained in intimate contact, fracture of the buffer occurred and led to large open volumes within the particle interior. These particle types were also discussed in Section 3.4.1 (Hunn et al. 2012b; Hunn et al. 2012c; Hunn et al. 2013b; Hunn et al. 2014c). The observed internal layer structure of the analyzed TRISO particles from the $1600^{\circ} \mathrm{C}$ safety tests indicated no correlation in layer structure with the ${ }^{110 \mathrm{~m}} \mathrm{Ag}$ retention behavior, as all types of structures were observed regardless of M/C (Hunn et al. 2012b; Hunn et al. 2012c; Hunn et al. 2013b; Hunn et al. 2014c). 

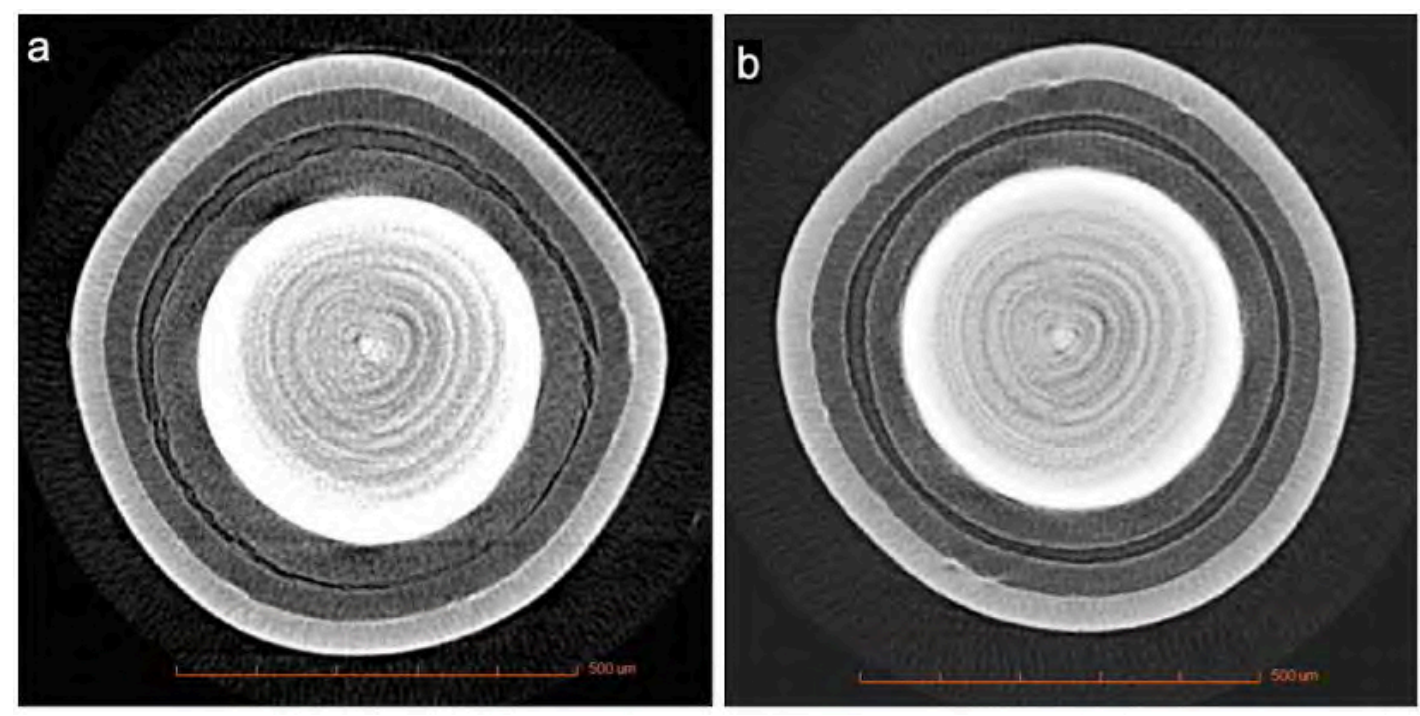

Figure 57. X-ray tomographs near midplane of Compact 5-3-3 particles, safety-tested at $1600^{\circ} \mathrm{C}$ : (a) particle with undetectable ${ }^{110 \mathrm{~m}} \mathrm{Ag}$ inventory $(\mathrm{M} / \mathrm{C}<0.22)$, and (b) particle with average ${ }^{110 \mathrm{~m}} \mathrm{Ag}$ inventory $(\mathrm{M} / \mathrm{C}=0.88)$. Bright features at the IPyC-SiC interface are fission products. Rings in kernel are tomography artifacts.

Particles analyzed by x-ray tomography from $1700^{\circ} \mathrm{C}$ safety tests included particles from Compacts 3-3-1, 4-4-3, and 5-1-1. Similar to the $1600^{\circ} \mathrm{C}$ safety-tested particles, no correlation between silver retention and internal particle structure was observed (Hunn et al. 2013b; Hunn et al. 2014c, Hunn et al. 2015a). The internal layer structure consisted of radiation-induced densification of the buffer with buffer delamination from the IPyC layer, which was consistent with the $1600^{\circ} \mathrm{C}$ safety-tested particles and as-irradiated particles. Select particles presented delamination of the buffer from the IPyC layer leading to buffer fracture. Excess dense fission product material was sometimes observed in the open volume generated by the buffer fracture. This is shown in Figure 58 where the bright areas in the buffer are associated with high-Z fission product features (Hunn et al. 2013b). Pileup of fission products at the IPyC-SiC interface was also suggested from x-ray tomography analysis of the $1700^{\circ} \mathrm{C}$ particles, which is consistent with the observations from $1600^{\circ} \mathrm{C}$ safety-tested particles (Hunn et al. 2013b).
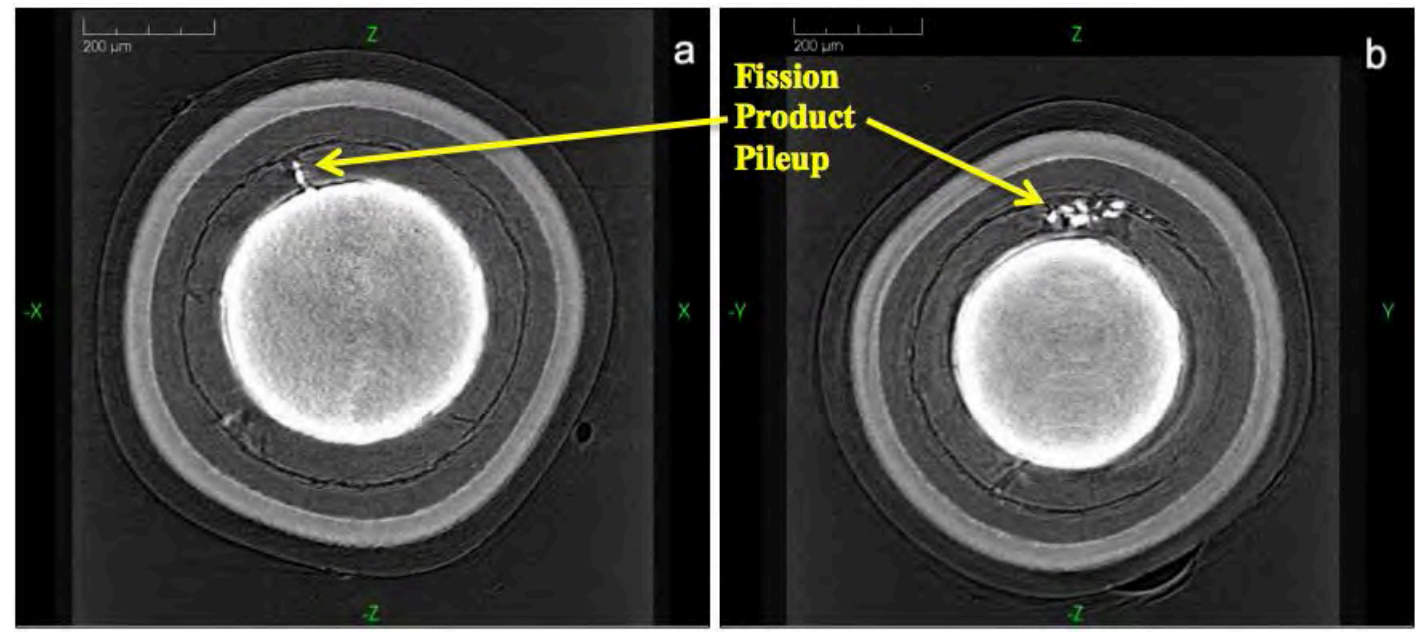

Figure 58. Orthogonal x-ray tomographs of a Compact 3-3-1 particle, safety tested at $1700^{\circ} \mathrm{C}$ with average ${ }^{110 \mathrm{~m}} \mathrm{Ag}$ inventory near midplane (a) and offset from midplane (b) showing a fractured buffer, but no apparent IPyC damage. Bright features in the fractured buffer are fission product buildup. 
X-ray tomography analysis was performed on particles from the $1800^{\circ} \mathrm{C}$ safety-tested Compacts 4-4-1, 5-1-3, and 3-2-3. Again, no correlation between internal particle structure and silver retention performance was noted and the internal particle structure displayed the typical radiation-induced buffer densification and IPyC delamination behavior (Hunn et al. 2014a). One structural variation identified in the $1800^{\circ} \mathrm{C}$ safety-tested particles by x-ray tomography was a larger gap between the $\mathrm{SiC}$ and OPyC layer, as is shown in Figure 59 (Hunn et al. 2013b). The presence of this gap is contrary to the generally accepted prediction that the OPyC layer shrinks to put a compressive stress on the $\mathrm{SiC}$ layer. It appears that a gap between the $\mathrm{SiC}$ and $\mathrm{OPyC}$ forms during irradiation due to radiation-induced shrinkage of the compact matrix. This is because the interfacial bond strength is higher between the porous OPyC layer and matrix than between the dense $\mathrm{SiC}$ and OPyC layers, causing the OPyC to pull away from the $\mathrm{SiC}$ as the compact matrix shrinks (Hunn et al. 2013b; Hunn et al. 2015a). The gap widens with increasing safety test temperature to the point that it can be resolved by $\mathrm{x}$-ray. The presence of a $\mathrm{SiC} / \mathrm{OPyC}$ gap is also suggested by $\mathrm{x}$-ray tomography in analyzed particles from the $1700^{\circ} \mathrm{C}$ safety-tests (Hunn et al. 2013b; Hunn et al. 2015a) and clearly shown in the optical micrographs presented below. Other features of interest noted in the x-ray tomography analysis of $1800^{\circ} \mathrm{C}$ safety-tested particles were unusually large fission product buildup in the buffer fracture areas of select particles and localized areas of heavy fission product pileup at the IPyC-SiC interface. The magnitude of the fission product pileup at the IPyC-SiC interface appears to be greater than that which is observed for particles exposed to lower safety testing temperatures (Hunn et al. 2014a) or as-irradiated particles. These observations suggest that fission products are being significantly redistributed at $1800^{\circ} \mathrm{C}$.

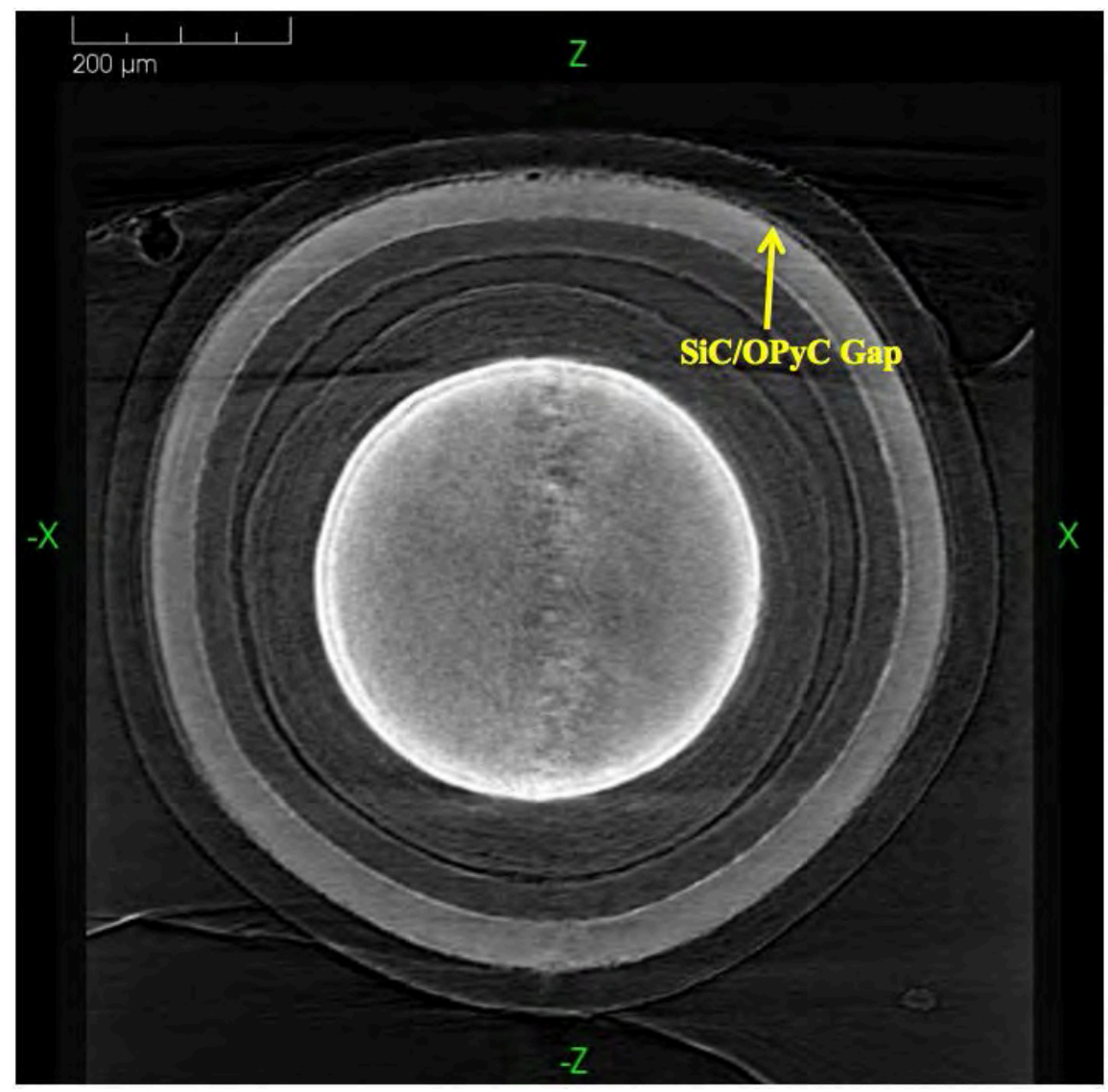

Figure 59. X-ray tomograph near midplane of an $1800^{\circ} \mathrm{C}$ safety-tested Compact 4-4-1 particle with low silver retention, showing the typical buffer densification and delamination from the IPyC, as well as a $\mathrm{SiC} / \mathrm{OPyC}$ gap. 
The 3-D x-ray tomography analysis of the safety-tested particles provided insight on the evolution of the individual layers over the entire particle volume after safety-testing. The analysis indicated no correlation in the behavior of the particle structure with silver retention performance. However, the analysis did suggest fission products were mobile and possibly released from the kernel during safety testing. This was evident in the buildup of fission products in the buffer fracture areas and increased fission product pileup at the IPyC-SiC interface in the $1800^{\circ} \mathrm{C}$ safety-tested particles. The presence of the $\mathrm{SiC} / \mathrm{OPyC}$ gap was important, as it suggests a different constraint on the TRISO layers during operation than is currently predicted by computational fuel performance models.

4.8.2.2 Materialography. Materialography was performed on selected particles from safety-tested compacts exposed to temperatures of $1600^{\circ} \mathrm{C}, 1700^{\circ} \mathrm{C}$, and $1800^{\circ} \mathrm{C}$ using the methodology described in Hunn et al. 2013a. Particles for analysis were selected based on their silver retention $(M / C)$ to determine any possible correlations in particle structure with silver retention behavior. The materialography analysis provides detailed insight on the particle cross sections as well as detail associated with the fuel kernel after safety testing, which is not obtainable from x-ray tomography.

Analysis of the particles from the $1600^{\circ} \mathrm{C}$ safety-tested particles presented similar findings to those from the x-ray tomography analysis presented in Section 4.8.2.1; namely, buffer densification with IPyC delamination and buffer fracture due to buffer/IPyC interface adherence during buffer densification. Examples are shown in Figure 60. The cross-section analysis also confirms that no correlation between particle structure and silver retention existed in the $1600^{\circ} \mathrm{C}$ safety-tested particles that were analyzed (Hunn et al. 2012c; Hunn et al. 2013b; Hunn et al. 2014c), which is consistent with the observations from the x-ray tomography analysis discussed in Section 4.8.2.1. The reduced constraint on the kernel due to buffer fracture led to the observed kernel protrusion and is also associated with an increase in kernel pore size as noted in Figure 60 (right). This behavior was noted in approximately $25 \%$ of the AGR-1 particles and is not expected to influence silver retention performance (Ploger et al. 2012a). Variations in kernel microstructure were observed for the analysis of Compact 5-3-3 particles, which all appeared to have intact buffers (Figure 61). However, there does not appear to be a correlation between silver retention performance and the post-irradiation/safety-tested kernel microstructure (Hunn et al. 2014a).

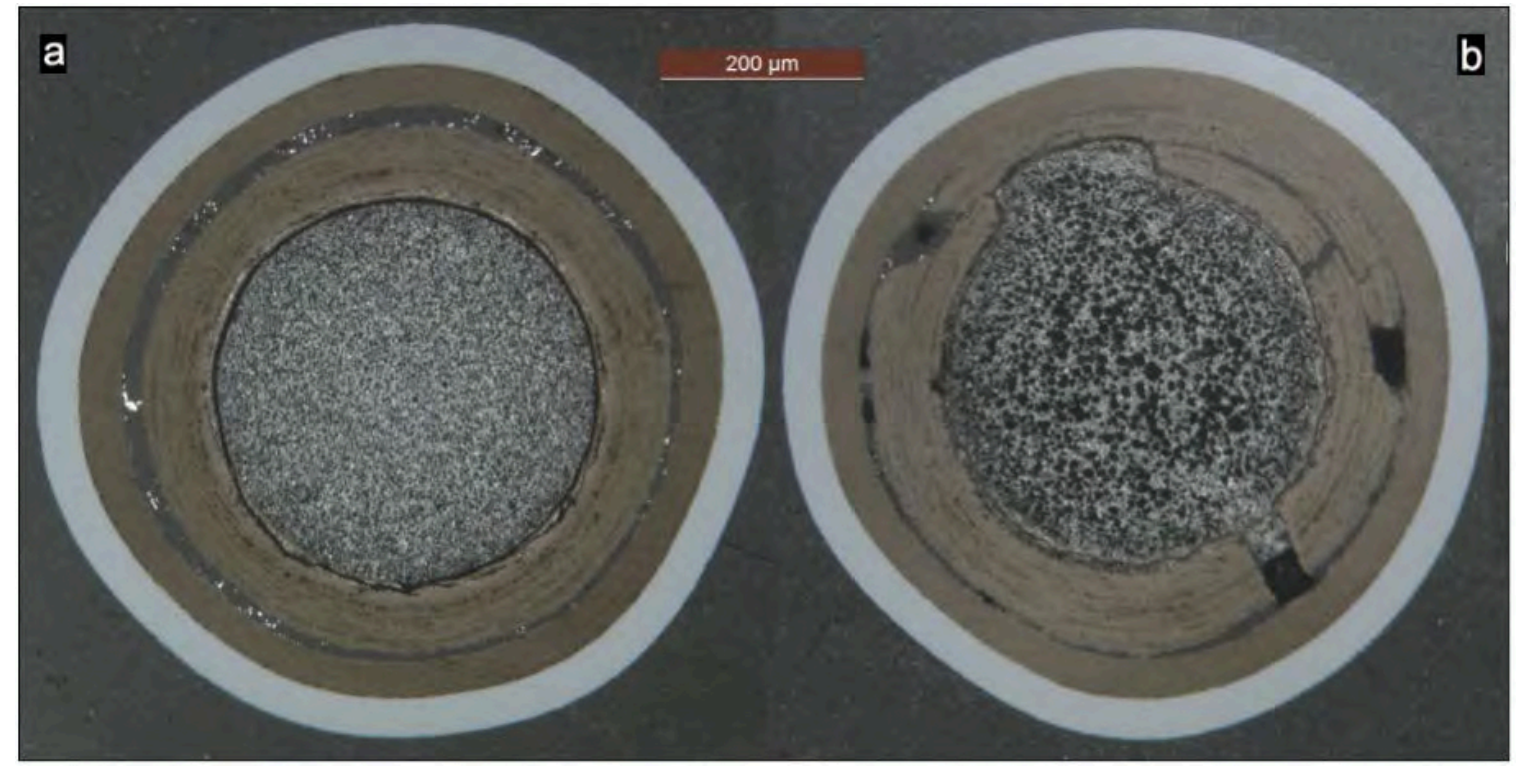

Figure 60. Optical micrographs of polished cross sections from $1600^{\circ} \mathrm{C}$ safety-tested Compact 3-2-2 particles with average silver retention, showing (a) typical buffer densification and delamination from the IPyC layer, and (b) buffer fracture and kernel protrusion due to limited delamination from the IPyC layer. 

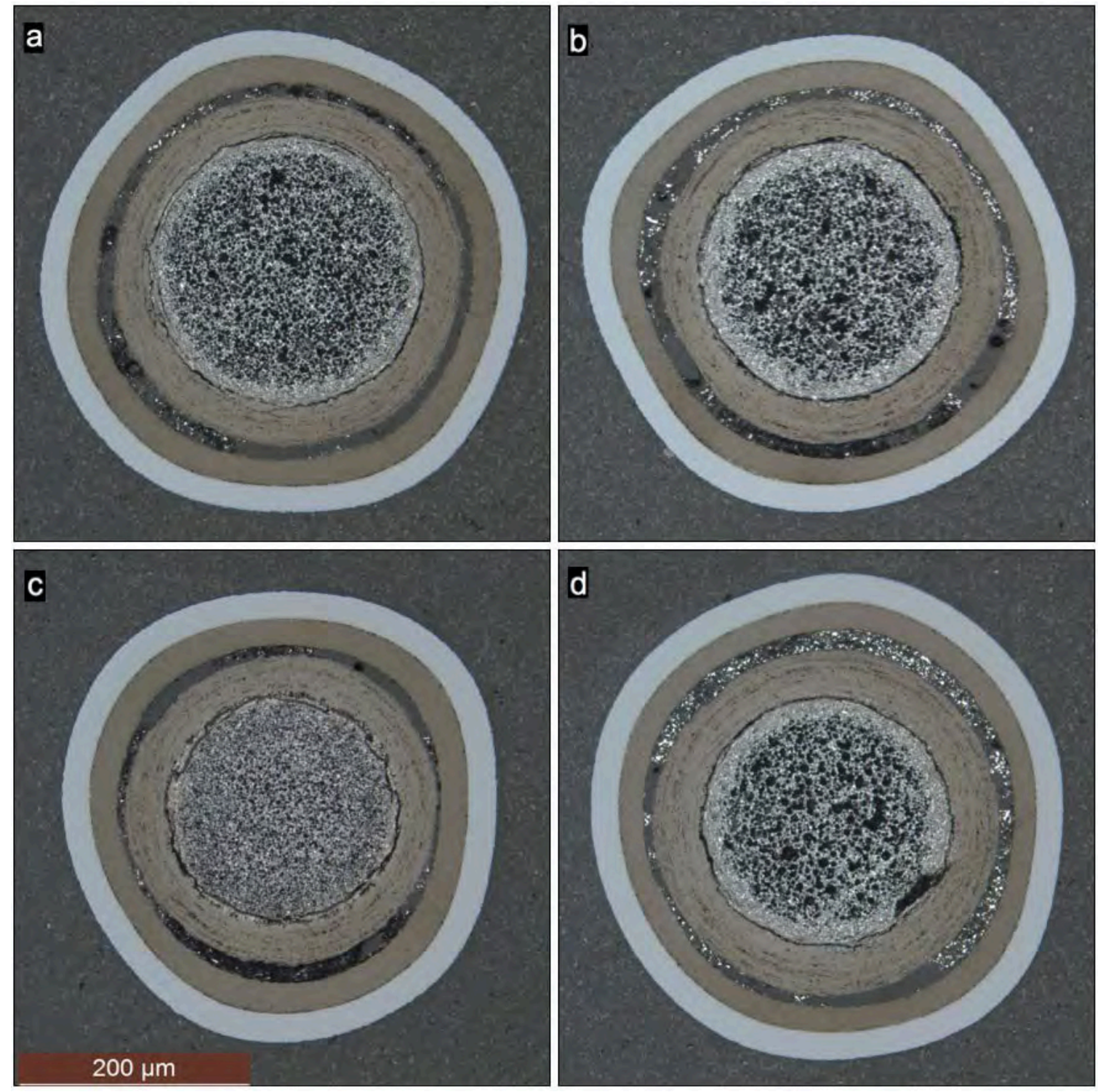

Figure 61. Optical micrographs near midplane of particles from $1600^{\circ} \mathrm{C}$ safety-tested Compact 5-3-3: (a) particle with high ${ }^{110 \mathrm{~m}} \mathrm{Ag}$ release $(\mathrm{M} / \mathrm{C}<0.21)$, (b) particle with moderate ${ }^{110 \mathrm{~m}} \mathrm{Ag}$ release $(\mathrm{M} / \mathrm{C}=0.58)$, (c) particle with approximately average ${ }^{110 \mathrm{~m}} \mathrm{Ag} \mathrm{M} / \mathrm{C}(0.81)$, suggesting low or negligible release, and $(\mathrm{d})$ particle with very low ${ }^{110 \mathrm{~m}} \mathrm{Ag}$ release $(\mathrm{M} / \mathrm{C}=1.10)$.

Cross-sectional analysis of the $1700^{\circ} \mathrm{C}$ safety-tested particles from Compacts 4-4-3 and 5-1-1 corroborated the insights gained from the x-ray analysis presented in Section 4.8.2.1, that is, no correlation was observed between internal particle structure and silver retention performance (Hunn et al. 2014c). Optical micrographs of particles from Compact 5-1-1 did indicate a gap between the $\mathrm{SiC}$ layer and $\mathrm{OPyC}$ layer after safety testing at $1700^{\circ} \mathrm{C}$ (Hunn et al. 2015a), which was suggested by $\mathrm{x}$-ray tomography analysis.

Materialography performed on particles from $1800^{\circ} \mathrm{C}$ safety-tested Compacts 4-4-1 and 5-1-3 indicated a change in the $\mathrm{SiC}$ microstructure relative to the as-irradiated and lower-temperature safety-tested particles. Figure 62 shows an optical micrograph of the top half of a typical Compact 4-4-1 particle. Two features stand out that were not previously observed: large white spots in the inner half of the $\mathrm{SiC}$ layer and a band of dark spots in the outer half of the $\mathrm{SiC}$ layer (Hunn et al. 2013b). The white 
spots are associated with metallic fission product inclusions in the SiC layer. The dark spots do not appear to be artifacts of sample preparation and are expected to be due to degradation of the SiC layer. These will be discussed in greater detail in Section 4.8.2.3. The gap at the SiC/OPyC interface is apparent in the optical image of the Compact 4-4-1 particle in Figure 62, where the gap is large enough to be impregnated with epoxy during back-potting. This observation corroborates the x-ray tomography observation of an increasing gap at the $\mathrm{SiC} / \mathrm{OPyC}$ interface as a function of safety-testing temperature.

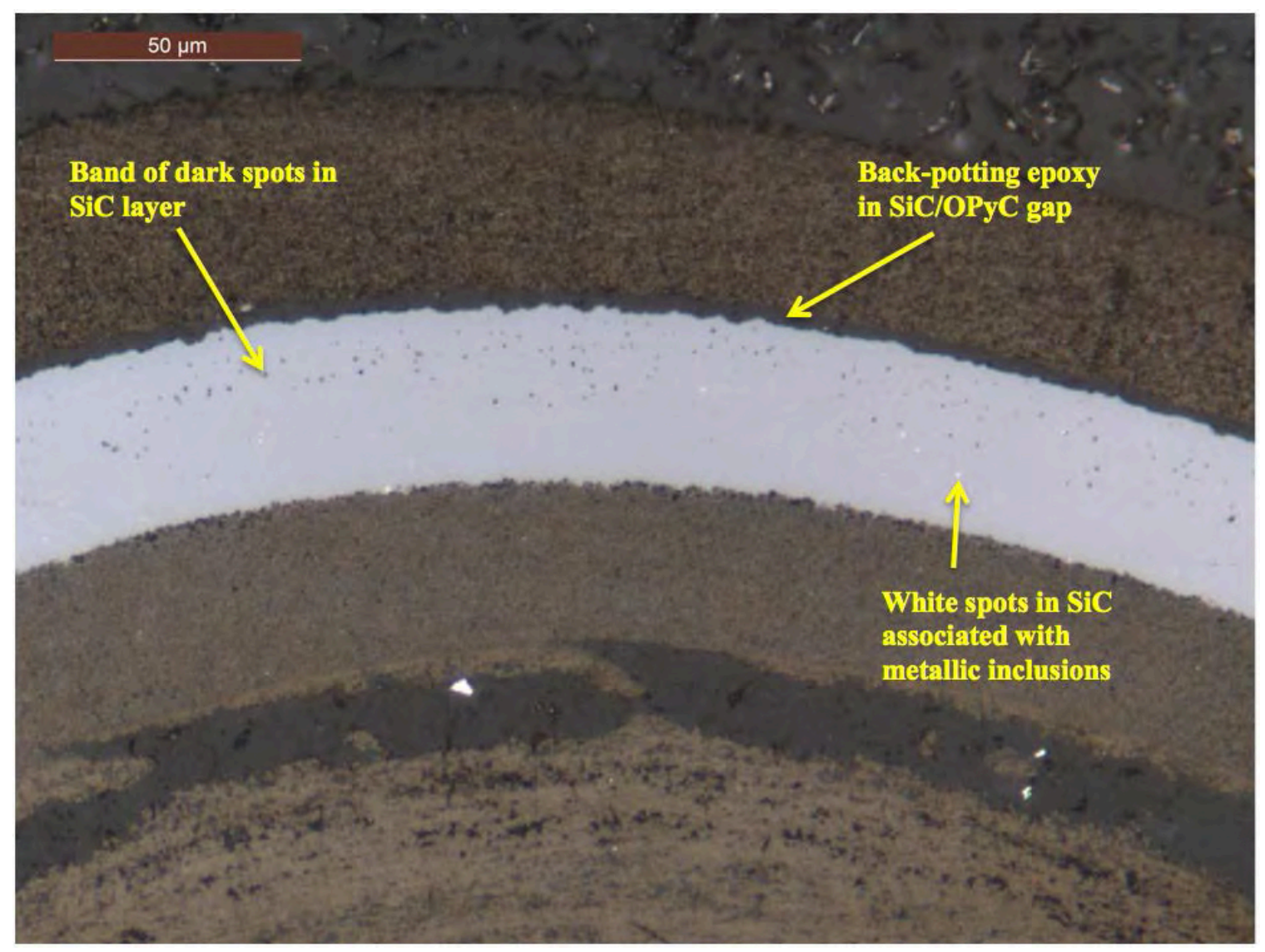

Figure 62. Optical micrograph near midplane of a typical particle from $1800^{\circ} \mathrm{C}$ safety-tested Compact 4-4-1 showing a wide gap between the $\mathrm{SiC}$ and $\mathrm{OPyC}$ (backfilled with epoxy during sample preparation), and a band of dark spots in the outer half of the $\mathrm{SiC}$ layer.

4.8.2.3 SEM with EDS Analysis. Scanning electron microscopy of particle cross sections was performed on select particles from safety-tested compacts exposed to temperatures of $1600^{\circ} \mathrm{C}, 1700^{\circ} \mathrm{C}$, and $1800^{\circ} \mathrm{C}$. The analysis was performed according to the same methodology discussed in Section 3.4.2.1. Particles for analysis were defined by their Ag retention (M/C) to allow for comparison of $\mathrm{Ag}$ retention behavior with fission production distribution.

The $1600^{\circ} \mathrm{C}$ safety tested particles analyzed by SEM included particles from two Baseline compacts (6-4-3 and 6-2-1), two Variant 3 compacts (4-1-2 and 4-3-3), and one Variant 1 compact (5-3-3). Figure 63 shows a comparison of a very low-Ag-retention particle $\left({ }^{110 \mathrm{~m}} \mathrm{Ag} \mathrm{M} / \mathrm{C} \leq 0.16\right.$ ) and high-Ag-retention particle $\left({ }^{110 \mathrm{~m}} \mathrm{Ag} \mathrm{M} / \mathrm{C}=1.12\right.$ ) from Compact $4-1-2$. The $1600^{\circ} \mathrm{C}$ exposure did not influence the quality of the IPyC-SiC interface as the SEI micrographs in Figure 63 show an intimately stitched IPyC-SiC interface. The BEC imaging of the TRISO layers indicated pileup of fission products at the IPyC-SiC and embedded fission product clusters in the SiC layers. The distribution and frequency of embedded fission products in the $\mathrm{SiC}$ layer showed a dependency on the $\mathrm{Ag}$ retention behavior such that particles with low Ag retention had a greater frequency of fission product clusters distributed deeper into 
the SiC layer relative to high Ag-retention particles (Hunn et al. 2012b; Hunn et al. 2013b; Hunn et al. 2014a; Hunn et al. 2014c). A correlation with the Pd-U and Pd features was also noted, with $\mathrm{Pd}-\mathrm{U}$ features predominant in the first $10 \mu \mathrm{m}$ of the SiC layer and Pd clusters with no detectable U more frequent in the outer half of the SiC layer (Hunn et al. 2014c). These observations are consistent with the fission product cluster distributions in the $\mathrm{SiC}$ layer of as-irradiated compacts discussed in Section 3.4.2.1 (Hunn et al. 2012a; Hunn et al. 2013a; Hunn et al. 2014b). In addition to Pd and U, other fission products, similar to those observed in the as-irradiated particles discussed in Section 3.4.2.1, were observed in select fission product features analyzed by EDS and located primarily near the IPyC-SiC interface (Hunn et al. 2014a; Hunn et al. 2014c).

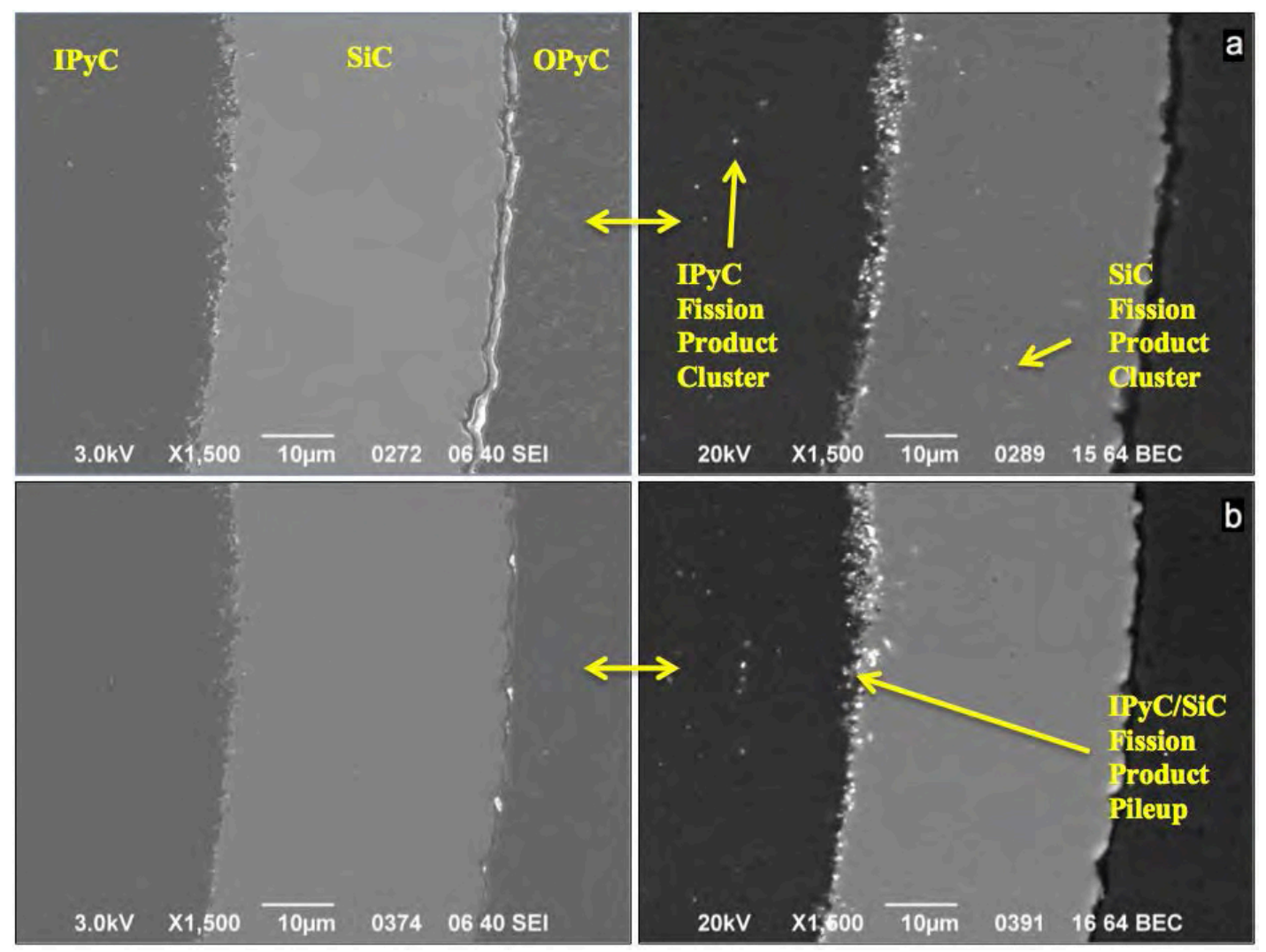

Figure 63. SEI/BEC-paired images of Compact 4-1-2, safety tested at $1600^{\circ} \mathrm{C}$ : (a) very low $\mathrm{Ag}$ retention particle $(\mathrm{M} / \mathrm{C} \leq 0.16)$ and $(\mathrm{b})$ high $\mathrm{Ag}$ retention particle $(\mathrm{M} / \mathrm{C}=1.12)$. Areas of bright contrast in $\mathrm{BEC}$ micrograph indicate isolated fission product features.

Comparison of the $1600^{\circ} \mathrm{C}$ safety-tested particles with as-irradiated particles identified some variations in fission product distribution. A high frequency of isolated fission product clusters was resolved with SEM/EDS in the center of the IPyC layer in all safety tested particles that were analyzed, such as those shown in Figure 63, and were not observed in as-irradiated particle cross sections using the same analysis technique. These features were predominantly $\mathrm{U}$ with rare features containing some $\mathrm{Pd}$ (Hunn et al. 2014a; Hunn et al. 2014c). The composition of the fission product pileup features contained numerous collocated Pd-U features that were U-rich, which were not frequently observed in the as-irradiated particles. In select particles with low Ag retention, an increased U presence was observed for large clusters in the $\mathrm{SiC}$ layer as well as decrease in relative Pd presence at the IPyC-SiC interface (Hunn et al. 2014a). These observations suggest that under the $1600^{\circ} \mathrm{C}$ safety testing conditions $\mathrm{U}$ is being liberated from the kernel, migrating into the IPyC layer, and segregating at the IPyC-SiC interface. Further analysis of safety-tested particles using advanced microanalysis methods (which may resolve the presence of fine fission product clusters not observable with SEM/EDS) may provide additional insight. 
Scanning electron microscopy of particle cross sections was performed on select particles from safety-tested Variant 3 Compact 4-3-3 exposed to a temperature of $1600^{\circ} \mathrm{C}$ (Demkowicz et al. 2015e). Montages and SEM images of the cross sections of particles AGR1-433-001 and AGR2-433-004 showed that fission product precipitate clusters were found in great abundance along the entire circumference of the observable IPyC-SiC interface for both particles. Precipitate clusters were also identified in the individual SiC and IPyC layers. High-Z element clusters found in the interlayer, SiC layer, and IPyC layer are marked with a blue oval, an orange triangle, and a green rectangle, respectively, on the montage of particle AGR1-433-001 shown in Figure 64. The SEM micrograph of the cross section of AGR1-433-004 (Figure 64b), shows several small fractures within the buffer layer. The radial edges of these fractures were traced and transferred onto the montage in Figure 64a to better visualize the precipitate distribution in relation to the buffer fracture zones. The maximum interlayer thickness and the maximum number of precipitates in the SiC layer for AGR1-433-001 were observed in areas in radial alignment with the buffer fracture zones in the upper region of the particle, indicating that the buffer fracture zones influence the precipitate distribution in the coating layers. More voids in the IPyC layer were observed in the particles from Compact 4-3-3, compared with other as-irradiated compacts. However, caution should be taken when comparing these microstructures, as the particles from other compacts that were examined were in some cases irradiated under different conditions.

The ${ }^{110 \mathrm{~m}} \mathrm{Ag} \mathrm{M} / \mathrm{C}$ ratios were 0.66 and 0.99 for particles AGR1-433-001 and AGR1-433-004, respectively, and no significant difference in precipitate distribution patterns was observed. Different kernel-buffer behavior was observed as shown in the low magnification images of particle AGR1-433-001 (Figure 65) and AGR1-433-004 (Figure 66); specifically, a conspicuous gap is present between the buffer and kernel in AGR1-433-004 that is not observed in AGR1-433-001. No SiC corrosion was observed for any of these two particles in the cross-sectional plane of examination. More detailed results of the examination of Compact 4-3-3 particles are presented in Van Rooyen et al. 2015c. Microstructure variations in these particles will be further explored using advanced microscopic techniques.

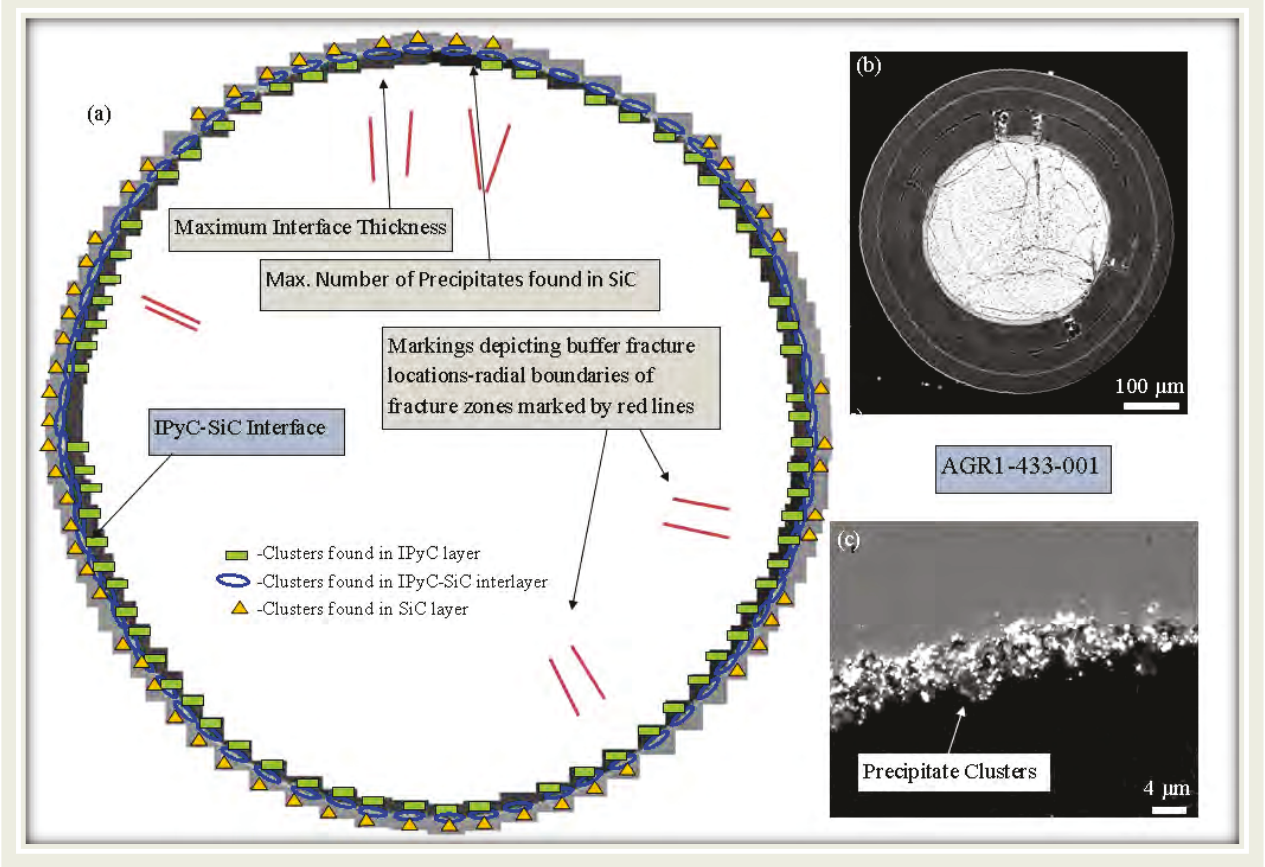

Figure 64. Particle AGR1-433-001 showing (a) an SEM image montage representing the distribution of precipitate clusters, (b) an optical micrograph of the particle cross section, and (c) a representative SEM image of the IPyC-SiC interface. 

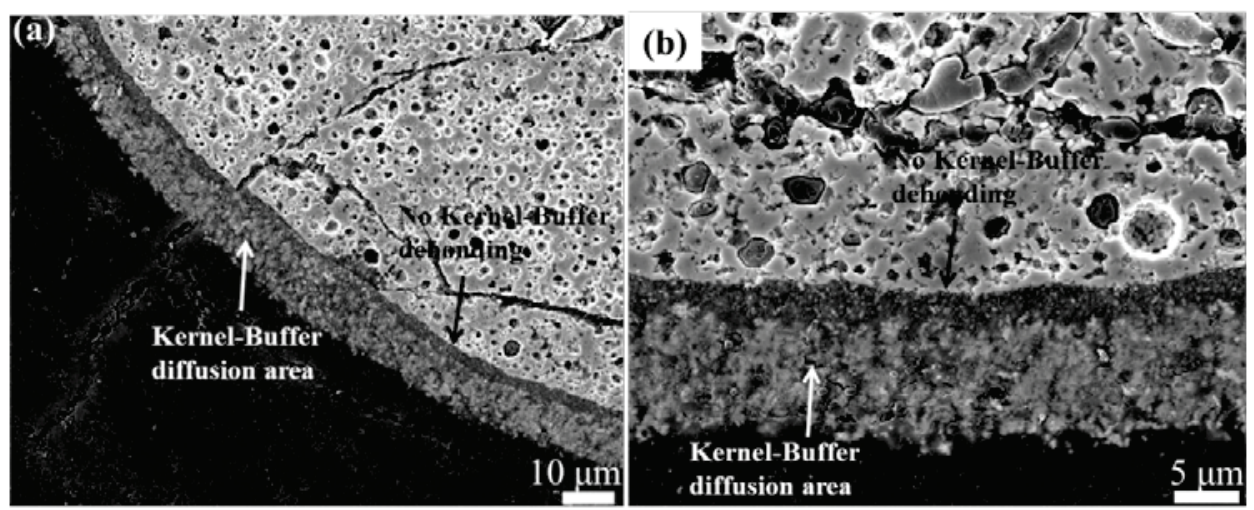

Figure 65. SEM images of AGR1-433-001 showing kernel-buffer diffusion area, with no kernel-buffer debonding.

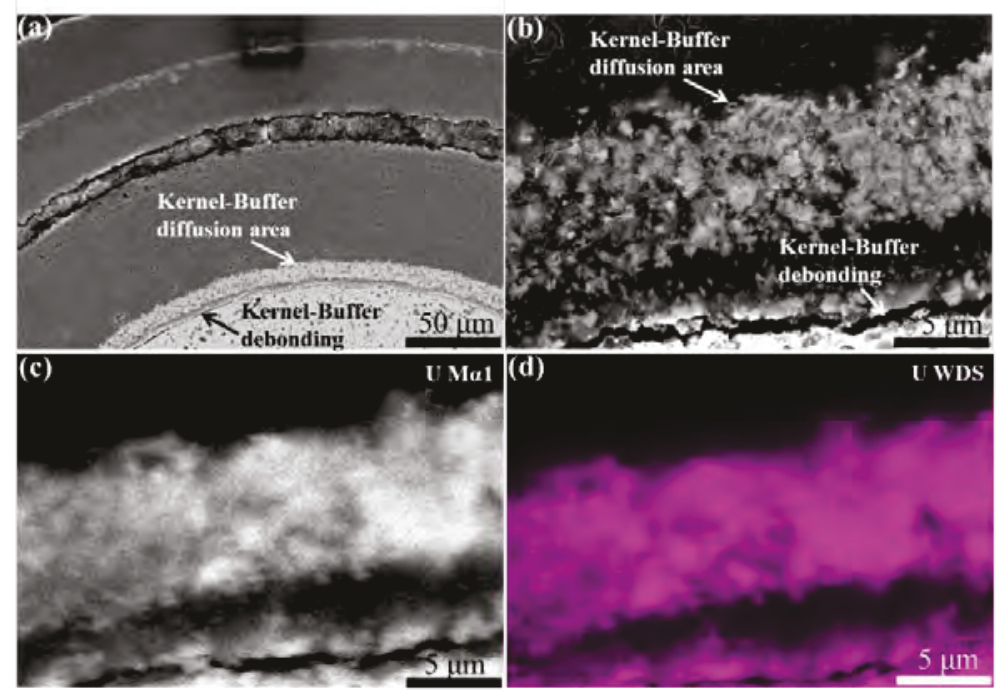

Figure 66. SEM images of AGR1-433-004 showing kernel-buffer diffusion area, with kernel-buffer debonding, and EDS and WDS maps of the area in (b).

The $1700^{\circ} \mathrm{C}$ safety tested particles analyzed by SEM included particles from Compacts 4-4-3 and 5-1-1. Figure 67 shows a comparison of a low Ag-retention particle $\left({ }^{110 \mathrm{~m}} \mathrm{Ag} \mathrm{M} / \mathrm{C}<0.61\right)$ and high Ag-retention particle $\left({ }^{110 \mathrm{~m}} \mathrm{Ag} \mathrm{M} / \mathrm{C}=1.01\right)$ from Compact 5-1-1. An increase in fission product cluster frequency throughout the $\mathrm{SiC}$ layer was observed for particles which released $\mathrm{Ag}$ relative to those that retained Ag (Hunn et al. 2014c; Hunn et al. 2015a). This is shown in the BEC image comparison in Figure 67. This correlation of fission product distribution with $\mathrm{Ag}$ retention behavior is consistent with the observation made in as-irradiated and $1600^{\circ} \mathrm{C}$ safety tested particles. The observed IPyC fission product clusters are predominantly U-bearing (Hunn et al. 2014c), which is again consistent with the $1600^{\circ} \mathrm{C}$ results. The fission product features near the IPyC-SiC interface were primarily composed of collocated Pd-U, while the features deepest in the SiC layer were primarily Pd (Hunn et al. 2014c; Hunn et al. 2015a). Features at the IPyC-SiC interface were often Pd-U with low relative Pd or solely U (Hunn et al. 2014c; Hunn et al. 2015a), suggesting a possible depletion of Pd from the area near the IPyC-SiC interface (Hunn et al. 2014c). In addition to Pd and U, other fission products, similar to those observed in the as-irradiated particles discussed in Section 3.4.2.1, were observed in select fission product features analyzed by EDS and located primarily near the IPyC-SiC interface (Hunn et al. 2015a). 


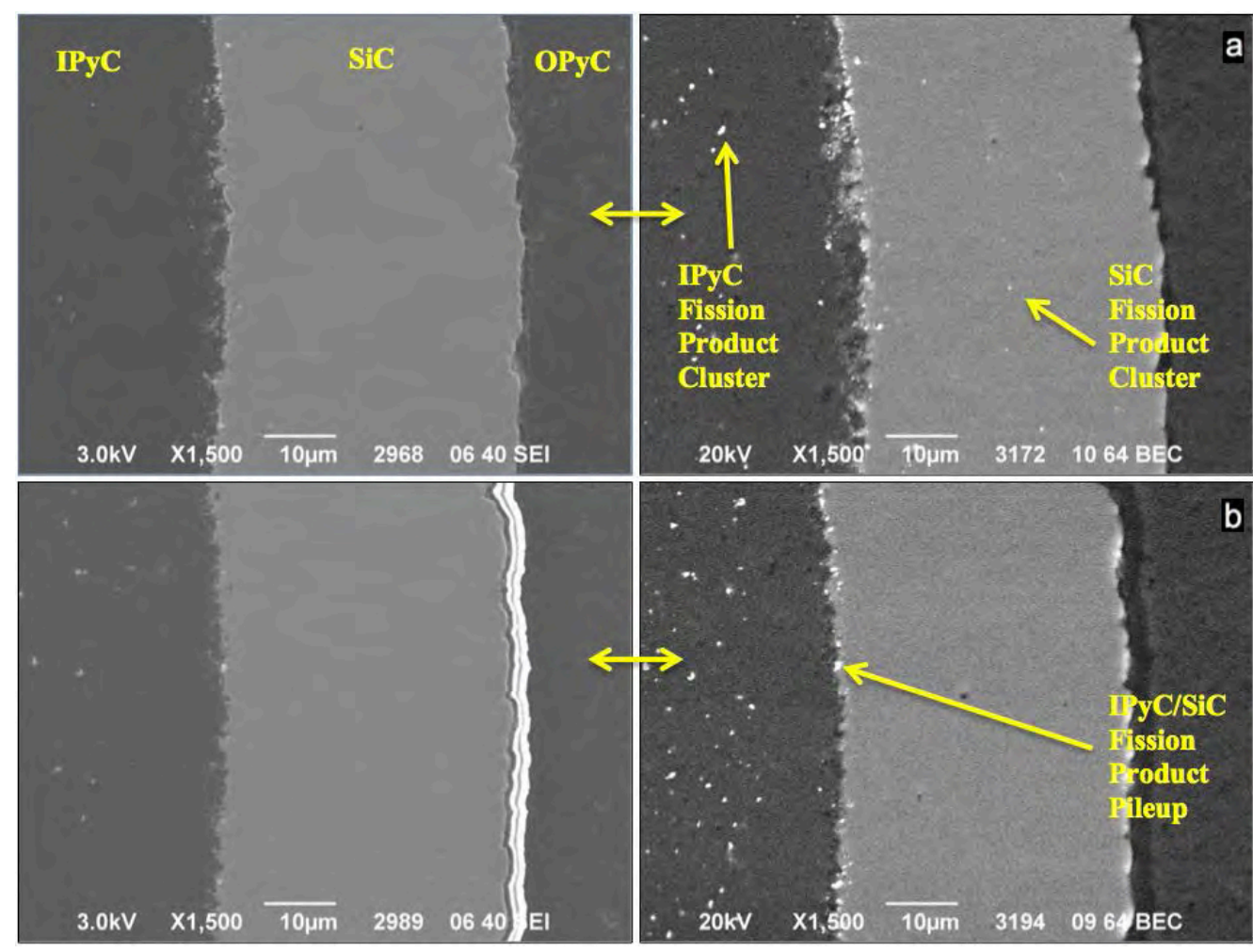

Figure 67. SEI/BEC-paired images of Compact 5-1-1, safety tested at $1700^{\circ} \mathrm{C}$ : (a) low $\mathrm{Ag}$ retention particle $(\mathrm{M} / \mathrm{C} \leq 0.61)$ and $(\mathrm{b})$ high $\mathrm{Ag}$ retention particle $(\mathrm{M} / \mathrm{C}=1.01)$. Spots of bright contrast in BEC micrograph indicate isolated fission product features. The bright material in the SEI image in the lower left corner is due to charging of epoxy infiltrating the gap between the $\mathrm{SiC}$ and OPyC.

Particles safety tested at $1800^{\circ} \mathrm{C}$ were analyzed by SEM, including particles from Compacts 4-4-1, 3-2-3, and 5-1-3. Figure 68 shows a comparison of a low Ag retention particle $(\mathrm{M} / \mathrm{C}<0.25)$ and high $\mathrm{Ag}$ retention particle $(\mathrm{M} / \mathrm{C}=1.17)$ from Compact 3-2-3. The fission product distribution observed in $1800^{\circ} \mathrm{C}$ safety-tested particles was significantly different relative to that observed in $1600^{\circ} \mathrm{C}$ (Figure 63) and $1700^{\circ} \mathrm{C}$ (Figure 67) safety tests. A primary difference was the uptake of fission product features in the $\mathrm{SiC}$ layer, as noted by the high frequency of large bright spots in the inner half of the SiC layer in Figure 68. This uptake is independent of Ag retention, as both low Ag and high Ag retention particles displayed this behavior (Hunn et al. 2013b; Hunn et al. 2014a). The uptake in fission products did not lead to significant degradation of the $\mathrm{SiC}$ layer, as the IPyC-SiC interface remained intact, as shown in the SEI micrographs in Figure 68. In select particles, where local disruptions in the IPyC layer were observed, SiC degradation was noted (Hunn et al. 2014a); these observations will be discussed further in Section 5. A second feature of interest is the presence of "dark" spots in the outer half of the SiC layer. These areas are associated with "pits" or possibly C-rich areas (Hunn et al. 2013b; Hunn et al. 2014a), these features were observed less frequently in select particles from $1700^{\circ} \mathrm{C}$ safety tests (Hunn et al. 2014a). These features may also be influenced by the irradiation conditions notably burnup and temperature. These features also appear to be located in the regions where Pd-dominant features were primarily observed in as-irradiated particles as well as those at $1600^{\circ} \mathrm{C}$ and $1700^{\circ} \mathrm{C}$. The composition of the fission product features at the IPyC-SiC interface and in the $\mathrm{SiC}$ layer were predominantly $\mathrm{U}$ with very limited Pd. The features where limited Pd was identified were observed on or near the IPyC-SiC interface in the $\mathrm{SiC}$ layer (Hunn et al. 2013b; Hunn et al. 2014a). The noted change in fission product distribution at $1800^{\circ} \mathrm{C}$ and "dark" spot features in the outer-half of the $\mathrm{SiC}$ layer suggests Pd is exiting the $\mathrm{SiC}$ layer and leaving behind voids or $\mathrm{C}$-rich features. The large U-rich fission product features in the first half of the $\mathrm{SiC}$ layer imply $\mathrm{U}$ transport in $\mathrm{SiC}$ is active at $1800^{\circ} \mathrm{C}$. 


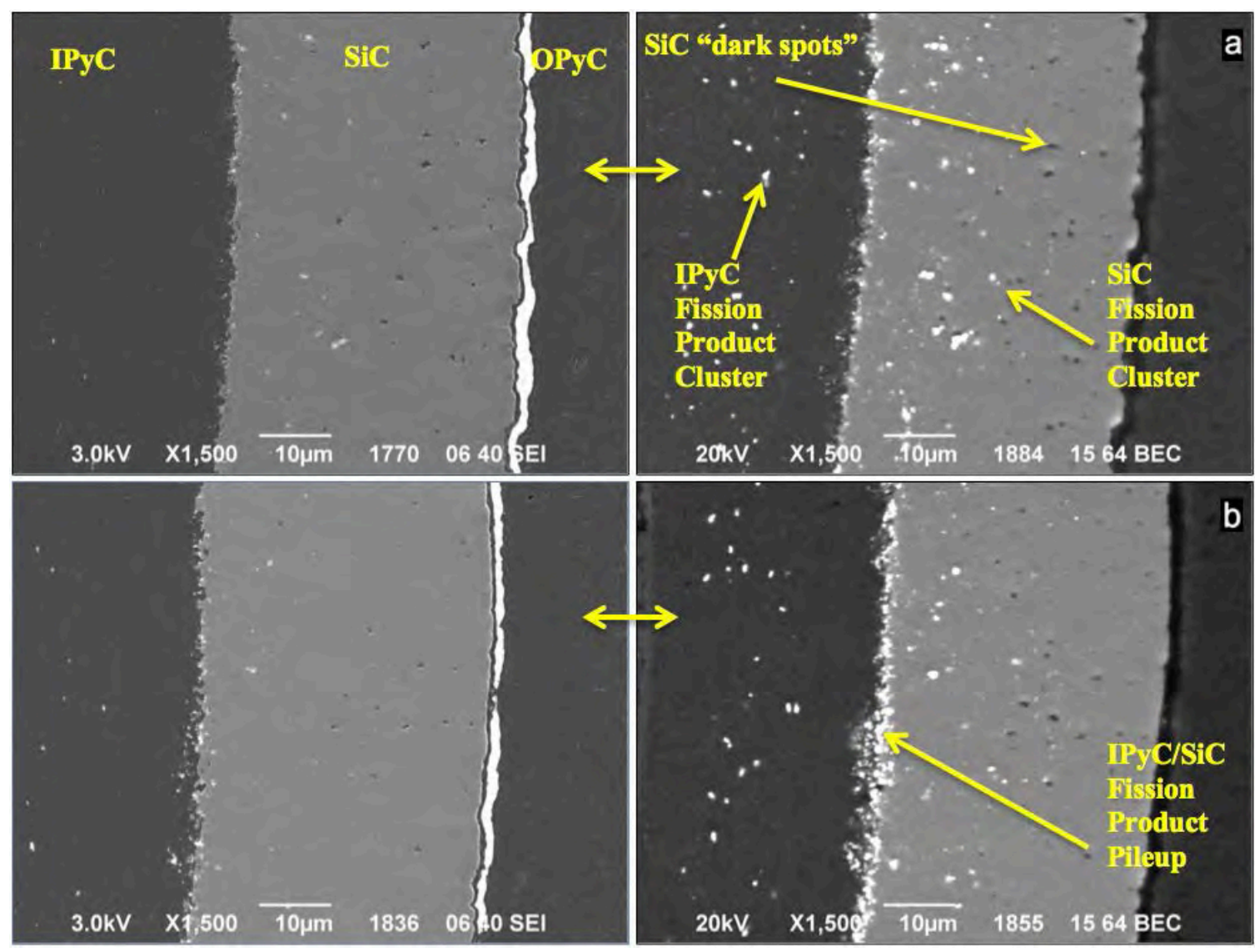

Figure 68. SEI/BEC-paired images of Compact 3-2-3, safety tested at $1800^{\circ} \mathrm{C}$ : (a) low $\mathrm{Ag}$ retention particle $(\mathrm{M} / \mathrm{C} \leq 0.25)$ and $(\mathrm{b})$ high $\mathrm{Ag}$ retention particle $(\mathrm{M} / \mathrm{C}=1.17)$. Areas of bright contrast in $\mathrm{BEC}$ micrograph indicate isolated fission product features.

Minor variation in the fission product cluster distribution in the $\mathrm{SiC}$ layer was noted in the $1600^{\circ} \mathrm{C}$ and $1700^{\circ} \mathrm{C}$ safety tested particles compared to the as-irradiated particles. The primary differences were an increase in frequency of U-rich features in the IPyC layer and at the IPyC-SiC interface. At $1700^{\circ} \mathrm{C}$, indication of $\mathrm{Pd}$ and $\mathrm{U}$ transport were suggested in limited particles. The analysis of $1800^{\circ} \mathrm{C}$ safety-tested particles indicated significant variation in fission product composition and distribution relative to the as-irradiated and $1600-1700^{\circ} \mathrm{C}$ safety-tested particles. The overall insight on fission product transport in the TRISO particles at the various safety testing conditions, based on SEM/EDS analysis, is that U is mobile in the graphite layers at $1600^{\circ} \mathrm{C}$ and above, while $\mathrm{U}$ and $\mathrm{Pd}$ are mobile in $\mathrm{SiC}$ at $1800^{\circ} \mathrm{C}$ and possibly at $1700^{\circ} \mathrm{C}$. The results suggest that $\mathrm{U}$ and $\mathrm{Pd}$ are mobile in the $\mathrm{SiC}$ layer at different rates and that their mobility is thermally driven. These observations also suggest that the $\mathrm{SiC}$ in intact TRISO particles retains its ability to act as a metallic fission product barrier at the maximum expected temperature of $1600^{\circ} \mathrm{C}$ in the absence of normal-operation pressurized-gas cooling, and that the $\mathrm{SiC}$ continues to serve as a fission product release barrier at 1700 and $1800^{\circ} \mathrm{C}$ by remaining intact and limiting transport across the $\mathrm{SiC}$ layer. Further study of these trends is needed to improve the understanding and validity of these initial observations. The further study should include an increase in the statistical sample size, an examination of particles heated at different temperatures and times, and analysis with higherresolution techniques of the microstructures surrounding the fission product clusters and regions were fission products have vacated. 


\section{CAUSES OF SIC FAILURE \\ 5.1 Detection of Particles with SiC Failure}

Cesium was well-retained by intact $\mathrm{SiC}$, both during irradiation testing and during safety testing. As-irradiated compact analysis yielded low quantities of exposed cesium during DLBL and high retention in individual gamma-counted particles. Safety testing showed low-cesium release in the absence of failed $\mathrm{SiC}$ (Figure 45). In all cases, cesium release from a compact in the absence of failed SiC was typically less than a few percent of a single particle's inventory. However, whereas cesium was well-retained by $\mathrm{SiC}$, it appeared to move relatively freely through intact pyrocarbon and compact matrix. Therefore, release of a significant fraction of a particle's inventory of cesium was a sensitive indicator of failed SiC.

Collimated-gamma scanning of the irradiation capsule graphite holders provided information on the spatial distribution of cesium that allowed for the identification of specific compacts that released cesium. Three such compacts were identified: two in Capsule 5 and one in Capsule 6. Figure 69 shows the cesium "hot spots" discovered in the Capsule 5 graphite holder next to two cesium-releasing compacts:

Compacts 5-2-1 and 5-2-3.

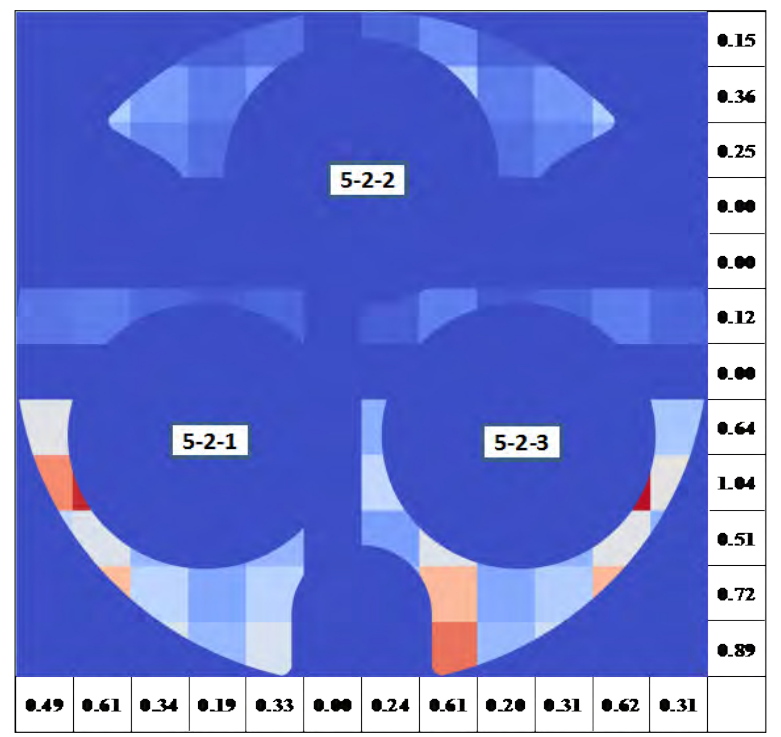

Figure 69. Intensity map of ${ }^{134} \mathrm{Cs}$ activity in one section of Capsule 5 graphite holder showing hot spots (red) adjacent to Compacts 5-2-1 and 5-2-3 (Harp et al. 2012).

During safety testing, cesium release due to $\mathrm{SiC}$ failure was easily resolved as an increase in the cesium collected by the water-cooled CCCTF deposition cups or FACS collection plates. Figure 70 shows the measured release rate for one of the $1600^{\circ} \mathrm{C}$ safety tests in the CCCTF. In this test, a burst of cesium was detected soon after reaching $1600^{\circ} \mathrm{C}$. After the initial release, the rate of cesium condensing on the cups slowly decreased back to background levels and the total integrated release was $68.5 \%$ of an average particle's inventory. Cesium release was more complicated during $1800^{\circ} \mathrm{C}$ safety testing due to releases from multiple particles with failed $\mathrm{SiC}$, with failures occurring at varied times and each particle releasing a varied fraction of its cesium inventory (Figure 71). 


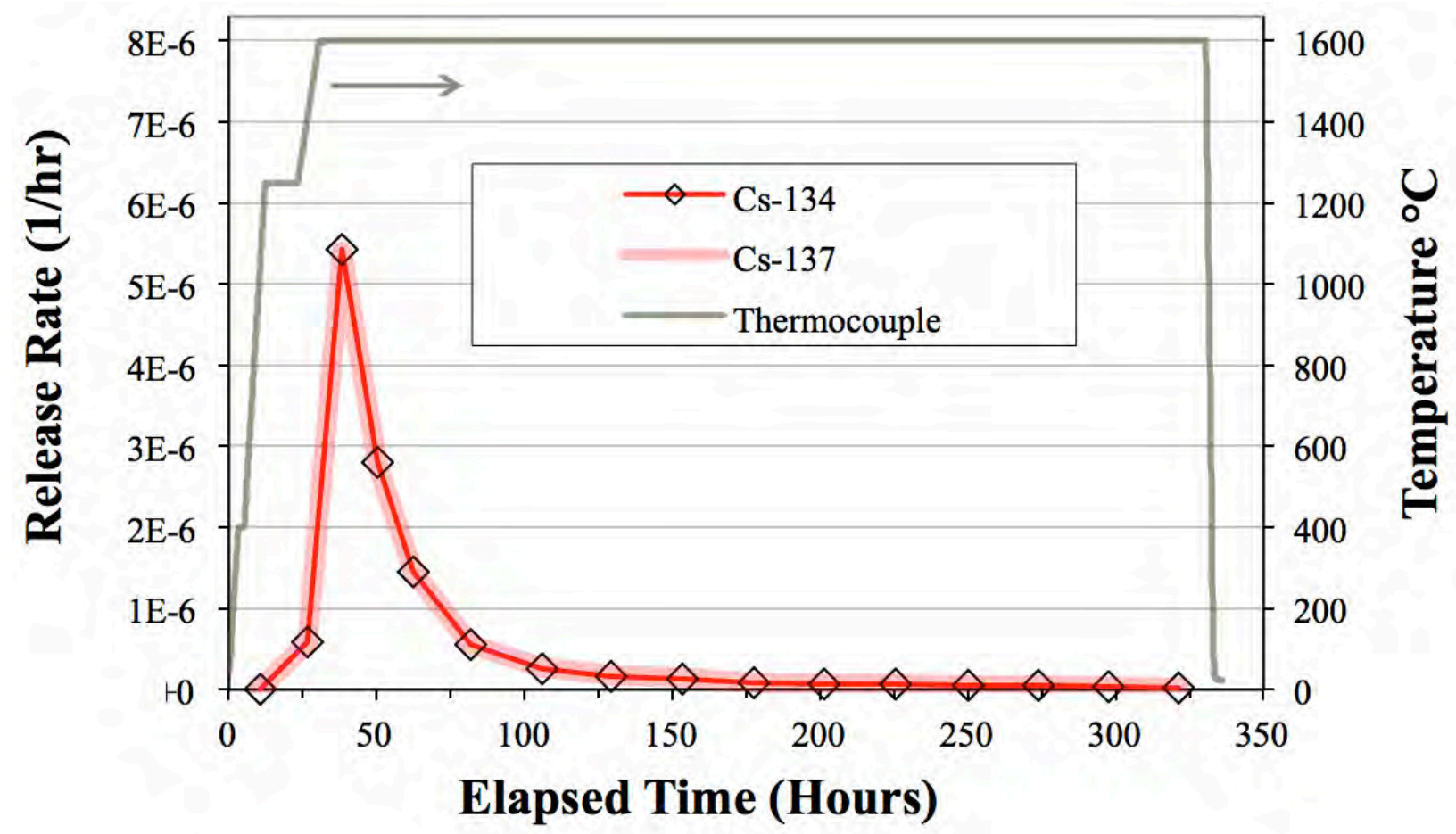

Figure 70. Fraction of the compact's cesium inventory released per hour during $1600^{\circ} \mathrm{C}$ safety testing of AGR-1 Compact 4-1-2.

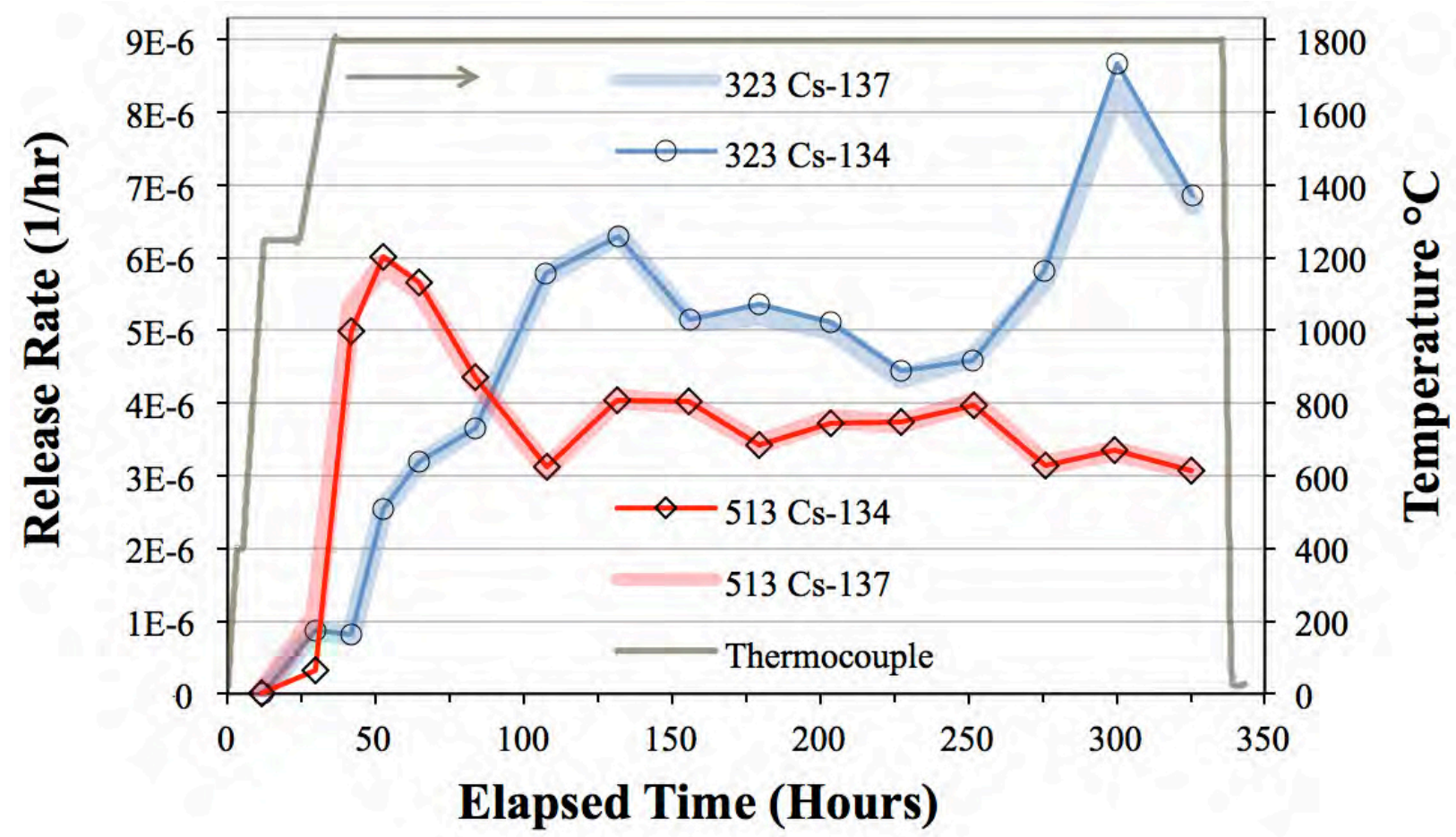

Figure 71. Fraction of the compact's cesium inventory released per hour during $1800^{\circ} \mathrm{C}$ safety testing of AGR-1 Compacts 3-2-3 and 5-1-3. 
As-irradiated and safety-tested compacts that exhibited cesium release indicative of failed $\mathrm{SiC}$ were subjected to electrolytic deconsolidation and acid leaching to separate the TRISO-coated particles from the encapsulating graphite matrix, followed by full IMGA survey of all particles. For example, Figure 72 shows the results from the IMGA survey of the Compact 3-2-3 particles recovered after $1800^{\circ} \mathrm{C}$ safety testing. Nine particles with cesium inventories from $13-80 \%$ of calculated were found to lie below the normal distribution and were automatically sorted out for further analysis. A few additional particles in the lower tail of the main distribution were also segregated for analysis.

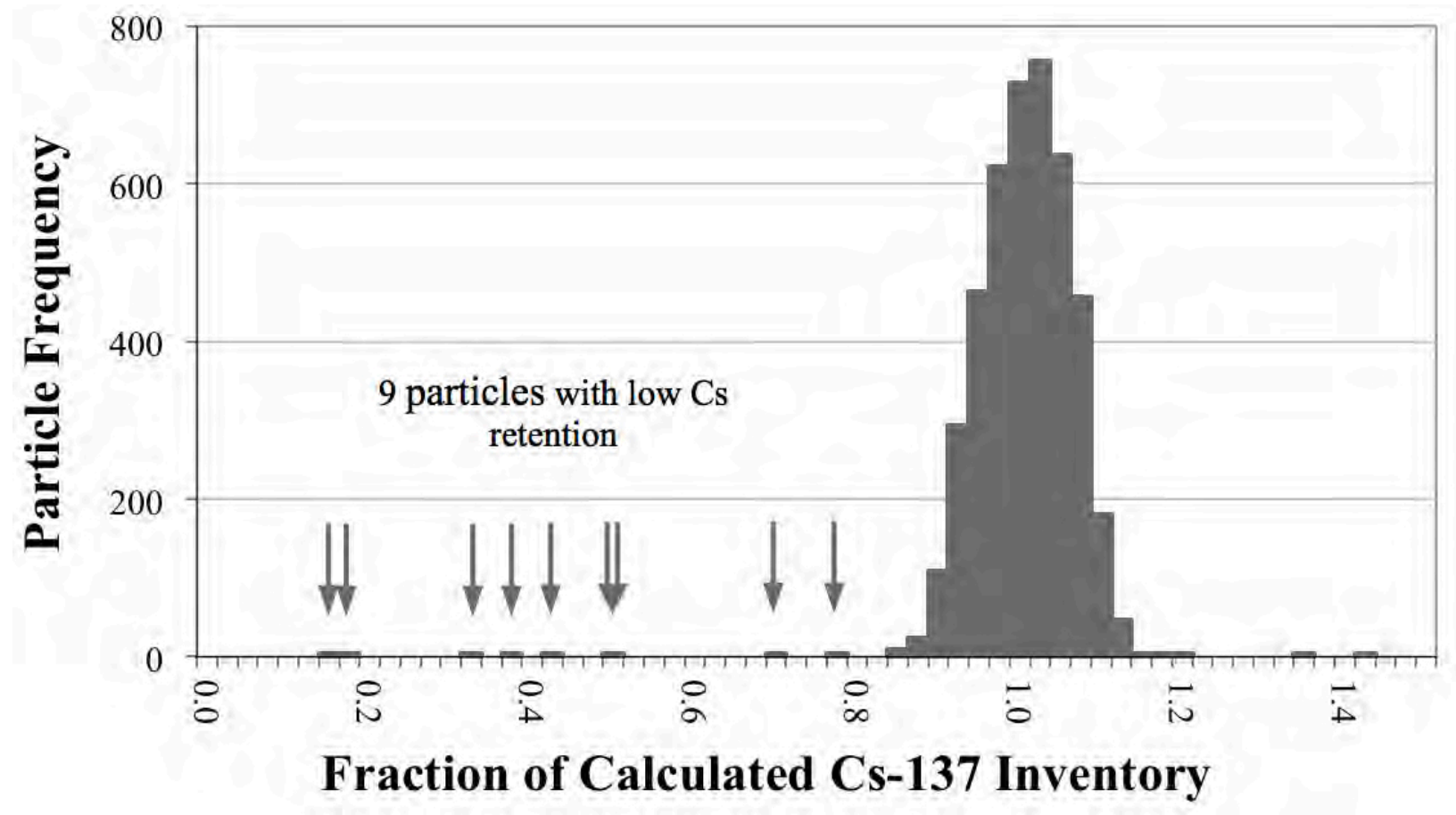

Figure 72. Cesium inventory distribution determined with IMGA for particles from $1800^{\circ} \mathrm{C}$ safety-tested AGR-1 Compact 3-2-3.

After using IMGA to isolate particles with significantly reduced cesium inventory, the particles were subjected to a series of analyses to investigate their internal microstructure. Particles were first imaged in three dimensions by non-destructive $\mathrm{x}$-ray tomography, which was very effective at identifying the presence of through-layer anomalies in the $\mathrm{SiC}$, as well as providing detailed internal structure data for all other layers and interfaces. Particles were then mechanically sectioned and polished for optical and SEM imaging, using the 3-D x-ray images to orient and guide the process; this approach offered a much higher probability that $\mathrm{SiC}$ failures could be successfully exposed for further study.

\subsection{Failure as a Result of As-Fabricated Defects}

Evidence of $\mathrm{SiC}$ failures were observed in only three of the eight $1600^{\circ} \mathrm{C}$ safety tests. The failure in Compact 6-4-1 was not analyzed. The other two $1600^{\circ} \mathrm{C}$ safety-tested compacts that released cesium from particles with failed $\mathrm{SiC}$ were subjected to IMGA survey and each contained one particle with failed SiC. Both of these particles failed due to as-fabricated defects, which could not withstand the elevated stress of the high-temperature safety testing. Figure 73 shows the particle that released cesium during safety testing of Compact 3-3-2; it had a malformed and very porous $\mathrm{SiC}$ layer that failed during safety testing. This fabrication defect was caused by momentary overfluidization of the particle between the IPyC and $\mathrm{SiC}$ coating steps, where the particle was ejected above the coating bed and picked up carbon soot from the chamber wall; subsequent $\mathrm{SiC}$ deposition infiltrated the soot and produced the abnormal structure (Phillips et al. 2010). The presence of soot inclusions in the $\mathrm{SiC}$ was monitored as part of the AGR-1 
quality control process and fluidization conditions were optimized to minimize the population and severity of these defects. Nevertheless, the fuel particle composite used in Compact 3-3-2 was known to have a small fraction of these defects $\left(\leq 10^{-3}\right.$, and most of those were less severe than this unusually extreme example).

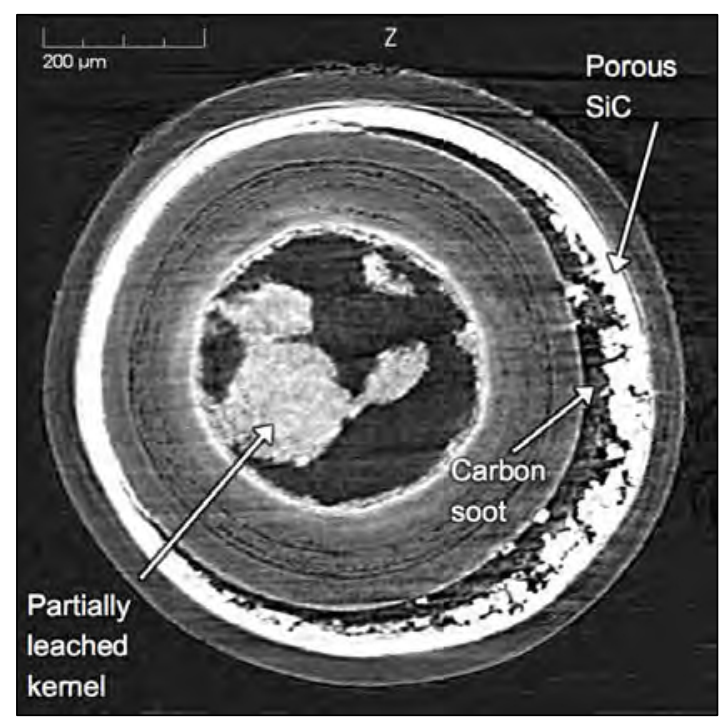

Figure 73. Particle that released cesium during $1600^{\circ} \mathrm{C}$ safety testing of Compact 3-3-2 due to an as-fabricated defect that led to $\mathrm{SiC}$ failure when the particle was heated above the irradiation temperature.

Figure 74 shows the particle that released cesium during safety testing of Compact 4-1-2; it also had a carbon soot inclusion, this time between the buffer and IPyC layers. The soot inclusion resulted in a noticeable dimple in the $\mathrm{SiC}$ layer. During irradiation, the buffer and IPyC did not separate; they appear to have fractured as a unit. Spearhead cracks through the buffer and IPyC led to regions of IPyC-SiC delamination, and fractures were observed in the $\mathrm{SiC}$ at the edges of these delamination regions that tended to curve around the particle in a circumferential direction, but in some locations the particles were connected to radial cracks through the layer (Figure 74a). The 3-D visualization of the $\mathrm{SiC}$ in Figure $74 \mathrm{~b}$ shows that one continuous, through-layer crack circumscribes the particle and runs about halfway around the rim of the dimple; at the locations marked A and B, secondary cracks branch off and continue around the dimple but do not connect. 


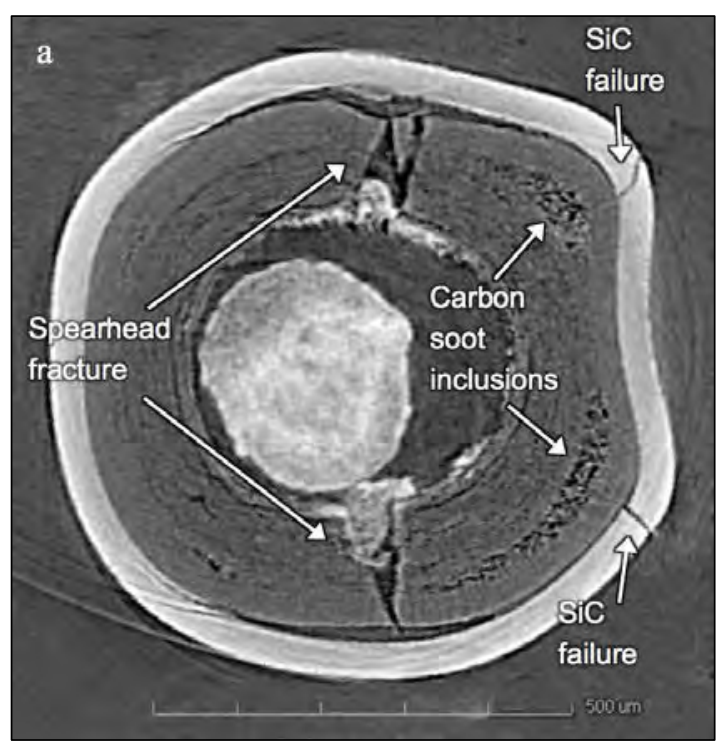

(a)

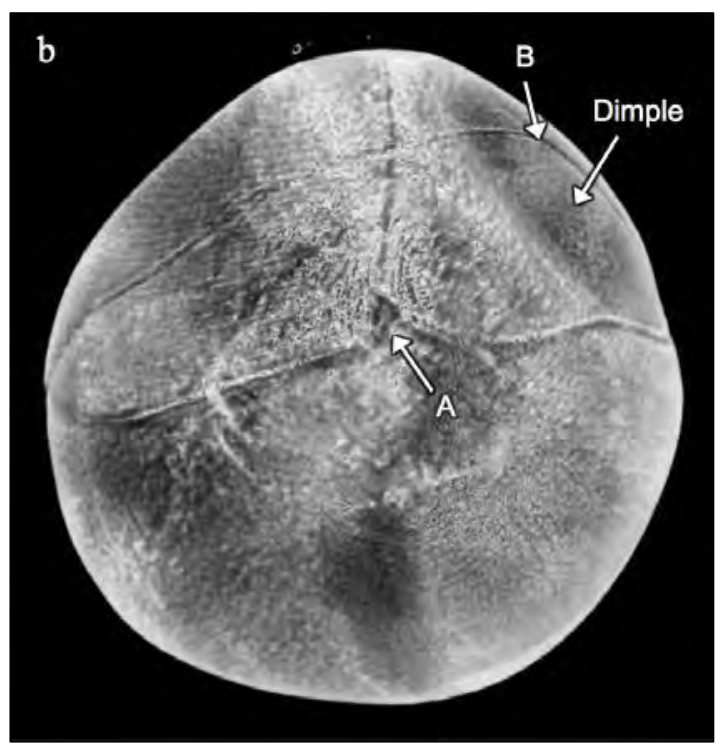

(b)

Figure 74. Particle that released cesium during safety testing of Compact 4-1-2; (a) x-ray tomograph and (b) semitransparent 3-D visualization of $\mathrm{SiC}$ surface.

The x-ray images of the failed-SiC particles from Compacts 3-3-2 and 4-1-2 show partially missing kernels. Figure 74a shows that the particle from Compact 4-1-2 is missing its OPyC layer. Exposed uranium detected during acid leaching indicated that the $\mathrm{OPyC}$ was initially intact during deconsolidation (consistent with no ${ }^{85} \mathrm{Kr}$ release during safety testing) but later broke off, allowing the acid to dissolve some of the kernel material. Similar acid leaching of the kernel appears to have occurred in the particle from Compact 3-3-2, but no cracks in the pyrocarbon layers were found.

Only one other particle has been observed to have experienced $\mathrm{SiC}$ failure due to an as-fabricated defect. This occurred during $1700^{\circ} \mathrm{C}$ safety testing of Compact 5-1-1, where once again the stress of the elevated test temperature caused the $\mathrm{SiC}$ layer to crack. X-ray tomographs of this particle (Figure 75), show another abnormal $\mathrm{SiC}$ layer structure that was caused by the particle getting temporarily trapped somewhere in the coater, such that it spent a significant fraction of the 140-minute SiC deposition period not circulating through the primary coating region. Because there was no large release of krypton during the safety test, it is reasonable to assume that the OPyC crack, visible in Figure 75b, did not occur until the deconsolidation or pre-burn acid leaching, at which time acid apparently penetrated to the kernel and removed material. 


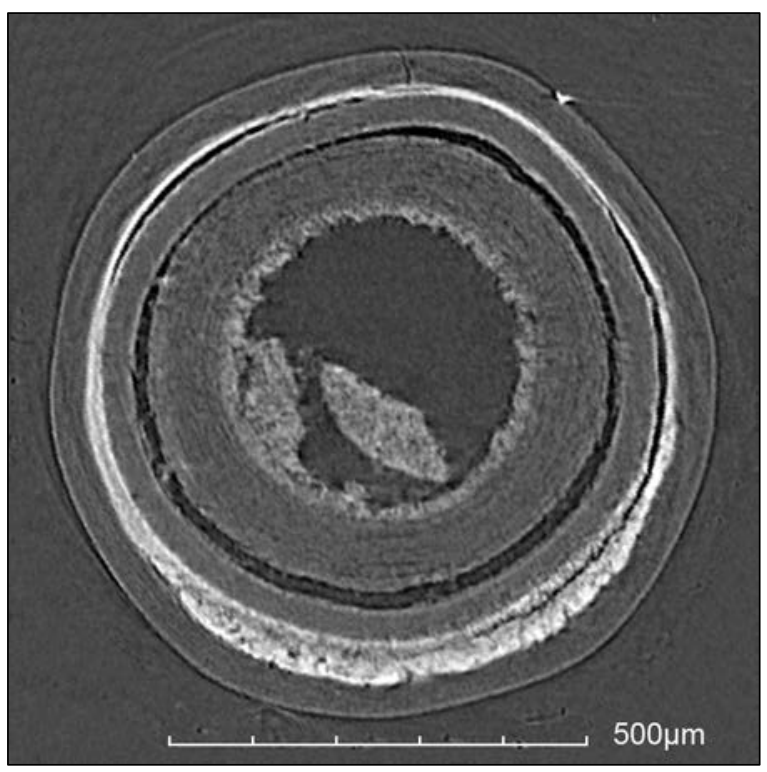

(a)

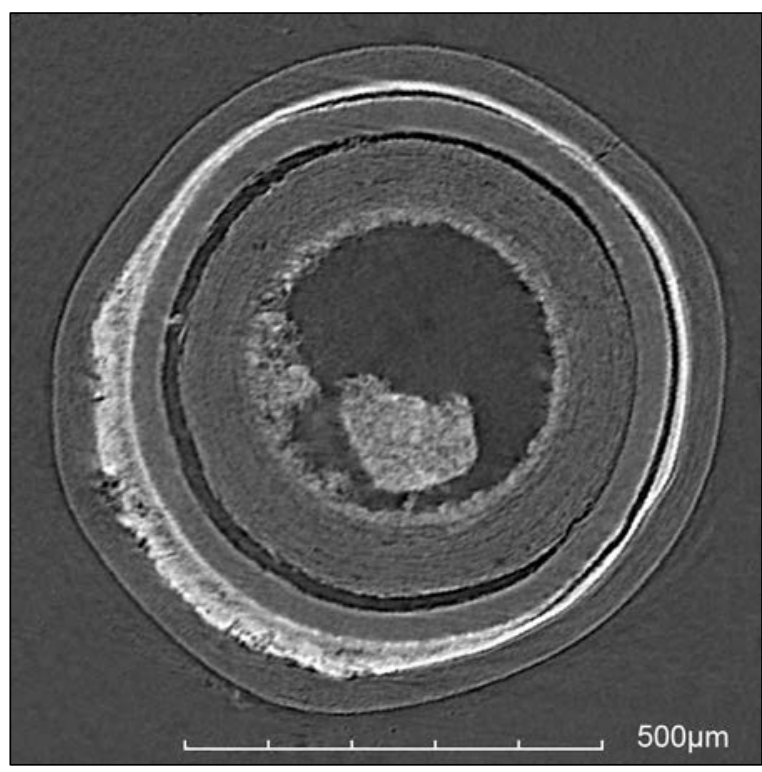

(b)

Figure 75. Low Cs/Ce Particle 3 (511-SP02): oblique orthogonal x-ray tomographs showing a gross SiC inclusion (pre-irradiation defect), and only residual kernel material remaining after pre-burn leaching.

Even with the gross soot inclusions present from the start of the AGR-1 irradiation test, all three particles survived the 3-year AGR-1 irradiation test without releasing significant quantities of cesium or krypton, only experiencing a through-layer $\mathrm{SiC}$ failure when heated above $1600^{\circ} \mathrm{C}$. Figure 76 shows a location on the outer edge of the soot inclusion in the cesium-releasing particle from Compact 3-3-2 where a crack extends from the defective $\mathrm{SiC}$ region through an intact overlayer. This implies that the porous structure in the defective region did not present a connected pathway through the SiC layer, and the abnormally thin $\mathrm{SiC}$ acting to seal this area remained intact until failure occurred after heating to $1600^{\circ} \mathrm{C}$. The crack shown in Figure 76 was at least one through-layer defect that could have been responsible for the observed cesium release.

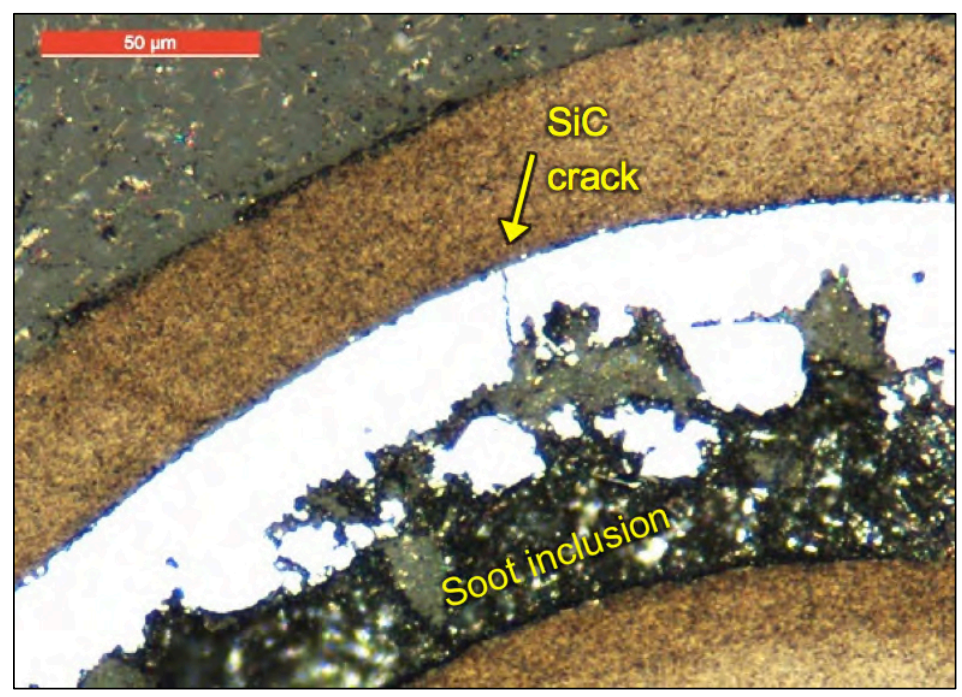

Figure 76. Compact 3-3-2 particle with soot inclusion defect that failed during $1600^{\circ} \mathrm{C}$ safety testing. A crack through intact $\mathrm{SiC}$ covering the porous region produced a pathway through the layer. 


\subsection{SiC Degradation}

All other SiC failures (both during irradiation and during $1700^{\circ} \mathrm{C}$ and $1800^{\circ} \mathrm{C}$ safety testing) that were directly examined exhibited a single common failure mechanism. Ironically, this failure mechanism was directly related to radiation-induced changes in the buffer, which traditionally is viewed as the least important layer for fission product retention. As already discussed, densification of the buffer from fission product recoil and neutron irradiation is unavoidable at the high burnup and neutron irradiation doses experienced by the AGR-1 fuel particles (Demkowicz et al. 2014). How the buffer responded to dimensional changes and interacted with the IPyC layer often determined whether the IPyC layer remained intact throughout the irradiation test. In the absence of as-fabricated defects as discussed above, all particles with failed $\mathrm{SiC}$ showed evidence that cracked IPyC had exposed the inner surface of the SiC and allowed buildup of fission products that chemically degraded the SiC structure.

Figure 77 shows various ways that IPyC cracking in particles with failed SiC was either directly related to buffer fracture or to the shrinking buffer pulling away from the IPyC. Although buffer fracture or incomplete delamination from the IPyC rarely resulted in IPyC cracking, evidence from materialography of AGR-1 particles suggests that strong bonding between the buffer and IPyC increased the likelihood for IPyC cracking. In the study of $\sim 1000$ particles in AGR-1 compact cross sections, spearhead-shaped fractures like the one shown in Figure 77a were observed in every particle that exhibited buffer fracture where the buffer/IPyC were still attached (Ploger et al. 2014). Overall, observation of the buffer/IPyC interaction in AGR-1 fuel particles has indicated that low interface strength to enhance buffer/IPyC separation would be preferable and could further minimize cracking in IPyC layers like those in the AGR-1 fuel, where pyrocarbon anisotropy and density were successfully tailored to reduce radiation-induced cracking (Demkowicz et al. 2014).

The x-ray images of the safety-tested particles in Figure 77 clearly show low-density regions (darker regions) penetrating the $\mathrm{SiC}$ where the IPyC cracks had reached the $\mathrm{SiC}$ interface (the pathway through the $\mathrm{SiC}$ is less evident in the as-irradiated particle shown in Figure 77c). Clusters of higher density material appear as bright spots in the images and are most prevalent in the areas around the degraded $\mathrm{SiC}$. These clusters are identified in the SEM discussion below as predominantly palladium and uranium and presumed to be linked with localized degradation of the $\mathrm{SiC}$ due to silicide formation. Similar clusters are often observed at intact IPyC-SiC interfaces in irradiated AGR-1 fuel, but at lower concentration and without any obvious adverse impact on the $\mathrm{SiC}$ structure.

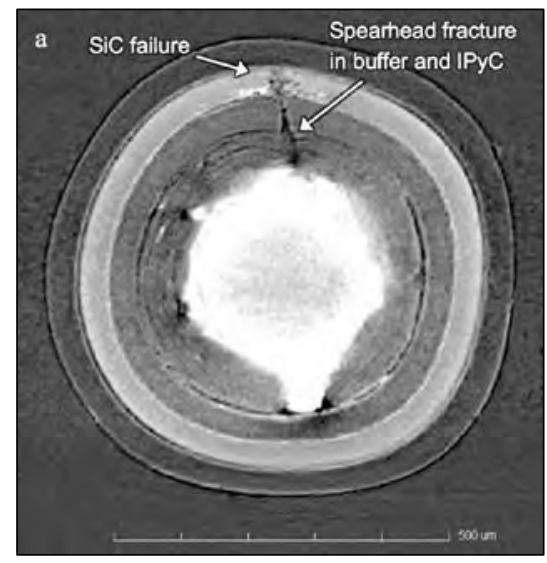

(a)

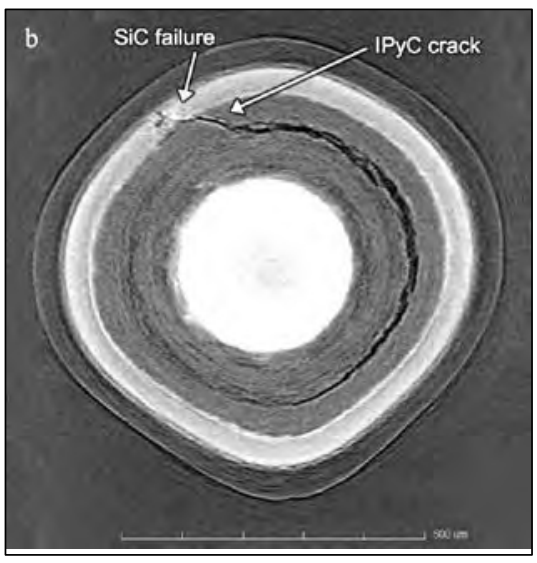

(b)

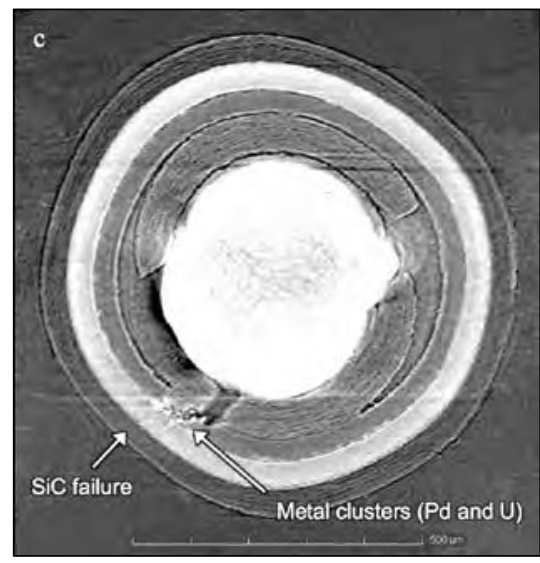

(c)

Figure 77. X-ray tomographs of AGR-1 particles with failed SiC; (a) Compact 3-2-3 Particle 5 after $1800^{\circ} \mathrm{C}$ safety testing, (b) Compact 3-3-1 Particle 1 after $1700^{\circ} \mathrm{C}$ safety testing, and (c) Compact 5-2-3 Particle 2 after completion of AGR-1 irradiation test. 
Figure 77 shows protrusion of kernel material into some of the gaps between the buffer fragments. This was not unusual behavior in particles with fractured buffers and, in general, did not appear to be connected with failed $\mathrm{SiC}$. However, Figure 78 shows a very unusual particle with failed $\mathrm{SiC}$ that was recovered after $1800^{\circ} \mathrm{C}$ safety testing, where the kernel protruded through a spearhead fracture and reached the $\mathrm{SiC}$ layer, resulting in enhanced interaction. Figure 78a also shows delamination at the IPyC-SiC interface extending away from the IPyC crack and leading to tangential cracks in the SiC. These $\mathrm{SiC}$ cracks ran circumferentially and did not result in a $\mathrm{SiC}$ failure. As discussed in Section 3.4.1.2, similar structure has been observed in as-irradiated AGR-1 fuel particles without associated cesium release that would indicate that $\mathrm{SiC}$ cracks traversed the layer; in this particle, the $\mathrm{SiC}$ failure during $1800^{\circ} \mathrm{C}$ safety testing did not occur in the region with circumferential $\mathrm{SiC}$ cracks.

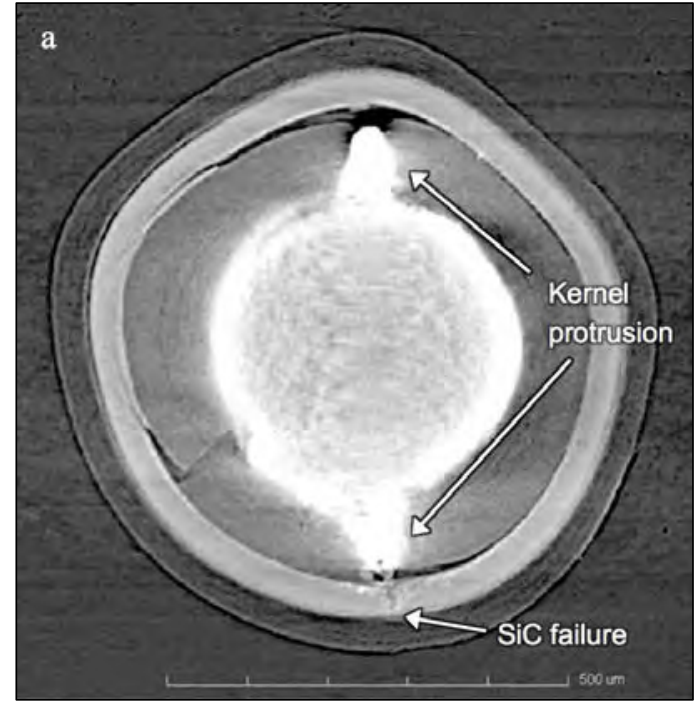

(a)

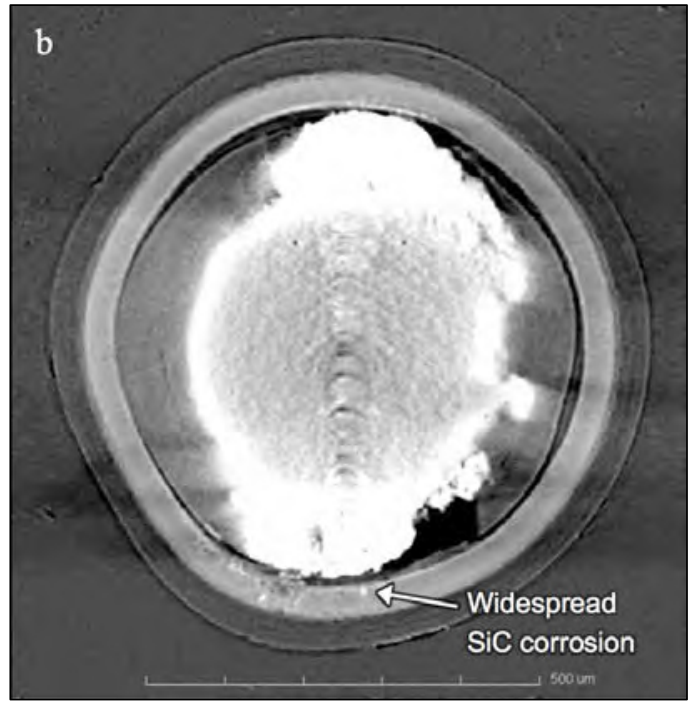

(b)

Figure 78. Orthogonal $\mathrm{x}$-ray tomographs showing kernel protruding to the $\mathrm{SiC}$ in Compact 3-2-3 Particle 6 after $1800^{\circ} \mathrm{C}$ safety testing.

After x-ray imaging, particles were mounted in epoxy and polished planar sections were prepared that revealed a portion of the $\mathrm{SiC}$ failure for detailed analysis. The 3-D x-ray data were studied to determine if the optimum mounting orientation and successive tomographs perpendicular to the grinding direction were compared to optical micrographs of the exposed section to periodically monitor progress and successfully arrive at the target depth by matching up features such as fractures and debonds (Figure 79). 

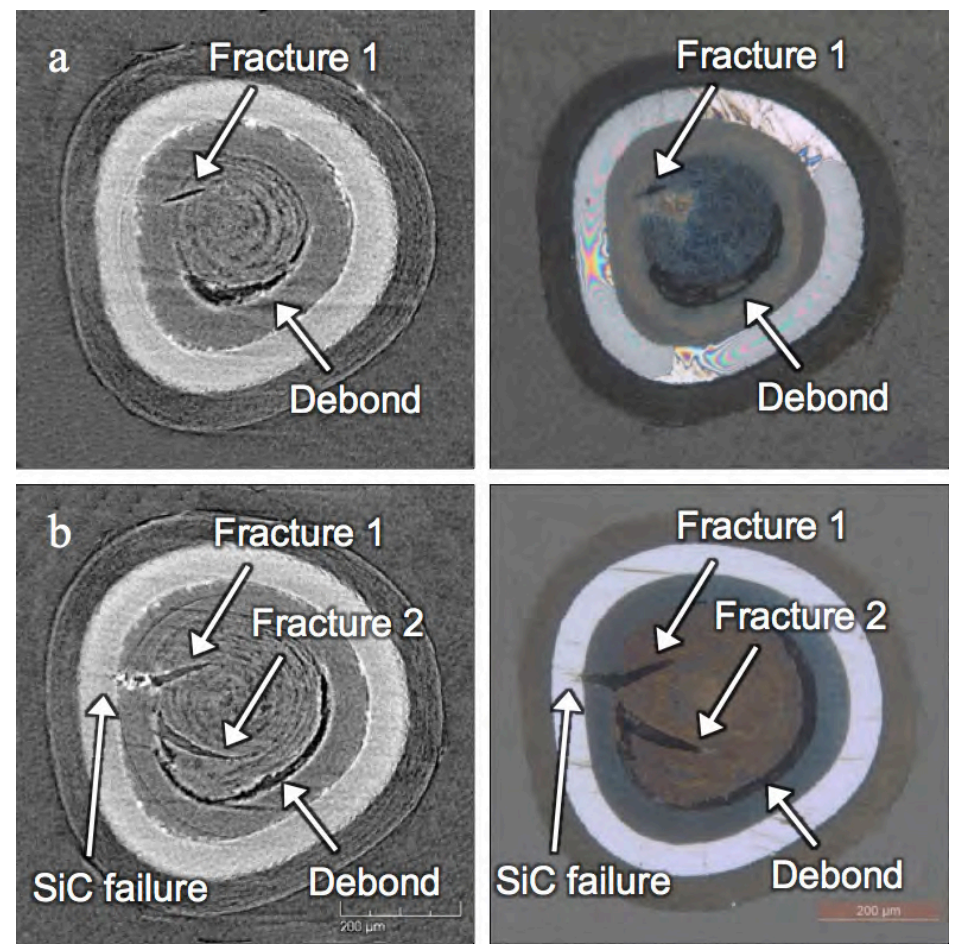

Figure 79. X-ray tomograph/optical micrograph pairs showing how x-ray imaging was used to guide materialographic preparation of the Compact 5-2-3 particle in Figure 77c (grinding up from the bottom of that image). Optical images (right) show in-progress sectioning prior to final polish and cleaning.

Optical microscopy provided additional detail of the region around the SiC failure, but was limited by the fact that the inherent 3-D structure could only be imaged in a single intersecting plane. Connecting pathways through the $\mathrm{SiC}$ layer were rarely visible in a single plane, so presumption of structure above and below the imaged plane must be inferred from the x-ray tomography data. Figure 80 and Figure 81 show planar sections that intersect the $\mathrm{SiC}$ corrosion found in two of the particles that released cesium during the AGR-1 irradiation test.

Particle 1 from Compact 5-2-3 (Figure 80) contained a crack through the IPyC layer; on one side of this crack the buffer was still intimately connected, while on the other side the buffer detached by separating away from itself (leaving some residual material attached to the IPyC). As discussed in Section 3.4.1, IPyC cracks have often been found to be located at a buffer/IPyC delamination boundary like this, and their formation can be presumed to be related to the detachment process. Foreign matter in the IPyC crack is discussed below, where SEM analysis showed the presence of palladium, which is presumed to have been the cause of the local degradation of the SiC layer. Damage in the SiC only penetrates about one-third of the way through the layer in this observation plane, and x-ray tomography could only marginally resolve a low-density pathway through the layer. However, cesium was released from this particle in concentrations too high to be explained by passage through intact $\mathrm{SiC}$ (based on the very low to non-existent cesium loss from particles and compacts in the absence of failed $\mathrm{SiC}$ ).

Presumably, there was damage deeper into the $\mathrm{SiC}$ layer in a plane above or below the image plane or a through-layer failure existed elsewhere in the particle. During grinding, a similar IPyC crack with clustered foreign matter and the onset of SiC attack was observed in Particle 2 from Compact 5-2-3 (Figure 77c), but additional grinding did not unveil the suspected penetration. 


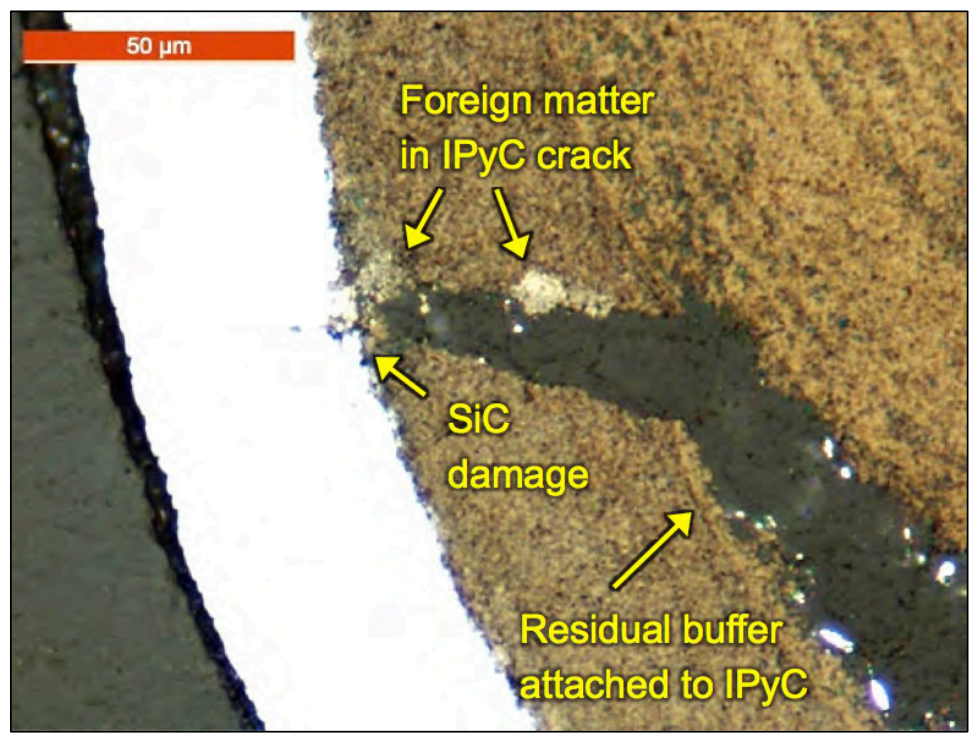

Figure 80. Compact 5-2-3 Particle 1 with $\mathrm{SiC}$ that failed during irradiation testing.

Detailed STEM examinations with associated STEM-EDS compositional analysis were performed on particle AGR1-523-SP01, focusing on the area of the crack tip (shown in Figure 80). This study revealed that pure carbon areas exist in the $\mathrm{SiC}$ layer close to the crack, with $\mathrm{Pd}_{2} \mathrm{Si}$ or $\mathrm{PdSi}$ inside the pure carbon areas, indicating localized corrosion of $\mathrm{SiC}$ by $\mathrm{Pd}$. Such corroded areas were not observed in locations in the $\mathrm{SiC}$ layer away from the crack. $\mathrm{Ag}$ and/or $\mathrm{Cd}$ are frequently identified in palladium silicides and $\mathrm{Pd}$ precipitates located in the carbon areas in the $\mathrm{SiC}$ layer, sometimes with very significant $\mathrm{Ag}$ or $\mathrm{Cd}$ concentrations. This finding suggests that $\mathrm{Ag}$ and $\mathrm{Cd}$ partition to palladium silicides and $\mathrm{Pd}$ in the carbon areas and migrate together with the palladium silicides and Pd through the carbon areas and across the $\mathrm{SiC}$ layer. Cs was identified separately in nano-cracks in the carbon areas in the SiC layer, indicating that nanocracks provide pathways for Cs transport. In addition, some palladium silicides in the carbon areas contain small concentrations of Cs. Some palladium silicides in the pure carbon areas in the SiC layer also contain small concentrations of $\mathrm{U}$. Ag and $\mathrm{Cd}$ do not coexist with $\mathrm{U}$ or $\mathrm{Cs}$ in palladium silicides examined in this particle (Wen et al. 2015c; Wen and Van Rooyen 2015d).

The particle from Compact 5-2-1 that released cesium during the AGR-1 irradiation test showed a more obvious through-layer penetration in the x-ray imaging (Figure 81a) and a large degraded area in the $\mathrm{SiC}$ was clearly evident while sectioning the particle. As grinding progressed through the damaged region, the position of the degraded area in the observed plane moved from the outer edge of the SiC toward the IPyC-SiC interface, indicating the corrosion pathway through the layer was oriented at an angle to the grinding plane. Sectioning was halted at the plane shown in Figure 81b so that SEM analysis could be performed prior to risking further material removal to reveal the initial point of attack at the IPyC-SiC interface where the IPyC crack extended to the $\mathrm{SiC}$ and corrosion presumably initiated. 


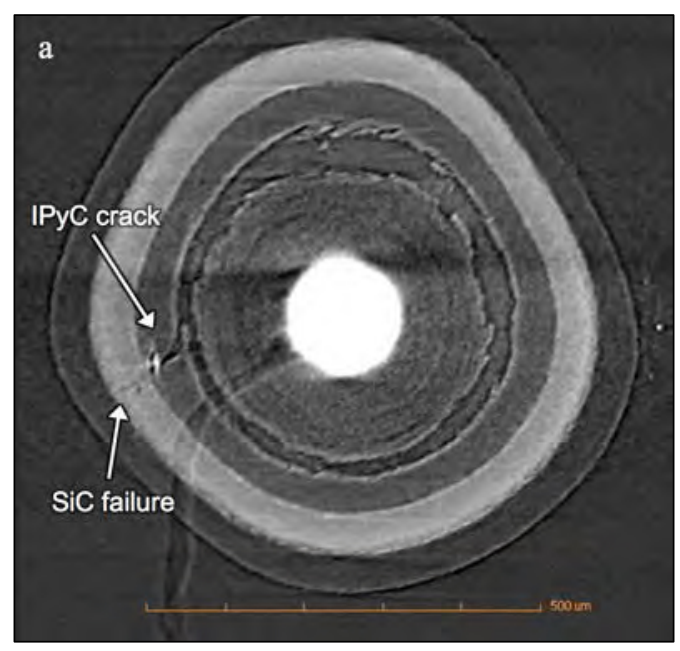

(a)

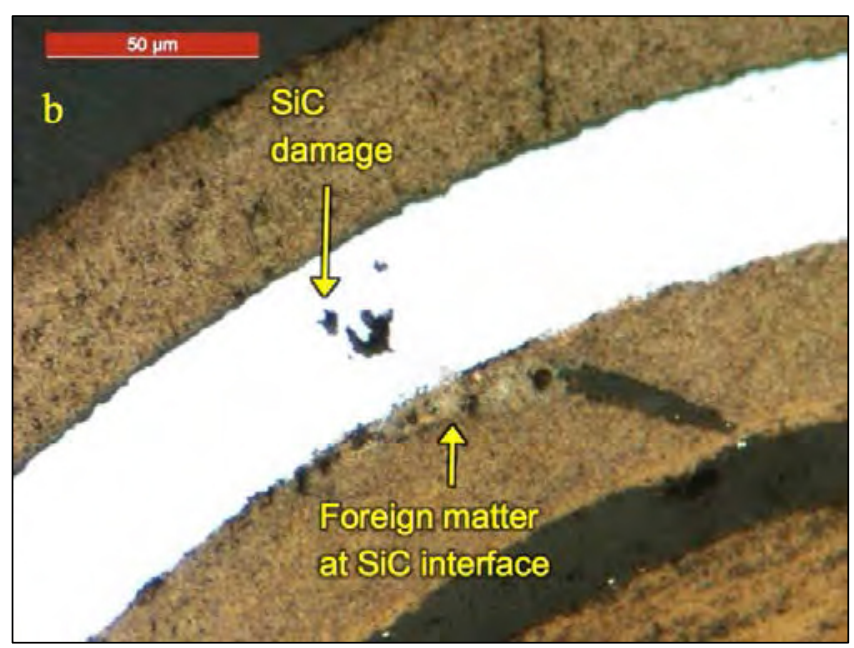

(b)

Figure 81. Particle from Compact 5-2-1 that failed during irradiation testing; (a) x-ray tomograph oriented to show low-density pathway through $\mathrm{SiC}$, and (b) optical micrograph showing degraded area.

Figure 82 shows SEI SEM images of two parallel planar sections through one of the two particles recovered from Compact 3-3-1 that released cesium during $1700^{\circ} \mathrm{C}$ safety testing; these two planes are slightly offset in the grinding direction and reveal the same degraded pathway through the $\mathrm{SiC}$ at two different positions. As with the particle from Compact 5-2-1 discussed in the previous paragraph, the degraded pathway was oriented at an angle to the grinding plane so the degradation site appears in two different positions in the images in Figure 82. The IPyC layer was decorated with high-Z clusters that EDS identified as mostly uranium, except in the region surrounding the IPyC crack where there appeared to be a depletion of these clusters. The corrosion pathway through the $\mathrm{SiC}$ was surrounded by numerous clusters of high-Z elements ranging in diameter from $<1$ to $5 \mu \mathrm{m}$ and identified by EDS to be predominantly palladium and uranium (these clusters may also contain silicon and carbon, which could not be resolved due to signal from surrounding material included in the electron excitation volume). Palladium and uranium were also observed at the IPyC-SiC interface around the entire circumference of the particle, but away from the degraded area, the IPyC-SiC interface remained intact and no significant $\mathrm{SiC}$ corrosion was observed. The predominance of palladium and uranium surrounding the degraded area, in conjunction with the free carbon that was observed within the area, suggests that these metals may have reacted with the $\mathrm{SiC}$ to form silicides that migrated away, leaving a carbon-filled pathway through the $\mathrm{SiC}$ that would not retain cesium. 


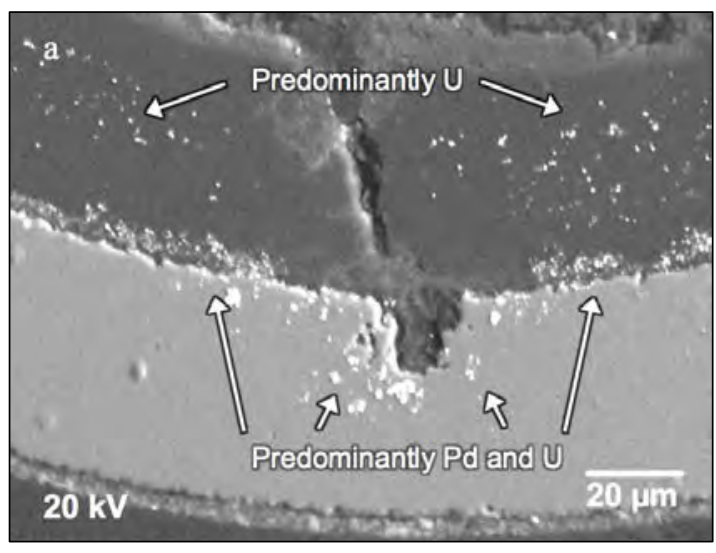

(a)

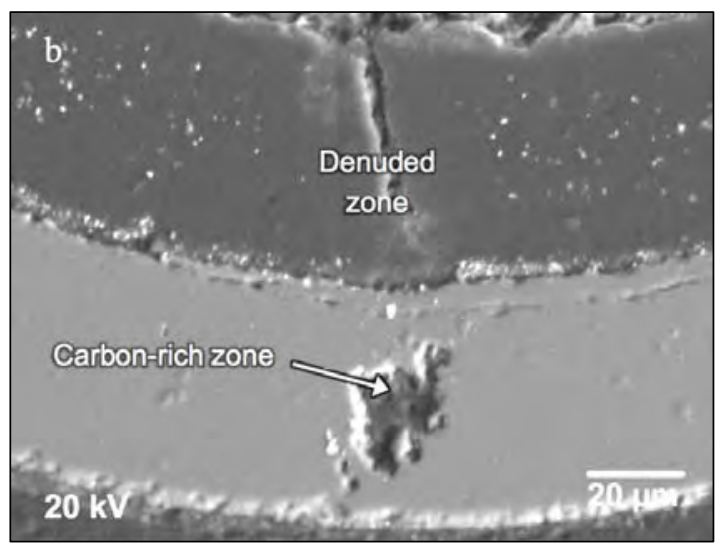

(b)

Figure 82. Successive polished planar sections showing corrosion progression through $\mathrm{SiC}$ of Compact 3-3-1 Particle 2 after $1700^{\circ} \mathrm{C}$ safety testing.

Figure 83 shows $\mathrm{SEI}$ and $\mathrm{BEC}$ images of a degraded area in the $\mathrm{SiC}$ that was revealed by sectioning the other particle recovered from Compact 3-3-1 that released cesium during $1700^{\circ} \mathrm{C}$ safety testing. The exposed plane in this figure was prepared by grinding down from the top of the particle (as shown in Figure 77b) and stopping at the edge of the corrosion site before the center of the low-density feature was exposed. A dense population of high-Z clusters decorates the degraded zone. The secondary electron image (Figure 83a) shows that the carbon-rich (gray) and metal-rich (white) features are flush with the polished surface and densely fill their resident volumes (except for the largest carbon-rich feature, which may have experienced some pullout during grinding and polishing).

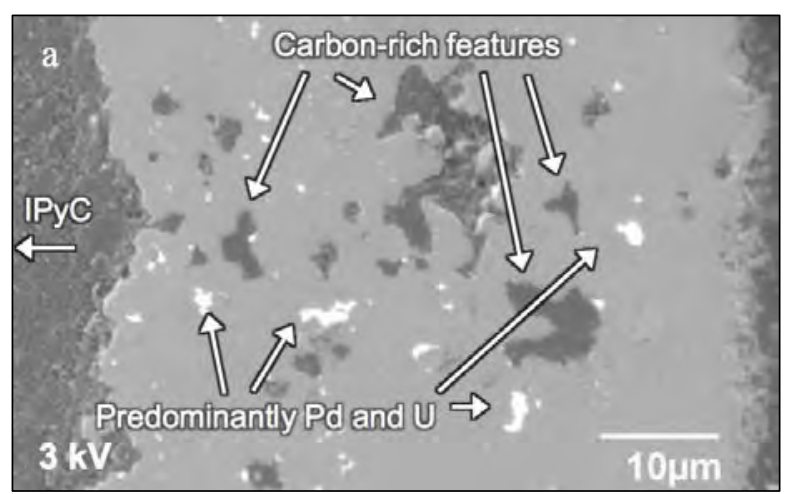

(a)

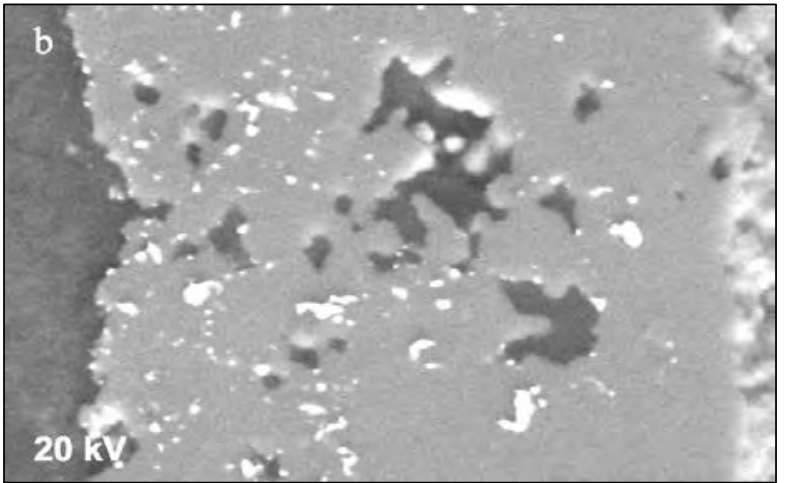

(b)

Figure 83. Polished planar section through degraded $\mathrm{SiC}$ area in Compact 3-3-1 Particle 1 (Figure 77b) after $1700^{\circ} \mathrm{C}$ safety testing; (a) SEI and (b) BEC images that show numerous white clusters of palladium and uranium and other dark gray areas that were predominately carbon. The SEI image shows bright spots where Pd and $\mathrm{U}$ are embedded close to the surface, while the BEC image shows additional Pd and U due to greater sensitivity and analysis depth. 


\subsection{Enumeration of Particles with Failed SiC}

Determination of the number of particles in each compact with failed $\mathrm{SiC}$ was based on a combination of data on the amount of cesium released from the compact, the amount of exposed cesium still in the compact outside of intact SiC layers (measured by DLBL), and the amount of cesium retained by the particles with failed $\mathrm{SiC}$ that were separated out and measured by IMGA. Supporting data for counting particles with failed SiC involved enumeration of the low-cesium retaining particles found with IMGA (with examination by $\mathrm{x}$-ray to verify the presence of failed $\mathrm{SiC}$ ) and additional DLBL data of uranium from exposed kernels indicative of the loss of particles with failed $\mathrm{SiC}$ during deconsolidation, leaching, and sieving prior to the IMGA survey. Table 20 and Table 21 present results using these two approaches.

While cesium and uranium measurements rarely summed to an integer value due to analysis uncertainty (typically $\sim 10 \%$ ), hot cell contamination, variation in actual isotopic content, and loss of volatile cesium during analysis, enumeration using the two methods in Table 20 and Table 21 agreed very well. Only two of the compacts safety tested at $1800^{\circ} \mathrm{C}$ yielded different estimated totals. Possible explanation for the disagreement for Compact 4-4-1 was that one particle broke during the sieving operation (indicated by uranium detected in the burn-leach of the matrix debris remaining after separating out the particles). Some of the cesium from this particle would have been lost during the $750^{\circ} \mathrm{C}$ burn and not included in Table 20, resulting in a lower total count compared to Table 21. In addition, the SiC in this particle may not have failed during safety testing (it may have been broken by handling during the sieving process), resulting in an overestimation of the number of particles with failed $\mathrm{SiC}$ in Table 21. It is unclear why the estimated totals for Compact 5-1-3 disagree; however, uncertainty in the ${ }^{134} \mathrm{Cs}$ analysis could be responsible.

Four particles with failed $\mathrm{SiC}$ were identified out of the 298,000 particles included in the AGR-1 irradiation experiment - a measured SiC failure fraction of $1.3 \times \mathrm{E}^{-5}$. The small amount of uranium detected in Compacts 5-2-1 and 5-2-3 was not from exposed kernels, and more than $75 \%$ was located in the $\mathrm{OPyC}$ of the main particle sample, which did not include the particles with failed SiC. This uranium was presumably released during irradiation and represents a compact fractional release of about $6.5 \times 10^{-5}$. Compact 6-3-2 was examined at INL and DLBL was used, in lieu of IMGA survey, to determine that only one particle with failed $\mathrm{SiC}$ was responsible for most of the cesium release from that compact during irradiation. Slightly more than one particle's average inventory of cesium and uranium was detected, but these values would also be impacted by analysis uncertainties and low-level releases from particles with intact $\mathrm{SiC}$.

Only three particles with failed $\mathrm{SiC}$ were detected in compacts safety tested at $1600^{\circ} \mathrm{C}$, one from each of three compacts. Eight compacts $(\sim 33,100$ particles $)$ were tested at $1600^{\circ} \mathrm{C}$, with no failed $\mathrm{SiC}$ in the other five; this equates to a measured $\mathrm{SiC}$ failure fraction of $9.1 \times \mathrm{E}^{-5}$. As shown in Figure 73 and Figure 74, the particles with failed $\mathrm{SiC}$ from Compacts 3-3-2 and 4-1-2 both had material missing from the kernel. This is in agreement with the uranium detected during DLBL of these compacts (Table 21). The particle from Compact 4-1-2 was missing its OPyC layer when recovered for IMGA, and this presumably was fractured during the third 24-hour nitric acid leach performed on the deconsolidated particles, which was when $80 \%$ of the exposed uranium was detected. In contrast, most of the exposed uranium in Compact 3-3-2 (91\%) was detected during the matrix burn after pre-burn leaching and separation of the particles for IMGA survey; this suggests that uranium may have come out of the Compact 3-3-2 particle with failed SiC during irradiation. The fact that 3-D x-ray examination revealed no cracks in the pyrocarbon layers of this particle makes penetration of acid to the kernel unlikely. During irradiation, the kernel was only encapsulated by a very thin layer of intact $\mathrm{SiC}$ due to the gross soot inclusion. Uranium may have escaped through this thin SiC. 
Table 20. Estimation of the number of particles with failed $\mathrm{SiC}$ based on recovery of ${ }^{134} \mathrm{Cs}$.

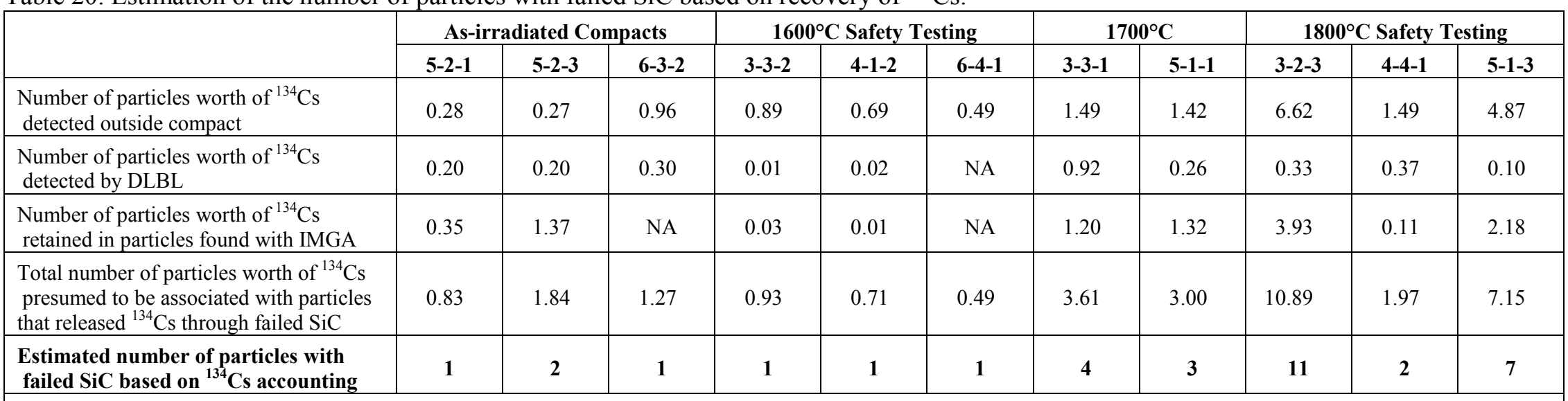

NA denotes that data is not available because analysis was not performed.

For compacts safety tested at $1800^{\circ} \mathrm{C},{ }^{134} \mathrm{Cs}$ detected in post-burn leach of particles analyzed after IMGA survey was not included because a few particles with normal cesium retention were broken by the process and particles with failed $\mathrm{SiC}$ had already been removed from sample and accounted for with IMGA.

No low-cesium particles from Compact 4-4-1 were found with IMGA, but fragments from at least two particles, including one buffer-coated kernel, were manually recovered after pre-burn leaching and gamma counted to measure ${ }^{134} \mathrm{Cs}$ inventory ( $\mathrm{SiC}$ in the recovered fragments showed signs of corrosion failure).

Table 21. Estimation of the number of particles with failed SiC based on identification by the IMGA and DLBL.

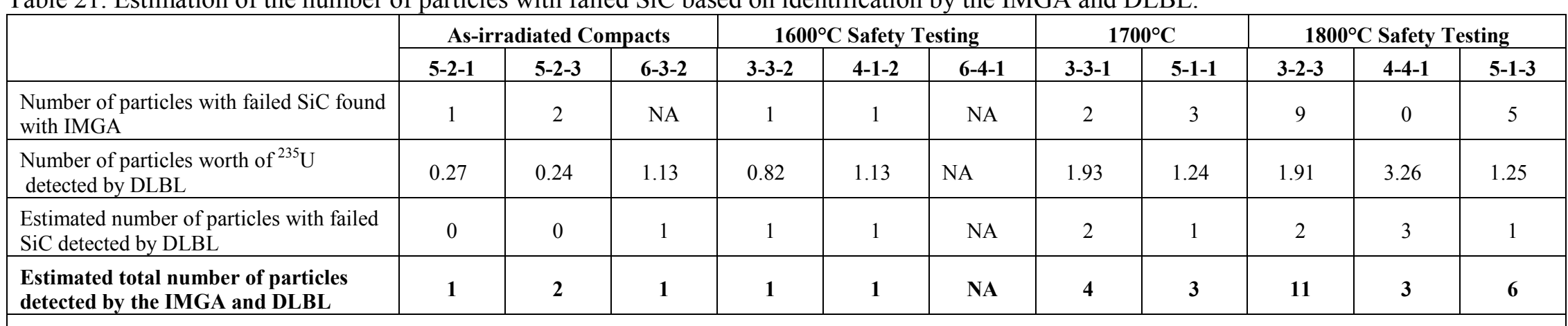

NA denotes that data is not available because analysis was not performed.

Compacts 3-3-2 and 4-1-2 each had one particle with failed SiC; uranium was leached prior to IMGA, but particles remained in one piece and were found during IMGA survey.

Compacts 5-1-1 had one particle with a gross $\mathrm{SiC}$ soot inclusion; uranium was leached prior to IMGA, but particle remained in one piece and was found during IMGA survey.

For compacts safety tested at $1800^{\circ} \mathrm{C}{ }^{235} \mathrm{U}$ detected in post-burn leach of particles analyzed after IMGA survey was not included because a few particles with normal cesium retention were broken by the process and particles with failed $\mathrm{SiC}$ had already been removed from sample and accounted for with IMGA. 
The likelihood of damaging particles during the deconsolidation, leaching, and sieving prior to IMGA survey seemed to increase for the higher temperature safety tests. This could be related to weakening of the OPyC layer, which was the only intact layer protecting the kernel from acid leaching in the particles with failed $\mathrm{SiC}$ recovered after 1700 and $1800^{\circ} \mathrm{C}$ safety testing. The debonding between the $\mathrm{SiC}$ and OPyC layers and increasing gap as a function of safety test temperature may contribute to the greater tendency for OPyC cracking during deconsolidation and leaching.

There was more variation in the number of $\mathrm{SiC}$ failures observed during the higher temperature safety testing. Three compacts $(\sim 12,400$ particles $)$ were tested at $1700^{\circ} \mathrm{C}$, with a total of seven particles with failed $\mathrm{SiC}$ in two of the compacts. Four compacts were safety tested at $1800^{\circ} \mathrm{C}(\sim 16,500$ particles $)$. Approximately 20 particles with $\mathrm{SiC}$ failures were detected in the three compacts in Table 20 and Table 21 that were tested at $1800^{\circ} \mathrm{C}$. A fourth compact, Compact 4-3-2, was determined by separate analysis to most likely have had three particles with failed SiC (Demkowicz et al. 2015e). This equates to measured $\mathrm{SiC}$ failure fractions of $5.6 \times 10^{-4}$ and $1.4 \times 10^{-3}$ for $1700^{\circ} \mathrm{C}$ and $1800^{\circ} \mathrm{C}$, respectively, with the overall trend being an increasing failure fraction as safety test temperature increased.

Table 22 summarizes the $\mathrm{SiC}$ and TRISO failure fractions calculated based on experimentally determined failure rates for the AGR-1 irradiation and safety testing. Failure fractions are presented in terms of the measured fraction in each tested sample and the $95 \%$-confidence upper-limit (predicted using binomial distribution statistics) for the four combined AGR-1 fuel composites.

Table 22. Summary of SiC and TRISO failure fractions in AGR-1 fuel during irradiation and safety testing.

\begin{tabular}{|c|c|c|c|c|c|c|c|}
\hline \multirow[b]{3}{*}{$\begin{array}{c}\text { Particle } \\
\text { Conditions }\end{array}$} & \multirow{3}{*}{$\begin{array}{l}\text { Number } \\
\text { of } \\
\text { Particles } \\
\text { Tested } \\
\end{array}$} & \multicolumn{3}{|c|}{ SiC Failures } & \multicolumn{3}{|c|}{ TRISO Failures } \\
\hline & & \multirow[b]{2}{*}{$\begin{array}{l}\text { Number of } \\
\text { Failures }\end{array}$} & \multicolumn{2}{|c|}{ Failure Fraction } & \multirow{2}{*}{$\begin{array}{c}\text { Number } \\
\text { of } \\
\text { Failures }\end{array}$} & \multicolumn{2}{|c|}{ Failure Fraction } \\
\hline & & & Measured & $\begin{array}{c}95 \% \\
\text { Confidence }\end{array}$ & & Measured & $\begin{array}{c}95 \% \\
\text { Confidence } \\
\end{array}$ \\
\hline As-irradiated & $\sim 298,000$ & 4 & $1.3 \times 10^{-5}$ & $\leq 3.1 \times 10^{-5}$ & 0 & 0 & $\leq 1.1 \times 10^{-5}$ \\
\hline $\begin{array}{l}1600^{\circ} \mathrm{C} \\
\text { safety-tested }\end{array}$ & $\sim 33,100$ & $\begin{array}{c}3 \\
(1)\end{array}$ & $\begin{array}{l}9.1 \times 10^{-5} \\
\left(3.0 \times 10^{-5}\right)\end{array}$ & $\begin{array}{l}\leq 2.4 \times 10^{-4} \\
\left(\leq 1.5 \times 10^{-4}\right)\end{array}$ & 0 & 0 & $\leq 9.1 \times 10^{-5}$ \\
\hline $\begin{array}{l}1700^{\circ} \mathrm{C} \\
\text { safety-tested }\end{array}$ & $\sim 12,400$ & $\begin{array}{c}7 \\
(6) \\
\end{array}$ & $\begin{array}{l}5.6 \times 10^{-4} \\
\left(4.8 \times 10^{-4}\right)\end{array}$ & $\begin{array}{l}\leq 1.1 \times 10^{-3} \\
\left(\leq 9.6 \times 10^{-4}\right)\end{array}$ & 0 & 0 & $\leq 2.5 \times 10^{-4}$ \\
\hline $\begin{array}{l}1800^{\circ} \mathrm{C} \\
\text { safety-tested }\end{array}$ & $\sim 16,500$ & $23^{\mathrm{a}}$ & $1.4 \times 10^{-3}$ & $\leq 2.0 \times 10^{-3}$ & 2 & $1.2 \times 10^{-4}$ & $\leq 3.9 \times 10^{-4}$ \\
\hline
\end{tabular}

\section{CONCLUSIONS}

The AGR-1 post-irradiation examination and safety testing campaign represents the most extensive such assessment of performance of U.S.-manufactured TRISO fuel. A diverse array of exams and tests was employed to evaluate in-pile fuel performance and out-of-pile performance at elevated temperatures. The work focused on assessing the degree of fission product release from the fuel, the behavior of fission products within the particles, and the evolution of kernel and coating morphology during irradiation. The work involved nondestructive examination of all 72 fuel compacts in the experiment, examination of the irradiation capsule components, destructive examination of 15 fuel compacts, and safety testing plus follow-on destructive examination on 17 fuel compacts. The results generally confirm the excellent performance of the fuel, and have elucidated some behaviors that have not been well understood based on previous examination of irradiated TRISO fuel.

Some of the key findings from the AGR-1 PIE and safety testing are summarized below. 


\subsection{Fission Product Behavior}

\subsubsection{Silver}

- Silver release from the fuel during irradiation can be high, and the range of values observed is presumed to be mostly due to time-dependent temperature variations in the fuel. Capsule-average

${ }^{110 \mathrm{~m}} \mathrm{Ag}$ fractional release from the compacts ranged from 0.01 to 0.38 ; fractional release from individual compacts ranged from near zero to 0.92 ; release from individual particles ranged from essentially zero to near 1.0.

- Silver release from compacts at 1600 and $1700^{\circ} \mathrm{C}$ appears to be dominated by inventory that was in the compact matrix at the end of irradiation and was released rapidly as the compacts were heated to the target safety test temperature. Any additional release from the particles at these temperatures can be considered insignificant to the overall fuel performance given the already high release under normal operation.

- No specific SiC microstructural differences among particles have been identified that can be related to different levels of silver release during irradiation. However, it has been observed that the Variant 3 (fine-grained) $\mathrm{SiC}$ exhibited an increase in silver release rate during heating at $1800^{\circ} \mathrm{C}$ that was not observed during similar heating of Baseline (coarser-grained) SiC. The results imply different diffusive behavior of silver that is related to the $\mathrm{SiC}$ microstructure differences. Individual Variant 3 particles heated for 650 hours (more than twice the normal safety test period of 300 hours) showed a continuation of silver release at this increased rate until their silver inventory was depleted.

- Some heating tests of irradiated fuel at operating temperatures (in the range of 1075 to $1375^{\circ} \mathrm{C}$ ) resulted in secondary silver releases beyond what was attributed to release that occurred during irradiation. Additional tests are planned to explore this phenomenon.

- Silver is found in small quantities in the SiC microstructure of irradiated particles, often co-located with other fission products (especially palladium). The location of the silver is within the normal polycrystalline $\mathrm{SiC}$ microstructure (at the grain boundaries and much more rarely inside the grains). There has been no evidence that the general release of silver is related to cracks or significant degradation of the microstructure.

\subsubsection{Cesium}

- Cesium release from intact particles is very low, both in-pile and at temperatures as high as $1800^{\circ} \mathrm{C}$. The capsule-average ${ }^{134} \mathrm{Cs}$ fraction release from the compacts in-pile was $<3 \times 10^{-6}$ for all capsules.

- Release from individual particles can be relatively high in the event of a failure of the SiC layer.

- Cesium release is a strong function of the number of $\mathrm{SiC}$ failures. The experimentally derived failure fractions of $\mathrm{SiC}$ were higher during safety testing than during the irradiation, and increased with a higher safety test temperature.

- Some fabrication defects can result in $\mathrm{SiC}$ failure and subsequent cesium release. This was only observed during safety testing of AGR-1 fuel and the related defect structures that were revealed testified to the resilience of the $\mathrm{SiC}$ layer at normal reactor operating temperature.

\subsubsection{Krypton}

- ${ }^{85} \mathrm{Kr}$ release is low at $1600^{\circ} \mathrm{C}\left(<5 \times 10^{-6}\right)$, and increases at 1700 and $1800^{\circ} \mathrm{C}$ due to failed $\mathrm{SiC}$ (maximum release in compacts with failed $\mathrm{SiC}$, but no failed TRISO, was $\sim 6 \times 10^{-5}$ after 300 hours at $1800^{\circ} \mathrm{C}$ ) or due to failed TRISO (a single compact heated at $1800^{\circ} \mathrm{C}$ experienced two particles with failed TRISO and reached a release of $5 \times 10^{-4}$ ), or essentially $100 \%$ of the ${ }^{85} \mathrm{Kr}$ inventory in those two particles). 


\subsubsection{Palladium}

- Palladium release has been observed in-pile $\left({ }^{105} \mathrm{Pd}\right.$ fractions of $6 \times 10^{-3}$ to $3 \times 10^{-2}$ in compact matrix or $\mathrm{OPyC})$.

- Palladium is routinely identified in small clusters at the IPyC-SiC interface and in smaller clusters within the $\mathrm{SiC}$ microstructure, often with other fission products and uranium.

- Inspite of the prevalent presence of palladium in contact with the $\mathrm{SiC}$, no extensive, widespread palladium corrosion of the $\mathrm{SiC}$ layer has been observed in particles with an intact IPyC layer; however, palladium corrosion appears to cause $\mathrm{SiC}$ failure in relatively rare particles that experience IPyC layer fracture, which appears to result in greater localized concentration of palladium.

\subsubsection{Strontium, Europium}

- Strontium and europium are released at low levels through intact $\mathrm{SiC}$ in-pile, but most remains trapped in the carbanaceous OPyC and compact matrix $-1 \times 10^{-6}$ to $3 \times 10^{-3}\left({ }^{90} \mathrm{Sr}\right)$ and $2 \times 10^{-4}$ to $1 \times 10^{-2}\left({ }^{154} \mathrm{Eu}\right)$.

- In-pile capsule-average fractional release from compacts was only a small fraction of what was released by the $\mathrm{SiC}-8 \times 10^{-7}$ to $3 \times 10^{-5}\left({ }^{90} \mathrm{Sr}\right)$ and $1 \times 10^{-4}$ to $5 \times 10^{-4}\left({ }^{154} \mathrm{Eu}\right)$.

- Release from compacts after approximately 300 hours at $1600^{\circ} \mathrm{C}$ was $10^{-5}$ to $2 \times 10^{-3}\left({ }^{90} \mathrm{Sr}\right)$ and $3 \times 10^{-4}$ to $2 \times 10^{-3}\left({ }^{154} \mathrm{Eu}\right)$. The maximum values were about a factor of 10 higher at $1800^{\circ} \mathrm{C}$.

- The majority of strontium and europium release during safety tests appears to be from inventory in the compact matrix at end of irradiation; however, some evidence of release from intact $\mathrm{SiC}$ at $1800^{\circ} \mathrm{C}$ was observed in Variant 3 fuel. This may be also occurring at less significant rates from other fuel types and at lower temperatures from all fuel types, but release at these levels is not readily discernable in the safety tests.

\subsection{Particle Microstructure}

- UCO fuel is effective at controlling the oxygen partial pressure within the particle and limiting kernel migration.

- Radiation-induced densification of the buffer occurs in all particles.

- Buffer fractures that occur due to densification are fairly common. These do not appear to cause damage to the pyrocarbon or $\mathrm{SiC}$ layers when the buffer detaches completely from the IPyC layer. Fractures of the IPyC layer are usually associated with buffer adhesion. Therefore, it is concluded that buffer-IPyC detachment is desirable.

- Buffer fracture is often accompanied by asymmetric swelling of the kernel into the open regions between buffer fragments and the kernel can sometimes protrude all the way to the inner surface of the IPyC or SiC. In contrast, intact buffers act to constrain kernel swelling.

- Kernel and coating morphology appears to have little dependence on burnup over the range $11-19 \%$ FIMA. Other factors besides local irradiation conditions appear to dominate the behavior.

- Our understanding of $\mathrm{SiC}$ failure mechanisms has greatly increased as a result of the location and extensive examination of particles, which experienced $\mathrm{SiC}$ failure; this was made possible through the use of automated gamma analysis and previously unavailable non-destructive high-resolution x-ray tomography. The predominant cause appears to be a two-part mechanism involving (1) fracture of the IPyC layer due to densification of adherent buffer layer and (2) localized palladium accumulation at the IPyC-SiC interface in the region of the IPyC fracture and subsequent degradation of the $\mathrm{SiC}$ layer through the formation of palladium silicides. Palladium accumulation and $\mathrm{SiC}$ degradation are accelerated at elevated temperatures. 
- Our understanding of Ag transport mechanisms increased significantly as Ag was identified to be predominantly present at $\mathrm{SiC}$ grain boundaries and triple points, with only two occurrences inside the $\mathrm{SiC}$ grains - one of which was located at a stacking fault. Ag was also identified to co-exist with palladium and cadmium in most cases and was never identified in co-existence with uranium.

- These results seem to be supportive of both grain boundary transport and chemical species (Pd and/or $\mathrm{Cd}$ ) assisted transport mechanisms. It is hypothesized that the $\mathrm{Ag}$ transport mechanism is likely more complex and may be a combination of mechanisms.

- Variant 3 fuel particles showed different fission product cluster compositional behavior compared with both Baseline and Variant 1 fuel types.

- Nano-sized fission products precipitates were identified through the full $\mathrm{SiC}$ layer thickness of intact particles examined using advanced microscopic techniques like STEM and HRTEM.

- Fission products favor precipitation on random, high-angle grain boundaries for a Baseline fuel particle, but can precipitate out on low-angle and CSL-related grain boundaries to a limited degree. Ag precipitates occur only at random high-angle boundaries and never low-angle or CSL boundaries.

- Fission product precipitates at grain boundaries and triple points consist of either single or multi-phases.

\subsection{General Observations}

- The measured burnup of the AGR-1 fuel compacts agrees very well with physics predictions. 


\section{REFERENCES}

\subsection{AGR-1 Post-Irradiation Examination Topical Reference List}

Table 23. AGR-1 PIE references listed by topical area.

\begin{tabular}{|c|c|}
\hline Topical area & References \\
\hline $\begin{array}{l}\text { Test train inspection, disassembly, and } \\
\text { metrology }\end{array}$ & Demkowicz et al. 2011 \\
\hline Flux and melt wire analysis & $\begin{array}{l}\text { Greenwood } 2012 \\
\text { Sterbentz et al. } 2015\end{array}$ \\
\hline Capsule component analysis & $\begin{array}{l}\text { Demkowicz et al. } 2013 \\
\text { Harp, Demkowicz, and Ploger } 2012 \\
\text { Harp and Ploger } 2011\end{array}$ \\
\hline Compact non-destructive analysis & Harp 2014 \\
\hline Compact cross section analysis & $\begin{array}{l}\text { Ploger et al. 2012a } \\
\text { Ploger et al. 2012b } \\
\text { Ploger et al. } 2014\end{array}$ \\
\hline $\begin{array}{l}\text { Compact deconsolidation-leach-burn-leach, } \\
\text { particle gamma counting, and } \\
\text { microanalysis }\end{array}$ & $\begin{array}{l}\text { Demkowicz et al. 2012 } \\
\text { Demkowicz et al. 2015a } \\
\text { Demkowicz et al. 2015b } \\
\text { Demkowicz et al. 2015c } \\
\text { Demkowicz et al. 2015d } \\
\text { Hunn et al. 2012a } \\
\text { Hunn et al. 2012b } \\
\text { Hunn et al. 2013a } \\
\text { Hunn et al. 2013b } \\
\text { Hunn et al. 2014b } \\
\text { Van Rooyen et al. 2012a } \\
\text { Van Rooyen et al. 2014b; } \\
\text { Van Rooyen et al. 2015c }\end{array}$ \\
\hline Burnup analysis & $\begin{array}{l}\text { Harp } 2014 \\
\text { Harp et al. } 2014 \\
\text { Sterbentz et al. } 2015 \\
\end{array}$ \\
\hline High temperature safety testing & $\begin{array}{l}\text { Hunn et al. 2012d } \\
\text { Hunn et al. 2013b } \\
\text { Hunn et al. 2013c } \\
\text { Hunn et al. 2013d } \\
\text { Hunn et al. 2014e } \\
\text { Hunn et al. 2014f } \\
\text { Morris et al. 2014 } \\
\text { Demkowicz et al. 2015e } \\
\text { Baldwin et al. 2012 } \\
\text { Baldwin et al. 2014 } \\
\end{array}$ \\
\hline
\end{tabular}

\begin{tabular}{|l|l|}
\hline \multicolumn{1}{|c|}{ Topical area } & \multicolumn{1}{|c|}{ References } \\
\hline & Van Rooyen et al. 2012b \\
& Van Rooyen et al. 2013 \\
& Van Rooyen et al. 2013a \\
& Van Rooyen, Lillo, and Wu 2014 \\
& Van Rooyen et al. 2014a \\
& Van Rooyen et al. 2014b \\
& Van Rooyen et al. 2014c \\
& Van Rooyen et al. 2015a \\
& Van Rooyen et al. 2015b \\
& Van Rooyen et al. 2015c \\
& Leng et al. 2015 \\
& Lillo and van Rooyen 2015a \\
& Lillo and van Rooyen 2015b \\
& Lillo and van Rooyen 2015c \\
& Lillo and van Rooyen 2015 \\
& Wen et al. 2015a \\
& Wen et al. 2015b \\
& Wen et al.2015c \\
& Wen and van Rooyen 2015d \\
\hline \multirow{5}{*}{ Causes of SiC failure } & Baldwin et al. 2012 \\
& Baldwin et al. 2014 \\
\hline analysis & Hunn et al. 2012b \\
& Hunn et al. 2012c \\
& Hunn et al. 2013b \\
& Hunn et al. 2014a \\
& Hunn et al. 2014c \\
& Hunn et al. 2015a \\
& Hunn et al. 2015b \\
& Demkowicz et al. 2015f \\
\hline & Hunn et al. 2015b \\
& Hunn et al. 2014b \\
& Hunn et al. 2014d \\
\hline & \\
\hline
\end{tabular}




\subsection{Bibliography}

Amian, W., D. Stöver, 1983, "Diffusion of silver and cesium in silicon-carbide coatings of fuel particles for high-temperature gas-cooled reactors," Nuclear Technology, Vol. 61, pp. 475-486.

Baldwin, C. A., J. D. Hunn, R. N. Morris, F. C. Montgomery, C. M. Silva, and P. A. Demkowicz, 2012, "First Elevated Temperature Performance Testing of Coated Particle Fuel Compacts from the AGR-1 Irradiation Experiment," Paper HTR2012-3-027, Proceedings of the 6th International Topical Meeting on High Temperature Reactor Technology, HTR 2012, Tokyo, Japan October 28November 1, 2012.

Baldwin, C. A., J. D. Hunn, R. N. Morris, F. C. Montgomery, C. M. Silva, and P. A. Demkowicz, 2014, "First elevated-temperature performance testing of coated particle fuel compacts from the AGR-1 irradiation experiment," Nuclear Engineering and Design, Vol. 271, pp. 131-141.

Barnes, C. M., 2006, AGR-1 Fuel Product Specification and Characterization Guidance, Rev. 8, INL/EDF-4380, Idaho National Laboratory, 2006.

Bower, G. R., S. A. Ploger, P. A. Demkowicz, J. D. Hunn, 2015, "Measurement of kernel swelling and buffer densification in irradiated UCO TRISO particles," to be submitted to Journal of Nuclear Materials, 2015.

Chadwick, M. B., et al., 2011, "ENDF/B-VII.1 Nuclear Data for Science and Technology: Cross sections, Covariances, Fission Product Yields and Decay Data," Nuclear Data Sheets, 112 (2011) 2887-2996. Specific decay data accessed at: http://www.nndc.bnl.gov/exfor/endf00.jsp.

Collin, B. P., 2015, AGR-1 Irradiation Test Final As-Run Report, INL/EXT-10-18097, Rev. 3, Idaho National Laboratory.

Collin, B. P., Petti, D. A., Demkowicz, P. A., Maki, J. T., 2014, "Comparison of fission product release predictions using PARFUME with results from the AGR-1 irradiation experiment," Proceedings of HTR2014, Weihai, China, October 27-31, 2014, Paper HTR2014-31382.

Demkowicz, P. A., 2010, “AGR-1 Post-Irradiation Examination Plan,” PLN-2828, March 2010.

Demkowicz, P. A., D. V. Laug, D. M. Scates, E. L. Reber, L. G. Roybal, J. B. Walter, J. M. Harp, and R. N. Morris, 2010, "The Fuel Accident Condition Simulator (FACS) Furnace System for High Temperature Performance Testing of VHTR Fuel," Paper HTR2010-115. Proceedings of the 5th International Topical Meeting on High Temperature Reactor Technology, HTR 2010, Prague, Czech Republic, October 18-20, 2010, also published in Nucl. Eng. and Design 251, pp. 164-172, 2012.

Demkowicz, P. A., L. Cole, Scott Ploger, and Philip Winston, 2011, AGR-1 Irradiated Test Train Preliminary Inspection and Disassembly First Look, INL/EXT-10-20722, Rev. 0, Idaho National Laboratory, 2010.

Demkowicz, P. A., L. Cole, S. Ploger, and P. Winston, 2011, AGR-1 Irradiated Test Train Preliminary Inspection and Disassembly First Look, INL/EXT-10-20722, Rev. 0, Idaho National Laboratory, 2010.

Demkowicz, P., J. Harp, P. Winston, and S. Ploger, 2012, AGR-1 Fuel Compact 6-3-2 Post-Irradiation Examination Results, INL/EXT-12-27123, Idaho National Laboratory, 2012.

Demkowicz, P. A., J. M. Harp, P. L. Winston, and S. A. Ploger, 2013, Analysis of Fission Products on the AGR-1 Capsule Components, INL/EXT-13-28483, Rev. 0, March 2013, Idaho National Laboratory, 2013. 
Demkowicz, P. A., J. D. Hunn, S. A. Ploger, R. N. Morris, C. A. Baldwin, J. M. Harp, P. L. Winston, T. J. Gerczak, I. J. van Rooyen, F. C. Montgomery, and C. M. Silva, 2014, "Irradiation Performance of AGR-1 High Temperature Reactor Fuel," Paper HTR2014-31182, Proceedings of the HTR 2014, Weihai, China, October 27-31, 2014.

Demkowicz, P. A., J. M. Harp, P. L. Winston, S. A. Ploger, and I. J. van Rooyen, 2015a, AGR 1 Compact 4-1-1 Post-Irradiation Examination Results, INL/EXT-15-36169, Idaho National Laboratory, 2015.

Demkowicz, P. A., S. A. Ploger, P. L. Winston, and J. M. Harp, 2015b, AGR-1 Compact 3-2-1 Post-Irradiation Examination Results, INL/EXT-15-36352, Idaho National Laboratory, 2015.

Demkowicz, P. A., P. L. Winston, J. M. Harp, and S. A. Ploger, 2015c, AGR-1 Compact 5-3-1 Post-Irradiation Examination Results, INL/EXT-15-36354, Idaho National Laboratory, 2015.

Demkowicz, P. A., S. A. Ploger, P. L. Winston, and J. M. Harp, 2015d, AGR-1 Compact 1-3-1 Post-Irradiation Examination Results, INL/EXT-15-36365, Idaho National Laboratory, 2015.

Demkowicz, P. A., E. L. Reber, D. M. Scates, L. Scott, 2015e, "First high temperature safety tests of AGR-1 TRISO fuel with the Fuel Accident Condition Simulator (FACS) furnace," Journal of Nuclear Materials, Vol. 464, pp. 320-330, 2015.

Demkowicz, P. A., S. A. Ploger, P. L. Winston, and J. M. Harp, 2015f, AGR-1 Safety Tested Compact 4-3-3 Post-Irradiation Examination Results, INL/EXT-15-36457, Idaho National Laboratory, 2015.

Greenwood, L. R., 2012, Analysis of AGR-1 Neutron Fluence and Melt Wire Capsules, Rev. 2, Pacific Northwest National Laboratory, Richland, Washington, USA.

Grover, S. B., D. A. Petti, J. T. Maki, 2010, Completion of the First NGNP Advanced Gas Reactor Fuel Irradiation Experiment, AGR-1, in the Advanced Test Reactor," Paper 104, Proceedings of HTR-2010, Prague, Czech Republic, October18-20, 2010.

Harp, J. M., 2014, "Analysis of Individual Compact fission Product Inventory and Burnup for the AGR-1 TRISO Experiment Using Gamma Spectrometry,” ECAR-1682 Rev. 3, Idaho National Laboratory.

Harp, J. M., P. A. Demkowicz, and S. A. Ploger, 2012, "Post-Irradiation Examination and Fission Product Inventory Analysis of AGR-1 Irradiation Capsules," Proceedings of the HTR 2012, Tokyo, Japan, October 28 - November 1, 2012, Paper HTR2012-3-006, INL/CON-12-24415, Idaho National Laboratory, ID.

Harp, J. M., P. A. Demkowicz, P. L. Winston, J. W. Sterbentz, 2014, “An Analysis of Nuclear Fuel Burnup in the AGR 1 TRISO Fuel Experiment Using Gamma Spectrometry, Mass Spectrometry, and Computational Simulation Techniques," Nuclear Engineering and Design, Vol. 278, pp. 395-405, 2014.

Harp, J. M., S. A. Ploger, 2011, "Examination of Graphite Fuel Compact Holders for the AGR-1 TRISO Experiment using Gamma Spectrometry,” ECAR-1709 Rev. 0, Idaho National Laboratory.

Hawkes, G. L., 2012, “AGR-1 Daily As-Run Thermal Analyses,” ECAR-968 Rev. 3, Idaho National Laboratory.

Hunn, J. D., and R. A. Lowden, 2006a, Data Compilation for AGR-1 Baseline Coated Particle Composite LEU01-46T, ORNL/TM-2006/019, Rev. 0, Oak Ridge National Laboratory, Oak Ridge, Tennessee, 2006.

Hunn, J.D., and R. A. Lowden, 2006b, Data Compilation for AGR-1 Variant 1 Coated Particle Composite LEU01-47T, ORNL/TM-2006/020, Rev. 0, Oak Ridge National Laboratory, Oak Ridge, Tennessee, 2006. 
Hunn, J. D., and R. A. Lowden, 2006c, Data Compilation for AGR-1 Variant 2 Coated Particle Composite LEU01-48T, ORNL/TM-2006/021, Rev. 0, Oak Ridge National Laboratory, Oak Ridge, Tennessee, 2006.

Hunn, J. D., and R. A. Lowden, 2006d, Data Compilation for AGR-1 Variant 3 Coated Particle Composite LEU01-49T, ORNL/TM-2006/022, Rev. 0, Oak Ridge National Laboratory, Oak Ridge, Tennessee, 2006.

Hunn, J. D., F. C. Montgomery, and P. J. Pappano, 2006a, Data Compilation for AGR-1 Baseline Compact Lot LEU01-46T-Z, ORNL/TM-2006/507, Oak Ridge National Laboratory, Oak Ridge, Tennessee, 2006.

Hunn, J. D., F. C. Montgomery, and P. J. Pappano, 2006b, Data Compilation for AGR-1 Variant 1 Compact Lot LEU01-47T-Z, ORNL/TM-2006/508, Oak Ridge National Laboratory, Oak Ridge, Tennessee, 2006.

Hunn, J. D., F. C. Montgomery, and P. J. Pappano, 2006c, Data Compilation for AGR-1 Variant 2 Compact Lot LEU01-48T-Z, ORNL/TM-2006/509, Oak Ridge National Laboratory, Oak Ridge, Tennessee, 2006.

Hunn, J. D., F. C. Montgomery, and P. J. Pappano, 2006d, Data Compilation for AGR-1 Variant 3 Compact Lot LEU01-49T-Z, ORNL/TM-2006/510, Oak Ridge National Laboratory, Oak Ridge, Tennessee, 2006.

Hunn, J. D., T. W. Savage, and C. M. Silva, 2012, AGR-1 Fuel Compact Pre-Irradiation Characterization Summary Report, ORNL/TM-2012/295, Oak Ridge National Laboratory, Oak Ridge, Tennessee, 2012.

Hunn, J. D., R. N. Morris, C. A. Baldwin, F. C. Montgomery, C. M. Silva, and T. J. Gerczak, 2012a, AGR-1 Irradiated Compact 6-1-1 PIE Report: Evaluation of As-Irradiated Fuel Performance using Leach Burn Leach, IMGA, Materialography, and X-ray Tomography, ORNL/TM-2012/233, Oak Ridge National Laboratory, Oak Ridge, Tennessee, 2012.

Hunn, J. D., R. N. Morris, C. A. Baldwin, F. C. Montgomery, and C. M. Silva, 2012b, PIE on Five Irradiated AGR-1 Compacts, ORNL/LTR-2012/397, Oak Ridge National Laboratory, Oak Ridge, Tennessee, 2012.

Hunn, J. D., R. N. Morris, C. A. Baldwin, F. C. Montgomery, 2012c, Summary of PIE on AGR-1 Compact 3-2-2. ORNL/LTR-2012/928, Oak Ridge National Laboratory, Oak Ridge, Tennessee, 2012.

Hunn, J. D., R. N. Morris, C. A. Baldwin, F. C. Montgomery, 2012d, Summary of Safety Test on Irradiated AGR-1 Compact 3-3-1, ORNL/LTR-2012/926, Oak Ridge National Laboratory, 2012.

Hunn, J. D., R. N. Morris, C. A. Baldwin, and F. C. Montgomery, 2012e, Safety Tests on Irradiated AGR-1 Compacts 3-3-2, 3-2-2, and 6-2-1, ORNL/LTR-2012/396, Oak Ridge National Laboratory, Oak Ridge, Tennessee, 2012.

Hunn, J. D., R. N. Morris, C. A. Baldwin, F. C. Montgomery, C. M. Silva, and T. J. Gerczak, 2013a, AGR-1 Irradiated Compact 4-4-2 PIE Report: Evaluation of As-Irradiated Fuel Performance with Leach Burn Leach, IMGA, Materialography, and X-ray Tomography, ORNL/TM-2013/236, Oak Ridge National Laboratory, Oak Ridge, Tennessee. 2013.

Hunn, J. D., R. N. Morris, C. A. Baldwin, F. C. Montgomery, C. M. Silva, and T. J. Gerczak, 2013b, PIE on Three Irradiated AGR-1 Compacts in FY2013, ORNL/LTR-2013/291, Oak Ridge National Laboratory, Oak Ridge, Tennessee, 2013. 
Hunn, J. D., R. N. Morris, C. A. Baldwin, and F. C. Montgomery, 2013c, Safety Tests on Irradiated AGR-1 Compacts 4-1-2, 4-4-3, and 4-4-1, ORNL/LTR-2013/290, Oak Ridge National Laboratory, Oak Ridge, Tennessee, 2013.

Hunn, J. D., R. N. Morris, C. A. Baldwin, and F. C. Montgomery, 2013d, Safety Tests on Irradiated AGR-1 Compacts 5-3-3 and 5-1-3, ORNL/LTR-2013/603, Oak Ridge National Laboratory, Oak Ridge, Tennessee, 2013.

Hunn, J. D., R. N. Morris, C. A. Baldwin, F. C. Montgomery, and T. J. Gerczak, 2014a, PIE on Safety-Tested AGR-1 Compacts 5-3-3, 5-1-3, and 3-2-3, ORNL/TM-2014/484, Oak Ridge National Laboratory, Oak Ridge, Tennessee, 2014

Hunn, J. D., C. A. Baldwin, T. J. Gerczak, F. C. Montgomery, R. N. Morris, and C. M. Silva, 2014b, AGR-1 Irradiated Compacts 5-2-3 and 5-2-1 PIE Report: Evaluation of As-Irradiated Fuel Performance with Leach Burn Leach, IMGA, Materialography, and X-ray Tomography, ORNL/TM-2014/171, Oak Ridge National Laboratory, Oak Ridge, Tennessee, 2014.

Hunn, J. D., R. N. Morris, C. A. Baldwin, F. C. Montgomery, and T. J. Gerczak, 2014c, PIE on Safety-tested AGR-1 Compacts 4-1-2 and 4-4-3, ORNL/LTR-2014/101 Rev. 0, Oak Ridge National Laboratory, Oak Ridge, Tennessee, 2014.

Hunn, J. D., C. A. Baldwin, T .J. Gerczak, F. C. Montgomery, R. N. Morris, C. M. Silva, P. A. Demkowicz, J. M. Harp, S. A. Ploger, I. J. van Rooyen, and K. E. Wright, 2014d, "Detection and Analysis of Particles with Failed SiC in AGR-1 Fuel Compacts," Paper HTR2014-31254, Proceedings of the HTR 2014, Weihai, China, October 27-31, 2014.

Hunn, J. D., R. N. Morris, C. A. Baldwin, and F. C. Montgomery, 2014e, Safety Test on Irradiated AGR-1 Compact 4-2-2, ORNL/LTR-2014/485, Oak Ridge National Laboratory, Oak Ridge, Tennessee, 2014.

Hunn, J. D., R. N. Morris, C. A. Baldwin, and F. C. Montgomery, 2014f, Safety Test on Loose Particles From Irradiated Compact 4-4-2,ORNL/LTR-2014/486, Oak Ridge National Laboratory, Oak Ridge, Tennessee, 2014.

Hunn, J. D., R. N. Morris, C. A. Baldwin, F. C. Montgomery, and T. J. Gerczak, 2015a, PIE on Safety-Tested AGR-1 Compact 5-1-1, ORNL/TM-2015/317, Oak Ridge National Laboratory, Oak Ridge, Tennessee. 2015.

Hunn, J. D., R. N. Morris, C. A. Baldwin, F. C. Montgomery, T. J. Gerczak, 2015b, PIE on Safety-Tested AGR-1 Compact 4-2-2, ORNL/TM-2015/033, Rev. 0, Oak Ridge National Laboratory, Oak Ridge, Tennessee, 2015.

Hunn, J. D., R. N. Morris, C. A. Baldwin, F. C. Montgomery, and T. J. Gerczak, 2015c, PIE on Safety-Tested Loose Particles from AGR-1 Compact 4-4-2, ORNL/TM-2015/161, Oak Ridge National Laboratory, Oak Ridge, Tennessee, 2015.

INL, 2014, "Technical Program Plan for the Very High Temperature Reactor Technology Development Office/Advanced Gas Reactor Fuel Development and Qualification Program," PLN-3636, Rev. 3.

Leng, B., I. van Rooyen, Y. Wu, I. Szlufarska, K. Sridharan, 2015, "STEM/EDS Analysis of Fission Products in Irradiated TRISO Coated Particles of the AGR-1 Experiment," Submitted to Journal of Nuclear Materials, August 3, 2015.

Lillo, T. M., I. J. van Rooyen, 2014, "Spatial distribution of Pd, Ag \& U in the SiC layer of an irradiated TRISO fuel particle, Microsc. Microanal. Vol. 20 (Suppl 3), 2014, pp. 1810.

Lillo, T. M., and I. J. Van Rooyen, 2015, “Associations of Pd, U and Ag in the SiC layer of neutron-irradiated TRISO fuel,” Journal of Nuclear Materials, Vol. 460, May 2015, pp. 97-106. 
Lillo, T. M., I. J. van Rooyen, 2015a, "Precession electron diffraction for SiC grain boundary characterization in unirradiated TRISO Fuel", to be submitted to Nuclear Engineering and Design or the Journal of Nuclear Materials, September 2015.

Lillo, T. M., I. J. van Rooyen, 2015b, "Influence of SiC grain boundary character on fission product transport in TRISO fuel," to be submitted to the Journal of Nuclear Materials, September 2015.

Lillo, T. M., I. J. van Rooyen, Y. Wu, 2015c, "Grain boundary character and fission product precipitation in SiC", Proceedings of the 2015 ANS Annual Meeting, June 7-11, 2015, San Antonio, Texas.

Lowden, R. A., 2006, Fabrication of Baseline and Variant Particle Fuel for AGR-1, ORNL/CF-2006/02, Oak Ridge National Laboratory, Oak Ridge, Tennessee, 2006.

Morris, R. N., C. A. Baldwin, P. A. Demkowicz, J. D. Hunn, and E. L. Reber, 2014, Performance of AGR-1 High-Temperature Reactor Fuel During Post-Irradiation Heating Tests," Proceedings of the 7th International Topical Meeting on High Temperature Reactor Technology, Weihai, China, October 27-31, 2014, HTR2014, Paper HTR2014-31135.

Morris, R. N., P. A. Demkowicz, J. D. Hunn, C. A. Baldwin, and E. L. Reber, 2015, "Performance of AGR-1 high temperature reactor fuel during post-irradiation heating tests," Nuclear Engineering and Design, submitted March 2015.

Nabielek, H., Brown, P. E., Offerman, P., 1977, "Silver release from coated particle fuel," Nuclear Technology, Vol. 35, pp. 483-493.

Nickel, H., Nabielek, N., Pott, G., Mehner, A.W., 2002, "Long time experience with the development of HTR fuel elements in Germany," Nuclear Engineering and Design, Vol. 217, pp. 141-151.

Pappano, P. J., 2006, Baseline and Variant Fuel Compact Fabrication Report for AGR-1, ORNL/TM-2006/528, Oak Ridge National Laboratory, Oak Ridge, Tennessee, 2006.

Pappano, P. J., T. D. Burchell, J. D. Hunn, and M. P. Trammell, 2008, "A novel approach to fabricating fuel compacts for the Next Generation Nuclear Plant (NGNP)," J. Nucl. Mater. Vol. 381, pp. 25-38.

Petti, D. A., J. T. Maki, J. D. Hunn, P. J. Pappano, C. M. Barnes, J. J. Saurwein, S. G. Nagley, J. M. Kendall, and R. R. Hobbins, 2010, "The DOE Advanced Gas Reactor Fuel Development and Qualification Program," JOM, Vol. 62, No. 9, pp. 62-66.

Phillips, J. A., C. M. Barnes, J. D. Hunn. 2010. "Fabrication and Comparison of Fuels for Advanced Gas Reactor Irradiation Tests," Paper HTR2010-236. Proceedings of the 5th International Topical Meeting on High Temperature Reactor Technology, HTR 2010, Prague, Czech Republic, October 18-20, 2010. Also published in Nucl. Eng. and Design, Vol. 251, 2012, pp. 164-172.

Ploger, S. A., P. A. Demkowicz, J. Hunn, and J. S. Kehn, 2012a, Ceramographic Examinations of Irradiated AGR-1 Fuel Compacts, INL/EXT-12-25301, Rev. 1, September 2012, Idaho National Laboratory.

Ploger, S. A., P. A. Demkowicz, J. D. Hunn, and J. S. Kehn, 2012b, "Microscopic Analysis of Irradiated AGR-1 Coated Particle Fuel Compacts," Paper HTR20212-3-020, Proceedings of the HTR 2012, Tokyo, Japan, November 1, 2012.

Ploger, S. A., P. A. Demkowicz, J. D. Hunn, and J. S. Kehn, 2014, "Microscopic analysis of irradiated AGR-1 coated particle fuel compacts," Nuclear Engineering and Design, Vol. 271, 2014, pp. 221-230.

Maki, J. T., 2009, AGR-1 Irradiation Experiment Test Plan, INL/EXT-05-00593, Rev. 3, Idaho National Laboratory. 
Schenk, W., D. Pitzer, and H. Knauf, 1993, "Simulation der max. MODUL-Störfallaufheizkurve (AVR-GLE 3, 90/20) und deren Extrapolation auf $1700^{\circ} \mathrm{C}$ (AVR-GLE 3, 91/31)," IWE-TN-17/93, Forschungszentrum Jülich GmbH (KFA).

Schenk, W., Pott, G., Nabielek, H., 1990, "Fuel accident performance testing for small HTRs," Journal of Nuclear Materials, Vol. 171, pp. 19-30.

Sterbentz, J. W., J. M. Harp, P. A. Demkowicz, G. L. Hawkes, and G. S. Chang, 2015, "Validation of the Physics Analysis used to characterize the AGR-1 TRISO Fuel Irradiation Test," Paper 15497, Proceedings of ICAPP 2015, Nice, France, May 03-06, 2015.

Sterbentz, J. W., 2013, "JMOCUP As-Run Daily Depletion Calculation for the AGR-1 Experiment in the ATR B-10 Position,” ECAR-958 Rev. 2, Idaho National Laboratory.

Van Rooyen, I. J., B. D. Miller, D. E. Janney, J. Riesterer, P. A. Demkowicz, and J. Harp, 2012a, Electron Microscopic Examination of Irradiated TRISO Coated Particles of Compact 6-3-2 of AGR-1 Experiment, INL/EXT-11-23911, 2012.

Van Rooyen, I. J, D. E. Janney, B. D. Miller, J. L. Riesterer, P. A. Demkowicz, “(2012b), Electron microscopic evaluation and fission product identification of irradiated TRISO coated particles from the AGR-1 experiment: A preliminary review," HTR2012-3-023, Proceedings of HTR-2012, Tokyo, Japan, October 28-November 1, 2012.

Van Rooyen, I. J., Y. Q. Wu, T. M. Lillo, T. L. Trowbridge, J. M. Madden, and D. Goran, 2013, "Advanced Electron Microscopic Techniques Applied to the Characterization of Irradiation Effects and Fission Product Identification of Irradiated TRISO Coated Particles from the AGR-1 Experiment," Proceedings of GLOBAL 2013, Salt Lake City, UT, USA, September 29 October 3, 2013.

Van Rooyen, I. J., 2013a, "Summary report on Advanced microscopy performed on Irradiated AGR-1 Specimens,” INL Interoffice Memorandum, CCN231379, September 2013.

Van Rooyen, I. J., E. J. Olivier, and J. H. Neethling, 2014a, "Investigation of the fission products silver, palladium and cadmium in neutron irradiated $\mathrm{SiC}$ using a Cs-corrected HRTEM," Proceedings of the 7th International Topical Meeting on High Temperature Reactor Technology, Weihai, China, October 27-31, 2014, (HTR2014), Paper HTR2014-31255.

Van Rooyen, I. J., D. E. Janney, B. D. Miller, P. A. Demkowicz, and J. Riesterer, 2014b, "Electron microscopic evaluation and fission product identification of irradiated TRISO coated particles from the AGR-1 experiment, A Preliminary Review," Nuclear Engineering and Design, Vol. 271, 2014, pp. 114-122.

Van Rooyen I. J., J. Youngsman, T. M. Lillo, Y. Q. Wu, D. Goran, M. E. Lee, W. E. Goosen, J. H. Neethling, T. L. Trowbridge and J. W. Madden, 2014c, "Methods for identification of crystallographic parameters of irradiated $\mathrm{SiC}$ to understand fission product transport," The $3 \mathrm{rd}$ Workshop on HTGR SiC Material Properties, Sept. 30-Oct 1, 2014, Jeju Island, South Korea.

Van Rooyen, I. J., T. M. Lillo, and Y. Q. Wu., 2014d, "Identification of Silver and Palladium in Irradiated TRISO Coated Particles of the AGR-1 Experiment," Journal of Nuclear Materials Vol. 446, No. 1-3, 2014, pp. 178-186.

Van Rooyen I. J., T Lillo, H Wen, K Wright, J Madden, 2015a ,Advanced Electron Microscopy and Micro analytical technique development and application for Irradiated TRISO Coated Particles from the AGR-1 Experiment, INL/EXT-15-36169, 2015.

Van Rooyen I. J., E. J. Olivier, J. H. Neethling, 2015b, Fission Products Silver, Palladium and Cadmium identification in Neutron Irradiated SiC using a Cs-Corrected HRTEM, submitted to Journal of Nuclear Materials, August 2015. 
Van Rooyen, I. J., C. Hill, H. Wen, T. Trowbridge, 2015c, Scanning Electron Microscopic Examination of Irradiated TRISO Coated Particles of Compacts 4-1-1, 5-3-1, 1-3-1 and Safety Tested Compact 4-3-3 of AGR-1 Experiment, INL external report in preparation, INL/EXT-15-36278, 2015.

Wen, H., I. J. Van Rooyen, J. D. Hunn, T. J. Gerczak, C. A. Baldwin, and F. C. Montgomery, 2015a, "Advanced electron microscopy study of fission product distribution in the failed SiC layer of a neutron irradiated TRISO coated particle," Proceedings of Microscopy and Microanalysis 2015, Portland, Oregon, August 2-7, 2015, M\&M2015.

Wen, H., I. J. Van Rooyen, C. Hill, T. Trowbridge, and B. Coryell, 2015b, "Fission product distribution in TRISO coated particles neutron irradiated to $3.22 \times 10^{25} \mathrm{n} / \mathrm{m}^{2}$ fast fluence at $1092^{\circ} \mathrm{C}$, ASME Power and Energy 2015, San Diego, California, June 28 - July 2, 2015.

Wen, H., I. J. van Rooyen, J. D. Hunn, T. J. Gerczak, 2015c, “Advanced electron microscopy study of Pd, $\mathrm{Ag}$ and $\mathrm{Cs}$ in carbon areas in the locally corroded $\mathrm{SiC}$ layer in a neutron irradiated TRISO fuel particle", to be submitted to Nuclear Engineering and Design or the Journal of Nuclear Materials, August 2015.

Wen, H., I. J. van Rooyen, 2015d "Fission products palladium, silver and cesium distribution in the SiC layer with local corrosion in a neutron irradiated TRISO fuel particle", to be submitted to Nuclear Engineering and Design or the Journal of Nuclear Materials, August 2015. 